Renato Seiji Tavares

\title{
Segmentação do Pulmão em Seqüências de Imagens de Ressonância Magnética Utilizando a Transformada de Hough
}

Dissertação apresentada à Escola Politécnica da Universidade de São Paulo para obtenção do Título de Mestre em Engenharia. 
Renato Seiji Tavares

\section{Segmentação do Pulmão em Seqüências de Imagens de Ressonância Magnética Utilizando a Transformada de Hough}

Dissertação apresentada à Escola Politécnica da Universidade de São Paulo para obtenção do Título de Mestre em Engenharia.

Área de concentração:

Automação e Controle

Orientador:

Prof. Dr. Marcos de Sales Guerra Tsuzuki 


\section{Ficha Catalográfica}

Tavares, Renato Seiji

Segmentação do Pulmão em Seqüências de Imagens de Ressonância Magnética Utilizando a Transformada de Hough. São Paulo, 2011. $131 \mathrm{p}$.

Dissertação (Mestrado) - Escola Politécnica da Universidade de São Paulo. Departamento de Engenharia de Mecatrônica e de Sistemas Mecânicos.

1. Segmentação do pulmão. 2. Transformada de Hough. 3. Ressonância Magnética. I. Universidade de São Paulo. Escola Politécnica. Departamento de Engenharia de Mecatrônica e de Sistemas Mecânicos. II. 
A meus pais, familiares, amigos e professores, que me deram grande apoio e incentivo durante minha jornada acadêmica. 


\section{Agradecimentos}

Ao meu orientador, Prof. Dr. Marcos de Sales Guerra Tsuzuki, pelas orientações durante a realização deste trabalho, por ter me orientado pelos caminhos da pesquisa, por seus ensinamentos e oportunidades oferecidos ao longo dos últimos anos.

Aos meus colegas de laboratório, que tanto me auxiliaram nesta jornada.

À minha família e amigos que indiretamente me ajudaram na conclusão deste curso de mestrado.

A todos que, de maneira direta ou indireta, colaboraram na execução deste trabalho. 


\section{Resumo}

A segmentação é uma etapa intermediária no registro e reconstrução 3D do pulmão. Geralmente, os métodos de segmentação são interativos e utilizam diferentes estratégias para combinar a expertise dos humanos e a velocidade e precisão dos computadores. A segmentação de imagens de RM do pulmão é particularmente difícil devido à grande variação na qualidade da imagem. Dois métodos para a segmentação do contorno do pulmão são apresentados. No primeiro, uma análise individual de cada imagem da série de imagens de RM é realizada, e a segmentação ocorre através de técnicas de limiarização e labeling. No segundo método, a respiração é associada a uma função respiração padrão, e através de técnicas de processamento de imagem 2D, detecção de bordas e transformada de Hough, padrões respiratórios são obtidos e, conseqüentemente, a posição dos pontos no tempo são estimados. Seqüências temporais de imagens de RM são segmentadas, considerando a coerência no tempo. Desta forma, a silhueta do pulmão pode ser determinada em cada quadro, mesmo em quadros com bordas obscuras. A região do pulmão é segmentada em três etapas, neste método: uma máscara contendo a região do pulmão é criada a partir do resultado do primeiro método de segmentação; a transformada de Hough é aplicada exclusivamente aos pixels da máscara em diversos planos; o contorno do pulmão é extraído do resultado da transformada de Hough utilizando contornos ativos. O formato da máscara pode ter uma grande variação, e a transformada de Hough modificada pode lidar com essa variação. Os resultados obtidos pelos dois métodos são comparados. 


\section{Abstract}

The segmentation of the lung is an intermediary step towards its registry and $3 \mathrm{D}$ reconstruction. Usually, segmentation methods are interactive and make use of different strategies to combine the expertise of the human and the computers' accuracy and speed. Segmentation of lung magnetic resonance (MR) images is particularly difficult because of the large variation in image quality. Two methods for the lung contour segmentation are presented. In the first method, an individual analysis of each image in the series approach is taken, and the segmentation is made through thresholding and labeling techniques. In the second method, the breathing is associated to a standard respiratory function, and through 2D image processing, edge detection and Hough transform, respiratory patterns are obtained and, consequently, the position of points in time are estimated. Temporal sequences of MR images are segmented by considering the coherence in time. This way, the lung silhouette can be determined in every frame, even on frames with obscure edges. The lung region is segmented in three steps: a mask containing the lung region is created from the results of the first method; the Hough transform is applied exclusively to mask pixels in different planes; and the lung contour is created from the results of the Hough transform through active contours. The shape of the mask can have a large variation, and the modified Hough transform can handle such shape variation. Results from both methods are compared. 


\section{Conteúdo}

\section{Lista de Figuras}

1 Introdução $\quad 24$

1.1 Organização do Texto . . . . . . . . . . . . . . . 25

2 Segmentação do Pulmão $\quad 27$

3 A Ressonância Magnética do Pulmão 29

3.1 Spin Nuclear. . . . . . . . . . . . . . . . . . . . . . . . . 29

3.2 Núcleo Imerso em um Campo Magnético . . . . . . . . . . . . . . 30

3.3 Excitação em Rádio-Freqüência . . . . . . . . . . . . . . . . . . . 32

3.4 O sinal da RM . . . . . . . . . . . . . . . . . . 33

3.5 Múltiplos pulsos de RF . . . . . . . . . . . . . . . . . . . 36

4 Principais Conceitos $\quad 39$

4.1 Padrões Respiratórios . . . . . . . . . . . . . . . . . . . . . . . . . 39

4.2 Segmentação Temporal do Pulmão . . . . . . . . . . . . . . . . . 42

4.3 Transformada de Hough Modificada . . . . . . . . . . . . . . . . . 43

4.3.1 Modificação para Deteç̧ão de Padrões Respiratórios . . . 45

4.3.2 Entendendo a Transformada de Hough Modificada ${ }^{[1]}$. . . 48

4.4 Aritmética Intervalar . . . . . . . . . . . . . . . . . . 50

4.4.1 Aritmética Intervalar aplicada à Transformada de Hough ${ }^{[1]} \quad 51$

4.5 Contornos Ativos . . . . . . . . . . . . . . . 52

4.5.1 Contornos Ativos com Gradient Vector Flow (GVF) . . . 58

4.6 Segmentação por Limiarização . . . . . . . . . . . . . . . . . . 60 
4.7 Filtro de Mediana . . . . . . . . . . . . . . . . 65

4.8 Morfologia Matemática . . . . . . . . . . . . . . . . . 69

4.8.1 O elemento estruturante . . . . . . . . . . . 70

4.8 .2 Dilatação . . . . . . . . . . . . . . . . 72

4.8.3 Erosão . . . . . . . . . . . . . . . . . 73

5 Segmentação do Pulmão através de Limiarização e Labeling $\quad 78$

6 Segmentação Temporal do Pulmão $\quad 82$

$\begin{array}{llr}7 & \text { Resultados } & 96\end{array}$

$\begin{array}{llr}8 & \text { Conclusões } & 127\end{array}$

$\begin{array}{lr}\text { Referências } & 129\end{array}$ 


\section{Lista de Figuras}

2.1 (a). Contorno definido pelo usuário - pontos de controles representados por círculos. (b) Contorno determinado automaticamente pelo algoritmo - pontos de controle representados por quadrados. . 28

3.1 Ilustração do movimento de precessão do vetor do momento angular do núcleo em torno de um campo magnético externo. . . . . . 31

3.2 Trajetória do vetor de magnetização resultante, que retorna ao estado de equilíbrio, em precessão. . . . . . . . . . . . . . . . . . 32

3.3 Formatos típicos para o pulso de RF. (a) Pulso retangular. (b) Pulso sinc. . . . . . . . . . . . . . . . . . . . 33

3.4 Componentes do vetor de magnetização. . . . . . . . . . . . . . . 34

3.5 Curva de decaimento da magnetização transversal. . . . . . . . . . . 34

3.6 Curva de recuperação da magnetização longitudinal. . . . . . . . . 35

4.1 Um exemplo de um STV construído a partir de 10 imagens coronais de RM do pulmão. . . . . . . . . . . . . . . . . . . . . . 40

4.2 Ilustração da intersecção de um dado STV com um plano arbitrário paralelo ao eixo do tempo. . . . . . . . . . . . . . . . . . . 40

4.3 Imagem de RM da região torácica e imagens 2DST. . . . . . . . . 41

4.4 Uma função respiração base $f_{s}(t) \ldots$. . . . . . . . . . . . . . . 41

4.5 Ilustração do princípio da transformada de Hough. (a) Três pontos pertencentes à mesma reta no plano da imagem. (b) As três retas se interseccionam em uma única célula no espaço paramétrico de Hough. . . . . . . . . . . . . . . . . . . . . . . 45

4.6 A transformada de Hough - a imagem 2DST está a esquerda e o espaço paramétrico está a direita. Um padrão respiratório na imagem 2DST é mapeada para uma célula no espaço paramétrico. 
4.7 A região que deve ser reamostrada negativamente em destaque. Esta região engloba todas as retas que passam pelo ponto de maior intensidade detectado e que possuem coeficiente angular dentro do intervalo $\left[0, f_{\max }\right] \ldots \ldots \ldots \ldots \ldots$

4.8 (a) Um padrão respiratório incoerente encontrado pela transformada de Hough modificada apontado por uma seta. (b) O espaço paramétrico de Hough é apresentado e a célula referente ao padrão respiratório apresentado em (a) indicado pela seta. . . . . . . .

4.9 A transformada de Hough após a mudança de variáveis - a nova imagem está a esquerda e o espaço paramétrico está a direita. Uma reta é mapeada para uma célula no espaço paramétrico. . . . . . .

4.10 A região que deve ser reamostrada em destaque, em verde. Esta região engloba todas as retas que passam pelo ponto de maior intensidade detectado e que possuem coeficiente angular dentro do intervalo $\left[0, f_{\max }\right] \ldots \ldots \ldots \ldots \ldots \ldots$

4.11 A transformada modificada de Hough utilizando aritmética intervalar - a imagem 2DST está a esquerda e o espaço paramétrico está a direita. Um pixel da imagem 2DST é mapeado para uma faixa no espaço paramétrico. . ....

4.12 (a) Uma imagem 2DST e os padrões respiratórios encontrados pela transformada de Hough modificada (acima) e pela transformada de Hough modificada utilizando aritmética intervalar (abaixo). (b) O espaço paramétrico de Hough é apresentado e a célula referente ao padrão respiratório apresentado em (a) está indicado pela seta. (c) O espaço paramétrico intervalar de Hough é apresentado e a célula referente ao padrão respiratório apresentado em (a) está indicado pela seta.

4.13 Uma função respiração resultante da transformada de Hough modificada. O algoritmo greedy de contornos ativos busca por uma posição de menor energia nos pontos adjacentes verticalmente. .

4.14 (a) Imagem de arestas original. (b) Função respiração encontrada pela transformada de Hough modificada intervalar. (c) Função respiração encontrada ajustada pelo algoritmo greedy de contornos 
4.15 Comparação de campos tradicionais de arestas com o GVF em um perfil de uma imagem. O traço preto indica a intensidade do pixel, o traço vermelho indica a magnitude do gradiente em um campo de arestas tradicional, e o traço azul representa a magnitude do gradiente em um campo GVF. . . . . . . . . . . . .

4.16 Ilustração do campo GVF.(a) Imagem de objeto em formato de U. (b) Campo GVF. (c) Parte do campo GVF ampliado para visualização. Esta parte se refere ao canto superior e à concavidade no centro da parte superior do objeto. . . . . . . . . . .

4.17 Demonstração da capacidade do método de contornos ativos de convergir para contornos subjetivos mesmo quando inicializado em posição afastada.(a) Contorno inicial. (b) a (d) Posições intermediárias da evolução do contorno. (e) Contorno final. . . . . . . . .

4.18 Exemplo da utilização do algoritmo de contornos ativos com GVF no contexto deste trabalho. (a) Pontos dispersos representando o contorno do pulmão. (b) Contorno inicial oval em vermelho. (c) Campo GVF, com duas regiões demarcadas em cores. (d) Ampliação da região em vermelho da imagem (c). (e) Ampliação da região em laranja da imagem (c). (f) Resultado da aplicação do método de contornos ativos. . . . . . . . . . . . . .

4.19 (a) Imagem em escala de cinza. (b) Histograma de níveis de cinza da imagem (a).

4.20 (a) Histograma da imagem da Fig. 4.19 com limiar $L$ indicado. Neste caso, $L=150$. (b) Resultado da limiarização com limiar 150. Objeto e fundo separados. . . . . . . . . . . . . . 64

4.21 (a) Imagem Lenna em escala de cinza. (b) Histograma de níveis de cinza da imagem $(\mathrm{a}) . \ldots \ldots \ldots \ldots$

4.22 (a) Histograma da imagem Lenna com limiar 68 indicado. (b) Resultado da limiarização da imagem Lenna com limiar 68. (c) Histograma da imagem Lenna com limiar 117 indicado. (d) Resultado da limiarização da imagem Lenna com limiar 117. (e) Histograma da imagem Lenna com limiar 187 indicado. (f) Resultado da limiarização da imagem Lenna com limiar 187. . . . . . . . . 
4.23 (a) Imagem em escala de cinza do pulmão. (b) Histograma de níveis de cinza da imagem (a). (c) Resultado da limiarização com $L=171 \ldots \ldots \ldots \ldots \ldots \ldots \ldots \ldots$

4.24 (a) Janela em cruz de tamanho 3. (b) Janela quadrada de lado 3.

(c) Janela retangular de tamanho $3 \times 5 . \ldots 68$

4.25 (a) Imagem Lenna com ruído do tipo sal e pimenta introduzido.

(b) Resultado da filtragem por filtro de mediana. . . . . . . . . . 69

4.26 (a) Imagem com a máscara do pulmão. (b) Resultado da filtragem por filtro de mediana. . . . . . . . . . . . . .

4.27 (a) Imagem binária 5x5 com objeto quadrado 3x3 em preto. (b) Outra representação para a imagem apresentada em (a). . . . . . 70

4.28 (a) Elemento estruturante do tipo disco, de tamanho 3. (b) Elemento estruturante do tipo disco, de tamanho 5. (c) Elemento estruturante quadrado, de tamanho 2. (d) Elemento estruturante quadrado, de tamanho 3. (e) Elemento estruturante quadrado, de tamanho 5. (f) Elemento estruturante retangular, de tamanho 1x2. (g) Elemento estruturante retangular, de tamanho 1x3. (h) Elemento estruturante retangular, de tamanho $1 \times 5$. . . . . . . .

4.29 Ilustração da operação de dilatação. (a) Imagem binária original, com região a ser ampliada indicada em vermelho. (b) Elemento estruturante todo contido no fundo da imagem. (c) Elemento estruturante todo contido na região de objeto da imagem. (d) Elemento estruturante posicionado em pixel de valor inicial igual ao fundo da imagem. (e) Elemento estruturante posicionado em pixel de valor inicial igual ao do objeto da imagem. . . . . . . . . . .

4.30 Ilustração da operação de dilatação em uma imagem binária qualquer utilizando um elemento estruturante quadrado de tamanho 13. (a) Imagem binária de entrada. (b) Imagem resultante da dilatação. O objeto original está marcado em branco, e o objeto resultante está indicado em cinza. . . . . . . . . . . .

4.31 Ilustração da operação de dilatação em uma imagem binária com a máscara do pulmão obtido neste trabalho. (a) Imagem binária de entrada com a máscara do pulmão. (b) Imagem resultante da dilatação. O objeto original está marcado em branco, e o objeto resultante está indicado em cinza. . . . . . . . . . . . . . . 
4.32 Ilustração da operação de erosão em uma imagem binária qualquer utilizando um elemento estruturante quadrado de tamanho 13. (a) Imagem binária de entrada. (b) Imagem resultante da erosão. O objeto original está marcado em branco, e o objeto resultante está indicado em cinza. . . . . . . . . . . . . . . 76

4.33 Ilustração da operação de erosão em uma imagem binária com a máscara do pulmão obtida neste trabalho. (a) Imagem binária de entrada com a máscara do pulmão. (b) Imagem resultante da erosão. O objeto original está marcado em branco, e o objeto resultante está indicado em cinza. . . . . . . . . . . . . 77

5.1 Processo de determinação da região do pulmão. (a) Imagem base. (b) Imagem binária. (c) Imagem após primeiro labeling. (d) Imagem após aplicação de filtro. (e) Imagem final, após segundo labeling. 79

5.2 Ilustração do algoritmo de labeling. (a) Imagem binária. (b) Resultado do labeling. . . . . . . . . . . . . . . . . . . 80

6.1 Criação de uma máscara que define o interior do pulmão com problemas. (a) Imagem de RM original. (b) Imagem binária criada. (c) Imagem com a região encontrada. . . . . . . . . . . . . . . . . 83

6.2 (a) Uma imagem ilustrando o plano que originou a imagem 2DST. (b) Uma imagem 2DST. (c) Os primeiros 21 padrões respiratórios encontrados. As setas mostram alguns padrões respiratórios encontrados pela transformada de Hough modificada que representam as diferentes estruturas internas do pulmão. . . . . . . . . . . .

6.3 Criação da máscara de busca do contorno a partir de região determinada anteriormente. (a) Imagem base. (b) Região do pulmão obtida. (c) Imagem após dilatação morfológica. (d) Imagem após erosão morfológica. (e) Máscara do contorno do pulmão. . . . . . 84

6.4 Máscara inadequada calculada. . . . . . . . . . . . . . . 85

6.5 Seqüência temporal de imagens sagitais de RM do pulmão. Imagens em (c), (g) e (k) apresentam o pulmão na expiração, (e) e (i), na inspiração, e as demais, em fases intermediárias. . . . . . . . . 86 
6.6 Processo de criação da máscara para imagem da Fig. 6.5(h). (a) Imagem base. (b) Imagem binária. (c) Imagem após primeiro labeling. (d) Imagem após aplicação de filtro. (e) Imagem após segundo labeling. (f) Imagem após dilatação morfológica. (g) Imagem após erosão morfológica. (h) Máscara do contorno do pulmão.

6.7 Ilustração do processamento temporal da imagem da Fig. 6.5(h) com uma imagem 2DST vertical.(a) Imagem sagital de RM do pulmão (posição da imagem 2DST relativa a esta imagem está indicada em verde). (b) Imagem 2DST vertical da imagem (a) criada na posição indicada. (c) O mapa de arestas referente ao contorno superior com a máscara aplicada. (d) O espaço paramétrico de Hough mostrando a função respiração encontrada em (c). (e) O mapa de arestas referente ao contorno inferior com a máscara aplicada. (f) O espaço paramétrico de Hough mostrando a função respiração encontrada em Fig. (e). . . . . . . . . . . . . .

6.8 Comparação dos padrões respiratórios encontrados pela transformada de Hough modificada antes e depois do ajuste feito pelo método de contornos ativos. (a) Espaço paramétrico de Hough. Ponto de máximo indicado por círculo vermelho. (b) Imagem de arestas com a máscara aplicada - contorno superior do pulmão. Padrão respiratório, antes do ajuste por contornos ativos, encontrado indicado em vermelho. (c) Mesma imagem de arestas que a exibida em (b), porém com o padrão respiratório indicado em vermelho após o ajuste pelo método de contornos ativos. (d) Espaço paramétrico de Hough. Ponto de máximo indicado por círculo vermelho. (e) Imagem de arestas com a máscara aplicada - contorno inferior do pulmão. Padrão respiratório, antes do ajuste por contornos ativos, encontrado indicado em vermelho. (f) Mesma imagem de arestas que a exibida em (e), porém com padrão respiratório indicado em vermelho após o ajuste pelo método de contornos ativos. . . . . . 
6.9 Ilustração do processamento temporal da imagem da Fig. 6.5(h) com uma imagem 2DST horizontal.(a) Imagem sagital de RM do pulmão (posição da imagem 2DST relativa a esta imagem está indicada em verde). (b) Imagem 2DST horizontal da imagem (a) criada na posição indicada. (c) O mapa de arestas referente ao contorno anterior com a máscara aplicada. (d) O espaço paramétrico de Hough mostrando a função respiração encontrada em (c). (e) O mapa de arestas referente ao contorno posterior com a máscara aplicada. (f) O espaço paramétrico de Hough mostrando a

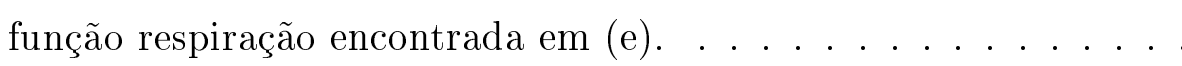

6.10 Ilustração do processamento temporal da imagem da Fig. 6.5(h) com uma imagem 2DST oblíqua $+45^{\circ}$.(a) Imagem sagital de RM do pulmão (posição da imagem 2DST relativa a esta imagem está indicada em verde). (b) Imagem $2 \mathrm{DST}$ oblíqua $+45^{\circ}$ da imagem (a) criada na posição indicada. (c) O mapa de arestas referente ao contorno posterior/superior com a máscara aplicada. (d) O espaço paramétrico de Hough mostrando a função respiração encontrada em (c). (e) O mapa de arestas referente ao contorno anterior/inferior com a máscara aplicada. (f) O espaço paramétrico de Hough mostrando a função respiração encontrada em (e). . . . 92

6.11 Ilustração do processamento temporal da imagem da Fig. 6.5(h) com uma imagem 2DST oblíqua $-45^{\circ}$.(a) Imagem sagital de RM do pulmão (posição da imagem 2DST relativa a esta imagem está indicada em verde). (b) Imagem 2DST oblíqua $-45^{\circ}$ da imagem (a) criada na posição indicada. (c) O mapa de arestas referente ao contorno anterior/superior com a máscara aplicada. (d) O espaço paramétrico de Hough mostrando a função respiração encontrada em (c). (e) O mapa de arestas referente ao contorno posterior/inferior com a máscara aplicada. (f) O espaço paramétrico de Hough mostrando a função respiração encontrada em (e). . . . . . 
6.12 Resultado da aplicação do processamento temporal em todas as imagens 2DST verticais, horizontais e oblíquas $\left(+45^{\circ}\right.$ e $\left.-45^{\circ}\right)$ válidas. As cores indicam a origem do ponto: pontos em vermelho e azul foram obtidos através do processamento de imagens 2DST verticais (vermelho representa o contorno superior e azul, o inferior); magenta (anterior) e laranja (posterior) foram obtidos com imagens 2DST horizontais; creme (anterior/inferior) e roxo (posterior/superior), de imagens 2DST oblíquas $+45^{\circ}$; e, por fim, bege (anterior/superior) e ciano (posterior/inferior), de imagens 2DST

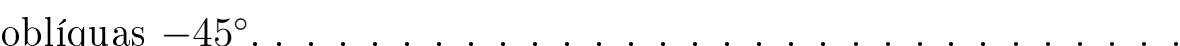

6.13 Obtenção de contorno a partir dos pontos encontrados pelo processamento temporal (referente ao resultado apresentando na Fig. 6.12). (a) Pontos encontrados. (b) Contorno inicial oval em vermelho. (c) Contorno resultado da aplicação de método de contornos ativos com GVF.

6.14 Resultado da aplicação dos contornos ativos com GVF. (a) Ilustração do resultado em relação à imagem. (b) Ilustração do resultado em relação aos pontos obtidos pelo processamento temporal. . . .

7.1 Segmentação do pulmão utilizando o primeiro método. (a) Imagem base. (b) Imagem binária. (c) Imagem após primeiro labeling. (d) Imagem após aplicação de filtro. (e) Imagem final, após segundo labeling

7.2 Segmentação do pulmão utilizando o primeiro método. (a) Imagem base. (b) Imagem binária. (c) Imagem após primeiro labeling. (d) Imagem após aplicação de filtro. (e) Imagem final, após segundo labeling. . . . . . . . . . . . . . . . . . .

7.3 Criação da máscara de busca do contorno a partir de região determinada anteriormente. (a) Imagem base. (b) Região do pulmão obtida. (c) Imagem após dilatação morfológica. (d) Imagem após erosão morfológica. (e) Imagem final. . . . . . . . . . . . . . . . . 98 
7.4 Processamento temporal com transformada de Hough modificada utilizando máscaras. (a) Imagem sagital - reta verde indica a posição da imagem 2DST vertical selecionada. (b) Imagem 2DST com pixels de alta intensidade filtrados. (c) Imagem de arestas com a máscara aplicada - contorno superior do pulmão. Padrão respiratório encontrado indicado em vermelho. (d) Espaço paramétrico de Hough. Ponto de máximo indicado por círculo vermelho. (e) Imagem de arestas com a máscara aplicada - contorno inferior do pulmão. Padrão respiratório encontrado indicado em vermelho. (f) Espaço paramétrico de Hough. Ponto de máximo indicado por

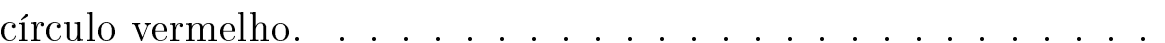

7.5 Processamento temporal com transformada de Hough modificada utilizando máscaras. (a) Imagem sagital - reta verde indica a posição da imagem 2DST horizontal selecionada. (b) Imagem 2DST com pixels de alta intensidade filtrados. (c) Imagem de arestas com a máscara aplicada - contorno anterior do pulmão. Padrão respiratório encontrado indicado em vermelho. (d) Espaço paramétrico de Hough. Ponto de máximo indicado por círculo vermelho. (e) Imagem de arestas com a máscara aplicada - contorno posterior do pulmão. Padrão respiratório encontrado indicado em vermelho. (f) Espaço paramétrico de Hough. Ponto de máximo indicado por círculo vermelho. . . . . . . . . . . . . . . . . . .

7.6 Processamento temporal com transformada de Hough modificada utilizando máscaras. (a) Imagem sagital - reta verde indica a posição da imagem 2DST oblíqua $+45^{\circ}$ selecionada. (b) Imagem 2DST com pixels de alta intensidade filtrados. (c) Imagem de arestas com a máscara aplicada - contorno posterior do pulmão. Padrão respiratório encontrado indicado em vermelho. (d) Espaço paramétrico de Hough. Ponto de máximo indicado por círculo vermelho. (e) Imagem de arestas com a máscara aplicada - contorno anterior do pulmão. Padrão respiratório encontrado indicado em vermelho. (f) Espaço paramétrico de Hough. Ponto de máximo indicado por círculo vermelho. . . . . . . . . . . . . . . . . . . . 100 
7.7 Processamento temporal com transformada de Hough modificada utilizando máscaras. (a) Imagem sagital - reta verde indica a posição da imagem 2DST oblíqua $-45^{\circ}$ selecionada. (b) Imagem 2DST com pixels de alta intensidade filtrados. (c) Imagem de arestas com a máscara aplicada - contorno anterior do pulmão. Padrão respiratório encontrado indicado em vermelho. (d) Espaço paramétrico de Hough. Ponto de máximo indicado por círculo vermelho. (e) Imagem de arestas com a máscara aplicada - contorno posterior do pulmão. Padrão respiratório encontrado indicado em vermelho. (f) Espaço paramétrico de Hough. Ponto de máximo indicado por círculo vermelho.

7.8 Resultados da segmentação temporal do pulmão para a mesma série apresentada na Fig. 7.2. As cores indicam a origem do ponto: pontos em vermelho e azul foram obtidos através do processamento de imagens 2DST verticais (vermelho representa o contorno superior e azul, o inferior); magenta (anterior) e laranja (posterior) foram obtidos com imagens 2DST horizontais; creme (anterior/inferior) e roxo (posterior/superior), de imagens 2DST oblíquas $+45^{\circ}$; e, por fim, bege (anterior/superior) e ciano (posterior/inferior), de imagens 2DST oblíquas $-45^{\circ}$. (a) Imagem 14. (b) Imagem 22. (c) Imagem 37. (d) Imagem 60. (e) Imagem 71. (f) Imagem 80.

7.9 Comparação dos resultados obtidos pelos dois métodos de segmentação do pulmão para a mesma série apresentada na Fig. 7.2. O resultado do primeiro método está apresentado em verde, e o resultado parcial do segundo método, em lilás. (a) Imagem 14. (b) Imagem 22. (c) Imagem 37. (d) Imagem 60. (e) Imagem 71. (f) Imagem 80 . . . . . . . . . . . . . . . . . . . . . 103

7.10 Ilustração da vantagem do segundo método apresentado. O resultado do primeiro método está apresentado em verde, e o resultado parcial do segundo método, em lilás. (a) Imagem 44. (b) Imagem 45. (c) Imagem 46. (d) Imagem 47. . . . . . . . . . . . . . . . . 104

7.11 Pontos processados da imagem da Fig. 7.8(a) apresentados em uma imagem binária. . . . . . . . . . . . . . . . . . . . . 105 
7.12 Campo GVF gerado a partir da imagem da Fig. 7.11. As setas indicam a direção do potencial dos gradientes. (a) Campo GVF. (b) Ampliação da região do canto superior direito da imagem (a). (c) Ampliação da região do canto inferior esquerdo da imagem (a). (d) Ampliação da região do canto inferior direito da imagem (a). . 105

7.13 Aplicação do método de contornos ativos com GVF. (a) Pontos provenientes do processamento temporal e contorno inicial oval indicado em vermelho. (b) Contorno resultante da aplicação de contornos ativos com GVF indicado em vermelho. . . . . . . . . 106

7.14 Resultado do segundo método proposto. (a) Contorno resultante comparado com a imagem original. (b) Contorno resultante comparado com os prontos obtidos por processamento temporal. . . . 107

7.15 Resultados da segmentação do contorno do pulmão pelo segundo método proposto comparados com as imagens da série. (a) Imagem 14. (b) Imagem 22. (c) Imagem 37. (d) Imagem 60. (e) Imagem 71. (f) Imagem 80. . . . . . . . . . . . . . . . . . . . 108

7.16 Resultados da segmentação do contorno do pulmão pelo segundo método proposto comparados com os pontos obtidos pelo processamento temporal. (a) Imagem 14. (b) Imagem 22. (c) Imagem 37. (d) Imagem 60. (e) Imagem 71. (f) Imagem 80. . . . . . . . . 109

7.17 Comparação dos resultados obtidos pelos dois métodos de segmentação do pulmão para a mesma série apresentada na Fig. 7.2. O resultado do primeiro método está apresentado em verde, e o resultado do segundo método, em lilás. (a) Imagem 14. (b) Imagem 22. (c) Imagem 37. (d) Imagem 60. (e) Imagem 71. (f) Imagem 80.110

7.18 Ilustração da vantagem do segundo método apresentado. O resultado do primeiro método está apresentado em verde, e o resultado do segundo método, em lilás. (a) Imagem 44. (b) Imagem 45. A seta amarela destaca o contorno inválido produzido pelo primeiro método. (c) Imagem 46. A seta amarela destaca o contorno inválido produzido pelo primeiro método. (d) Imagem 47. . . . . . . . 112

7.19 Resultados da segmentação do contorno do pulmão pelo segundo método proposto comparados com as imagens da série. (a) Imagem 07. (b) Imagem 15. (c) Imagem 30. (d) Imagem 45. (e) Imagem 54. (f) Imagem 64. . . . . . . . . . . . . . . . . . . . . . . . . 113 
7.20 Resultados da segmentação do contorno do pulmão pelo segundo método proposto comparados com os pontos obtidos pelo processamento temporal. (a) Imagem 07. (b) Imagem 15. (c) Imagem 30. (d) Imagem 45. (e) Imagem 54. (f) Imagem 64. . . . . . . . . 114

7.21 Comparação dos resultados obtidos pelos dois métodos de segmentação do pulmão para a mesma série apresentada na Fig. 7.19. O resultado do primeiro método está apresentado em verde, e o resultado do segundo método, em lilás. (a) Imagem 07. (b) Imagem 15. (c) Imagem 30. (d) Imagem 45. (e) Imagem 54. (f) Imagem 64.115

7.22 Segmentação do pulmão utilizando o primeiro método. (a) Imagem base. (b) Imagem binária. (c) Imagem após primeiro labeling. (d) Imagem após aplicação de filtro. (e) Imagem final, após segundo labeling. . . . . . . . . . . . . . . . . . . . . . 116

7.23 Criação da máscara de busca do contorno a partir de região determinada na Fig. 7.22. (a) Imagem base. (b) Região do pulmão obtida. (c) Imagem após dilatação morfológica. (d) Imagem após erosão morfológica. (e) Imagem final. . . . . . . . . . . . . . . . . 116

7.24 Processamento temporal com transformada de Hough modificada utilizando máscaras. (a) Imagem original - reta verde indica a posição da imagem 2DST vertical selecionada. (b) Imagem 2DST com pixels de alta intensidade filtrados. (c) Imagem de arestas com a máscara aplicada - contorno superior do pulmão. Padrão respiratório encontrado indicado em vermelho. (d) Espaço paramétrico de Hough. Ponto de máximo indicado por círculo vermelho. (e) Imagem de arestas com a máscara aplicada - contorno inferior do pulmão. Padrão respiratório encontrado indicado em vermelho. (f) Espaço paramétrico de Hough. Ponto de máximo indicado por círculo vermelho. . . . . . . . . . . . . . . . . . . . 117 
7.25 Comparação dos padrões respiratórios encontrados pela transformada de Hough modificada antes e depois do ajuste feito pelo método de contornos ativos. (a) Espaço paramétrico de Hough. Ponto de máximo indicado por círculo vermelho. (b) Imagem de arestas com a máscara aplicada - contorno superior do pulmão. Padrão respiratório, antes do ajuste por contornos ativos, encontrado indicado em vermelho. (c) Mesma imagem de arestas que a exibida em (b), porém com o padrão respiratório indicado em vermelho após o ajuste pelo método de contornos ativos. (d) Espaço paramétrico de Hough. Ponto de máximo indicado por círculo vermelho. (e) Imagem de arestas com a máscara aplicada - contorno inferior do pulmão. Padrão respiratório, antes do ajuste por contornos ativos, encontrado indicado em vermelho. (f) Mesma imagem de arestas que a exibida em (e), porém com padrão respiratório indicado em vermelho após o ajuste pelo método de contornos ativos. . . . . . 119

7.26 Processamento temporal com transformada de Hough modificada utilizando máscaras. (a) Imagem original - reta verde indica a posição da imagem 2DST horizontal selecionada. (b) Imagem 2DST com pixels de alta intensidade filtrados. (c) Imagem de arestas com a máscara aplicada - contorno anterior do pulmão. Padrão respiratório encontrado indicado em vermelho. (d) Espaço paramétrico de Hough. Ponto de máximo indicado por círculo vermelho. (e) Imagem de arestas com a máscara aplicada - contorno posterior do pulmão. Padrão respiratório encontrado indicado em vermelho. (f) Espaço paramétrico de Hough. Ponto de máximo indicado por círculo vermelho. . . . . . . . . . . . . . . . . . . . . 120

7.27 Comparação dos padrões respiratórios encontrados pela transformada de Hough modificada antes e depois do ajuste feito pelo método de contornos ativos. (a) Espaço paramétrico de Hough. Ponto de máximo indicado por círculo vermelho. (b) Imagem de arestas com a máscara aplicada - contorno posterior do pulmão. Função respiração, antes do ajuste por contornos ativos, encontrada indicada em vermelho. (c) Mesma imagem de arestas que a exibida em (b), porém com a função respiração indicada em vermelho após o ajuste pelo método de contornos ativos. . . . . . . . . . . . . . . 120 
7.28 Resultados da segmentação temporal do pulmão para a mesma série apresentada na Fig. 7.22. As cores indicam a origem do ponto: pontos em vermelho e azul foram obtidos através do processamento de imagens 2DST verticais (vermelho representa o contorno superior e azul, o inferior); magenta (anterior) e laranja (posterior) foram obtidos com imagens 2DST horizontais; creme (anterior/inferior) e roxo (posterior/superior), de imagens 2DST oblíquas $+45^{\circ}$; e, por fim, bege (anterior/superior) e ciano (posterior/inferior), de imagens 2DST oblíquas $-45^{\circ}$. (a) Imagem 14 . (b) Imagem 23. (c) Imagem 39. (d) Imagem 50. . . . . . . . . . . 121

7.29 Comparação dos dois métodos para imagens coronais, com a segmentação do pulmão direito. O resultado do primeiro método está apresentado em verde, e o resultado parcial do segundo método, em lilás. (a) Imagem 23. (b) Imagem 42. (c) Imagem 50. . . . . . 122

7.30 Resultados da segmentação do contorno do pulmão direito em imagem coronal pelo segundo método proposto comparados com as imagens da série. (a) Imagem 14. (b) Imagem 23. (c) Imagem 39. (d) Imagem 50

7.31 Resultados da segmentação do contorno do pulmão direito em imagem coronal pelo segundo método proposto comparados com os pontos obtidos pelo processamento temporal. (a) Imagem 14. (b) Imagem 23. (c) Imagem 39. (d) Imagem 50. . . . . . . . . . . . . 125

7.32 Comparação dos resultados obtidos pelos dois métodos de segmentação do pulmão direito em imagem coronal para a série abordada. O resultado do primeiro método está apresentado em verde, e o resultado do segundo método, em lilás. (a) Imagem 14. (b) Imagem 23. (c) Imagem 39. (d) Imagem 50. . . . . . . . . . . . . . . . . 126 


\section{Introdução}

O pulmão apresenta algumas características que não permitem sua observação in vivo. O movimento do pulmão é passivo, sendo o resultado da movimentação de outras partes do corpo, como o diafragma e a caixa torácica, e não é possível observar diretamente o pulmão, pois este colapsa ao se abrir a caixa torácica. Assim, o uso de dispositivos de imageamento indireto dos órgãos internos é a única forma para a visualização do pulmão.

Métodos atuais de diagnóstico do pulmão apresentam problemas diversos. Teste de função pulmonar e espirometria apresentam somente medidas globais da funcionalidade do pulmão. Sistemas de tomografia computadorizada (TC) de alta velocidade estão em desenvolvimento e permitem a visualização tridimensional de estruturas internas do pulmão no tempo, como descrito por Mori et al. ${ }^{[2]}$. Atualmente, diversos métodos para descrever o movimento do pulmão durante a respiração, a partir de imagens de TC, foram propostos, tentando-se manter doses de radiação limitadas e controladas ${ }^{[3-6]}$. O grande field-of-view (FOV) do pulmão, porém, torna proibitivo o uso repetitivo de tais métodos. Considerandose a segurança do paciente, o uso do imageamento por ressonância magnética (RM) torna-se, portanto, preferível. Mas esta técnica de imageamento também apresenta seus problemas: a baixa quantidade de tecido interno significa baixa quantidade de prótons e pouco sinal para aquisição. Além disso, a extensa área de interface tecido-ar provoca alta suscetibilidade a artefatos, além da introdução de artefatos devido aos movimentos do pulmão e coração ${ }^{[7,8]}$.

Independente do método de imageamento utilizado, as imagens obtidas de órgãos internos sofrem de algumas imperfeições características, pois como as imagens são geradas de maneira indireta, as intensidades dos pixels são determinadas a partir de médias de volumes, o que resulta em intensidades heterogêneas, resolução limitada e baixa relação sinal-ruído. A conseqüência direta disso é o fato de que muitas vezes os contornos dos órgãos internos não são fechados, pois algumas partes não são visíveis, e, portanto, desconectadas.

Métodos de segmentação totalmente automáticos por vezes falham, produ- 
zindo resultados incorretos e que exigem a intervenção de um operador humano. Isso é muito comum em aplicações médicas, onde a segmentação de imagem é particularmente difícil devido às restrições impostas pelos processos de aquisição, patologias e variações biológicas. Como conseqüência, a intervenção de um operador humano muitas vezes é necessária para iniciar o método, verificar a precisão do resultado produzido automaticamente, ou mesmo para corrigir o resultado da segmentação manualmente ${ }^{[9]}$.

A segmentação automática de estruturas anatômicas, tais como os pulmões em imagens de RM pulmonar, é uma tarefa fundamental, porém complicada, devido tanto à grande variação do formato do pulmão quanto à variação na qualidade de imagem. Artefatos de aquisição, baixo contraste e contornos mal definidos nessas imagens fazem da segmentação automática do pulmão um grande desafio ${ }^{[10]}$.

O imageamento do movimento respiratório pode ser dividido em duas abordagens: a abordagem estática, que utiliza procedimentos e seqüências padrões aplicados em ciclos de breath-hold, em que o paciente segura a respiração, para se adquirir imagens em diferentes fases da respiração; e a abordagem com procedimentos e seqüências de imageamento rápidos durante a respiração livre do paciente. Na segunda abordagem, o movimento do pulmão obtido ao longo da série de imagens representa com maior fidelidade a respiração do paciente, ao custo da resolução e qualidade de imagem. A utilização de padrões respiratórios, porém, permite que imperfeições presentes em imagens individuais sejam amenizadas ao se considerar a informação presente na série como um todo.

\subsection{Organização do Texto}

O capítulo 2 apresenta um resumo de outras técnicas presentes na literatura para o problema de segmentação do pulmão e o estudo de seu movimento.

O capítulo 3 apresenta os conceitos básico da física do imageamento por RM.

O capítulo 4 apresenta os principais conceitos utilizados ao longo dos métodos introduzidos nesta dissertação. A seção 4.1 introduz o conceito de padrões respiratórios. Na seção 4.2, faz-se uma breve revisão de um método que utiliza o conceito de padrão respiratório para efetuar uma segmentação temporal do pulmão. Na seção 4.3, a transformada de Hough é revisada, e uma modificação, para que utilize os padrões respiratórios, é proposta. Na seção 4.4, apresenta-se a aritmética intervalar. Mostra-se sua vantagem sobre a aritmética 
em ponto flutuante, e explica-se como utilizá-la com a transformada de Hough. A seção 4.5 explora os modelos de contornos ativos, também chamado de snakes, e apresenta-se o algoritmo adotado neste trabalho. Na seção 4.6, a segmentação por limiarização é brevemente explicada e exemplos são apresentados. O filtro de mediana é apresentado, junto com exemplos, na seção 4.7. Por fim, na seção 4.8 é feita uma pequena introdução à morfologia matemática e seus operadores utilizados neste trabalhado são apresentados.

O capítulo 5 apresenta um primeiro método de segmentação do pulmão. O algoritmo é explicado detalhadamente. Nesta abordagem, cada imagem é segmentada individualmente. Exemplos são apresentados.

O capítulo 6 apresenta um segundo método para a segmentação do pulmão, que corrige as falhas do primeiro método através de processamentos adicionais. Este método realiza uma segmentação temporal, ou seja, utiliza informação de todas as imagens da série, através dos padrões respiratórios.

No capítulo 7, os resultados obtidos são apresentados, para diversos conjuntos de imagens, e os dois métodos são comparados.

Por fim, no capítulo 8, as conclusões feitas a partir dos resultados apresentados são apresentadas. 


\section{Segmentação do Pulmão}

Vários métodos têm sido propostos para a segmentação dos pulmões a partir de imagens de CT ${ }^{[11]}$. A maioria dos algoritmos utiliza operação de limiarização de nível de cinza seguido por segmentação por contornos ativos. No entanto, trabalhos anteriores demonstraram que as imagens de RM não podem ser segmentadas de forma tão precisa quanto imagens de CT, devido a diferentes razões, tais como a natureza não-uniforme dos dados. De fato, nessas imagens, a segmentação ideal não pode ser obtida somente através de informações do nível de cinza, e conhecimento a priori tem de ser incorporado ao processo.

Até o momento, existem poucos estudos sobre o movimento do pulmão, em particular a segmentação das cavidades pulmonares, a partir de imagens de RM pulmonar. Iwasawa et al. ${ }^{[12]}$ avaliaram o movimento do pulmão de forma quantitativa a partir de imagens de RM utilizando a área de deslocamento e o movimento total do diafragma do pulmão em um ciclo respiratório. Cluzel et al. ${ }^{[13]}$ obtiveram imagens tridimensionais de RM obtidas em breath-hold (isto é, com o paciente segurando a respiração) reduzindo-se o tempo de aquisição de cada imagem. Middleton e Damper ${ }^{[14]}$ abordaram a segmentação do pulmão a partir de imagens de RM através de uma combinação de classificadores de redes neurais supervisionadas e modelos de contornos ativos paramétricos para delinear os pulmões em várias fatias de RM. Ray et al. ${ }^{[15]}$ atacaram o mesmo problema utilizando modelos de contornos ativos paramétricos que poderiam mesclar múltiplos contornos para segmentar o ar pulmonar total. Este método utilizava um campo de forças externas, baseado em equações diferenciais parciais com condições de contorno que foram definidas pela posição inicial dos contornos. Osareh e Shadgar ${ }^{[16]}$ utilizaram contornos ativos geométricos para segmentar cavidades pulmonares em imagens de RM.

Asakura et al. ${ }^{[17]}$ propuseram um método para a segmentação temporal da região do pulmão em seqüências de imagens de RM. Um perito médico é responsável por definir o contorno da região do pulmão na imagem inicial (ver Fig. 2.1(a)) e o algoritmo o determina nas demais imagens da seqüência (ver Fig. 2.1(b)). Este 


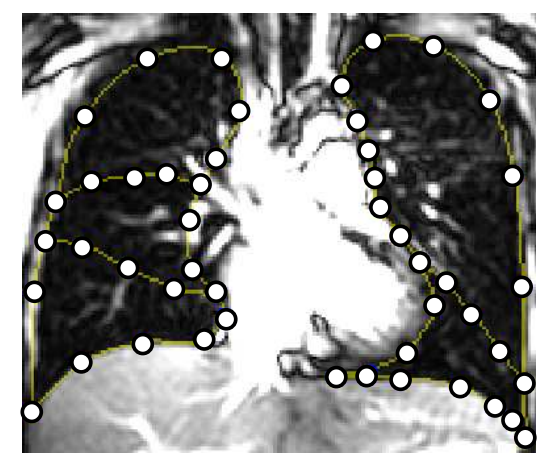

(a)

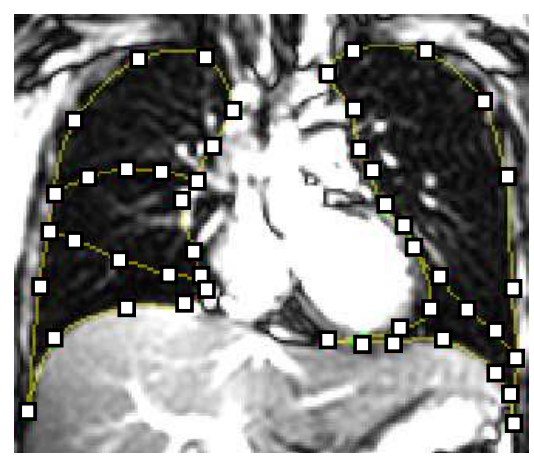

(b)

Figura 2.1: (a). Contorno definido pelo usuário - pontos de controles representados por círculos. (b) Contorno determinado automaticamente pelo algoritmo pontos de controle representados por quadrados.

método produz resultados aceitáveis, mas é muito dependente do especialista médico que define o contorno inicial do pulmão. E como indicado por Asakura et al. ${ }^{[17]}$, em algumas situações é necessária a correção de alguns pontos de controle determinados pelo algoritmo.

Tsuzuki et al. ${ }^{[18]}$ utilizaram este método para reconstruir uma animação 3D do pulmão, unindo diversas seqüências de imagens temporais sagitais e coronais. Imagens sagitais e coronais possuem um segmento de interseção vertical, e foi possível observar neste segmento que um especialista médico pode ser induzido a erros na segmentação temporal, principalmente como conseqüência dos contornos mal definidos.

Matsushita et al. ${ }^{[19]}$ propuseram um método para detectar a presença de padrões respiratórios em imagens temporais baseado em transformada de Hough. Este método determina diversos padrões respiratórios, do pulmão e de todas as demais estruturas internas e demais órgãos no seu entorno, sendo, portanto incapaz de determinar qual dos diversos padrões respiratórios detectados pertence ao contorno do pulmão. 


\section{A Ressonância Magnética do Pulmão}

O fenômeno da RM na matéria foi demonstrado pelo primeira vez por Bloch ${ }^{\text {[20] }}$ e por Purcell et al. ${ }^{[21]}$. Desde então, a RM se desenvolveu em uma técnica sofisticada com aplicações em uma grande diversidade de áreas, permitindo desde a determinação de estruturas moleculares até o estudo de tecidos vivos, como no caso da medicina.

A RM é uma técnica de imageamento tomográfico que produz imagens de características físicas e químicas internas ao objeto de estudo a partir de sinais medidos externamente. Como outros métodos de imageamento tomográfico, na RM obtém-se uma matriz de dados multi-dimensional que representa a distribuição espacial de alguma quantidade física medida. Diferentemente de muitos métodos tomográficos, porém, a RM é capaz de gerar imagens bi-dimensionais em qualquer orientação. Além disso, a técnica de imageamento por RM utiliza, para a criação da imagem, sinais provenientes do próprio objeto de estudo. Neste ponto, a RM se assemelha a técnicas como PET e SPECT, mas, diferente destes, não requer a injeção de isótopos radioativos.

Nesta seção, os princípios físicos básicos da RM são apresentados. O texto apresentado aqui baseou-se nos textos escritos por Maria Santarelli ${ }^{[22]}$ e Jiri Jan ${ }^{[23]}$.

\subsection{Spin Nuclear}

O princípio da RM é uma propriedade possuída por certos núcleos, o momento angular do spin $(p)$. O momento angular do spin do núcleo pode ser considerado como o resultado do movimento de rotação do núcleo em torno de seu próprio eixo, e depende do número quântico magnético do spin $(I)$, sendo expresso como

$$
|\vec{p}|=\hbar \cdot \sqrt{I \cdot(I+1)}
$$


onde $\hbar=h / 2 \pi$ e $h$ é a constante de Planck. O valor do número quântico magnético do spin, representado por $I$, depende da estrutura do núcleo do átomo - número de prótons e nêutrons. O hidrogênio $\left({ }^{1} H\right.$, com I $\left.=1 / 2\right)$, o elemento químico mais abundante na natureza e no corpo humano, é muito receptivo a experimentos de RM. Por outro lado, outros elementos químicos presentes no corpo humano, os isótopos mais comuns de carbono $\left({ }^{12} C\right)$ e oxigênio $\left({ }^{16} O\right)$ possuem núcleos com $\mathrm{I}=0$ e, portanto, não podem ser observados em experimentos de RM.

Como o núcleo é uma partícula carregada, o momento angular do spin é acompanhado por um momento magnético $(\vec{\mu})$, dado por

$$
\vec{\mu}=\gamma \vec{p}
$$

onde $\gamma$ é a razão giromagnética. A razão giromagnética é particular de cada núcleo, sendo proporcional à razão carga-massa. Nota-se que tanto $\vec{p}$ quanto $\vec{\mu}$ são valores vetoriais, possuindo magnitude, direção e sentido.

\subsection{Núcleo Imerso em um Campo Magnético}

Em experimentos de RM, estuda-se o comportamento de núcleos expostos a campos magnéticos externos. A presença de um momento magnético significa que o núcleo se comporta de forma semelhante a um imã, possuindo ambos os pólos norte e sul, e interagindo com campos magnéticos externos. No caso de um imã, a presença de outro campo magnético iria induzi-lo a se alinhar com as linhas de campo. No caso do núcleo, porém, a presença de um momento angular faz com que ao invés de simplesmente se alinhar, o núcleo realize uma movimento de precessão em torno da direção do campo magnético (como ilustrado na Fig. 3.1). A interação do campo magnético $\overrightarrow{B_{0}}$ com o momento angular $\vec{\mu}$ gera o seguinte torque $(\vec{L})$ que tenta alinhar ambos os vetores

$$
\vec{L}=\vec{\mu} \times \overrightarrow{B_{0}}
$$

O torque que causa o movimento de precessão do núcleo em torno de $\overrightarrow{B_{0}}$ também altera o momento angular. Então

$$
d \vec{p} / d t=\vec{L}=\vec{\mu} \times \overrightarrow{B_{0}}
$$




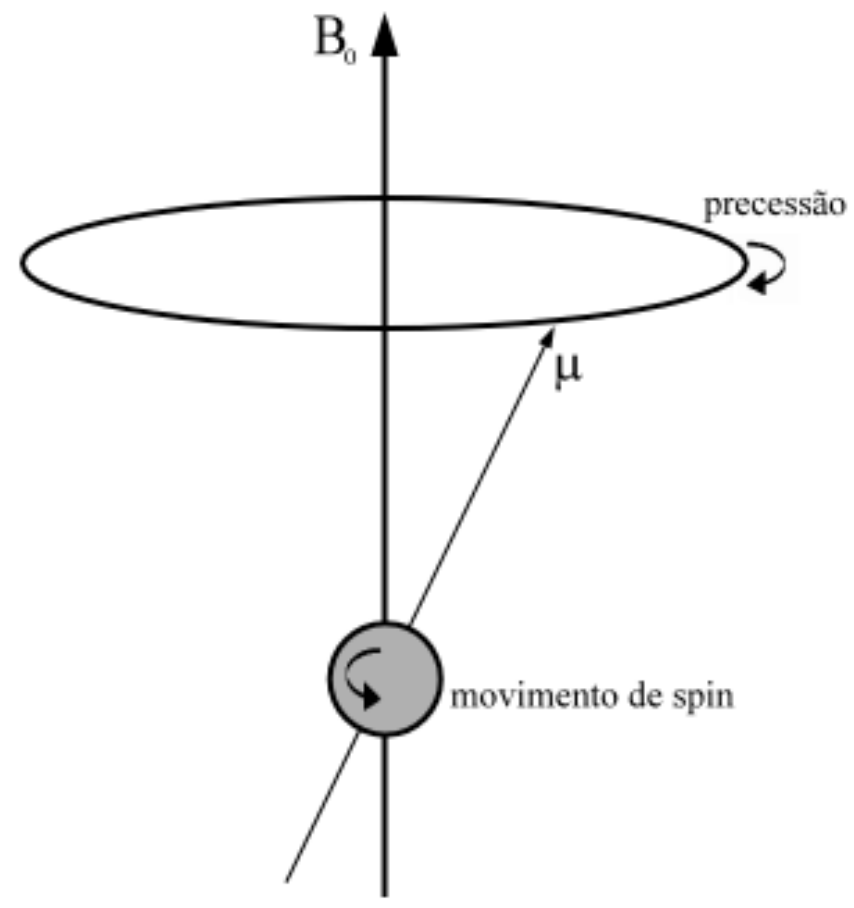

Figura 3.1: Ilustração do movimento de precessão do vetor do momento angular do núcleo em torno de um campo magnético externo.

e como $\vec{p}=\vec{\mu} / \gamma$, temos

$$
d \vec{\mu} / d t=\vec{\mu} \times \gamma \overrightarrow{B_{0}}=\overrightarrow{\omega_{0}} \times \vec{\mu}
$$

onde $\overrightarrow{\omega_{0}}=-\gamma \overrightarrow{B_{0}}$ é a freqüência de precessão, e é chamada de freqüência de Larmor. Portanto, quanto maior o campo magnético, maior a freqüência de precessão.

Levando para escalas macroscópicas, o vetor de magnetização $\vec{M}$ é o vetor resultante da soma de todos os momentos angulares microscópicos

$$
\vec{M}=\sum \overrightarrow{\mu_{i}}
$$

O vetor de magnetização resultante é zero em equilíbrio e não-zero quando um campo magnético externo, $\overrightarrow{B_{0}}$, é aplicado, e possui a mesma direção de $\overrightarrow{B_{0}}$. Da mesma forma que os núcleos microscópicos, o vetor de magnetização também atua como um dipolo e precessa em torno de $\overrightarrow{B_{0}}$. Em um experimento de RM, o sinal detectado provém da precessão do vetor de magnetização resultante. 


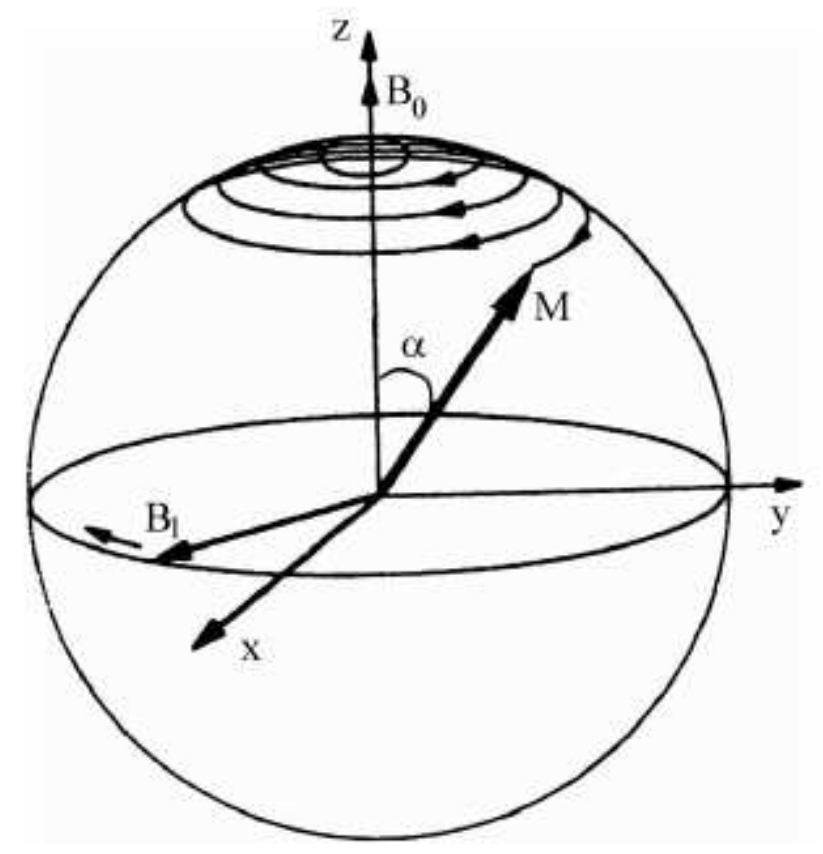

Figura 3.2: Trajetória do vetor de magnetização resultante, que retorna ao estado de equilíbrio, em precessão.

\subsection{Excitação em Rádio-Freqüência}

O sistema inicialmente em equilíbrio não gera sinal para ser detectado, com $\vec{M}$ e $\overrightarrow{B_{0}}$ alinhados. Dessa forma, para se remover o sistema desse estado de equilíbrio, aplica-se um segundo campo magnético $\overrightarrow{B_{1}}$, perpendicular a $\overrightarrow{B_{0}}$, com rotação de $\overrightarrow{\omega_{0}}$ em torno de $\overrightarrow{B_{0}}$. O campo magnético aplicado, $\overrightarrow{B_{1}}$, faz com que $\vec{M}$ se desalinhe de $\overrightarrow{B_{0}}$ e inicie o movimento de precessão, realizando um movimento em espiral até retornar ao estado de equilíbrio, como ilustrado na Fig. 3.2. Como a freqüência do pulso, $\overrightarrow{\omega_{0}} / 2 \pi$ está dentro da faixa de ondas de rádio, esse campo magnético aplicado também é chamado de pulso de rádio-freqüência $(\mathrm{RF})$. O ângulo de inclinação $\alpha$ entre $\vec{M}$ e $\overrightarrow{B_{0}}$, forçado pela aplicação de $\overrightarrow{B_{1}}$ depende da duração e da amplitude do pulso de RF aplicado. Um pulso $\overrightarrow{B_{1}}$ típico é da forma

$$
\overrightarrow{B_{1}}(t)=\overrightarrow{B_{e}}(t) e^{-i\left(\omega_{0} t+\varphi\right)}
$$

onde $\vec{B}_{e}(t)$ é uma função-envelope que dá o formato do pulso. Dois exemplo típicos de $\overrightarrow{B_{e}}(t)$ são o pulso retangular (Fig. 3.3(a)) e o pulso sinc (Fig. 3.3(b)). De maneira geral, porém, para uma amplitude constante $\overrightarrow{B_{1}}$, um pulso de duração $\tau$ faz com que o vetor de magnetização resultante precesse por um ângulo de inclinação 


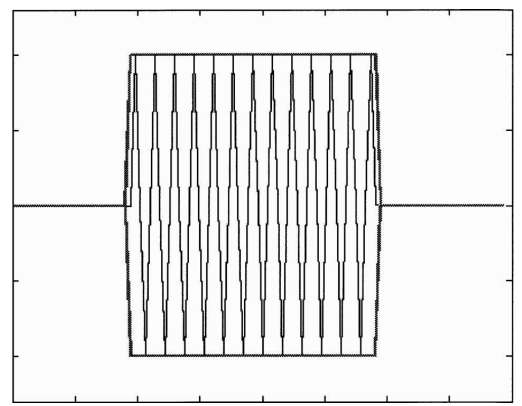

(a)

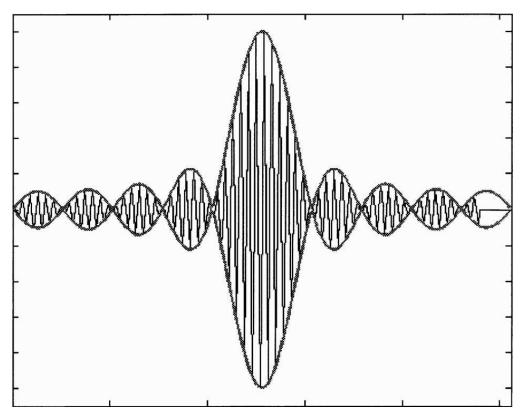

(b)

Figura 3.3: Formatos típicos para o pulso de RF. (a) Pulso retangular. (b) Pulso sinc.

$$
\alpha=\gamma \overrightarrow{B_{1}} \tau
$$

ou, de maneira mais geral, caso a amplitude de $\overrightarrow{B_{1}}$ varie no tempo,

$$
\alpha=\gamma \int_{0}^{\tau}\left|\overrightarrow{B_{1}}(t)\right| d t
$$

\subsection{O sinal da RM}

Sendo $\vec{M}$ o vetor de magnetização resultante, $M_{z}$ é sua componente no eixo $z$ ( $\overrightarrow{B_{0}}$ é aplicado na mesma direção e sentido deste eixo), $M_{x}$ é sua componente no eixo $x$ e $M_{y}$, no eixo $y$, e $M_{x y}$ é a resultante no plano $x y$ (ver Fig. 3.4). O plano $x y$, portanto, é transversal à direção do campo magnético externo $\overrightarrow{B_{0}}$. No estado de equilíbrio, $M_{z}=M$ e $M_{x}=M_{y}=0$.

Devido à aplicação do pulso de RF, o vetor de magnetização $\vec{M}$ sofre uma inclinação em relação ao eixo $z$, e inicia o movimento de precessão em torno do campo externo $\overrightarrow{B_{0}}$, na freqüência de Larmor. O efeito disto é o mesmo de um imã em rotação e, portanto, gera-se um campo magnético resultante no plano transversal $\vec{M}_{x y}$ que também está rotacionando. O uso de bobinas de recepção em torno da amostra torna possível detectar esses campos magnéticos variantes, devido à lei de indução de Faraday.

Pode-se mostrar que a amplitude da voltagem alternada induzida nas bobinas de recepção é proporcional ao vetor de magnetização transversal, $\vec{M}_{x y}$. Portanto, a máxima amplitude de sinal é obtida quando se aplica um pulso que provoca um ângulo de inclinação de $\pi / 2$. De maneira geral, um pulso de RF que provoca um ângulo de inclinação $\alpha$ gera um sinal de voltagem alternada com amplitude 


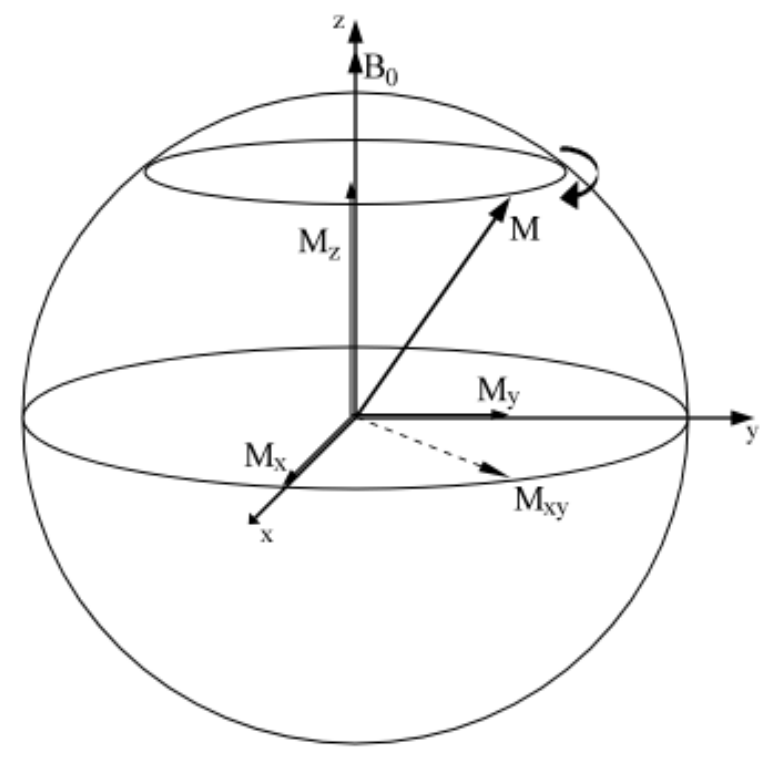

Figura 3.4: Componentes do vetor de magnetização.

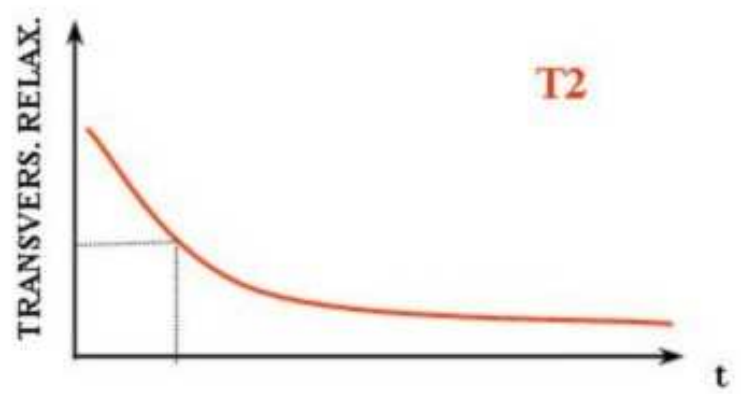

Figura 3.5: Curva de decaimento da magnetização transversal.

proporcional a $|\vec{M} \operatorname{sen}(\alpha)|$.

Após a aplicação do pulso de RF, o sistema passa a perder energia e o vetor de magnetização resultante $\vec{M}$, em precessão, tende a se realinhar com o campo magnético externo $\overrightarrow{B_{0}}$. Neste período, chamado de relaxamento, o vetor de magnetização transversa $\vec{M}_{x y}$ tende a decair para zero e, ao mesmo tempo, a componente do vetor de magnetização $M_{z}$ retorna ao valor de equilíbrio inicial $M_{z}=|\vec{M}|$. O decaimento de $\vec{M}_{x y}$ e a recuperação de $M_{z}$ são dois processos distintos.

O decaimento do vetor de magnetização transversa $\vec{M}_{x y}$ após um pulso de RF com ângulo de inclinação $\alpha$ pode ser expresso como 


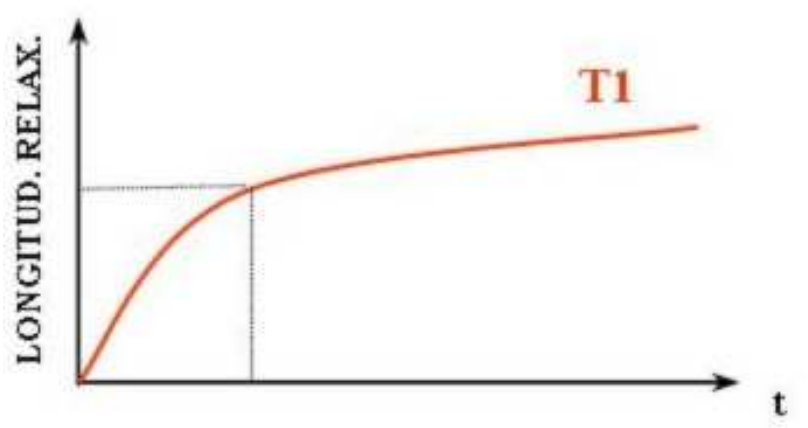

Figura 3.6: Curva de recuperação da magnetização longitudinal.

$$
\vec{M}_{x y}(t)=\vec{M}_{x y}(0) e^{-t / T_{2}}
$$

onde o parâmetro $T_{2}$ é o tempo de relaxamento da magnetização transversa e representa o tempo necessário para que a magnitude do vetor de magnetização transversa decaia para cerca de $37 \%$ do valor inicial. A curva de relaxamento transversal está apresentada na Fig. 3.5.

A recuperação do vetor de magnetização longitudinal $\vec{M}_{z}$ após um pulso de RF com ângulo de inclinação $\alpha$ pode ser expressa como

$$
\vec{M}_{z}(t)=\vec{M}-\left(\vec{M}-\vec{M}_{z}(0)\right) e^{-t / T_{1}}
$$

onde o parâmetro $T_{1}$ é o tempo de relaxamento longitudinal e representa o tempo necessário para que a magnitude do vetor de magnetização longitudinal se recupere para cerca de $63 \%$ do valor de equilíbrio. A curva de relaxamento longitudinal está apresentada na Fig. 3.6.

Em uma imagem gerada por RM, podem estar presentes pontos em diversas intensidades. Pontos mais escuros, em tons próximos de preto, indicam que aquela região da amostra gerou pouco sinal, e essa região (tecido) é chamada de hipointensa. Já pontos mais claros, em tons mais próximos do branco, significam que na região foi gerado sinal mais forte, e essa região (tecido) é chamada de hiperintensa. Tecidos diferentes geram quantidades diferentes de sinal, o que permite sua distinção na imagem. Um determinado tecido gera um sinal muito forte caso possua grande magnitude do vetor de magnetização transversa $\left(\vec{M}_{x y}\right)$ capaz de gerar um grande sinal na bobina receptora. Um tecido envia um sinal fraco à bobina receptora quando este seu vetor de magnetização transversa for de pequena amplitude. 
O contraste das imagens é conseqüência principalmente dos mecanismos de recuperação em $T_{1}$ e decaimento em $T_{2}$. O tecido adiposo, por exemplo, possui $T_{1} \approx 250 \mathrm{~ms}$ e $T_{2} \approx 70 \mathrm{~ms}$ (em um campo externo $\left|\overrightarrow{B_{0}}\right|=1.5 T$ ), ou seja, possui tempo de recuperação e relaxação curtos se comparados, por exemplo, com o sangue $\left(T_{1} \approx 1350 \mathrm{~ms}\right.$ e $T_{2} \approx 200 \mathrm{~ms}$, também em $\left.\left|\overrightarrow{B_{0}}\right|=1.5 T\right)$. Imagens ponderadas em $T_{1}$, portanto, apresentam o tecido adiposo hiperintenso e o sangue hipointenso. Por outro lado, imagens ponderadas em $T_{2}$, portanto, apresentam o tecido adiposo hipointenso e o sangue hiperintenso. A escolha de valores para $T_{1}$ e $T_{2}$, então, permitem selecionar os tecidos de interesse.

\subsection{Múltiplos pulsos de RF}

Até agora, foram discutidos os efeitos de um único pulso de RF aplicado sobre uma amostra. A utilização de seqüências com múltiplos pulsos permite a obtenção de informação que não está disponível em experimentos com pulsos de RF únicos. Nesta seção, serão apresentadas as principais seqüências de pulsos. Observase que diferentes fabricantes podem ter diferentes designações para uma mesma seqüência de pulsos.

As principais seqüências são:

- Gradient Echo (GE) - A seqüência GE envolve a utilização de um pulso de RF com ângulo de inclinação $\alpha$ seguido de um gradiente de campo magnético para se gerar e receber sinal de eco de gradiente. O gradiente aplicado pode defasar e refasar o sinal de maneira controlada. Após a aplicação do pulso, um gradiente pode ser aplicado, por exemplo, ao longo do eixo $x$. Assim, pontos da amostra em diferentes posições no eixo $x$ estarão em fases diferentes. Após o decaimento do sinal para zero, um novo gradiente é aplicado em sentido oposto, recolocando os pontos em fase e, então, um sinal de eco é gerado. Geralmente, menores valores de $\alpha$ são utilizados para experimentos mais rápidos. O tempo entre a aplicação do primeiro gradiente e a aplicação do segundo gradiente é chamado de tempo de eco (TE).

- Inversion Recovery (IR) - Na seqüência IR, o vetor de magnetização inicialmente em equilíbrio é perturbado por um pulso de $\mathrm{RF} \operatorname{com} \alpha=180^{\circ}$. Após um pequeno tempo, chamado de tempo de inversão (TI), um novo pulso de $\mathrm{RF} \operatorname{com} \alpha=90^{\circ}$ é aplicado. Durante o tempo de inversão, a magnetização sofre o relaxamento, mas o vetor de magnetização resultante continua alinhado ao eixo $z$, ou seja, $\vec{M}_{x y}=0$, e nenhum sinal é gerado nas 
bobinas de recepção. Em seguida, com a aplicação do pulso $\alpha=90^{\circ}$, uma componente de magnetização $\vec{M}_{x y}$ é criada, e um sinal pode ser capturado do relaxamento do vetor de magnetização. Este experimento pode ser utilizado para a determinação do parâmetro $T_{1}$ ou para se obter maior sensibilidade neste parâmetro.

- Spin Echo (SE) - A seqüência SE constitui a maior parte das aquisições para obtenção de imagens, sendo usadas em quase todos os exames. As imagens ponderadas em $T_{1}$ fornecem nessa seqüência um excelente detalhamento anatômico e, as ponderadas em $T_{2}$, reproduzem com grande fidelidade as condições patológicas, graças ao conteúdo hídrico das mesmas que se apresentam com sinais hiperintensos. Consiste de um pulso de RF inicial de $\alpha=90^{\circ}$, seguido de outro pulso com $\alpha=180^{\circ}$ após um tempo $T E / 2$. No tempo $T E$, um eco ocorre, gerando o máximo sinal devido ao refasamento de toda a amostra. Esta seqüência permite compensar algumas inomogeneidades do campo magnético que provocam o defasamento de parte da amostra.

- Short TI Inversion Recovery (STIR) - É uma seqüência IR modificada com tempo TI curto para a supressão do sinal do tecido adiposo. Após a aplicação do pulso $\alpha=180^{\circ}$, aguarda-se o relaxamento em $T_{1}$ do tecido adiposo (que é mais curto do que outros tecidos), e então aplica-se a mesma seqüência de pulsos da SE. Nota-se que no momento em que se inicia os pulsos da SE, não há magnetização longitudinal no tecido adiposo, e portanto nenhum sinal é gerado nessa região.

- Fast Spin Echo (FSE) - Esta seqüência é uma modificação da SE para imageamento mais rápido. Após o primeiro eco, devido ao relaxamento, $\vec{M}_{x y}$ tende a zero e $\vec{M}_{z}$ tende a $\vec{M}$. Pode-se, porém, aplicar outro pulso com $\alpha=180^{\circ}$ para se obter um novo eco e, portanto, obter o sinal referente à outra posição espacial. Desta forma, varre-se mais rapidamente o espaço da amostra, e o tempo de imageamento é reduzido.

- Balanced Gradient Echo (BGE) - Esta seqüência é uma variação da Steady State Gradient Echo (SSGE), com gradientes balanceados. Na SSGE, a magnetização transversal residual é conservada, participando do sinal gerado. Em seqüências da família GE, tempos de repetição (TR) baixos $\left(T R<T_{2}\right)$ causam magnetização transversal residual (isto é, $\vec{M}_{x y} \neq 0$ no início de outro pulso semelhante ao aplicado). Nas seqüências da família SSGE, essa magnetização residual é utilizada para a geração do sinal do 
novo eco, e o seu ângulo de inclinação diferente de zero é aproveitado. A seqüência BGE é chamada, em equipamentos da Siemens, de TrueFISP, é a sequiência utilizada para a geração das imagens deste trabalho, e é o método ideal para imageamento do pulmão por $\mathrm{RM}^{[8]}$ por possuir eficiente relação sinal-ruído. 


\section{Principais Conceitos}

Neste capítulo será apresentado o conceito de função respiração, que será utilizado pela transformada de Hough modificada para determinar padrões respiratórios. A transformada de Hough será tornada mais robusta com a introdução da aritmética intervalar. Assim, movimentos síncronos à função respiração serão determinados. Entretanto, como o pulmão não se movimenta de modo totalmente síncrono, o resultado da transformada de Hough será ajustado pelo algoritmo de contornos ativos.

\subsection{Padrões Respiratórios}

Um volume espaço temporal (STV - Spatio Temporal Volume), $I_{s}(x, y, t)$ é definido pelo empilhamento de imagens de seqüências temporais, onde $x$ e $y$ são as coordenadas de cada pixel da imagem e $t$ é o tempo. Fig. 4.1 mostra um exemplo de um STV, construído a partir de 10 imagens coronais do mesmo plano de corte do pulmão feitas em instantes de tempo diferentes.

Um plano $Q_{s}\left(x_{s}, y_{s}, \theta_{s}\right)$ é definido, de modo que ele contém o ponto $\left(x_{s}, y_{s}\right)$, faz um ângulo de $\theta_{s}$ com o eixo $x$ e é paralelo ao eixo de tempo $t$. A intersecção do $\mathrm{STV} I_{s}(x, y, t)$ com $Q_{s}\left(x_{s}, y_{s}, \theta_{s}\right)$ define uma imagem espaço-temporal 2D (2DST) como ilustrado na Fig. 4.2. A imagem 2DST $F_{s}\left(t, y_{s}\right)$ corresponde à intersecção do STV $I_{s}(x, y, t) \operatorname{com} Q_{s}\left(x_{s}, y_{s}, \theta_{s}\right)$. Fig. 4.3 mostra imagens 2DST obtidas em três ângulos diferentes, vertical, horizontal e oblíquo $\left(\theta_{s}=90^{\circ}, \theta_{s}=0^{\circ}\right.$ e $\theta_{s}=-45^{\circ}$, respectivamente).

Figura 4.3 mostra que ao longo do movimento ocorrem súbitas alterações de intensidade, algo comum em imagens de RM devido a alterações nas condições de magnetização. Para se determinar o contorno do pulmão em seqüências temporais de imagens de RM de uma determinada fatia, mesmo em quadros onde não é visível, toma-se como hipótese inicial que todas as estruturas relacionadas com os pulmões movem-se de maneira quase síncrona, e a sincronização será feita através de um padrão chamado função respiração ${ }^{[17-19]}$. 


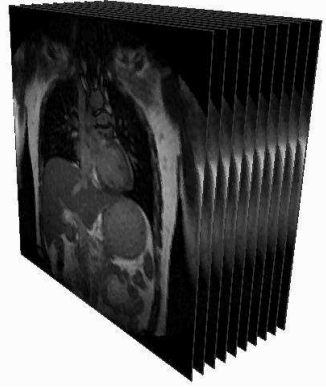

(a)

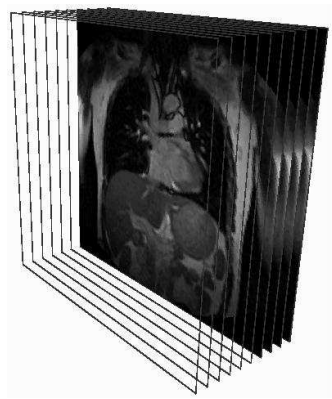

(d)

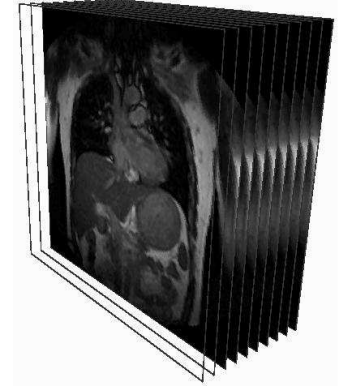

(b)

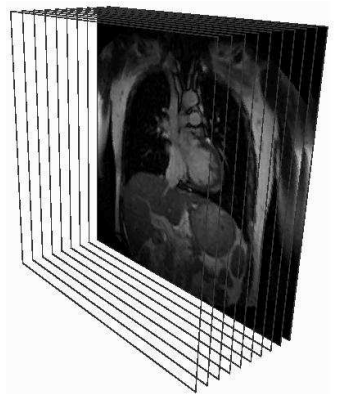

(e)

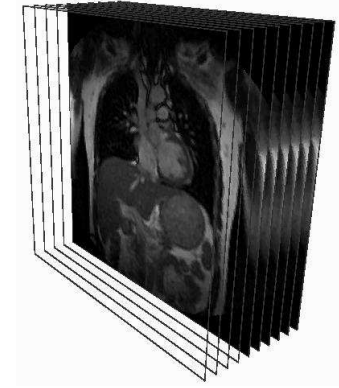

(c)

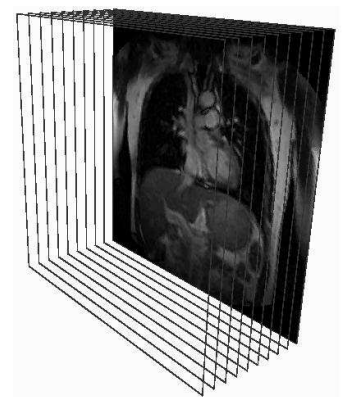

(f)

Figura 4.1: Um exemplo de um STV construído a partir de 10 imagens coronais de RM do pulmão.

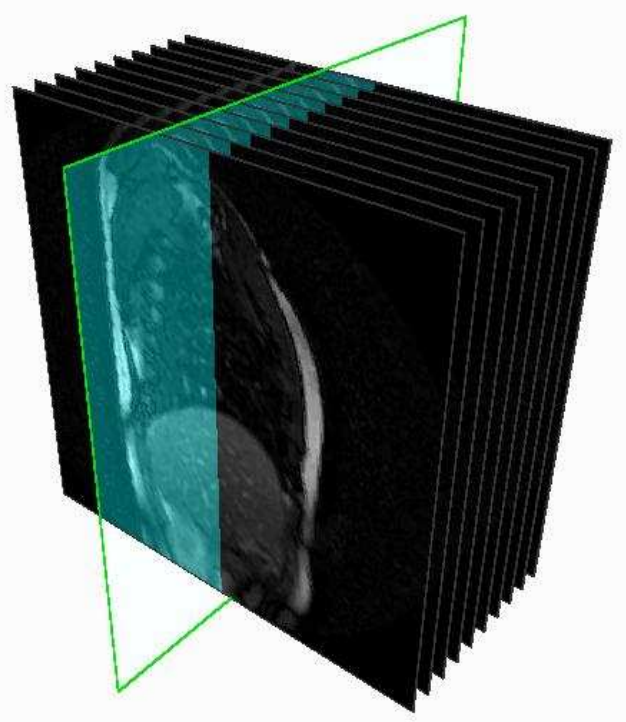

Figura 4.2: Ilustração da intersecção de um dado STV com um plano arbitrário paralelo ao eixo do tempo. 


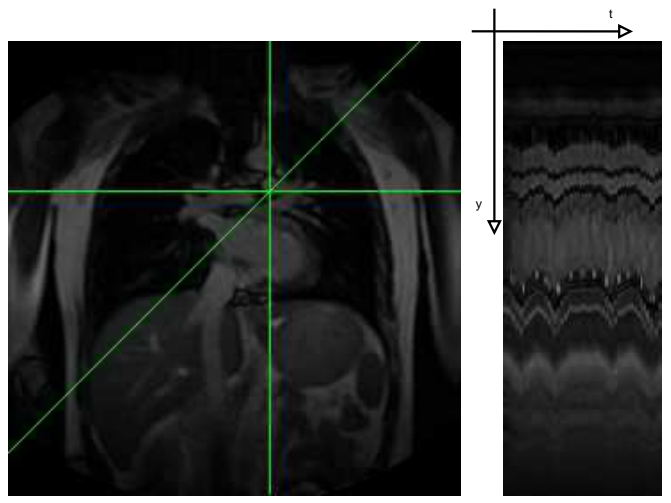

(a) Imagem de RM da região torácica e uma imagem 2DST vertical.

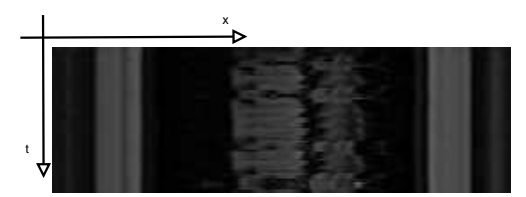

(b) Uma imagem 2DST horizontal.

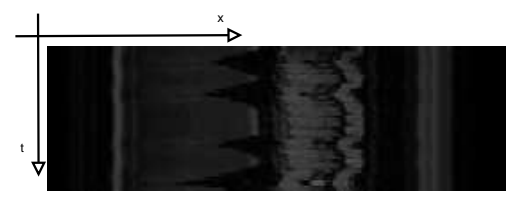

(c) Uma imagem 2DST oblíqua.

Figura 4.3: Imagem de RM da região torácica e imagens 2DST.

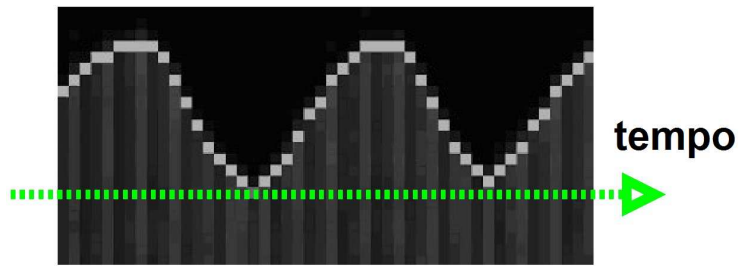

Figura 4.4: Uma função respiração base $f_{s}(t)$. 
Uma função respiração base $f_{s}(t)$ é determinada na região diafragmática. A superfície diafragmática é mais fácil de observar, com altos gradientes, e seu movimento tem uma maior amplitude quando comparado a outras estruturas da caixa torácica. Uma $f_{s}(t)$ é mostrada na Fig. 4.4, que representa uma seqüência de valores inteiros não-negativos no tempo. A $f_{s}(t)$ está dentro do intervalo $\left[0, f_{\max }\right]$, onde $f_{\max }$ é a sua amplitude máxima.

Portanto, a função respiração é a estimativa de um padrão de movimento do pulmão e estruturas relacionadas na imagem 2DST. A função respiração base é um dado de entrada para a transformada de Hough para se determinar a presença de movimentos sincronizados com a respiração.

\subsection{Segmentação Temporal do Pulmão}

Como mencionado anteriormente, Asakura et al. ${ }^{[17]}$ propuseram um método para a segmentação temporal da região do pulmão em seqüências de imagens de RM. Um perito médico é responsável por definir o contorno da região do pulmão na imagem inicial (ver Fig. 2.1(a)) e o algoritmo o determina nas demais imagens da seqüência (ver Fig. 2.1(b)). O algoritmo busca pelo movimento respiratório representado por $\left(\psi_{s x}(t), \psi_{s y}(t)\right)$, associado a um ponto $\psi_{s}$. Considerando-se a hipótese de que o pulmão move-se de maneira síncrona, a seguinte expressão pode ser escrita

$$
\left(\psi_{s x}(t), \psi_{s y}(t), t\right)=\left(f_{s}(t) \cdot \zeta \cdot \cos \varphi+\psi_{s x}\left(\tau_{s}\right), f_{s}(t) \cdot \zeta \cdot \operatorname{sen} \varphi+\psi_{s y}\left(\tau_{s}\right), t\right)
$$

onde $\zeta$ e $\varphi$ representam a escala e a orientação do movimento respiratório associado ao ponto $\psi_{s}$, e $f_{s}(t)$ é a função respiração base, como apresentada na seção 4.1. O algoritmo, então, busca por $\zeta$ e $\varphi$ que representam o movimento respiratório mais adequado, considerando-se que o ponto deve estar sobre um contorno e deve ser coerente com $f_{s}(t)$.

A busca é feita varrendo-se o plano definido por $\zeta$ e $\varphi$ (amplitude e ângulo). $\left(\psi_{s x}(t), \psi_{s y}(t), t\right)$ define uma seqüência de pixels para um dado par de $\zeta$ e $\varphi$. A intensidade do pixel utilizado é a obtida após a aplicação de um detector de arestas, como o operador de gradientes. Assim, deseja-se que a média das intensidades dos pixels da seqüência seja alta e que seu desvio padrão seja baixo. Asakura et al. ${ }^{[17]}$ utilizaram como critério a seguinte expressão 


$$
E(\psi, \varphi, \zeta)=0.9^{|\zeta|}\left(1-\frac{S(\psi, \varphi, \zeta)}{3 A(\psi, \varphi, \zeta)}\right)
$$

onde $A(\psi, \varphi, \zeta)$ é a média das intensidades dos pixels da seqüência, e $S(\psi, \varphi, \zeta)$ o desvio padrão. Um ponto de controle sobre a superfície diafragmática pode possuir diversas formas de movimentos respiratórios. A equação 4.2 enfatiza movimentos com pequenas amplitudes (comparadas à função respiração base) ao penalizar valores altos de $\zeta$. A função respiração associada ao ponto de controle $\psi_{s}$ é dada por $\max (E(\psi, \varphi, \zeta))$. Este método produz resultados aceitáveis, mas é muito dependente do especialista médico que define o contorno inicial do pulmão. E como indicado por Asakura et al. ${ }^{[17]}$, em algumas situações é necessária a correção de alguns pontos de controle determinados pelo algoritmo.

Ainda que os resultados obtidos não sejam definitivos, no sentido de ainda não atenderem completamente o problema da segmentação do pulmão, o conceito de segmentação temporal para a obtenção do contorno do pulmão é amplamente utilizado. A informação do movimento, que só pode ser obtida analisando-se todas as imagens da seqüência, é utilizada.

\subsection{Transformada de Hough Modificada}

A transformada de Hough é uma técnica de extração de características utilizada em análise de imagem, visão computacional e processamento de imagens ${ }^{[24]}$. Foi originalmente proposta por Hough ${ }^{[25]}$ para a detecção de um conjunto de pontos na imagem que pertenciam a uma curva específica, tal como segmento de reta e circunferência. Essas curvas são da forma

$$
f(v, p)=0
$$

em que $v$ é um vetor de coordenadas (ou ponto da imagem) e $p$ é um vetor de parâmetros característicos da curva. O objetivo da técnica é encontrar ocorrências imperfeitas de padrões dentro de uma determinada classe de formas através de um processo de votação.

A equação da reta pode ser escrita como

$$
y=a \cdot x-b
$$

em que $a$ é o coeficiente angular da reta e $b$ é o ponto de intersecção da reta 
com o eixo $y$. Para diferentes valores de $a$ e $b$, infinitas retas passam por um ponto $p_{1}\left(x_{1}, y_{1}\right)$, todas satisfazendo a equação 4.4 , como $y_{1}=a \cdot x_{1}-b$. Da mesma forma, infinitas retas passam por $p_{2}\left(x_{2}, y_{2}\right)$ e podem ser expressas por $y_{2}=a \cdot x_{2}-b$.

A equação 4.4 pode ser reescrita como $b=a \cdot x-y$. Supondo-se $x$ e $y$ constantes, definimos um novo plano $(a, b)$, chamado de espaço paramétrico de Hough. Neste espaço, todas as retas que passam por $p_{1}\left(x_{1}, y_{1}\right)$ são representadas pela curva $b=a \cdot x_{1}-y_{1}$. Da mesma forma, todas as curvas que passam por $p_{2}\left(x_{2}, y_{2}\right)$ são representadas pela reta $b=a \cdot x_{2}-y_{2}$. Supondo uma intersecção entre essas retas, temos que

$$
\begin{aligned}
-y_{1}+a \cdot x_{1} & =-y_{2}+a \cdot x_{2} \\
a \cdot x_{2}-a \cdot x_{1} & =y_{2}-y_{1} \\
a \cdot\left(x_{2}-x_{1}\right) & =y_{2}-y_{1}
\end{aligned}
$$

para $x_{1} \neq x_{2}$

$$
a=\frac{y_{2}-y_{1}}{x_{2}-x_{1}}
$$

que é o coeficiente angular da reta que passa por $p_{1}$ e $p_{2}$. Ou seja, a intersecção das retas $b=a \cdot x_{1}-y_{1}$ e $b=a \cdot x_{2}-y_{2}$ no espaço paramétrico de Hough ocorre no ponto que define a reta que passa pelos pontos $p_{1}$ e $p_{2}$ no espaço de imagem. A Fig. 4.5 ilustra o mapeamento do espaço da imagem e do espaço paramétrico de Hough, para retas.

Considerando-se ainda um novo ponto $p_{3}$ tal que $y_{3}=a \cdot x_{3}-b, p_{3}$ pertencerá a uma reta que passa por $p_{1}$ se $b=a \cdot x_{3}-y_{3}$ e $b=a \cdot x_{1}-y_{1}$ possuírem uma intersecção no espaço paramétrico de Hough. Analogamente, pertencerá a uma reta que também passa por $p_{2}$ se $b=a \cdot x_{3}-y_{3}$ e $b=a \cdot x_{2}-y_{2}$ possuírem uma intersecção no espaço paramétrico de Hough. E, por fim, serão colineares se as três retas $b=a \cdot x_{1}-y_{1}, b=a \cdot x_{2}-y_{2}$ e $b=a \cdot x_{3}-y_{3}$ possuírem uma única intersecção, como mostrado na Fig. 4.5.

Esse é o conceito base da transformada de Hough para a detecção de retas. Pontos no espaço da imagem são convertidos em retas no espaço paramétrico de Hough, um espaço discretizado por células. Neste espaço, as coordenadas $(a, b)$ são, portanto, consideradas células de acumulação. Quando um ponto é transformado em uma reta no espaço paramétrico de Hough, todas as células pelas quais esta reta passa são adicionadas do valor de intensidade do ponto 


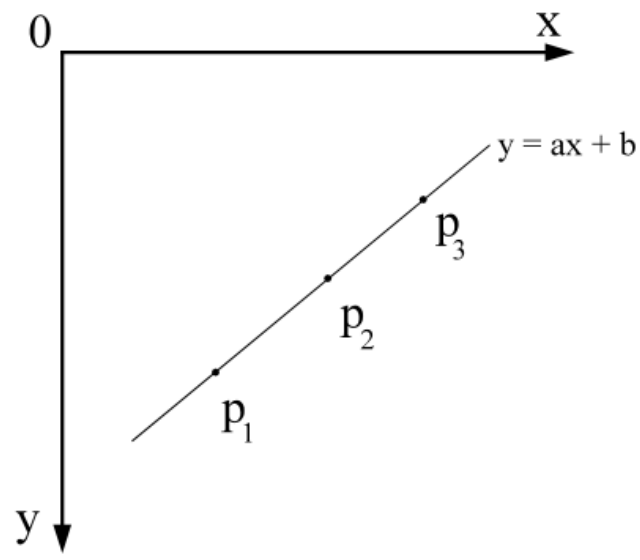

(a)

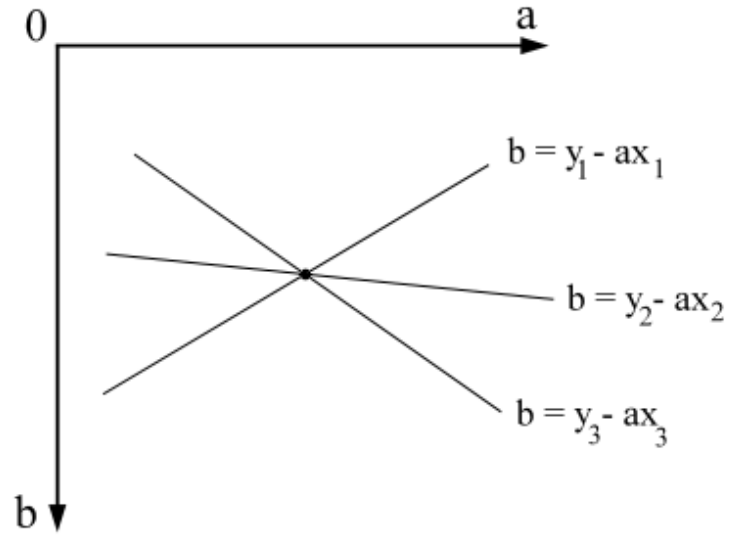

(b)

Figura 4.5: Ilustração do princípio da transformada de Hough. (a) Três pontos pertencentes à mesma reta no plano da imagem. (b) As três retas se interseccionam em uma única célula no espaço paramétrico de Hough.

original. Desta forma, pontos em que ocorrem intersecção são adicionados da intensidade de mais de um ponto, e, portanto, possuem valores acumulados mais altos. Todos os pontos são transportados ao espaço paramétrico. Ao final do processo, algumas células possuirão valores mais altos. Essas células representam com maior probabilidade a presença de retas na imagem original.

Para o funcionamento adequado do algoritmo, utiliza-se um detector de arestas, como, por exemplo, um operador de gradientes, para a criação de uma imagem de arestas. Desta forma, apenas arestas são encontradas.

\subsubsection{Modificação para Detecção de Padrões Respiratórios}

Uma transformada de Hough modificada foi proposta para se determinar a presença de padrões respiratórios $f_{k}(t)$ em imagens 2DST por Matsushita et al. ${ }^{[19]}$. Cada ponto deve se mover no tempo de acordo com um padrão respiratório base, alterada por uma escala e um deslocamento. Figura 4.3 mostra a presença de padrões de movimento. Portanto, o movimento de cada ponto no tempo é descrito pela seguinte equação

$$
f_{k}(t)=y=a \cdot f_{s}(t)-b
$$

onde $a$ e $b$ são a escala e o deslocamento de $f_{s}(t)$, respectivamente. A busca por padrões respiratórios $f_{k}(t)$ pode ser resumida como sendo a identificação de um conjunto de pares $(a, b)$ no maior número possível de imagens 2DST de um determinado STV. 


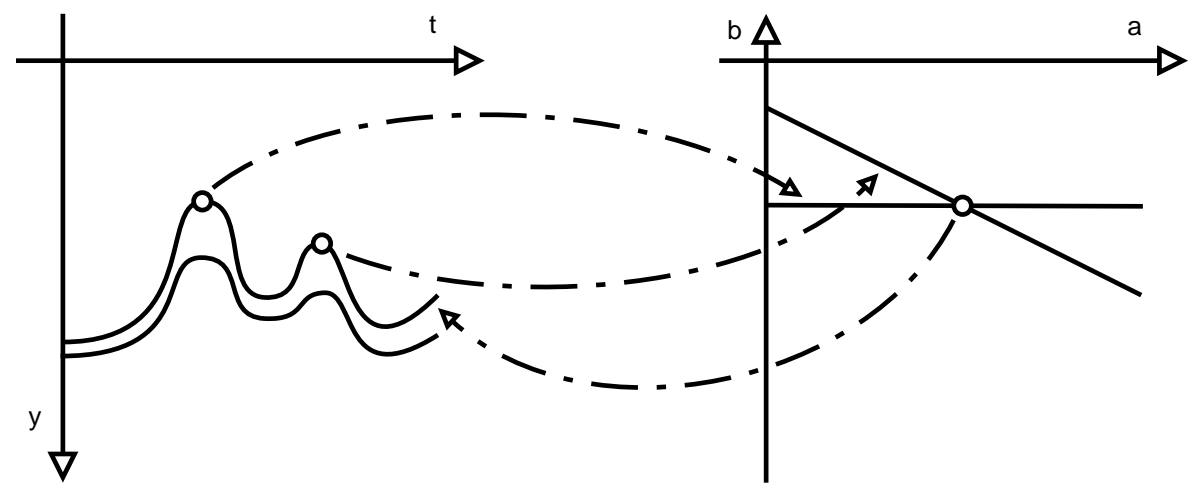

Figura 4.6: A transformada de Hough - a imagem 2DST está a esquerda e o espaço paramétrico está a direita. Um padrão respiratório na imagem 2DST é mapeada para uma célula no espaço paramétrico.

Uma imagem de arestas é criada a partir da imagem 2DST utilizando-se um filtro de gradiente ${ }^{[26]}$. Um padrão respiratório é, portanto, completamente especificado por um par de parâmetros $(a, b)$. Para a detecção de padrões respiratórios, a transformada de Hough mapeia cada pixel $(t, y)$ da imagem de arestas da imagem 2DST para um espaço paramétrico de Hough em $(a, b)$, no qual as contribuições de cada ponto no espaço de imagem para cada célula no espaço paramétrico são acumuladas. Uma matriz multidimensional é utilizada para representar esse espaço paramétrico.

$$
b=a \cdot f_{s}(t)-y
$$

Da mesma forma que na detecção de retas, cada ponto presente no espaço de imagem $(t, y)$ representa uma reta no espaço paramétrico (equação 4.6), e as células pelas quais esta reta passa são incrementadas de acordo com o valor do ponto no espaço de imagem. Este processo é repetido para todos os pontos do espaço de imagem. Cada célula $(a, b)$ no espaço paramétrico representa um padrão respiratório na imagem 2DST.

Assim, após todos os pontos da imagem de arestas terem sido transportados para o espaço paramétrico de Hough, a intensidade de cada célula $(a, b)$ no espaço paramétrico indica a somatória das intensidades dos pontos de arestas que pertencem ao padrão respiratório com tal escala e deslocamento na imagem 2DST de arestas. A Fig. 4.6 ilustra o procedimento da transformada de Hough modificada, que apesar de ser utilizada para a detecção de padrões respiratórios, possui um procedimento muito semelhante à transformada de Hough para detecção de retas. Dois pixels da imagem 2DST são mapeados para duas retas no espaço paramétrico. Estas duas retas se cruzam em uma célula no espaço paramétrico, e esta 


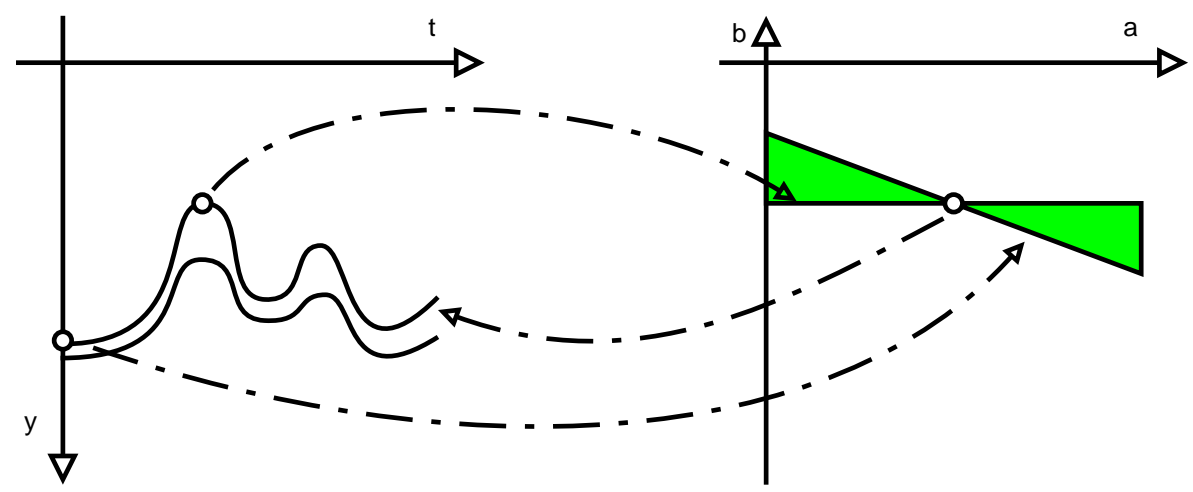

Figura 4.7: A região que deve ser reamostrada negativamente em destaque. Esta região engloba todas as retas que passam pelo ponto de maior intensidade detectado e que possuem coeficiente angular dentro do intervalo $\left[0, f_{\max }\right]$.

célula é mapeada para um padrão respiratório na imagem 2DST. O processo de quantização determina que a célula com maior intensidade, representa com mais confiança um padrão respiratório. Supondo que a célula de maior intensidade é $\left(a_{1}, b_{1}\right)$, representando com maior probabilidade um padrão respiratório.

$$
f_{k}(t)=y=a_{1} \cdot f_{s}(t)-b_{1}
$$

Para continuar procurando por outros pares $(a, b)$, utiliza-se da hipótese de que dois padrões respiratórios não podem se cruzar. Se ocorrer o cruzamento de dois padrões respiratórios significa que um ponto em um dado instante de tempo está acima de uma determinada estrutura, e em um instante de tempo posterior esse ponto está abaixo da mesma estrutura. Assim, todos os pontos que representam um padrão respiratório que intersecta um padrão respiratório encontrado devem ser removidos do espaço paramétrico. Este é o processo de reamostragem negativa. Então, um novo pico de intensidade, representando um novo padrão respiratório, pode ser encontrado.

Sabemos que $f_{s}(t)$ é definido no intervalo $\left[0, f_{\max }\right]$. Portanto, o coeficiente angular na equação 4.6 pode ser definido interno ao mesmo intervalo. Assim, toda reta que passa por $\left(a_{1}, b_{1}\right)$ no espaço paramétrico e possui tal coeficiente angular deve ser removida (definindo uma região de remoção limitada pelas retas que passam por $\left(a_{1}, b_{1}\right)$ e possuem coeficiente angular $f_{s}=0$ e $f_{s}=f_{\text {max }}$ ver Fig. 4.7). Este processo é repetido para que novos padrões respiratórios possam ser obtidos. Este algoritmo encontra padrões respiratórios incoerentes em determinadas ocasiões, como apresentado na Fig. 4.8, devido principalmente a erros decorrentes da discretização - o padrão respiratório incoerente indicado pela seta à esquerda corresponde ao pico encontrado no espaço paramétrico indicado 


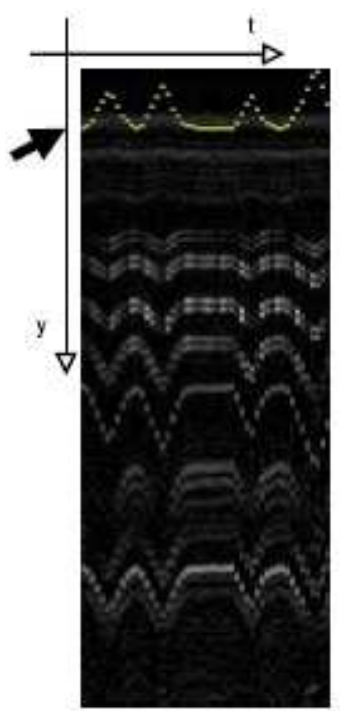

(a)

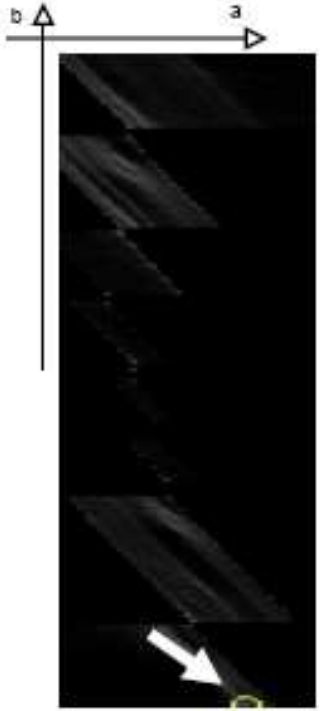

(b)

Figura 4.8: (a) Um padrão respiratório incoerente encontrado pela transformada de Hough modificada apontado por uma seta. (b) $\mathrm{O}$ espaço paramétrico de Hough é apresentado e a célula referente ao padrão respiratório apresentado em (a) indicado pela seta.

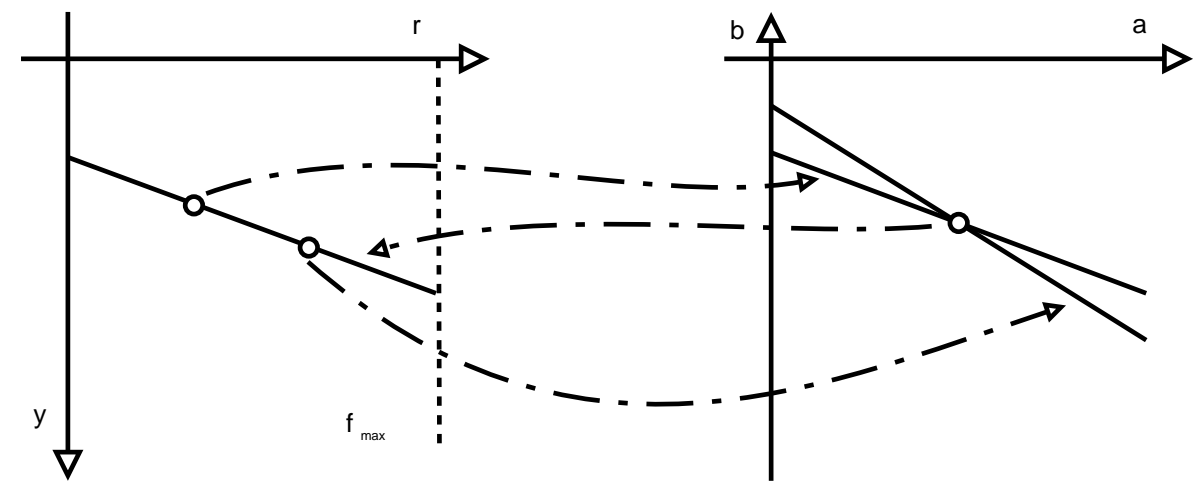

Figura 4.9: A transformada de Hough após a mudança de variáveis - a nova imagem está a esquerda e o espaço paramétrico está a direita. Uma reta é mapeada para uma célula no espaço paramétrico.

por uma seta à direita.

\subsubsection{Entendendo a Transformada de Hough Modificada ${ }^{[1]}$}

Considerando-se a seguinte mudança de variáveis $r=f_{s}(t)$, a equação (4.5) pode ser reescrita da seguinte forma

$$
y=a \cdot r-b
$$

onde $r$ é um inteiro e pertence ao intervalo $\left[0, f_{\text {max }}\right]$. Esta é uma transformada de Hough típica, para se detectar retas. A Fig. 4.9 mostra a transformada 


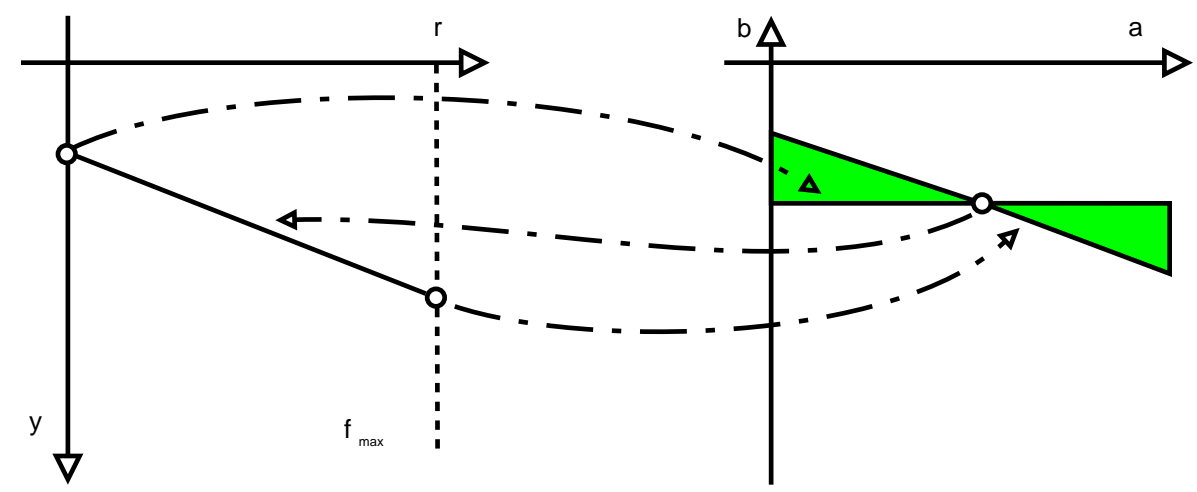

Figura 4.10: A região que deve ser reamostrada em destaque, em verde. Esta região engloba todas as retas que passam pelo ponto de maior intensidade detectado e que possuem coeficiente angular dentro do intervalo $\left[0, f_{\text {max }}\right]$.

de Hough após a mudança de variáveis. Porém, dependendo do padrão respiratório, alguns valores entre 0 e $f_{\max }$ podem não estar presentes. A substituição de variáveis $r=f_{s}(t)$ corresponde ao rearranjo de retas verticais. Como afirmado anteriormente, supõe-se que $f_{s}(t)$ corresponde a um padrão respiratório com amplitude próxima do máximo (no caso de uma imagem 2DST vertical tomada próxima ao centro de um dos pulmões).

Supondo que o par $\left(a_{1}, b_{1}\right)$ foi selecionado na célula de maior intensidade. Os pontos extremos do segmento mapeado são dados por

$$
\left.\begin{array}{c}
r=0 \Rightarrow y=-b_{1} \\
r=f_{\text {max }} \Rightarrow a_{1} \cdot f_{\text {max }}-b_{1}
\end{array}\right\} \Rightarrow \begin{gathered}
\left(0,-b_{1}\right) \\
\left(f_{\text {max }}, a_{1} \cdot f_{\text {max }}-b_{1}\right)
\end{gathered}
$$

Então o valor mínimo de $y$ é dado por

$$
y_{\min }=\left\{\begin{array}{cc}
-b_{1} & \text { se } a_{1} \geq 0 \\
a_{1} \cdot f_{\max }-b_{1} & \text { se } a_{1}<0
\end{array}\right.
$$

e o valor máximo de $y$ é dado por

$$
y_{\max }=\left\{\begin{array}{cc}
a_{1} \cdot f_{\max }-b_{1} & \text { se } a_{1} \geq 0 \\
-b_{1} & \text { se } a_{1}<0
\end{array}\right.
$$

O segmento de reta que passa por $\left(a_{1}, b_{1}\right)$ está dentro do intervalo [ $\left.y_{\min }, y_{\max }\right]$, e o padrão respiratório também está dentro desse mesmo intervalo. A reamostragem é apresentada na Fig. 4.10; toda reta que passa por uma dada célula $\left(a_{1}, b_{1}\right)$ no espaço paramétrico com coeficiente angular no intervalo $\left[0, f_{\text {max }}\right]$ deve ser reamostrada negativamente. 


\subsection{Aritmética Intervalar}

De maneira geral, algoritmos de processamento de imagem assumem que um pixel representa uma posição exata. Na prática, a discretização prevalece, e os dados são obtidos em um domínio discreto, como no caso da RM. No processo de quantização, da transformada de Hough, o algoritmo é executado utilizando-se um espaço paramétrico discreto. Porém, este deveria ser, teoricamente, contínuo. Dessa forma, algoritmos que não levam em consideração a discretização do sistema podem falhar e invalidar todos os processos seguintes. Nesta seção, a aritmética intervalar ${ }^{[27,28]}$ é explicada de forma sucinta.

Um intervalo de números reais é definido da seguinte forma

$$
[c, d]=\{x \mid c \leq x \leq d\}
$$

O intervalo $[c, d]$ é degenerado se $c=d$. A intersecção de dois intervalos $c=d$ e $e=f$ é vazia se $c>f$ ou $e>d$, caso contrário

$$
[c, d] \cap[e, f]=[\max (c, e), \min (d, f)]
$$

A união de dois intervalos com intersecção não-vazia é

$$
[c, d] \cup[e, f]=[\min (c, e), \max (d, f)]
$$

A comparação entre dois intervalos pode resultar em um dos três casos: certamente iguais, possivelmente iguais ou certamente diferentes. Dois intervalos $[c, d]$ e $[e, f]$ são considerados certamente iguais se $c=e$ e $d=f$, certamente diferentes se a intersecção entres eles for vazia e possivelmente iguais se a intersecção entre eles for não-vazia. As seguintes operações algébricas são definidas na aritmética intervalar

$$
\begin{aligned}
& {[c, d]+[e, f]=[c+e, d+f]} \\
& {[c, d]-[e, f]=[c-e, d-f]} \\
& {[c, d] \cdot[e, f]=[\min (c \cdot e, c \cdot f, d \cdot e, d \cdot f), \max (c \cdot e, c \cdot f, d \cdot e, d \cdot f)]} \\
& {[c, d] /[e, f]=[\min (c / e, c / f, d / e, d / f), \max (c / e, c / f, d / e, d / f)] \quad 0 \notin[e, f]}
\end{aligned}
$$

O seguinte exemplo mostra como duas expressões algébricas equivalentes podem obter resultados diferentes na aritmética intervalar. Considere a seguinte 


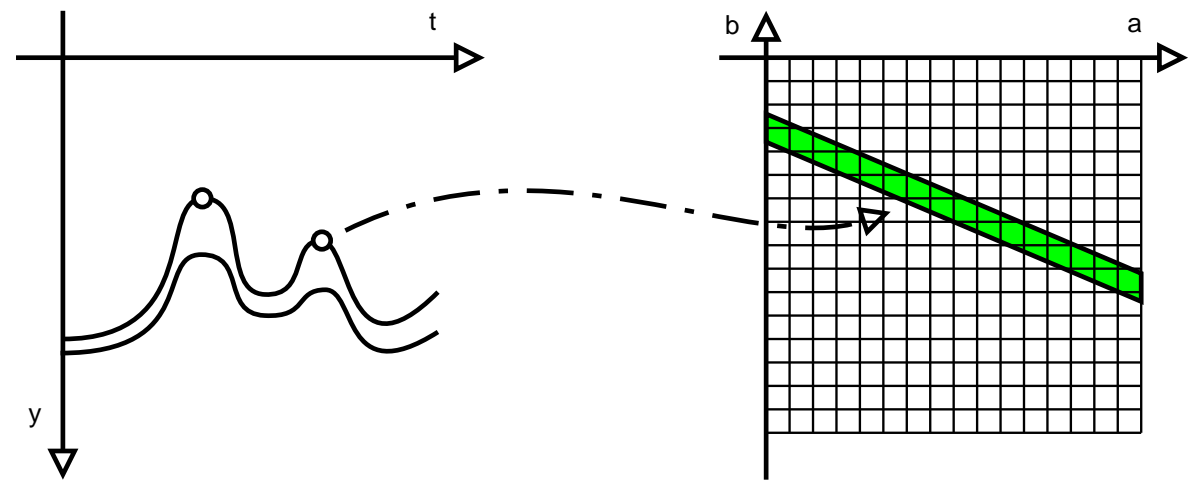

Figura 4.11: A transformada modificada de Hough utilizando aritmética intervalar - a imagem 2DST está a esquerda e o espaço paramétrico está a direita. Um pixel da imagem 2DST é mapeado para uma faixa no espaço paramétrico.

expressão

$$
f(x)=\frac{x}{1-x} \quad x \neq 1
$$

e para $[x]=[2,3]$, temos

$$
f([x])=\frac{[2,3]}{1-[2,3]}=[-3,-1]
$$

Mas para $x \neq 0$, podemos reescrever $f(x)$ como

$$
f_{1}(x)=\frac{x}{1-x}=\frac{1}{\frac{1}{x}-1} \quad x \neq 0
$$

Novamente, fazendo $[x]=[2,3]$, obtemos

$$
f_{1}([x])=\frac{x}{1-x}=\frac{1}{\frac{1}{[2,3]}-1}=\left[-2,-\frac{2}{3}\right] \neq[-3,-1]
$$

O motivo disso é o fato de que a aritmética intervalar não segue as mesmas regras da aritmética para números em ponto flutuante.

\subsubsection{Aritmética Intervalar aplicada à Transformada de Hough ${ }^{[1]}$}

Cada pixel $([x],[y])$ na imagem é representado como um par intervalar

$$
([x-0.5, x+0.5],[y-0.5, y+0.5])
$$

e a intensidade de cada pixel é representado por um intervalo $[I-0.5, I+0.5]$. 
A Fig. 4.11 mostra que cada pixel intervalar $(t,[y])$ na imagem 2DST representa uma faixa no espaço paramétrico. Considere que o valor do deslocamento intervalar $[b]$, para um dado $[a]$, é determinado pela seguinte expressão

$$
[b]=[a] \cdot\left[f_{s}(t)\right]-[y]
$$

onde $(t,[y])$ é o pixel intervalar considerado. O valor resultante de $[b]$ corresponde a um intervalo. O par intervalar $([a],[b])$ define um retângulo que representa a área que deve ser incrementada com o valor de intensidade da aresta do pixel intervalar $(t,[y])$. De maneira geral, este retângulo não corresponde a uma célula do espaço paramétrico. Quando uma célula do espaço paramétrico é totalmente interna ao intervalo resultante $[b]$, então a célula é incrementada da intensidade do pixel $(t,[y])$. No caso de uma intersecção parcial, a célula é incrementada por um valor proporcional à área de intersecção. Este procedimento é muito semelhante ao algoritmo de anti-aliasing. O espaço paramétrico resultante é mais suave que o obtido na abordagem anterior. A Fig. 4.12(b) mostra o espaço paramétrico obtido com a transformada modificada de Hough apresentada na seção anterior, e a Fig. 4.12(c) mostra o espaço paramétrico obtido utilizando-se a transformada de Hough modificada com aritmética intervalar. As abordagens obtiveram diferentes células de máxima intensidade.

A célula de maior intensidade representa uma faixa de padrão respiratório. O padrão respiratório resultante é obtido, então, da seguinte forma. No caso de a faixa conter completamente seu ponto médio, então este ponto é selecionado. Caso contrário, o pixel com a maior área de intersecção é escolhido.

Para continuar com a busca por mais células de alta intensidade no espaço paramétrico, os pixels pertencentes ao padrão respiratório encontrado devem ser reamostrados negativamente antes da obtenção de um novo pico. É importante observar que o processo de reamostragem negativa deve levar em consideração a discretização dos valores, como explicado anteriormente. O processo continua até que a quantidade desejada de padrões respiratórios tenha sido encontrada.

\subsection{Contornos Ativos}

Todo o processamento utilizado até o momento presseupõe que todo o pulmão e suas estruturas movimentam-se todos em perfeita sincronia, de acordo com a função respiração base utilizada. Esta foi uma hipótese realizada no início para que pudéssemos encontrar movimentos respiratórios. Porém, esta hipótese 


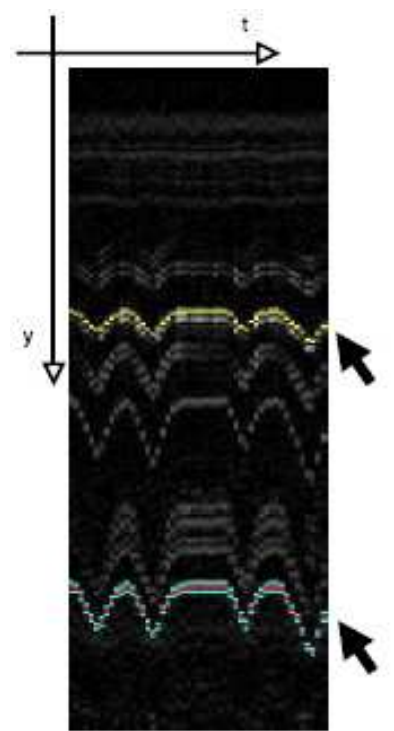

(a)

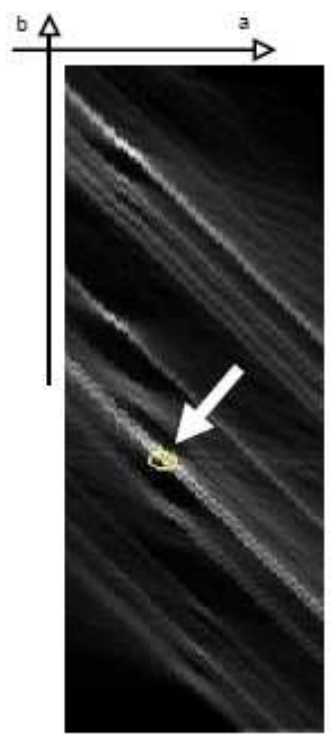

(b)

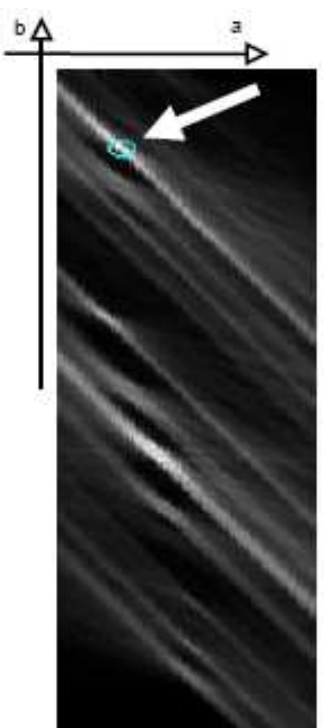

(c)

Figura 4.12: (a) Uma imagem 2DST e os padrões respiratórios encontrados pela transformada de Hough modificada (acima) e pela transformada de Hough modificada utilizando aritmética intervalar (abaixo). (b) O espaço paramétrico de Hough é apresentado e a célula referente ao padrão respiratório apresentado em (a) está indicado pela seta. (c) O espaço paramétrico intervalar de Hough é apresentado e a célula referente ao padrão respiratório apresentado em (a) está indicado pela seta.

não é necessariamente verdadeira para todos os pontos presentes na imagem devido, entre outros motivos, à histerese do movimento do pulmão - e, apesar de o movimento real ser próximo do obtido, não necessariamente existe esta sincronia imposta. Assim, a partir desta seção, essa hipótese será relaxada com a utilização de contornos ativos para o ajuste dos movimentos respiratórios síncronos aos movimentos respiratórios presentes na imagem.

Kass et al. ${ }^{[29]}$ propuseram um método de extração de contornos baseado em um modelo de contorno deformável que consistia de segmentos spline conectados e se deformava através de forças internas e externas. A primeira poderia ser definida através de uma analogia à linha elástica, da teoria de vigas mecânicas. A segunda, por sua vez, era proveniente de características da imagem - no caso, utilizava-se a magnitude do vetor gradiente. Este modelo tornou-se também conhecido por Snakes, e recebeu diversas implementações. Neste trabalho, é utilizada uma adaptação do algoritmo greedy de contornos ativos, inicialmente apresentado por Williams e Shah ${ }^{[30]}$. O método de segmentação por contornos ativos necessita de um esboço de solução inicial que será, então, refinada ao longo das iterações. Nesta seção, os conceitos básicos do modelo de contornos ativos serão introduzidos e sua aplicação na segmentação do contorno do pulmão será apresentada. 
$\mathrm{Na}$ formulação dos contornos ativos, o contorno é representado como uma curva $v(s)=(x(s), y(s))$ com comprimento de arco $s$ como parâmetro. O funcional de energia do contorno foi definido da seguinte forma

$$
E\left(f_{k}(t)\right)=\int\left(E_{\text {int }}(v(s))+E_{\text {ext }}(v(s))\right) d s
$$

onde $E_{\text {int }}$ é a energia interna do contorno, que determina a suavidade da curva, e $E_{\text {ext }}$, a energia externa, que é responsável, de maneira geral, por atrair a curva à borda do objeto. O contorno obtido por este método é o que minimiza o funcional de energia. A energia interna está relacionada à curvatura e à continuidade do contorno. A equação que representa a energia interna é a que se segue

$$
E_{\text {int }}(v(s))=\frac{1}{2}\left(\alpha(s) \cdot\left|v^{\prime}(s)\right|^{2}+\beta(s) \cdot\left|v^{\prime \prime}(s)\right|^{2}\right)
$$

em que $v^{\prime}(s)$ e $v^{\prime \prime}(s)$ são as derivadas de primeira e segunda ordens, respectivamente, de $v(s)$, com respeito a $s$. Pode-se demonstrar que o primeiro termo está relacionado à continuidade, enquanto o segundo termo está relacionado à curvatura da curva. Os parâmetros $\alpha(s)$ e $\beta(s)$ controlam o peso de cada termo, e tanto podem ser fixados globalmente, ou serem dependentes de características locais do contorno.

A continuidade pode ser definida meramente como a distância entre o nó de interesse e seu nó vizinho seguinte. Isto, porém, possui duas desvantagens. Primeiro, a minimização da energia se equivaleria à minimização da distância entre os dois nós, levando o contorno a sempre encolher. Enquanto pode-se pensar que isto seria uma característica desejável, principalmente quando o esboço inicial se encontra em volta do contorno real desejado, isto gera uma tendência na movimentação na curva pouco desejável considerando-se o caso geral. Segundo, utilizando-se apenas a distância entre o nó de interesse e o nó seguinte, pode-se gerar, eventualmente, uma movimentação de pixels ao longo do contorno, também pouco desejável, podendo levar ao acúmulo de pixels em dadas regiões em detrimento de outras ou mesmo dificultar a determinação de um critério de parada (por exemplo, utilizando um critério de parada que leva em consideração o número de nós que se movimentaram, pode-se estar movimentando ciclicamente eternamente, onde o nó seguinte sempre puxa o anterior). Uma proposta feita por Sakalli et al. ${ }^{[31]}$, então, é a determinação da distância entre nós desejada. Sempre que dois nós se afastarem dessa distância, a energia será penalizada.

Como mostrado por Williams e Shah ${ }^{[30]}$, há diversas maneiras para se calcular 
a curvatura de uma curva discreta. Apesar de métodos diferentes concordarem em dizer, dadas duas curvas, qual a que possui a maior curvatura, o grau de curvatura dado por cada um é diferente. Considere o método do produto escalar. Dado um ponto de interesse e seus dois vizinhos, - anterior e posterior - pode-se considerar dois vetores. Um que parte do nó anterior e chega ao nó de interesse, e outro que parte do nó de interesse e chega ao nó vizinho seguinte. A curvatura em um dado nó está diretamente relacionada ao ângulo formado pelos dois vetores considerados. Quando os vetores estão alinhados na mesma direção e sentido, o ângulo é zero e a curvatura também. No caso da mesma direção e sentidos opostos, o ângulo é $180^{\circ}$ e a curvatura é máxima. Desta forma, o problema de determinação da curvatura passa a ser calcular um ângulo entre dois vetores e normalizá-lo para um intervalo desejado.

Por fim, a energia externa pode ser expressa como

$$
E_{\text {ext }}(v(s))=E_{i m g}(v(s))+E_{b n d}(v(s))
$$

onde o termo $E_{i m g}(v(s))$ representa características presentes na imagem (por exemplo, arestas) e $E_{b n d}(v(s))$ são demais condições de contorno e restrições impostas (por exemplo, o uso de forças de balão, que geram uma tendência do contorno inflar $\left.{ }^{[32]}\right)$. Para $E_{i m g}(v(s))$, o mais comum é utilizar intensidade de arestas, sendo expresso da seguinte forma

$$
E_{i m g}(v(s))=-\gamma \cdot|\nabla I(v(s))|^{2}
$$

onde $\nabla$ é o operador gradiente, aplicado à imagem no ponto $I(v(s))$. Com o sinal negativo, $E_{i m g}(v(s))$ assume valores baixos onde o gradiente é alto (por exemplo, nas arestas).

Uma das maiores dificuldades dos modelos de contornos ativos é a geração do contorno inicial. Um contorno inicial mal determinado, não estando suficientemente próximo ao objeto de interesse, pode impedir o correto funcionamento do algoritmo, uma vez que a curva pode não ser atraída ao contorno do objeto. Outras dificuldades comuns são a correta escolha dos parâmetros $(\alpha, \beta$ e $\gamma)$, e a convergência para mínimos locais ou mesmo a instabilidade entre dois estados de mínimos locais.

Neste trabalho, a primeira dificuldade já foi abordada. A função respiração obtida pela transformada de Hough modificada é o contorno inicial para o algo- 
ritmo greedy de contornos ativos. Uma função respiração $f_{k}(t)$ é um conjunto de pixels com apenas um pixel por linha vertical (ver Fig. 4.13) e cada pixel somente se movimenta ao longo dessa linha vertical. A função respiração então é dada como

$$
f_{k}(t)=\left\{y_{0}, y_{1}, \ldots, y_{n}\right\}
$$

onde $0 \leq t \leq n$ e $n$ é o número de imagens na série. Desta forma, as equações $4.16,4.17$ e 4.18 podem ser reescritas como

$$
\begin{gathered}
E\left(f_{k}(t)\right)=E_{\text {int }}\left(f_{k}(t)\right)+E_{\text {ext }}\left(f_{k}(t)\right) \\
E_{\text {int }}\left(f_{k}(t)\right)=\frac{1}{2}\left(\alpha \cdot\left|\frac{\partial f_{k}(t)}{\partial t}\right|^{2}+\beta \cdot\left|\frac{\partial^{2} f_{k}(t)}{\partial t^{2}}\right|^{2}\right) \\
E_{\text {ext }}\left(f_{k}(t)\right)=-\frac{\gamma}{\sigma\left(f_{k}(t)\right)} \cdot\left|\nabla I\left(f_{k}(t)\right)\right|
\end{gathered}
$$

onde $\alpha, \beta$ e $\gamma$ são parâmetros positivos fixos, $\sigma\left(f_{k}(t)\right)$ é a média da intensidade dos pixels pertencentes ao padrão respiratório e $\nabla I\left(f_{k}(t)\right)$ é a soma da intensidade dos gradientes dos pontos que pertencem ao padrão respiratório.

Com a adoção do padrão respiratório como contorno inicial do método de modelos ativos, algumas outras restrições se impõem de forma a simplificar o algoritmo. Como os pontos do contorno possuem movimentação em apenas uma direção (estritamente vertical), tanto as energias de continuidade quanto curvatura calculadas em um dado ponto levam em consideração apenas as distâncias nesta direção de movimentação do ponto considerado e seus vizinhos anterior e posterior.

O algoritmo greedy analisa primeiro as verticais ímpares em seqüência e depois as verticais pares em seqüência. Na busca por um padrão respiratório com menor energia, os pontos adjacentes na vertical ao pixel do padrão respiratório atual são considerados na análise. O tamanho da adjacência, na busca, é definido pelo usuário, gerando mais um parâmetro de controle. Em cada iteração, todos os vizinhos possíveis, na direção de movimento, possuem sua energia calculada e o ponto então é movido para a posição de menor energia. O número de iterações também é definido pelo usuário. A Fig. 4.14 mostra o resultado do algoritmo greedy de contornos ativos após a aplicação da transformada de Hough. 


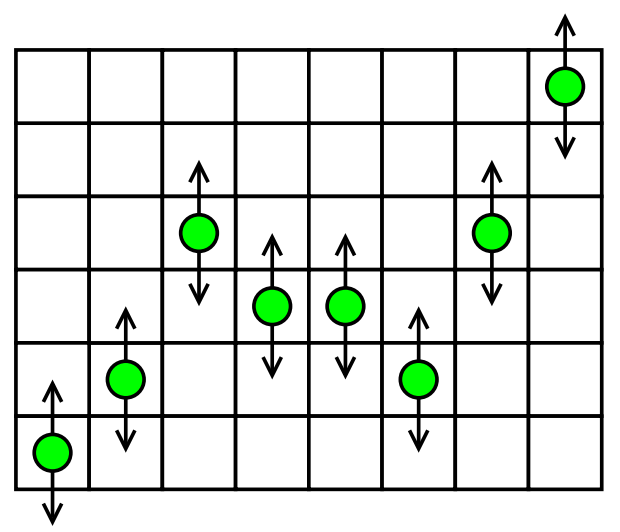

Figura 4.13: Uma função respiração resultante da transformada de Hough modificada. O algoritmo greedy de contornos ativos busca por uma posição de menor energia nos pontos adjacentes verticalmente.

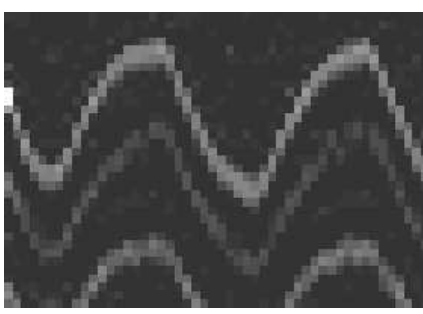

(a)

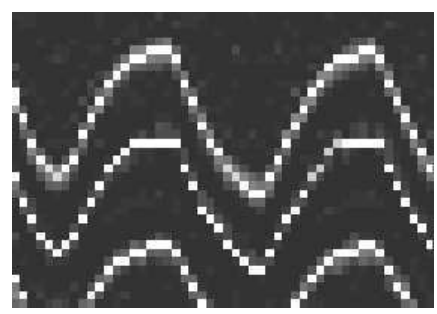

(b)

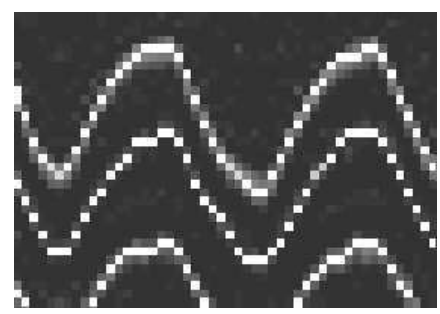

(c)

Figura 4.14: (a) Imagem de arestas original. (b) Função respiração encontrada pela transformada de Hough modificada intervalar. (c) Função respiração encontrada ajustada pelo algoritmo greedy de contornos ativos. 
De maneira geral, os parâmetros utilizados neste trabalho foram os seguintes: $\alpha=0.7, \beta=0.7, \gamma=1.2$ e iterations $=10$. Observou-se que como o contorno inicial, obtido com a transformada de Hough, já está próximo de arestas da imagem 2DST, poucas iterações são necessárias para a convergência. Os parâmetros da curva também privilegiam a intensidade das arestas sobre a continuidade e curvatura do contorno. Por fim, no segundo método para a segmentação do contorno do pulmão apresentado (apresentado no capítulo 6), optou-se pela utilização de dois valores para a adjacência, dependendo da superfície sendo determinada. Para a superfície diafragmática do pulmão, que possui maior amplitude de movimento, utilizou-se neighborhood $=6$, enquanto para as demais superfícies do pulmão, neighborhood $=3$ se mostrou suficiente.

\subsubsection{Contornos Ativos com Gradient Vector Flow (GVF)}

Xu et al. ${ }^{[33]}$ propuseram um novo método de cálculo para contornos ativos que solucionava dois grandes problemas de contornos ativos. Esses problemas são o fato de que os contornos ativos não são atraídos para objetos muito distantes (o que, como explicado anteriormente, adiciona importância à inicialização do contorno), e a dificuldade dos contornos ativos de entrar em regiões côncavas e reentrâncias.

O método dos contornos ativos tradicional utiliza um mapa de arestas - geralmente construído com operadores de gradientes - como componente geradora de forças externas. Um mapa de arestas tradicional apresenta três características importantes neste contexto. Primeiro, os gradientes presentes neste mapa de arestas possuem direções normais às arestas. Segundo, esses vetores geralmente possuem magnitudes elevadas somente na região vizinha às arestas. Terceiro, em regiões homogêneas, as magnitudes dos gradientes tende a zero. Analisando estas características, por causa da primeira característica, um contorno próximo às arestas tende a convergir a elas. Porém, por causa da segunda característica, o alcance das arestas para atrair um contorno é curto, e por causa da terceira característica, pontos do contorno posicionados em regiões homogêneas dependem apenas das demais componentes para se movimentar, o que por vezes não é suficiente, e a convergência é inadequada. Assim, somente a primeira das características mencionadas é desejável.

A proposta de Xu et al. ${ }^{[33]}$ é um campo de forças chamado Gradient Vector Flow $(\mathrm{GVF}) v(x, y)=[u(x, y), v(x, y)]$ que minimiza o funcional de energia 


$$
\epsilon=\iint \mu\left(u_{x}^{2}+u_{y}^{2}+v_{x}^{2}+v_{y}^{2}\right)+|\nabla f|^{2}|v-\nabla f|^{2} d x d y
$$

onde $\nabla f$ é o campo de gradientes da imagem. Observa-se que, quando $|\nabla f|$ é pequeno (como em uma região homogênea), a energia é dominada pelo termo com a soma dos quadrados das derivadas parciais do campo de forças, o que proporciona um campo suave. Por outro lado, quando $|\nabla f|$ é grande, o segundo termo se torna dominante, e a energia é minimizada com $v=\nabla f$. Isso produz o efeito desejado de manter $v$ aproximadamente igual a $\nabla f$ quando os gradientes possuírem grandes magnitudes, e, ao forçar o campo a ser suave, garante que regiões do campo em que os gradientes da imagem são de pequena magnitude podem possuir magnitudes altas devido às baixas variações ao longo do campo. O parâmetro $\mu$ é um parâmetro que regulariza o equilíbrio entre os dois termos do integrando, e é utilizado de acordo com a quantidade de ruído na imagem. Neste trabalho, utilizou-se $\mu=0.2$.

Figura 4.15 ilustra uma comparação simples entre as magnitudes dos vetores gradientes em campos de arestas tradicional e GVF. Nesta figura, ilustra-se um trecho de uma imagem, em perfil. O traço preto indica o nível de intensidade dos pixels, o traço vermelho representa a magnitude do vetor gradiente em um campo de arestas tradicional e o traço azul representa a magnitude do vetor gradiente em um campo GVF. Como explicado anterior, pode-se observar nesta figura que na presença de bordas, um operador de gradiente comum constrói um campo de arestas em que as magnitudes dos gradientes possuem valores altos em regiões próximas às bordas, e baixos valores em regiões onde não há bordas, e a transição é muito rápida. Em um campo GVF, os gradientes continuam possuindo magnitudes de altos valores nas bordas, mas a transição para as regiões sem arestas é muito mais suave.

Para uma primeira ilustração do método, considere o exemplo apresentado por Xu et al. ${ }^{[33]}$ do objeto em forma de "U", mostrado na Fig. 4.16(a). O campo GVF criado para esta imagem está apresentado na Fig. 4.16(b) - as setas indicam a direção do maior potencial no campo de forças. A Fig. 4.16(c) apresenta uma parte ampliada da imagem da Fig. 4.16(b) (a região ampliada está localizada na parte superior esquerdo, e envolve o canto superior esquerdo e a concavidade em "U" no centro da parte superior do objeto). Pode-se observar a presença de vetores de forças mesmo em regiões afastadas das bordas, como na região interna. Isso que permite o longo alcance deste método.

Uma das vantagens do método de contornos ativos é a sua capacidade de 


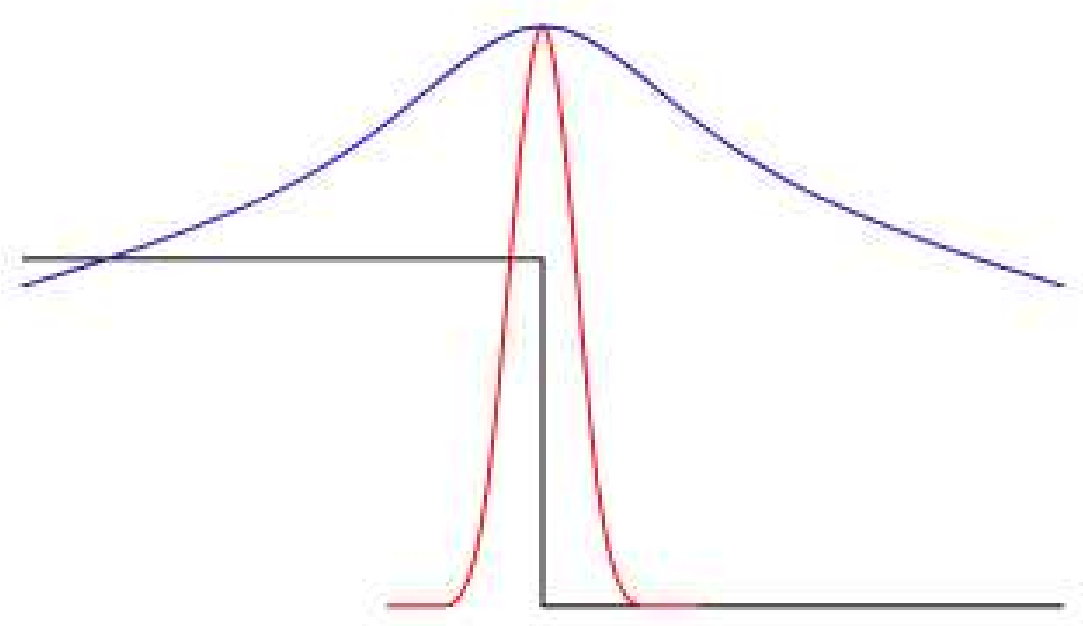

Figura 4.15: Comparação de campos tradicionais de arestas com o GVF em um perfil de uma imagem. O traço preto indica a intensidade do pixel, o traço vermelho indica a magnitude do gradiente em um campo de arestas tradicional, e o traço azul representa a magnitude do gradiente em um campo GVF.

convergir para contornos subjetivos, isto é, contornos que não estão de fato na imagem, como no exemplo apresentado por Xu et al. e mostrado na Fig. 4.17. A vantagem da utilização de contornos ativos com GVF sobre contornos ativos tradicional, neste caso, é o fato de podermos utilizar um contorno inicial arbitrário qualquer e mesmo assim obter a convergência para o contorno desejado.

Neste trabalho, contornos ativos com GVF é utilizado como neste último caso apresentado: dado um conjunto de pontos dispersos que formam um conjunto subjetivo, contornos ativos com GVF deve fornecer um contorno válido. A Fig. 4.18(a) apresenta uma imagem binária com pontos dispersos em branco. Esses pontos formam um contorno subjetivo do pulmão, que desejamos extrair utilizando contornos ativos com GVF. Um contorno inicial oval arbitrário está apresentado na Fig. 4.18(b). O campo GVF está apresentado na Fig. 4.18(c), com duas regiões demarcadas para melhor visualização do campo. A região em vermelho está ampliada e apresentada na Fig. 4.18(d). A região em laranja está ampliada e apresentada na Fig. 4.18(e). O contorno resultante está apresentado na Fig. 4.18(f).

\subsection{Segmentação por Limiarização}

A limiarização, ou thresholding, é uma das técnicas mais simples de segmentação, e consiste na classificação dos pixels de uma imagem de acordo com suas intensidades e como estes se situam em relação a um ou mais limiares. A Fig. 4.19 


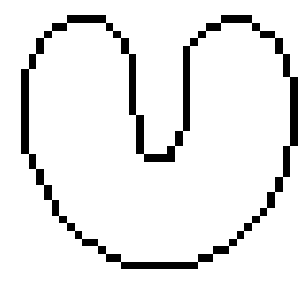

(a)

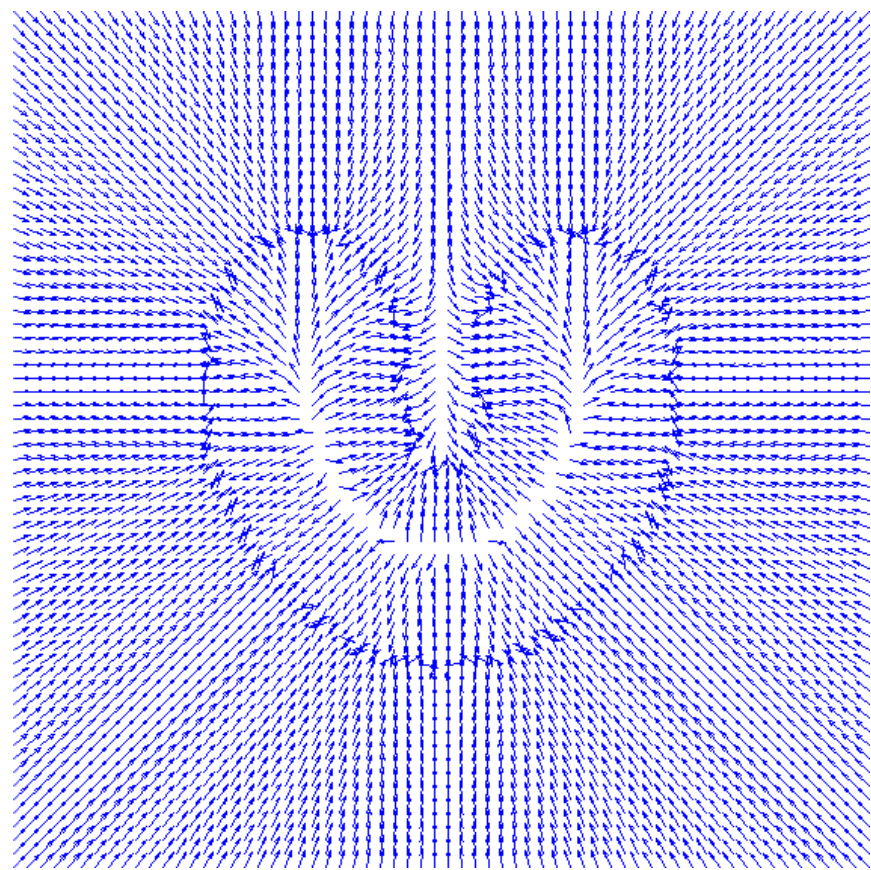

(b)
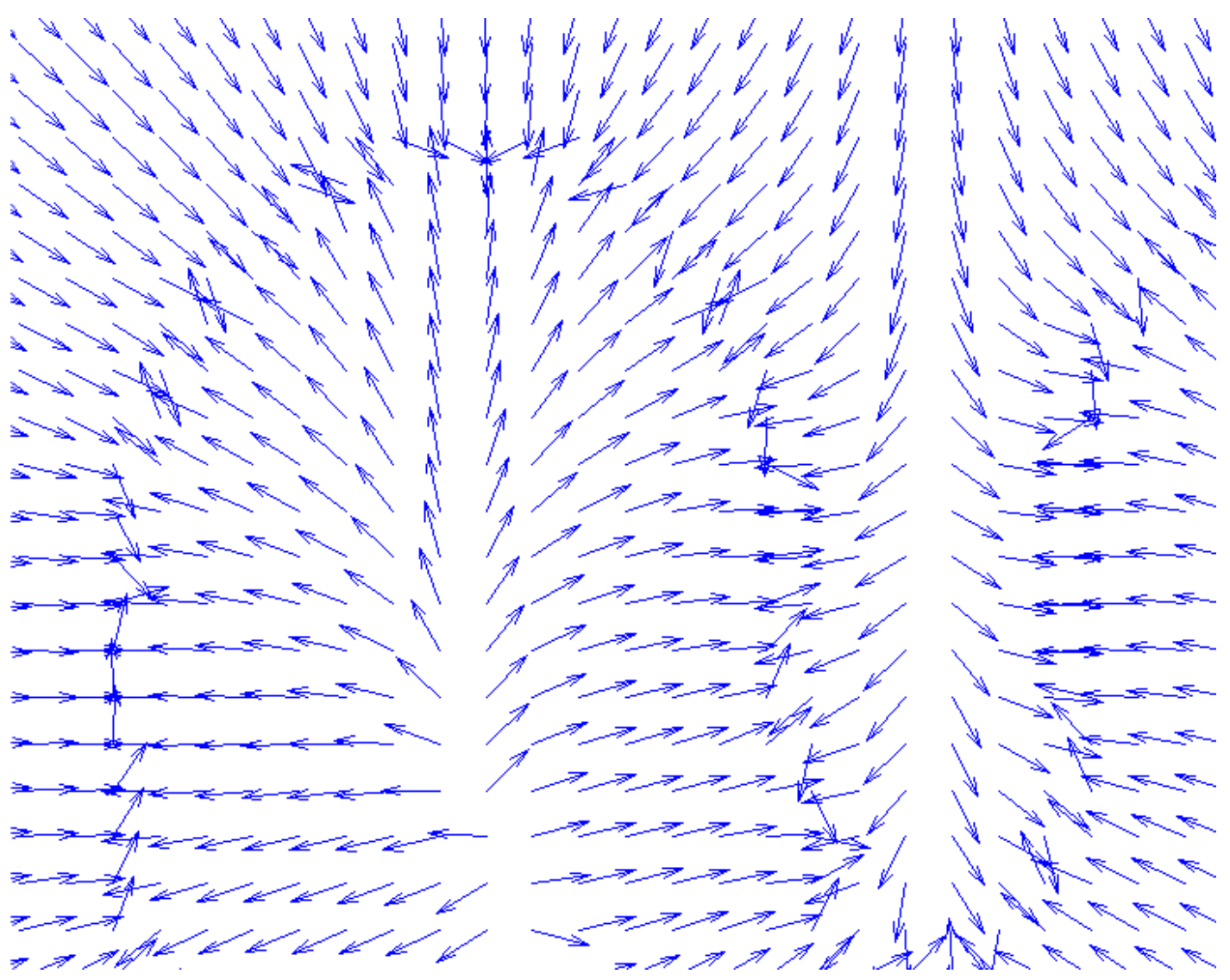

(c)

Figura 4.16: Ilustração do campo GVF.(a) Imagem de objeto em formato de U. (b) Campo GVF. (c) Parte do campo GVF ampliado para visualização. Esta parte se refere ao canto superior e à concavidade no centro da parte superior do objeto. 


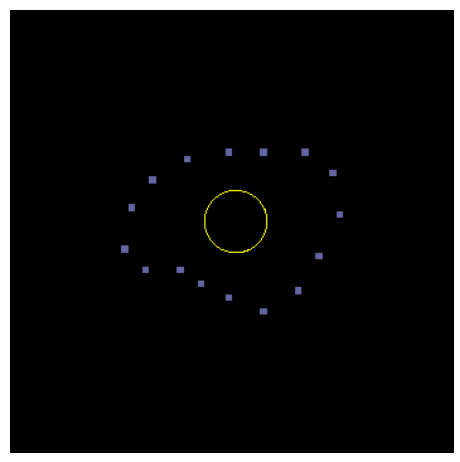

(a)

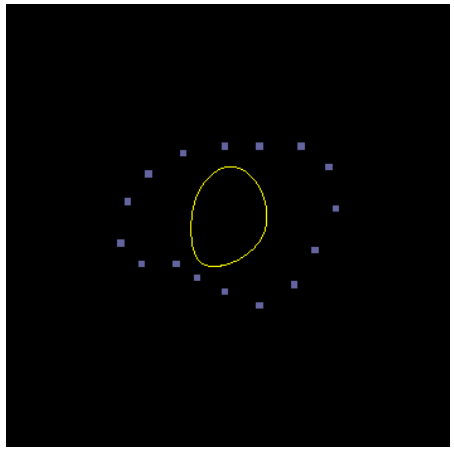

(b)

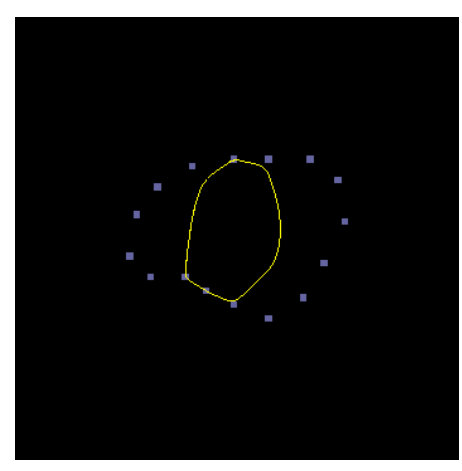

(c)

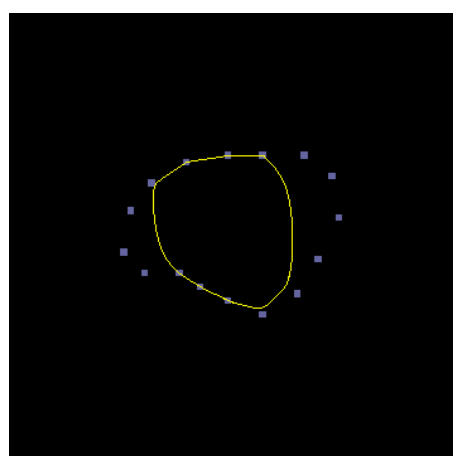

(d)

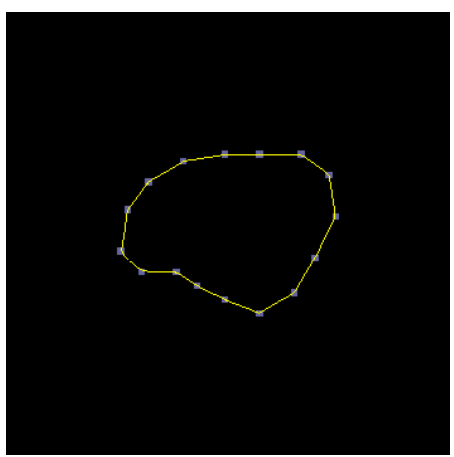

(e)

Figura 4.17: Demonstração da capacidade do método de contornos ativos de convergir para contornos subjetivos mesmo quando inicializado em posição afastada.(a) Contorno inicial. (b) a (d) Posições intermediárias da evolução do contorno. (e) Contorno final. 


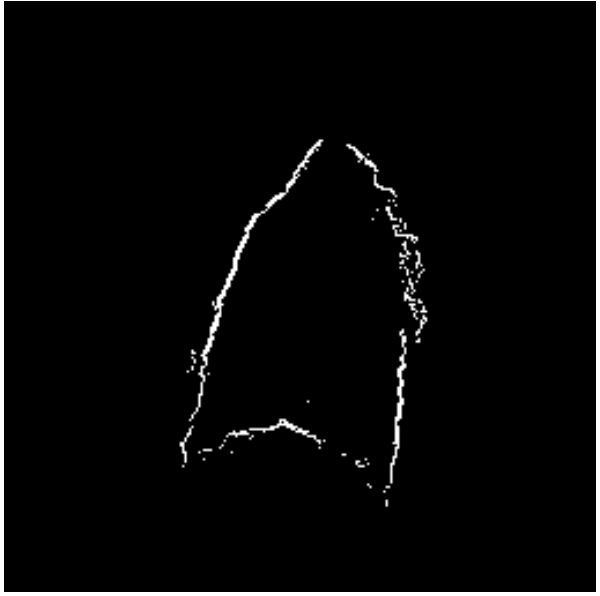

(a)

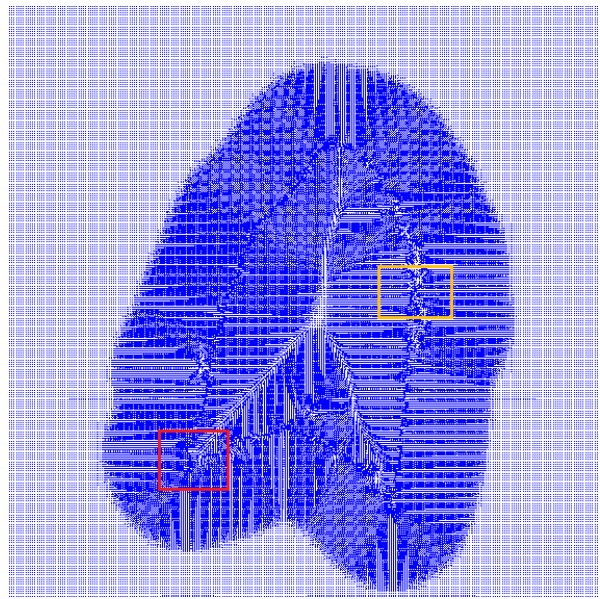

(c)

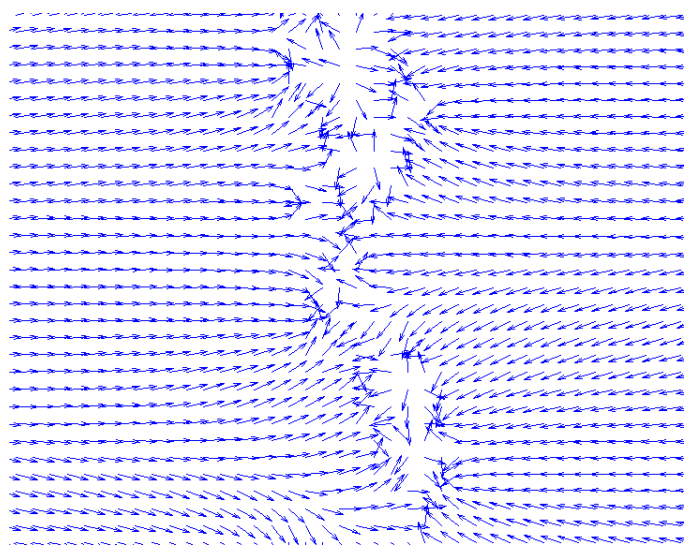

(e)

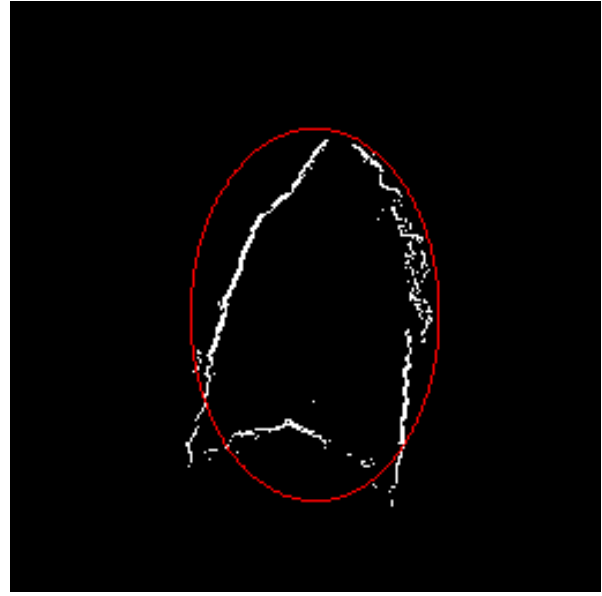

(b)

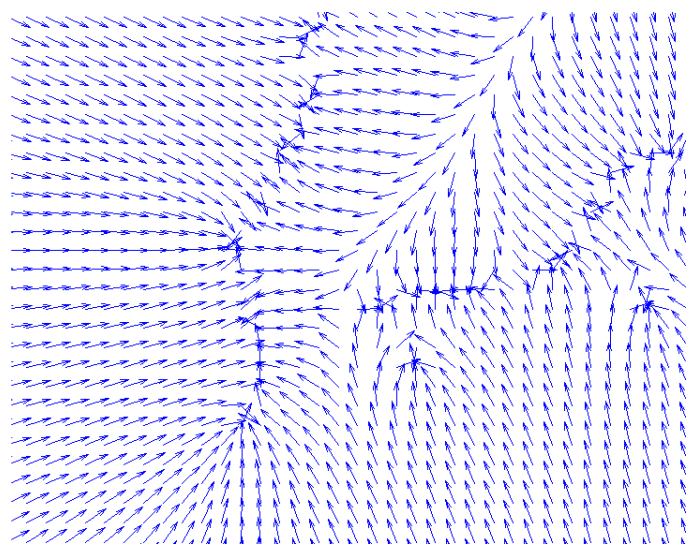

(d)

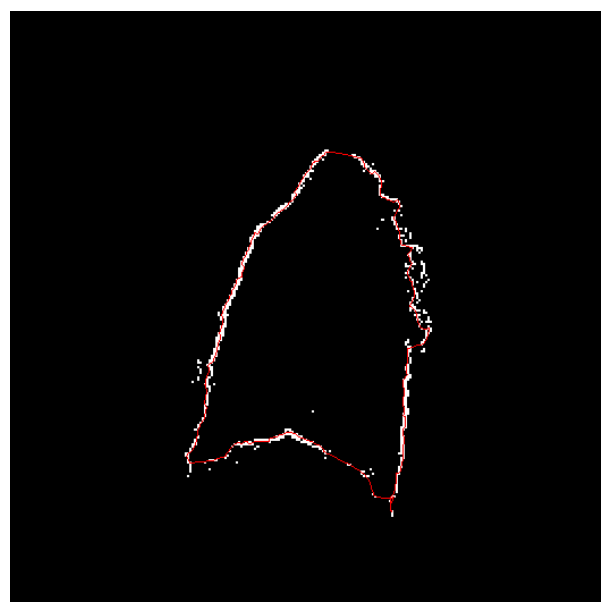

(f)

Figura 4.18: Exemplo da utilização do algoritmo de contornos ativos com GVF no contexto deste trabalho. (a) Pontos dispersos representando o contorno do pulmão. (b) Contorno inicial oval em vermelho. (c) Campo GVF, com duas regiões demarcadas em cores. (d) Ampliação da região em vermelho da imagem (c). (e) Ampliação da região em laranja da imagem (c). (f) Resultado da aplicação do método de contornos ativos. 


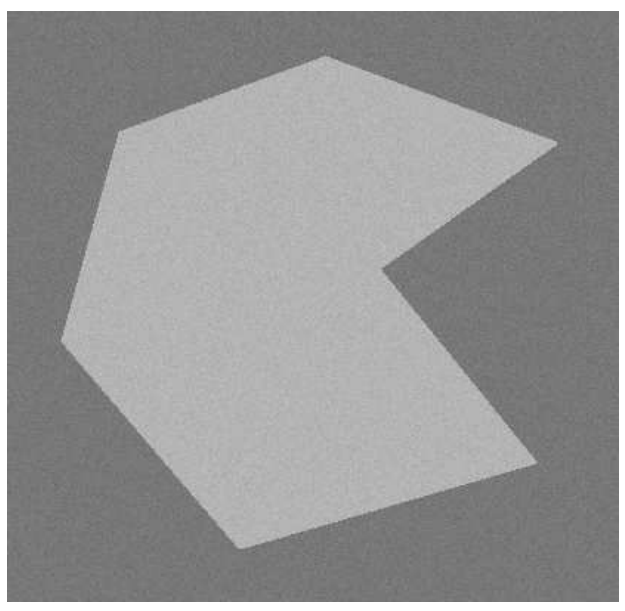

(a)

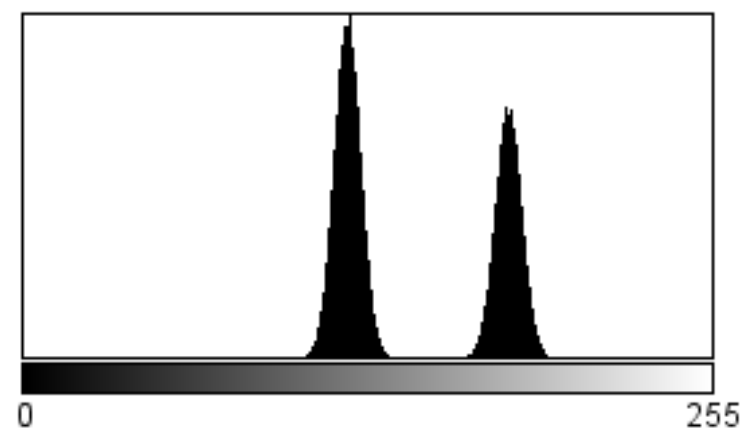

(b)

Figura 4.19: (a) Imagem em escala de cinza. (b) Histograma de níveis de cinza da imagem (a).

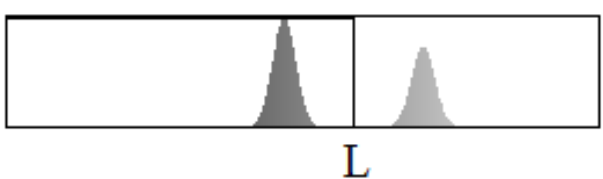

(a)

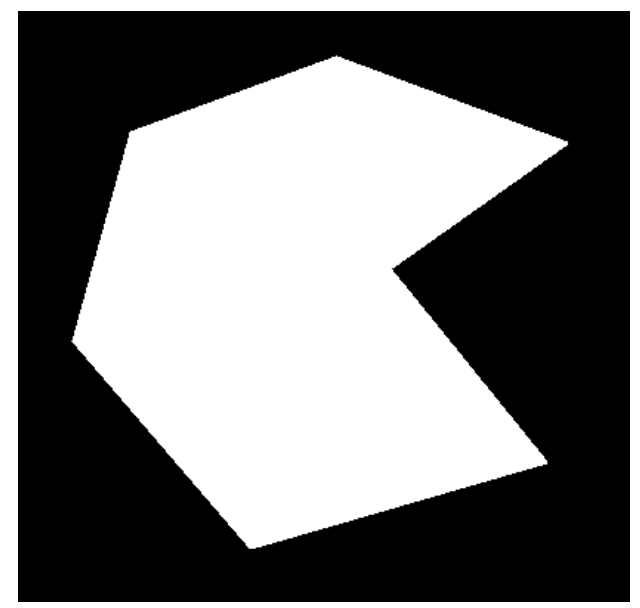

(b)

Figura 4.20: (a) Histograma da imagem da Fig. 4.19 com limiar $L$ indicado. Neste caso, $L=150$. (b) Resultado da limiarização com limiar 150 . Objeto e fundo separados.

apresenta uma imagem em escala de cinza e seu histograma. O valor de intensidade de cada pixel dessa imagem é representado por $f(x, y)$. Essa imagem é tal que seu histograma é bimodal, ou seja, os pixels do objeto da imagem e os pixels do fundo da imagem podem ser separados em dois grupos dominantes.

Uma maneira simples de separar o objeto do fundo da imagem é a escolha de um limiar $L$ como apresentado na Fig. 4.20(a) (um limiar que separaria o objeto do fundo está representado pela letra 'L'). Neste caso, $L=150$ é um limiar que separa o objeto do fundo da imagem, como mostrado na Fig. 4.20(b). Dessa forma, todo pixel $(x, y)$ tal que $f(x, y)>L$ é denominado como sendo do objeto, caso contrário pertence ao fundo. Assim, a imagem de saída $g(x, y)$, limiarizada, pode ser definida como 


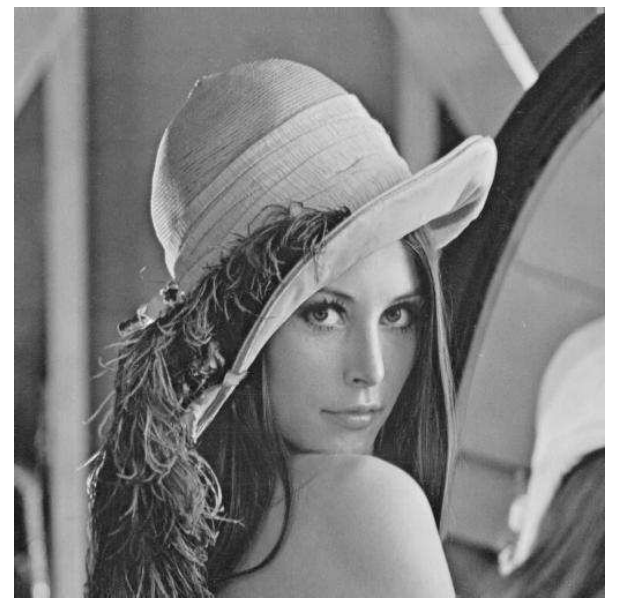

(a)

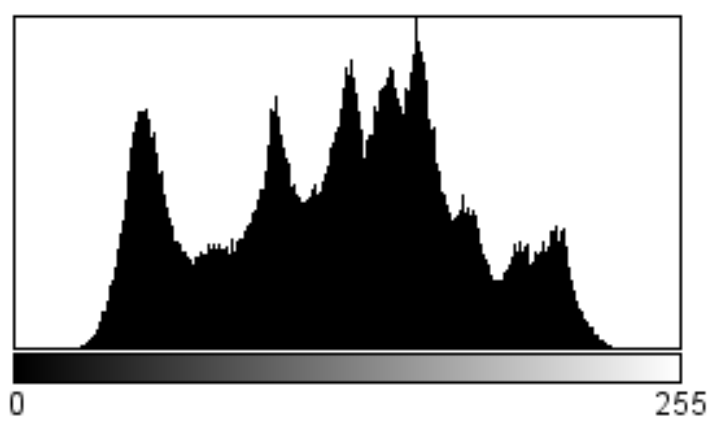

(b)

Figura 4.21: (a) Imagem Lenna em escala de cinza. (b) Histograma de níveis de cinza da imagem (a).

$$
g(x, y)= \begin{cases}0, & \text { se } f(x, y) \leq L \\ 1, & \text { se } f(x, y)>L\end{cases}
$$

Portanto, todos os pixels que receberam o valor 1 correspondem ao objeto de interesse, enquanto aqueles que receberam o valor 0 se referem ao fundo da imagem. A Fig. 4.21(a) apresenta a imagem Lenna, em escala de cinza e a Fig. 4.21(b) apresenta seu histograma de níveis de cinza. Neste caso, não é possível uma separação do objeto do fundo da imagem através de um único limiar, e resultados diversos podem ser obtidos utilizando-se valores diferentes para o limiar (ver Fig. 4.22).

Figura 4.23 mostra um exemplo da limiarização aplicada a uma imagem de RM do pulmão. A Fig. 4.23(a) apresenta a imagem original, em escala de cinza. A Fig. 4.23 apresenta o histograma desta imagem e, por fim, a Fig. 4.23 apresenta o resultado da limiarização com limiar $L=171$.

\subsection{Filtro de Mediana}

O filtro de mediana é um filtro que atua no domínio espacial, ou seja, opera diretamente sobre os pixels da imagem. Geralmente, a filtragem no domínio espacial envolve operações de convolução com máscaras, ou janelas, diretamente na imagem de entrada. A filtragem de imagem no domínio espacial pode, então, ser expressa como

$$
g\left(x_{i}, y_{i}\right)=T\left[f\left(x_{i}, y_{i}\right)\right]
$$




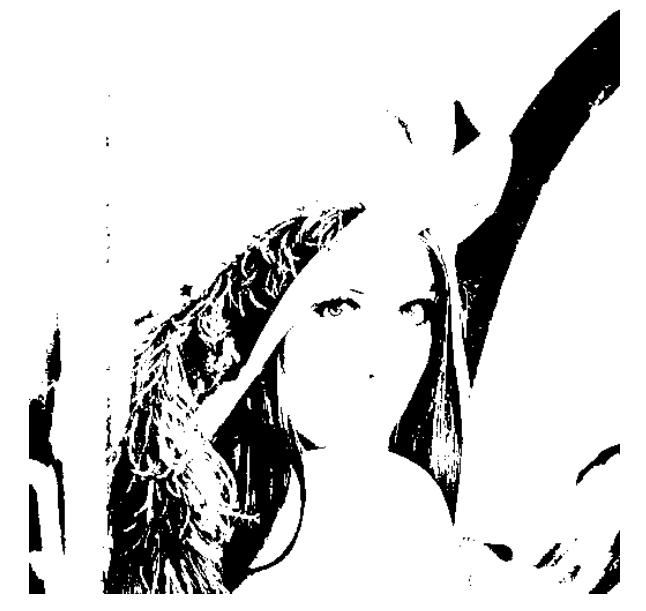

(a)

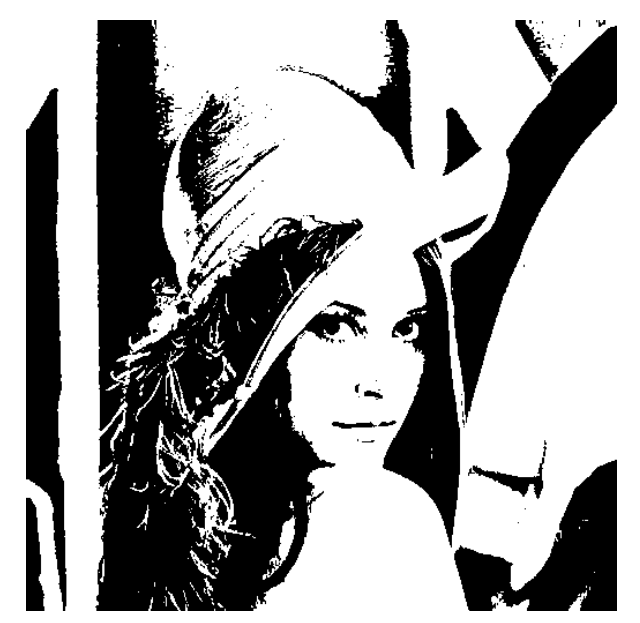

(c)

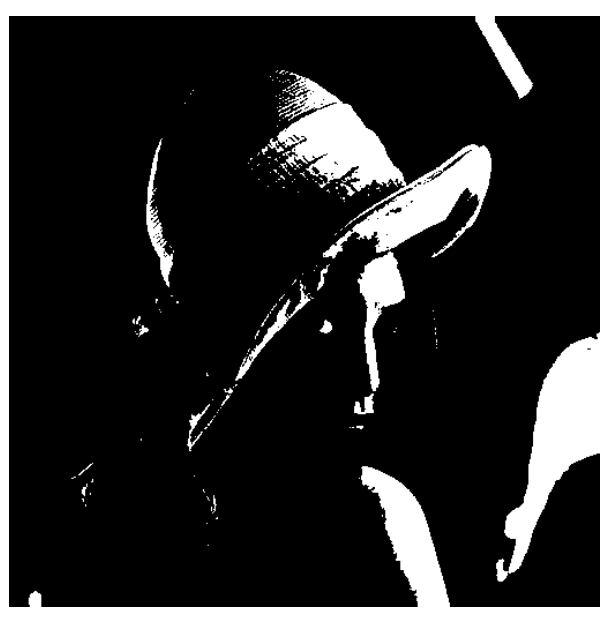

(e)

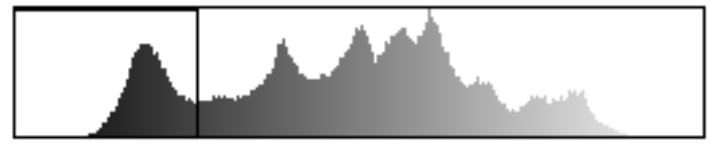

(b)

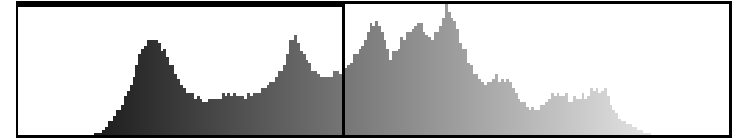

(d)

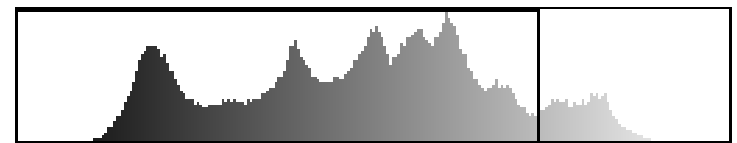

(f)

Figura 4.22: (a) Histograma da imagem Lenna com limiar 68 indicado. (b) Resultado da limiarização da imagem Lenna com limiar 68. (c) Histograma da imagem Lenna com limiar 117 indicado. (d) Resultado da limiarização da imagem Lenna com limiar 117. (e) Histograma da imagem Lenna com limiar 187 indicado. (f) Resultado da limiarização da imagem Lenna com limiar 187. 


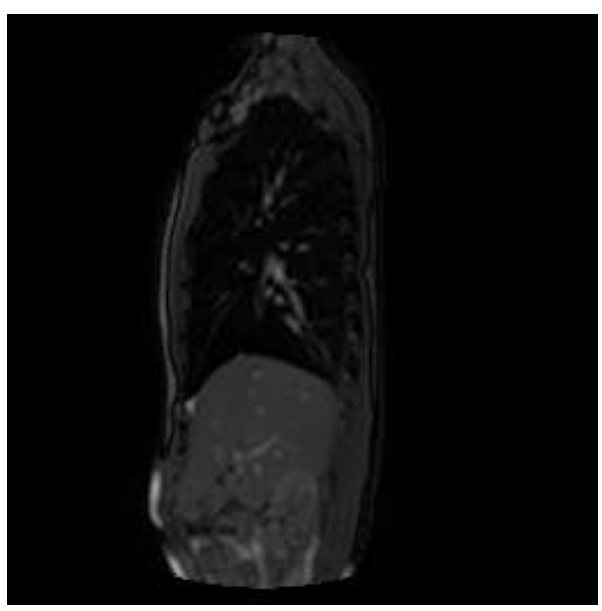

(a)

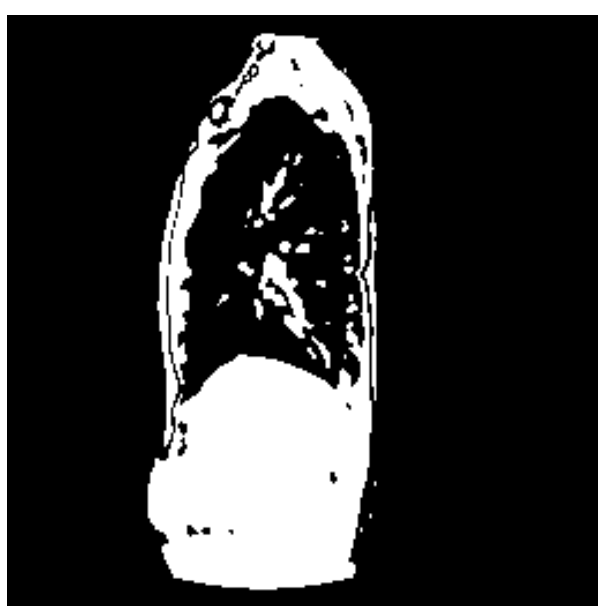

(c)

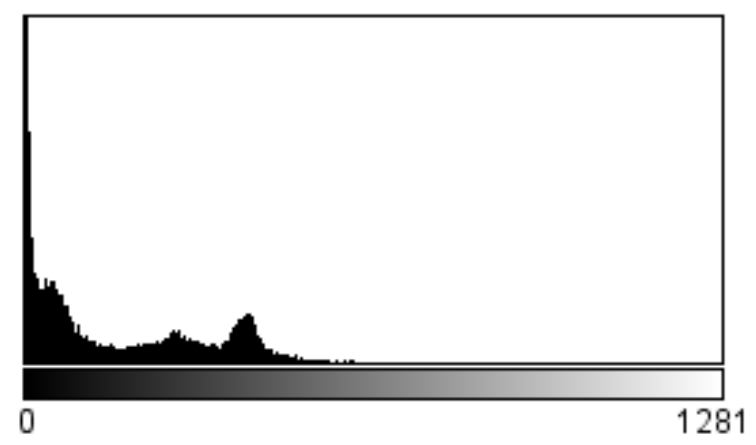

(b)

Figura 4.23: (a) Imagem em escala de cinza do pulmão. (b) Histograma de níveis de cinza da imagem (a). (c) Resultado da limiarização com $L=171$. 


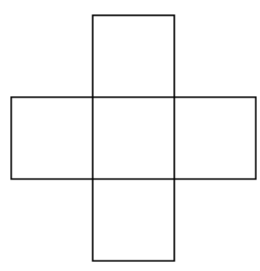

(a)

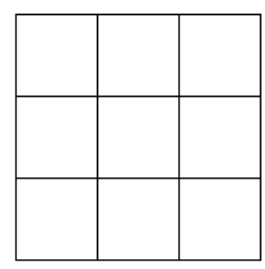

(b)

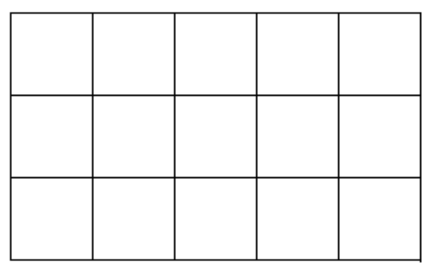

(c)

Figura 4.24: (a) Janela em cruz de tamanho 3. (b) Janela quadrada de lado 3. (c) Janela retangular de tamanho $3 \times 5$.

onde $f\left(x_{i}, y_{i}\right)$ representa cada pixel da imagem de entrada, $g\left(x_{i}, y_{i}\right)$, cada pixel da imagem de saída, e $T$ é um operador sobre $f$, definido em alguma vizinhança do pixel de posição $\left(x_{i}, y_{i}\right)$. A vizinhança é determinada pela janela utilizada. O resultado em cada pixel na imagem de saída, portanto, é o resultado de uma operação que envolve o valor da intensidade do mesmo pixel na imagem de entrada e de seus vizinhos nesta mesma imagem. Ou seja, para cada pixel $\left(x_{i}, y_{i}\right)$, o operador calcula uma novo valor de intensidade $g\left(x_{i}, y_{i}\right)$, e o centro da janela é movido para o pixel seguinte.

Apesar de diversas formas de janelas poderem ser utilizadas, como ilustrado na Fig. 4.24, as janelas retangulares e, particularmente, quadradas são as mais comuns. Neste trabalho, foram utilizadas sempre máscaras quadradas de lado ímpar, geralmente de valor 5 .

No filtro de mediana, o valor do pixel do centro da janela é substituído pela mediana das intensidades de todos os pixels vizinhos situados dentro da janela. A mediana $m$ de um conjunto de $n$ elementos é o valor tal que metade dos $n$ elementos estão abaixo de $m$ e a outra metade está acima de $m$. Se $n$ é ímpar, a mediana $m$ é o próprio valor central dos $n$ elementos ordenados. Se $n$ é par, $m$ é a média aritmética dos dois elementos centrais do conjunto ordenado. Como neste trabalho, porém, somente janelas quadradas de lado ímpar foram utilizadas, $n$ será sempre ímpar.

O filtro de mediana é eficaz contra ruídos impulsivos (não contínuos e que consistem de pulsos irregulares de altas intensidades) ou do tipo sal e pimenta (descontinuidades abruptas e isoladas na imagem), como ilustrado na Fig. 4.25. Além disso, no caso de imagens em escala de cinza, não introduz novos valores de níveis de cinza, utilizando sempre valores presentes na imagem (caso $n$ ímpar).

Neste trabalho, o filtro de mediana foi utilizado para a suavização do contorno da máscara do pulmão e a eliminação de regiões menores (ver Fig. 4.26), que representariam estruturas internas ao pulmão. O tamanho padrão da janela 


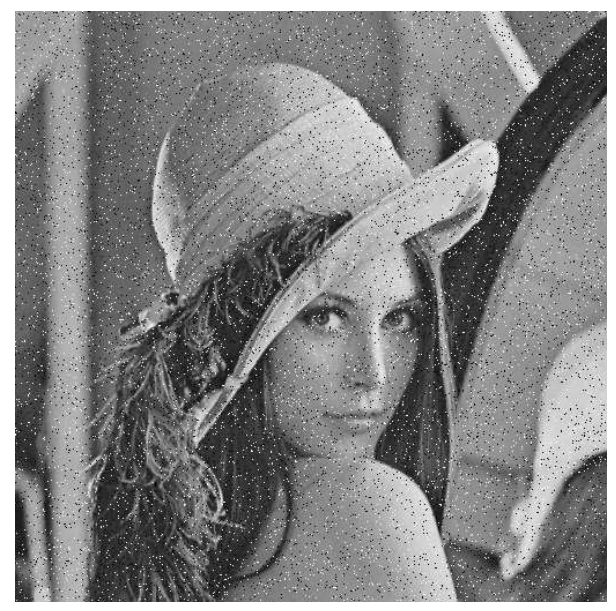

(a)

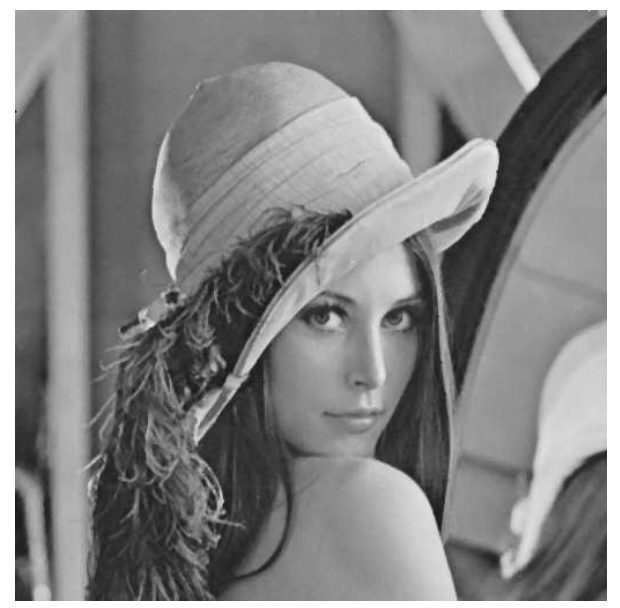

(b)

Figura 4.25: (a) Imagem Lenna com ruído do tipo sal e pimenta introduzido. (b) Resultado da filtragem por filtro de mediana.

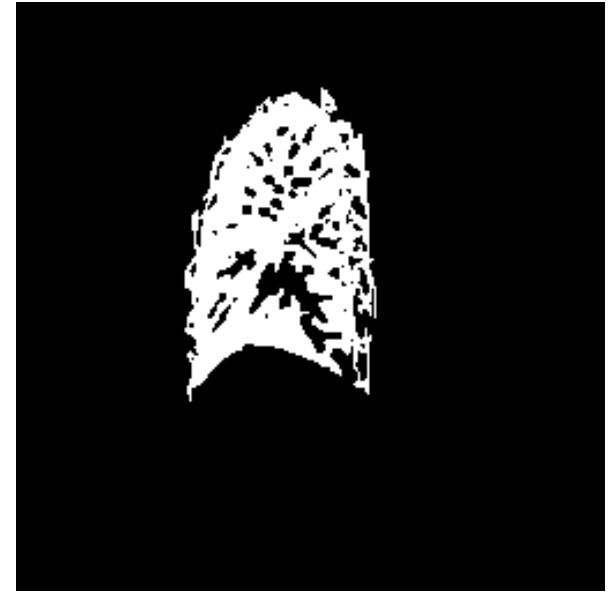

(a)

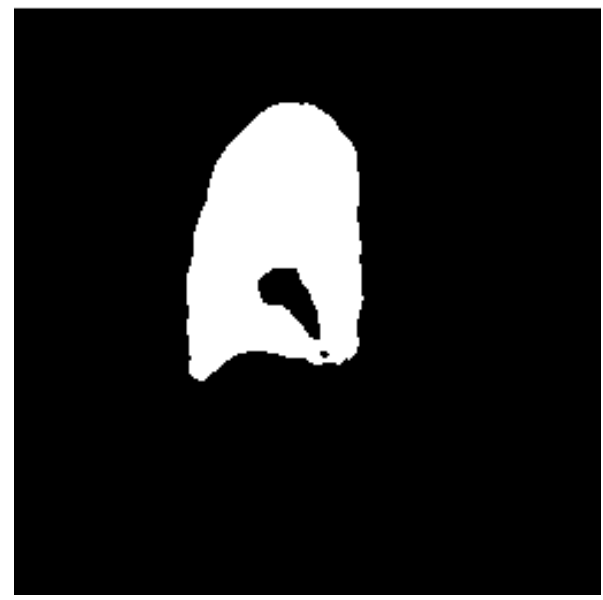

(b)

Figura 4.26: (a) Imagem com a máscara do pulmão. (b) Resultado da filtragem por filtro de mediana.

utilizado foi 5 .

\subsection{Morfologia Matemática}

Inicialmente introduzida por Georges Matheron e Jean Serra na década de 1960, a morfologia matemática é o ramo de processamento digital de imagens que se concentra na análise e processamento da estrutura geométrica da imagem. Originalmente desenvolvida para manipular imagens binárias, a morfologia matemática foi posteriormente estendida para tratar imagens em níveis de cinza. Os operadores morfológicos podem ser utilizados em um grande número de aplicações em processamento e análise de imagens, tais como extração de componentes conexos, busca de padrões específicos na imagem, delimitação do fecho convexo, extração 


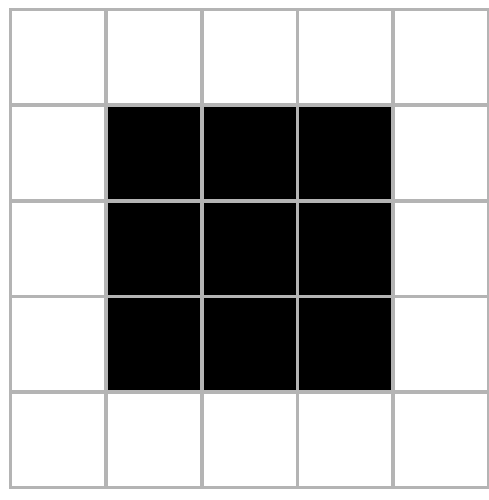

(a)

\begin{tabular}{|l|l|l|l|l|}
\hline 1 & 1 & 1 & 1 & 1 \\
\hline 1 & 0 & 0 & 0 & 1 \\
\hline 1 & 0 & 0 & 0 & 1 \\
\hline 1 & 0 & 0 & 0 & 1 \\
\hline 1 & 1 & 1 & 1 & 1 \\
\hline
\end{tabular}

(b)

Figura 4.27: (a) Imagem binária 5x5 com objeto quadrado $3 \times 3$ em preto. (b) Outra representação para a imagem apresentada em (a).

de bordas dos objetos, afinamento de bordas, entre outras ${ }^{[34]}$.

A morfologia matemática está baseada na teoria de conjuntos para representar a forma dos objetos em uma imagem. Fornecendo-se a imagem binária de tamanho cinco por cinco pixels da Fig. 4.27(a) como exemplo, e convencionandose que pixels pretos representam o objeto (valor 1) e pixels brancos representam o fundo (valor 0), a mesma imagem poderia ser representada pela Fig. 4.27(b), ou ainda expressa pelo conjunto $\{(x, y) \mid f(x, y)=1\}$. Este conjunto é definido no espaço bidimensional $Z^{2}$, em que todos os elementos do conjuntos são vetores bidimensionais denotados pelo par de coordenadas $(x, y)$, com respeito a uma origem fixada no canto superior esquerdo da imagem.

\subsubsection{O elemento estruturante}

Um operador morfológico é uma operação que mapeia dois conjuntos. O primeiro conjunto representa a imagem e o outro é chamado de elemento estruturante. Diferentemente da imagem, porém, no elemento estruturante a origem é especificada. A Fig. 4.28 apresenta alguns elementos estruturantes típicos. O pixel que funciona como origem no elemento estruturante é marcado pela letra $C$.

Na morfologia matemática binária, empregada neste trabalho, a idéia básica é verificar como o elemento estruturante, uma forma pré-definida, se encaixa ou não nas formas presentes na imagem.

Neste trabalho, somente elementos estruturantes quadrados foram utilizados, de tamanhos sempre ímpares para que a origem do elemento estruturante ficasse sempre no centro do quadrado. 


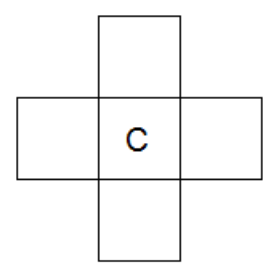

(a)

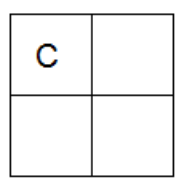

(c)

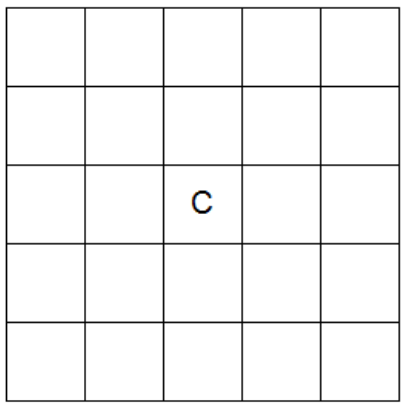

(e)

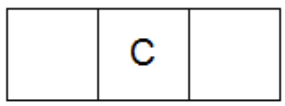

$(\mathrm{g})$

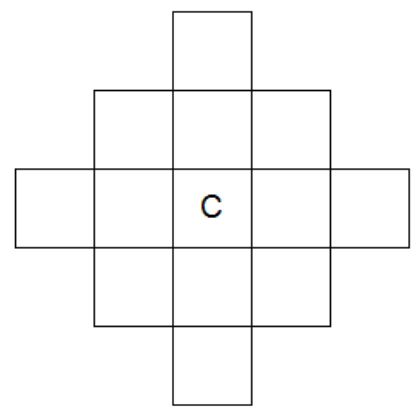

(b)

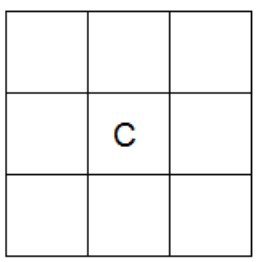

(d)

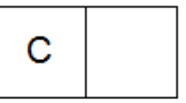

(f)

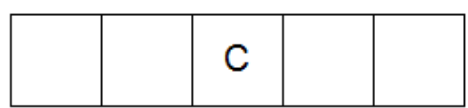

(h)

Figura 4.28: (a) Elemento estruturante do tipo disco, de tamanho 3. (b) Elemento estruturante do tipo disco, de tamanho 5. (c) Elemento estruturante quadrado, de tamanho 2. (d) Elemento estruturante quadrado, de tamanho 3. (e) Elemento estruturante quadrado, de tamanho 5. (f) Elemento estruturante retangular, de tamanho $1 \times 2$. (g) Elemento estruturante retangular, de tamanho 1x3. (h) Elemento estruturante retangular, de tamanho 1x5. 


\subsubsection{Dilatação}

A operação de dilatação entre a imagem $A$ e o elemento estruturante $B$ é definida como a adição de Minkowski ${ }^{[34]}$, ou seja

$$
D(A, B)=A \oplus B=\bigcup_{b \in B}(A+b)
$$

sendo que $A+b$ é a translação de $A$ pelo elemento $b$, e é definida como

$$
A+p=\{a+p \mid a \in A\}
$$

Assim, de acordo com a equação 4.27, a operação de dilatação entre a imagem $A$ e o elemento estruturante $B$ corresponde ao conjunto de todas as translações de $B$ com os pontos em que há pelo menos um elemento não nulo, ou seja, com valor diferente de zero, em comum com o conjunto da imagem $A$.

Na operação de dilatação, o centro do elemento estruturante é posicionado em um dado pixel da imagem. Todos os pixels vizinhos, contidos no elemento estruturante, são avaliados, isto é, podem ser transladados para a posição do pixel em análise. Na prática, o valor de intensidade do pixel em análise é substituído pelo maior valor de intensidade entre seus pixels vizinhos que estão contidos no elemento estruturante.

Figura 4.29 apresenta um exemplo da operação de dilatação em uma imagem binária. O elemento estruturante utilizado foi um quadrado de tamanho 3, com sua origem posicionada na posição central. Na Fig. 4.29(a), a imagem binária está apresentada, com um objeto branco em um fundo preto. Uma região menor está indicada em vermelho, e esta região, ampliada, é mostrada nas imagens das Fig. 4.29(b) a (e). Nessas imagens, quatro pontos diferentes para a posição do centro do elemento estruturante são ilustrados. Na Fig. 4.29(b), o elemento estruturante está todo contido na região de fundo, e portanto o pixel analisado mantém o valor do fundo (valor de intensidade 0). Na Fig. 4.29(c), o elemento estruturante está todo contido na região de objeto, e portanto o pixel analisado mantém seu valor de objeto (valor 1). Na Fig. 4.29(d), o ponto analisado possui valor inicial de fundo, mas entre seus vizinhos contidos no elemento estruturante nele posicionado, há pixels com valores de objeto, e portanto este pixel analisado terá seu valor de intensidade alterado para o valor de objeto. Por fim, na Fig. 4.29(e), o pixel analisado possui valor de objeto e mantém este valor, mesmo existindo pixels com valor de fundo dentro do elemento estruturante. 
Figura 4.30 ilustra o resultado da dilatação aplicado na mesma imagem, porém agora com um quadrado de tamanho maior (mudança feita apenas para facilidade de observação). Na dilatação, portanto, o objeto é expandido em direção ao fundo, e seu novo tamanho está indicado em cinza. Isso acontece pois pixels que antes representavam o fundo, quando sendo analisados na origem do elemento estruturante, podem receber por translação o valor de intensidade de pelo menos um pixel do objeto.

Por fim, a Fig. 4.31 ilustra a operação de dilatação aplicada a uma imagem utilizada neste trabalho. A Fig. 4.31(a) mostra uma máscara do pulmão obtida, e a Fig. 4.31(b) mostra o resultado da dilatação aplicada nesta máscara. A máscara original está apresentada em branco, e a nova máscara está indicada em cinza. Observa-se, no entanto, que nesta imagem de entrada o objeto está apresentado em preto, e o fundo em branco. Todo o procedimento apresentado até este momento permanece válido, com a diferença de que neste caso o fundo irá se expandir sobre o objeto.

\subsubsection{Erosão}

A operação de erosão entre a imagem $A$ e o elemento estruturante $B$ é definida como a subtração de Minkowski ${ }^{[34]}$, ou seja

$$
E(A, B)=A \ominus B=\bigcap_{b \in B}(A-b)=\bigcap_{b \in \hat{B}}(A+b)
$$

sendo que $\hat{B}$ é a reflexão de $B$ e é definida como

$$
\hat{B}=\{-b \mid b \in B\}
$$

Assim, de acordo com a equação 4.29, a operação de erosão entre a imagem $A$ e o elemento estruturante $B$ corresponde ao conjunto de todas as translações de $\hat{B}$. Na prática, a erosão é como a operação oposta da dilatação.

Assim como na operação de dilatação, na erosão o centro do elemento estruturante é posicionado em um dado pixel da imagem. Todos os pixels vizinhos, contidos no elemento estruturante, são avaliados, isto é, podem ser transladados para a posição do pixel em análise, mas com seu valor oposto. O valor de intensidade do pixel em análise é substituído pelo menor valor de intensidade entre seus pixels vizinhos que estão contidos no elemento estruturante. 


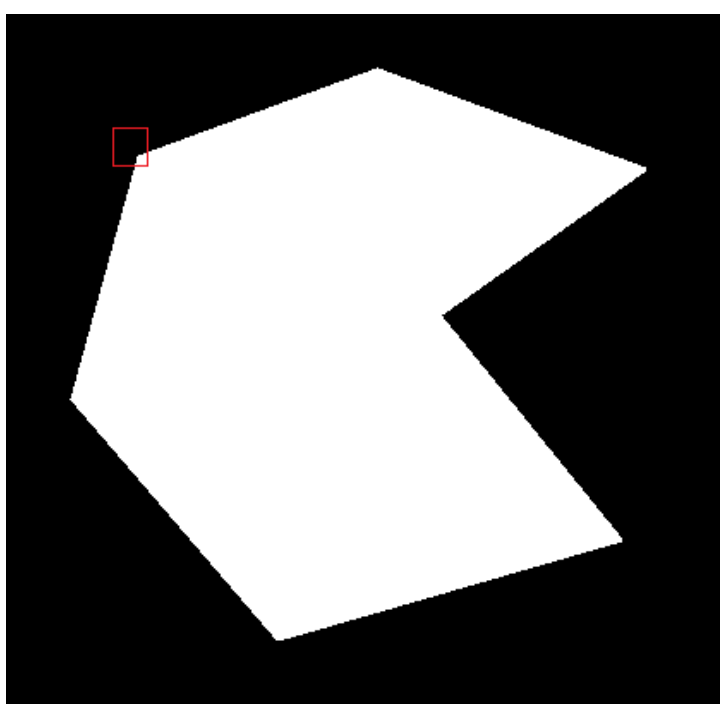

(a)

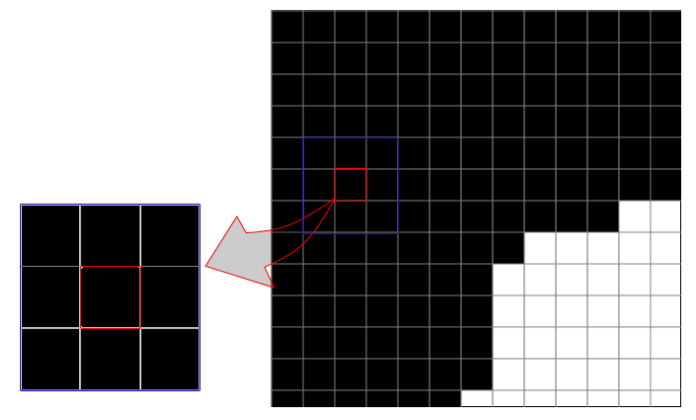

(b)

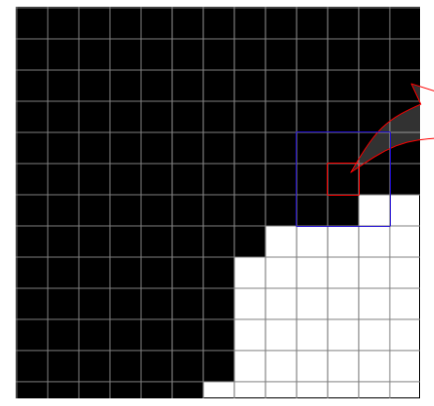

(d)

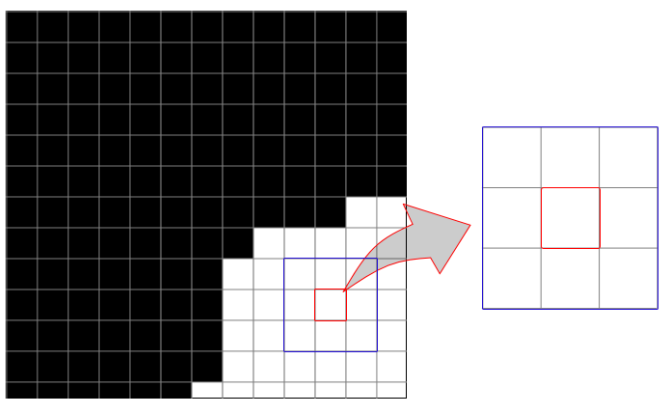

(c)

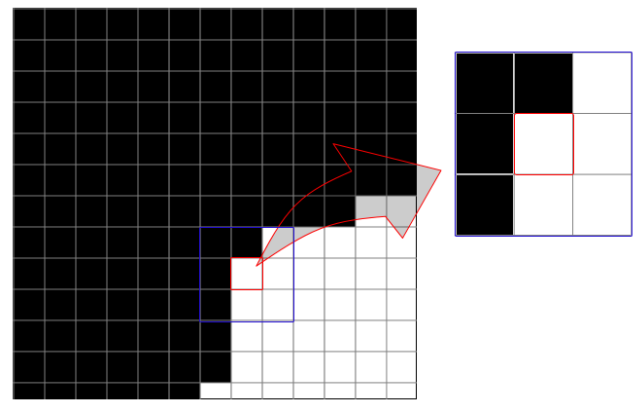

(e)

Figura 4.29: Ilustração da operação de dilatação. (a) Imagem binária original, com região a ser ampliada indicada em vermelho. (b) Elemento estruturante todo contido no fundo da imagem. (c) Elemento estruturante todo contido na região de objeto da imagem. (d) Elemento estruturante posicionado em pixel de valor inicial igual ao fundo da imagem. (e) Elemento estruturante posicionado em pixel de valor inicial igual ao do objeto da imagem. 


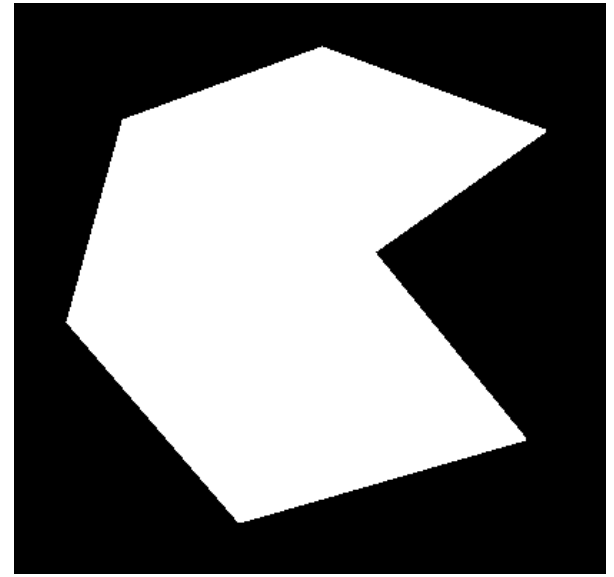

(a)

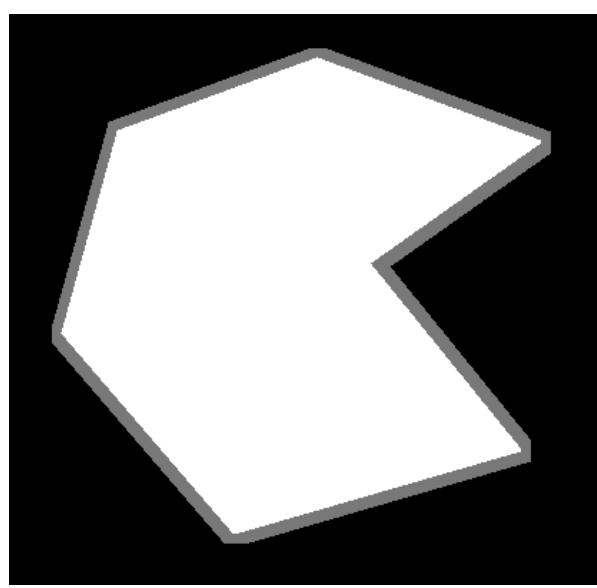

(b)

Figura 4.30: Ilustração da operação de dilatação em uma imagem binária qualquer utilizando um elemento estruturante quadrado de tamanho 13. (a) Imagem binária de entrada. (b) Imagem resultante da dilatação. O objeto original está marcado em branco, e o objeto resultante está indicado em cinza.

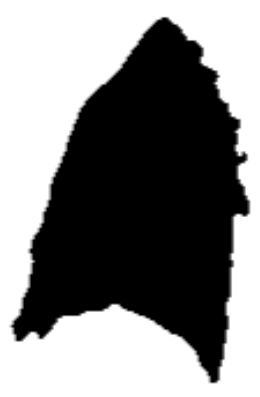

(a)

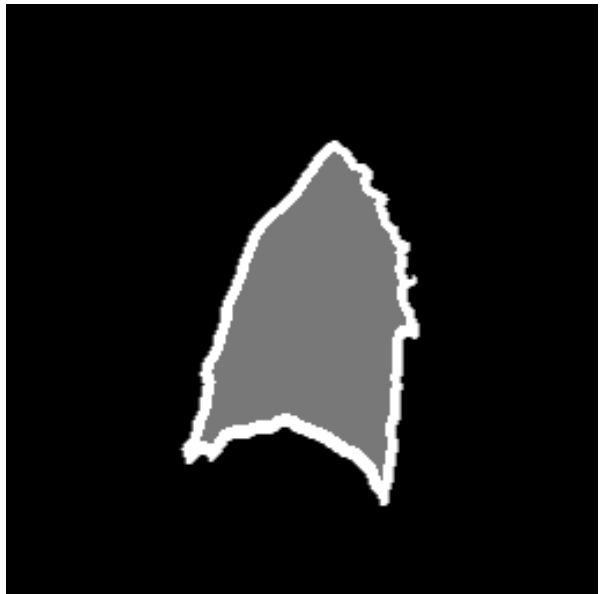

(b)

Figura 4.31: Ilustração da operação de dilatação em uma imagem binária com a máscara do pulmão obtido neste trabalho. (a) Imagem binária de entrada com a máscara do pulmão. (b) Imagem resultante da dilatação. O objeto original está marcado em branco, e o objeto resultante está indicado em cinza. 


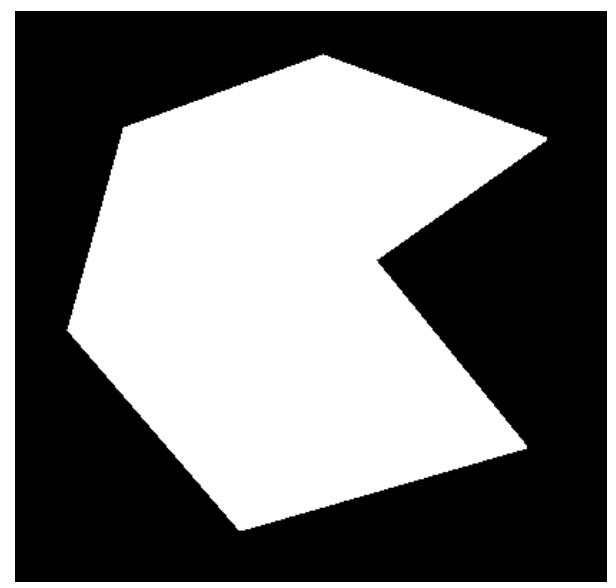

(a)

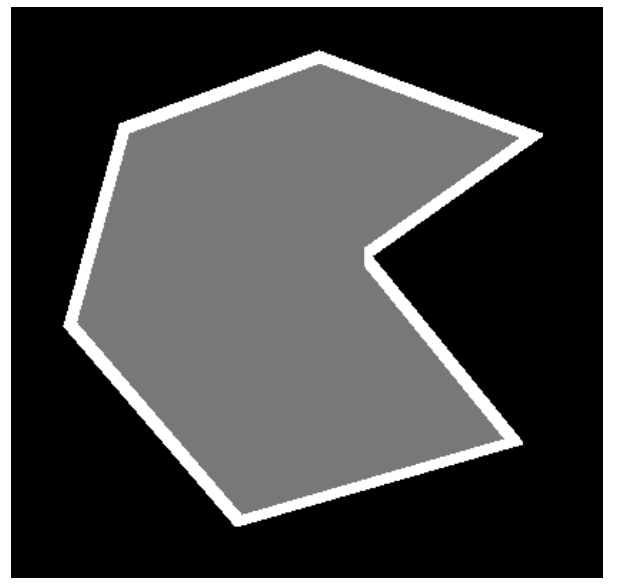

(b)

Figura 4.32: Ilustração da operação de erosão em uma imagem binária qualquer utilizando um elemento estruturante quadrado de tamanho 13. (a) Imagem binária de entrada. (b) Imagem resultante da erosão. O objeto original está marcado em branco, e o objeto resultante está indicado em cinza.

Figura 4.29 também pode ser utilizada como um exemplo da operação de erosão em uma imagem binária. Na Fig. 4.29(b), o elemento estruturante está todo contido na região de fundo, e portanto o pixel analisado mantém o valor do fundo (valor de intensidade 0). Na Fig. 4.29(c), o elemento estruturante está todo contido na região de objeto, e portanto o pixel analisado mantém seu valor de objeto (valor 1). Na Fig. 4.29(d), o ponto analisado possui valor inicial de fundo e mantém este valor, mesmo existindo pixels com valor de fundo contidos no elemento estruturante. Por fim, na Fig. 4.29(e), o pixel analisado possui valor de objeto, mas entre seus vizinhos contidos no elemento estruturante nele posicionado, há pixels com valores de fundo, e portanto este pixel analisado terá seu valor de intensidade alterado para o valor de fundo.

Figura 4.32 ilustra o resultado da erosão aplicado na mesma imagem, porém agora com um quadrado de tamanho maior (mudança feita apenas para facilidade de observação). Na erosão, portanto, o fundo é expandido em direção ao objeto, e seu novo tamanho está indicado em cinza. Isso acontece pois pixels que antes representavam o objeto, quando sendo analisados na origem do elemento estruturante, podem receber por translação o valor de intensidade de pelo menos um pixel do fundo.

Por fim, a Fig. 4.33 ilustra a operação de erosão aplicada a uma imagem utilizada neste trabalho. A Fig. 4.33(a) mostra uma máscara do pulmão obtida, e a Fig. 4.33(b) mostra o resultado da erosão aplicada nesta máscara. A máscara original está apresentada em branco, e a nova máscara está indicada em cinza. Observa-se, no entanto, que nesta imagem de entrada o objeto está apre- 


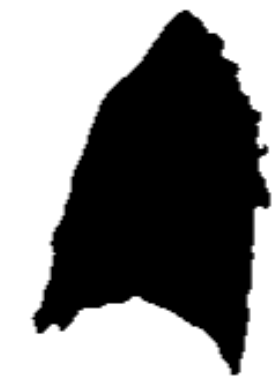

(a)

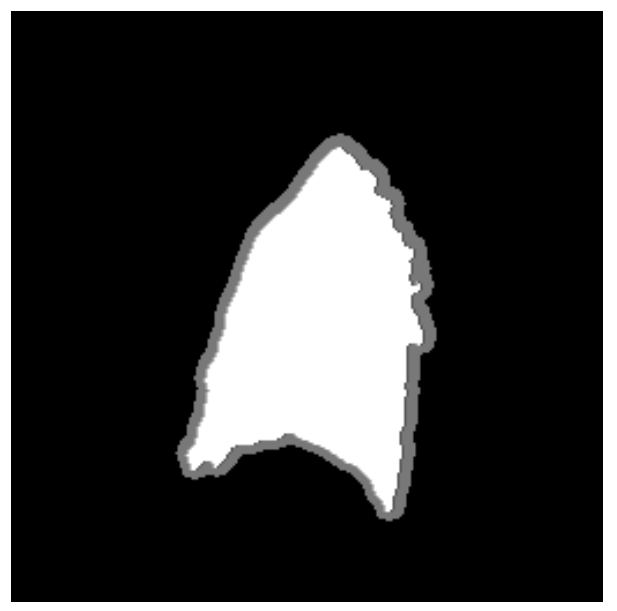

(b)

Figura 4.33: Ilustração da operação de erosão em uma imagem binária com a máscara do pulmão obtida neste trabalho. (a) Imagem binária de entrada com a máscara do pulmão. (b) Imagem resultante da erosão. O objeto original está marcado em branco, e o objeto resultante está indicado em cinza.

sentado em preto, e o fundo em branco. Todo o procedimento apresentado até este momento permanece válido, com a diferença de que neste caso o objeto irá se expandir sobre o fundo. 


\section{Segmentação do Pulmão através de Limiarização e Labeling}

Figura 5.1 mostra todos os passos deste método para obtenção do contorno do pulmão. A Fig. 5.1(a) mostra uma imagem sagital de RM do pulmão. Como quase todo o volume do pulmão é preenchido por ar, à parte das estruturas internas, e como em uma imagem de RM o ar gera muito pouco sinal, é possível obter um esboço de segmentação do pulmão apenas através da segmentação por limiarização.

Figura 5.1(b) mostra a imagem resultante da binarização por limiarização da Fig. 5.1(a). Nessa imagem, todos os pixels com intensidade inferior ao limiar na imagem da Fig. 5.1(a) foram alterados para o valor máximo na imagem da Fig. 5.1(b), enquanto os que possuíam valor de intensidade superior ao limiar foram alterados para o valor mínimo. Desta forma, podemos separar as regiões da imagem em que predomina ar - os pulmões e o fundo - do restante da imagem.

De maneira geral, no caso de imagens sagitais, duas grandes regiões são determinadas. Uma grande região é o fundo e a outra é um esboço do pulmão. Para separarmos o pulmão do restante desta imagem, será utilizado um método chamado labeling. O labeling classifica os pixels conexos para que cada grupo possa ser processado posteriormente. O algoritmo de labeling está apresentado abaixo.

1. Cria-se uma nova imagem idêntica à imagem binária ao qual se aplicará o algoritmo de labeling;

2. Encontra-se um pixel de interesse na imagem binária, ou seja, um pixel com valor de intensidade máximo;

3. Altera-se o valor desse pixel para o número do grupo sendo determinado atualmente; 


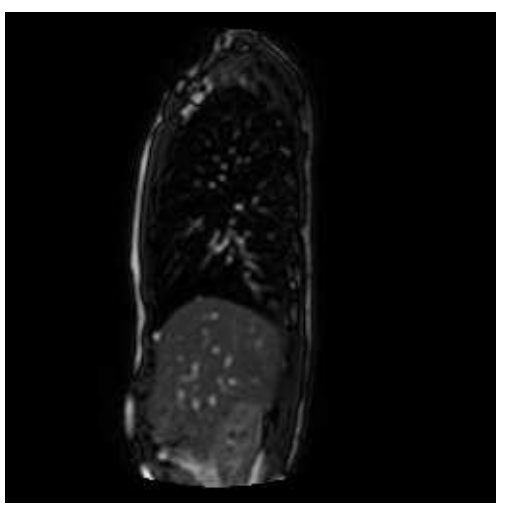

(a)

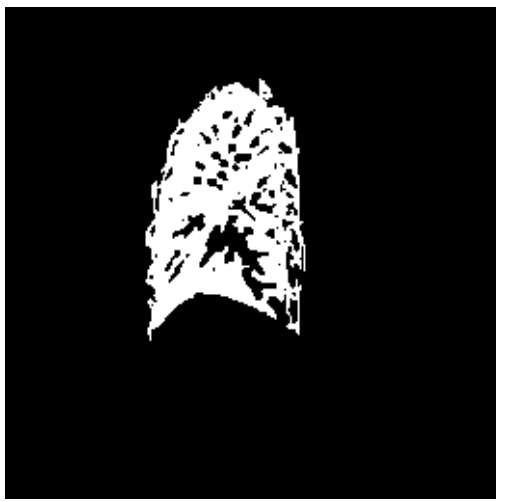

(c)

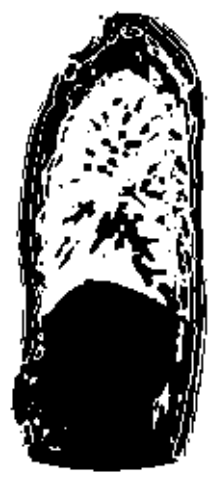

(b)

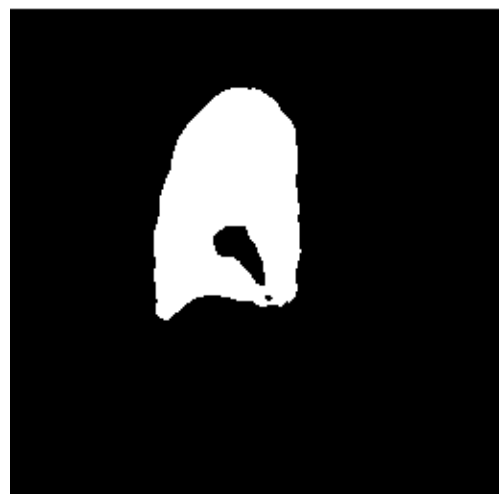

(d)

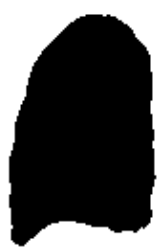

(e)

Figura 5.1: Processo de determinação da região do pulmão. (a) Imagem base. (b) Imagem binária. (c) Imagem após primeiro labeling. (d) Imagem após aplicação de filtro. (e) Imagem final, após segundo labeling. 


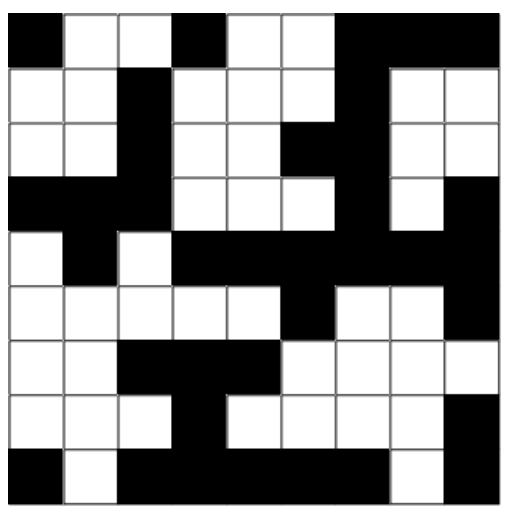

(a)

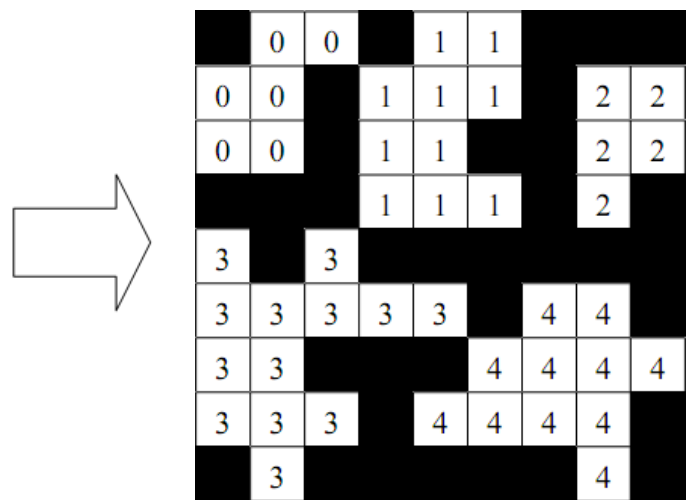

(c)

Figura 5.2: Ilustração do algoritmo de labeling. (a) Imagem binária. (b) Resultado do labeling.

4. Executa-se o algoritmo de crescimento de região para vizinhança de quatro pixels - acima, abaixo, à direita e à esquerda. Os pixels visitados são alterados para valor de intensidade mínima para não serem reavaliados;

5. Pixels conectados recebem um valor correspondente ao seu grupo;

6. Detectada toda a região, procura-se outro pixel de interesse e repete-se o procedimento até que todas as regiões tenham sido classificadas.

Figura 5.2 ilustra um resultado de aplicação do labeling. Com a aplicação do labeling, as regiões estão separadas em grupos que podem ser agora avaliados. Utilizando-se do critério de tamanho da região, podemos separar o pulmão do restante da imagem. A Fig. 5.1(c) apresenta o resultado desta etapa.

Neste ponto, já possuímos um esboço do pulmão, mas este ainda possui muito ruído, e seu contorno é pouco suave e natural. Aplica-se um filtro de mediana para a remoção do ruído e para suavizar o contorno. O tamanho da janela utilizada pode ser controlado. A Fig. 5.1(d) apresenta o resultado desta etapa.

Aplicando-se novamente o algoritmo de labeling, pode-se remover as regiões pretas internas ao pulmão - que representam as suas estruturas internas - e obter a máscara da região interna do pulmão, como mostra a Fig. 5.1(e). A maior região com valor de intensidade mínimo é considerada como sendo não pertencente ao pulmão e o restante é alterado para o mesmo valor de intensidade da região do pulmão. Assim, removem-se as regiões pretas internas à região do pulmão. $\mathrm{O}$ contorno do pulmão pode, então, ser extraído.

Esta segmentação do contorno do pulmão não é totalmente automática. Podese alterar o andamento do algoritmo em diversas etapas. Na primeira etapa, 
o limiar pode ser fornecido manualmente, ou pode-se optar por uma obtenção automática, em que o algoritmo determina o limiar que maximiza a área da região do pulmão. Neste caso, cria-se a máscara do pulmão com diversos valores de limiar, e seleciona-se o valor de limiar que fornece a máscara de maior área.

O tamanho da janela do filtro de mediana também pode ser alterado para uma maior ou menor força do filtro. 


\section{Segmentação Temporal do Pulmão}

O método apresentado no capítulo anterior obtém o contorno do pulmão em cada imagem individualmente. É um método simples e pouco custoso de se obter o contorno do pulmão, mas que não consegue encontrar um contorno adequado em todas as imagens, como mostrado na Fig. 6.1. Neste capítulo, o método anterior será expandido para que utilize informação temporal na obtenção do contorno, através dos padrões respiratórios.

Utilizando-se da transformada de Hough modificada apresentada na seção 4.3, para uma imagem 2DST com plano vertical - o plano vertical está representado na Fig. 6.2(a) pela reta verde e a imagem 2DST está apresentada na Fig. 6.2(b) - , podemos obter diversas funções respiração, como mostrado na Fig. 6.2(c). Porém, não é possível determinar com confiança quais delas representam a movimentação do contorno do pulmão e quais representam a movimentação de suas estruturas.

A partir dos resultados obtidos pelo método apresentado no capítulo anterior, pode-se restringir a busca de padrões respiratórios apenas nas regiões em que o contorno pode estar presente. Para isso, o contorno obtido anteriormente será transformado em uma região de busca. A Fig. 6.3(b) mostra novamente o resultado obtido pelo método apresentado no capítulo anterior. O pulmão ainda é representado por uma região e não um contorno. A essa região, aplicam-se duas operações morfológicas paralelamente, dilatação e erosão. Desta forma, a região do pulmão será diminuída e aumentada, como mostrado, respectivamente, nas Fig. 6.3(c) e (d). A região de interesse é exatamente a diferença entre as duas regiões, então aplica-se o operador XOR lógico para se obter uma máscara de busca do contorno do pulmão. A Fig. 6.3(e) mostra essa máscara. O tamanho do elemento estruturante pode ser alterado de forma a aumentar ou diminuir a área de busca.

Essa máscara é criada para todas as imagens do STV, e o processamento temporal utilizando a transformada de Hough modificada é aplicado. Por estarmos 


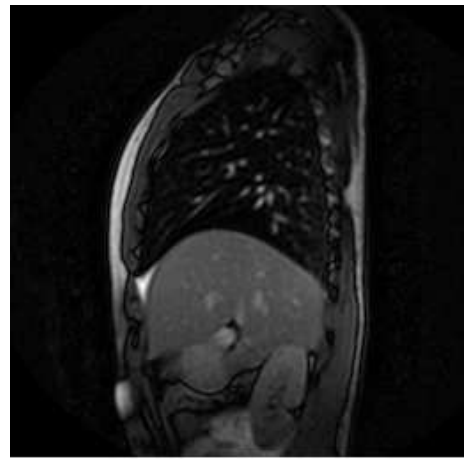

(a)

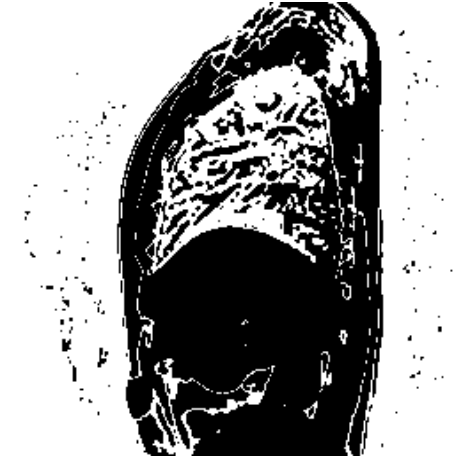

(b)

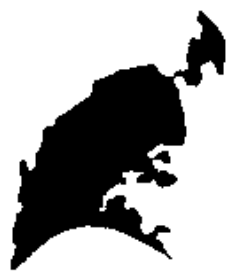

(c)

Figura 6.1: Criação de uma máscara que define o interior do pulmão com problemas. (a) Imagem de RM original. (b) Imagem binária criada. (c) Imagem com a região encontrada.

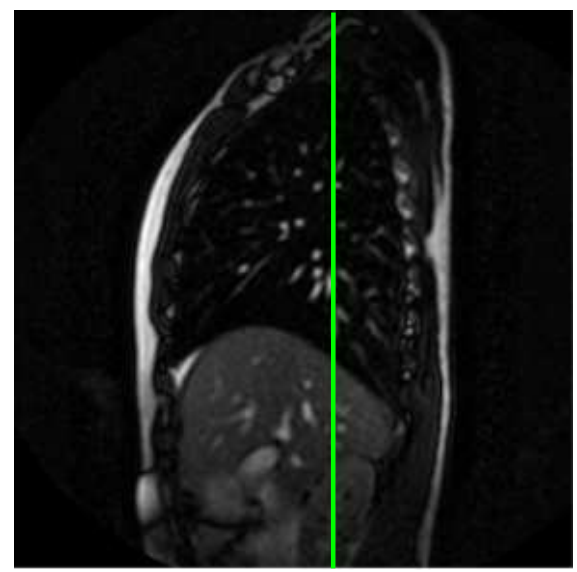

(a)

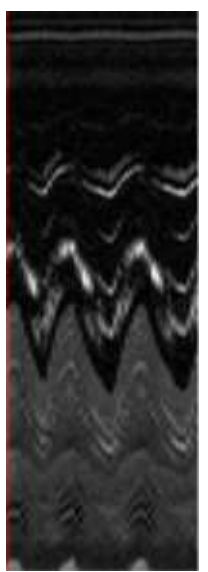

(b)

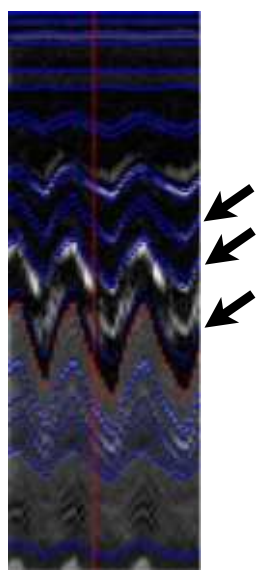

(c)

Figura 6.2: (a) Uma imagem ilustrando o plano que originou a imagem 2DST. (b) Uma imagem 2DST. (c) Os primeiros 21 padrões respiratórios encontrados. As setas mostram alguns padrões respiratórios encontrados pela transformada de Hough modificada que representam as diferentes estruturas internas do pulmão. 


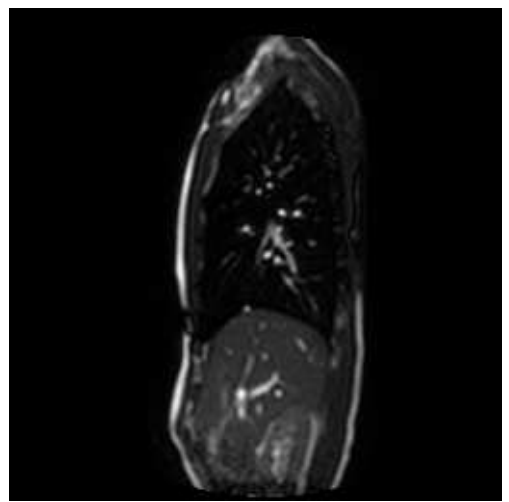

(a)

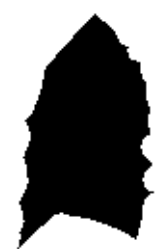

(c)

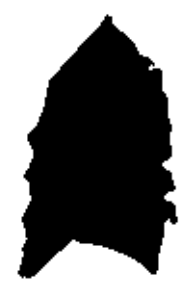

(b)

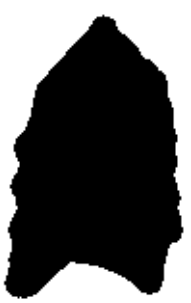

(d)

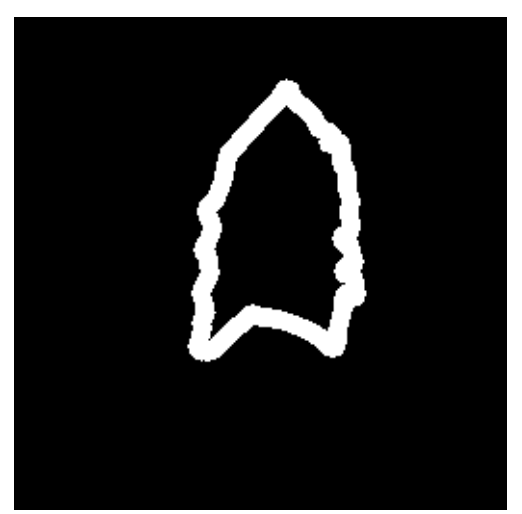

(e)

Figura 6.3: Criação da máscara de busca do contorno a partir de região determinada anteriormente. (a) Imagem base. (b) Região do pulmão obtida. (c) Imagem após dilatação morfológica. (d) Imagem após erosão morfológica. (e) Máscara do contorno do pulmão. 


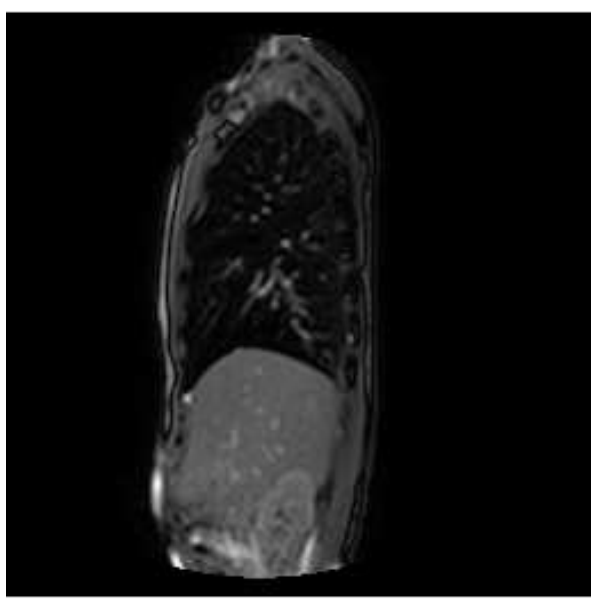

(a)

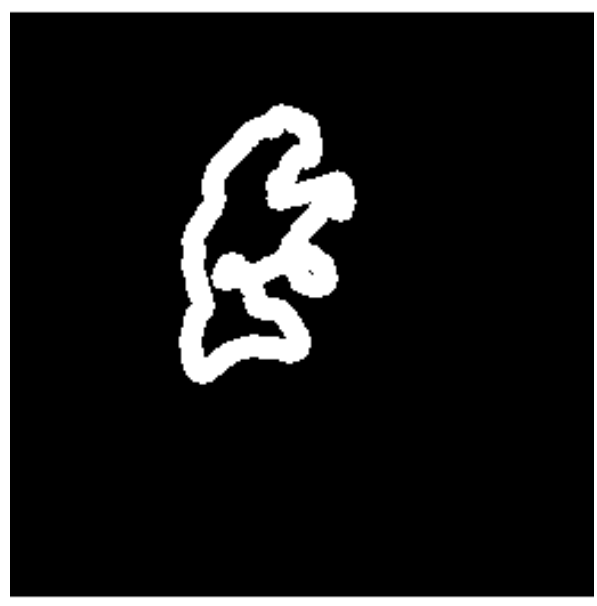

(b)

Figura 6.4: Máscara inadequada calculada.

utilizando informação da respiração presente na série como um todo, máscaras inadequadas, como a apresentada na Fig. 6.4, não afetam o resultado final.

Considere a seqüência temporal de imagens sagitais de RM do pulmão apresentada na Fig. 6.5. É possível observar o ciclo de respiração ao longo da série. As imagem das Fig. 6.5(c), 6.5(g) e 6.5(k) apresentam o pulmão em fase da respiração próxima à expiração máxima, as Fig. 6.5(e) e 6.5(i) apresentam o pulmão o pulmão em fase próxima à inspiração máxima, e as demais imagens apresentam o pulmão em fases intermediárias. Utilizaremos esta série, com a imagem da Fig. 6.5(h), para ilustrar o procedimento.

Figura 6.6 ilustra a criação da máscara para a imagem da Fig. 6.5(h). Na Fig. 6.6(a), a repetição da imagem na Fig. 6.5(h). Na Fig. 6.6(b), temos o resultado da limiarização. Na Fig. 6.6(c), é apresentado o resultado da primeira aplicação do algoritmo de labeling - a região do pulmão é extraída do restando da imagem. Na Fig. 6.6(d), a aplicação do filtro de mediana, para a suavização do contorno. Na Fig. 6.6(e), o resultado da segunda aplicação do algoritmo de labeling, isolando o pulmão. Na Fig. 6.6(f), o resultado da aplicação da operação morfológica de dilatação (que diminui a área do pulmão), e na Fig. 6.6(g), o resultado da aplicação da operação morfológica de erosão (que aumenta a área do pulmão). A diferença das duas áreas é apresentado na Fig. 6.6(h), e é a máscara obtida para esta imagem base.

A máscara determina uma região de busca do contorno na aplicação da transformada de Hough modificada. Primeiramente, criamos uma imagem 2DST a partir do STV da série, e a essa imagem 2DST aplica-se um operador de gradien- 


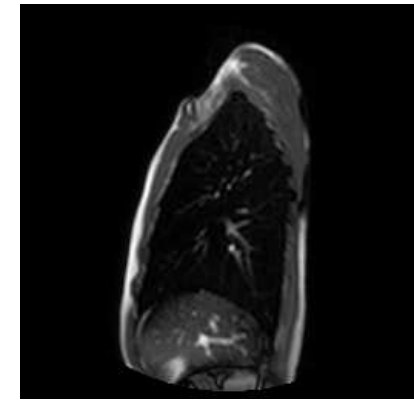

(a)

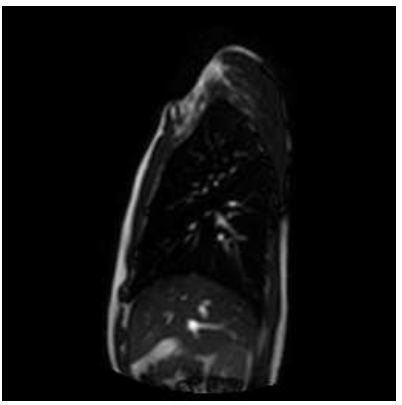

(d)

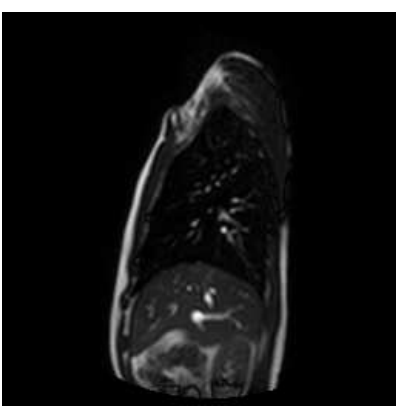

(g)

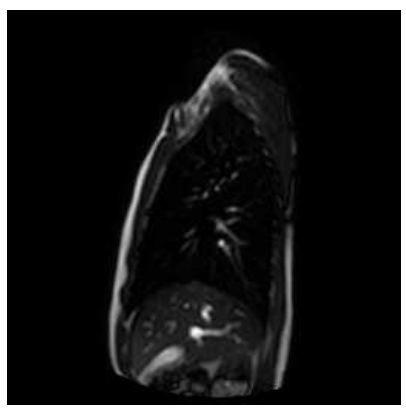

(j)

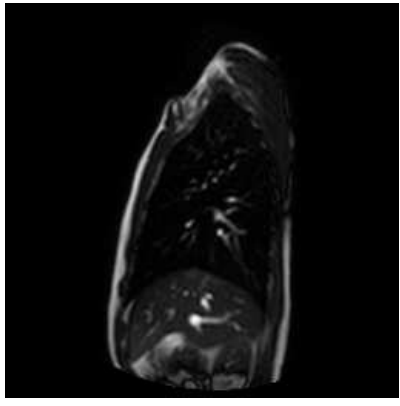

(b)

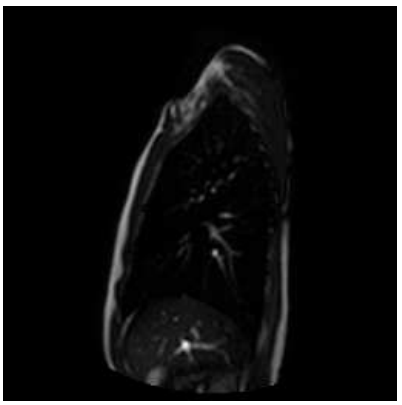

(e)

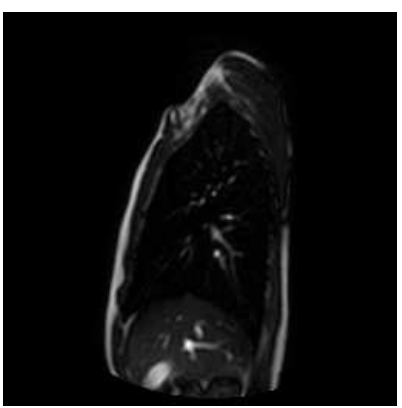

(h)

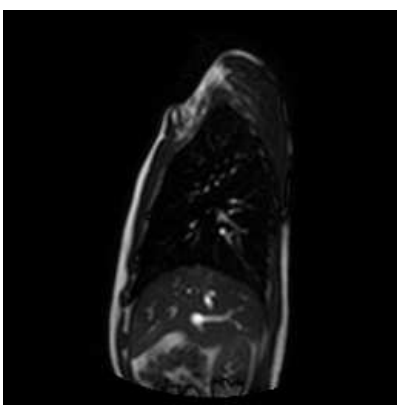

(k)

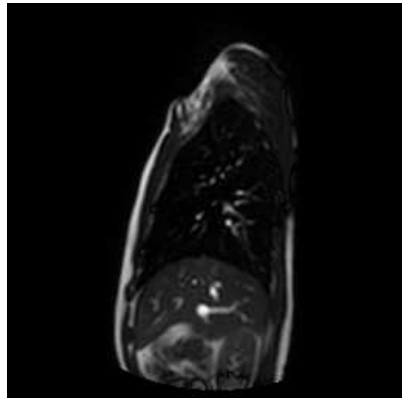

(c)

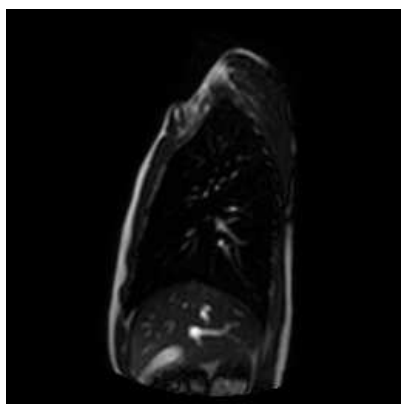

(f)

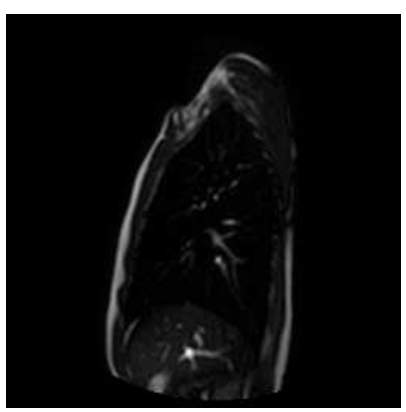

(i)

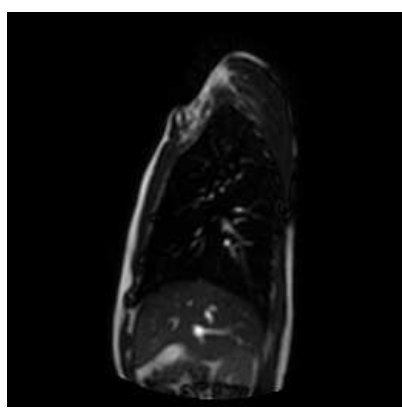

(1)

Figura 6.5: Seqüência temporal de imagens sagitais de RM do pulmão. Imagens em (c), (g) e (k) apresentam o pulmão na expiração, (e) e (i), na inspiração, e as demais, em fases intermediárias. 


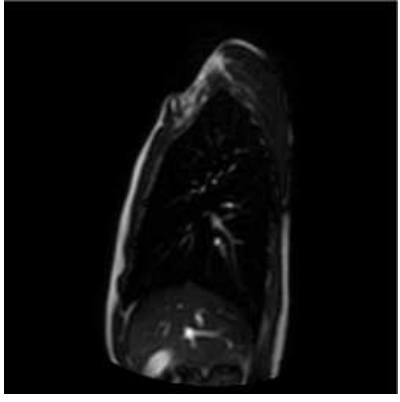

(a)

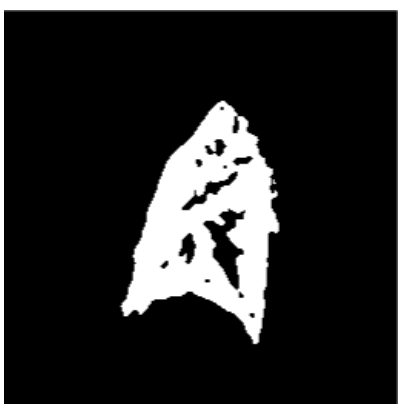

(d)

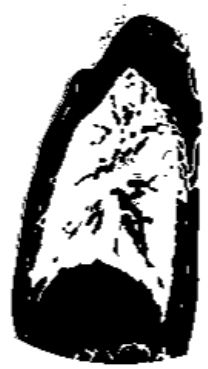

(b)

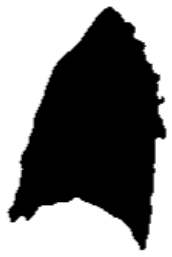

(e)

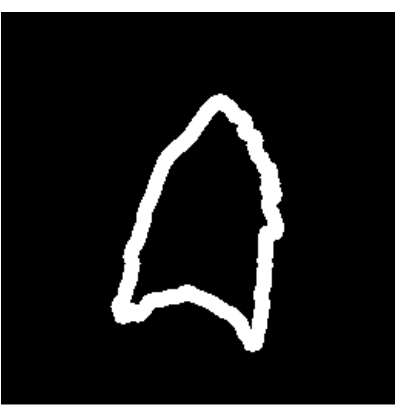

(h)

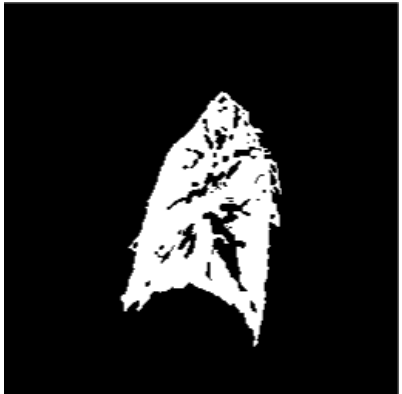

(c)

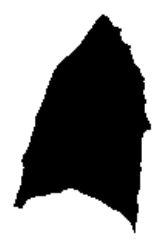

(f)

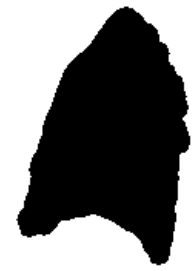

$(\mathrm{g})$

Figura 6.6: Processo de criação da máscara para imagem da Fig. 6.5(h). (a) Imagem base. (b) Imagem binária. (c) Imagem após primeiro labeling. (d) Imagem após aplicação de filtro. (e) Imagem após segundo labeling. (f) Imagem após dilatação morfológica. (g) Imagem após erosão morfológica. (h) Máscara do contorno do pulmão. 
tes para se obter uma imagem de arestas. Aplicando-se o processo de criação de máscaras para todas as imagens da série, obtemos um STV de máscaras. Podese, então, criar uma imagem 2DST de máscara, na mesma posição da imagem 2DST criada a partir do STV da série. Supondo-se que existirão dois contornos presentes nessa imagem 2DST (em uma imagem 2DST vertical, por exemplo, os contornos superior e inferior do pulmão), podemos separá-los e processá-los independentemente.

A transformada de Hough modificada detecta a presença de padrões respiratórios através de um procedimento de votação. Para se evitar detecções incorretas em pixels de alto gradiente, pixels com intensidades muito altas, que, de maneira geral, representam gordura ou vasos sanguíneos (ou seja, partes que não interessam a este trabalho) são removidos.

Como afirmado anteriormente, e mostrado na Fig. 4.3, as imagens 2DST podem ser definidas com diferentes ângulos. Neste trabalho foram utilizadas imagens 2DST vertical, horizontal e oblíquas $\left(-45^{\circ} \mathrm{e}+45^{\circ}\right)$. O algoritmo seleciona planos em que a maior parte das máscaras possui duas intersecções - representando os dois contornos presentes na imagem 2DST. Desta forma, dois padrões respiratórios são encontrados em cada imagem 2DST considerada.

Figura 6.7(a) mostra a mesma imagem da Fig. 6.5(h). A reta verde indica a posição em que a imagem 2DST será criada. Fig. 6.7(b) mostra a imagem 2DST vertical criada, com os pixels com alto valor de intensidade filtrados. A intersecção dessa imagem 2DST com a máscara equivalente resulta em duas imagens de arestas. Fig. 6.7(c) e 6.7(e), respectivamente, mostram imagens de arestas referentes aos contornos superior e inferior do pulmão. Fig. 6.7(d) e 6.7(f), respectivamente, mostram o espaço paramétrico de Hough obtido de cada imagem de aresta. Os pontos com maior intensidade em cada espaço paramétrico de Hough são detectados e representam padrões respiratórios apresentados, respectivamente, nas Fig. 6.7(c) e 6.7(e).

Observa-se que pode-se utilizar uma informação adicional nesta etapa. O pulmão se expande e se contrai durante a respiração e apresenta o movimento de maior amplitude na caixa torácica. Assim, os dois contorno presentes em uma imagem 2DST devem ter movimentos - padrões respiratórios - com fases complementares. Em outras palavras, devem estar em semiplanos diferentes no espaço paramétrico de Hough. Tomando-se como hipótese que a função respiração base foi criada na região diafragmática, então temos que o movimento do contorno inferior em uma imagem 2DST vertical deve possuir a mesma fase que a função 


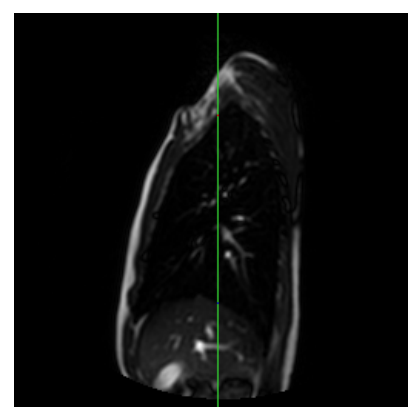

(a)

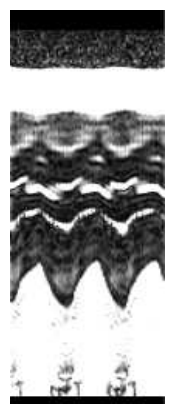

(b)

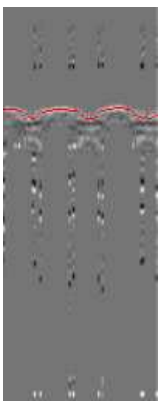

(c)

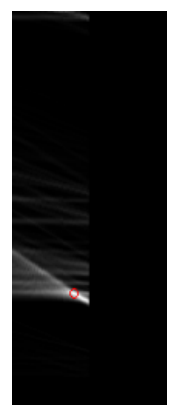

(d)

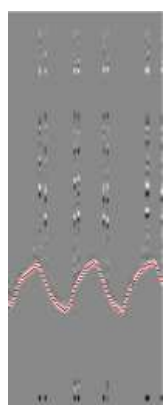

(e)

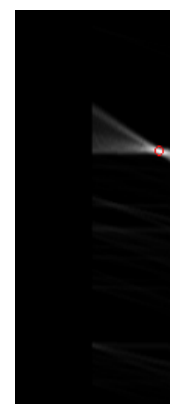

(f)

Figura 6.7: Ilustração do processamento temporal da imagem da Fig. 6.5(h) com uma imagem 2DST vertical.(a) Imagem sagital de RM do pulmão (posição da imagem 2DST relativa a esta imagem está indicada em verde). (b) Imagem 2DST vertical da imagem (a) criada na posição indicada. (c) O mapa de arestas referente ao contorno superior com a máscara aplicada. (d) O espaço paramétrico de Hough mostrando a função respiração encontrada em (c). (e) O mapa de arestas referente ao contorno inferior com a máscara aplicada. (f) O espaço paramétrico de Hough mostrando a função respiração encontrada em Fig. (e).

respiração base e, portanto, estar no semiplano do espaço paramétrico de Hough em que a coordenada $a$ é não-negativa. Analogamente, o contorno superior nessa mesma imagem deve estar no semiplano do espaço paramétrico de Hough em que $a$ é não-positiva. Isso restringe a busca por pontos de máximos no espaço paramétrico e impede que esse tipo de padrões respiratórios incoerentes sejam encontrados.

Em algumas situações, uma máscara não terá duas intersecções com a imagem 2DST, devido à forma da máscara ou mesmo devido à máscara inadequada ou vazia. Considere, por exemplo, a máscara mostrada na Fig. 6.1. Neste caso, em determinadas imagens 2DST, a máscara não é utilizada e a imagem de arestas criada utiliza a imagem completa. Dessa forma, as limitações da criação da máscara não afetarão significativamente a aplicação da transformada de Hough modificada. Somente imagens 2DST em planos que respeitem o critério de seleção serão consideradas para a análise. Neste trabalho, analisaram-se planos em que a média de intersecções estivesse entre 1.75 e 2.25, a não ser que seja mencionado o contrário.

O algoritmo de contornos ativos é utilizado para refinar os padrões respiratórios encontrados e relaxar a hipótese de movimentos síncronos de todo o pulmão e suas estruturas. A Fig. 6.8 mostra uma comparação dos padrões respiratórios obtidos sem e com o ajuste feito por contornos ativos. Nas Fig. 6.8(a) e (d), os espaços paramétricos de Hough com as células de máximo indicadas em vermelho. Os padrões respiratórios referentes a essas células de máximo estão apresentados 
nas Fig. 6.8(b) e (e). Nestas imagens, os padrões respiratórios encontrados e apresentados são totalmente síncronos com o padrão respiratório base utilizado. Nas Fig. 6.8(c) e (f), os resultados dos ajustes dos padrões respiratórios em (b) e (e), respectivamente. Pode-se observar que os padrões respiratórios ajustados aproximam melhor as arestas presentes nas imagens de arestas em vez de respeitar totalmente o padrão respiratório base.

Todos os planos verticais são processados, e os resultados (dois padrões respiratórios por plano) são guardados em listas. Em seguida, analisam-se os planos horizontais. Então, processam-se os planos oblíquos $+45^{\circ}$ e, por último, os planos oblíquos $-45^{\circ}$. Todos os padrões respiratórios são guardados em listas. O resultado desta fase de processamento é um conjunto de padrões respiratórios dispersos e não ordenados. Deseja-se obter um contorno em cada imagem, e no momento o que se tem são pontos não-ordenados. É necessário transformar esses conjuntos de pontos em conjuntos de contornos. Neste contexto, define-se um contorno como uma lista circular e ordenada de pontos.

Figuras 6.9, 6.10 e 6.11 ilustram a aplicação do processamento temporal em imagens horizontal (Fig. 6.9), oblíqua $+45^{\circ}$ (Fig. 6.10) e oblíqua $-45^{\circ}$ (Fig. 6.11).

Como mencionado, esse processamento temporal com a transformada modificada de Hough é feito com todas as imagens 2DST verticais, horizontais e oblíquas $\left(+45^{\circ} \mathrm{e}-45^{\circ}\right)$. O resultado desse processamento para todas as imagens 2DST consideradas válidas está apresentado na Fig. 6.12.

Figura 6.13(a) apresenta uma imagem binária com fundo em preto e com os pontos determinados pelo processamento temporal até aqui explicado em branco. O algoritmo dos contornos ativos pode ser utilizado para determinar contornos subjetivos (isto é, contornos que não estão explicitamente presentes na imagem), e pode ser utilizado para obtermos um contorno a partir dos pontos processados. Porém, diferente da aplicação anterior, neste estágio do processamento e para esta tarefa específica, não temos um contorno inicial próximo ao contorno que desejamos obter, e o método de contornos ativos depende fortemente da sua inicialização. Assim, a utilização do algoritmo de contornos ativos com GVF se mostra vantajoso nesta etapa, por diminuir a importância do contorno inicial.

Um contorno circular inicial qualquer pode ser calculado a partir das posições dos pontos obtidos. O centro geométrico de todos os pontos é o centro do contorno circular, e a distância média dos pontos ao centro, é o raio da circunferência que serve de base para o contorno inicial. Como o pulmão, de maneira geral, possui maior altura do que largura ou profundidade, o contorno é esticado 


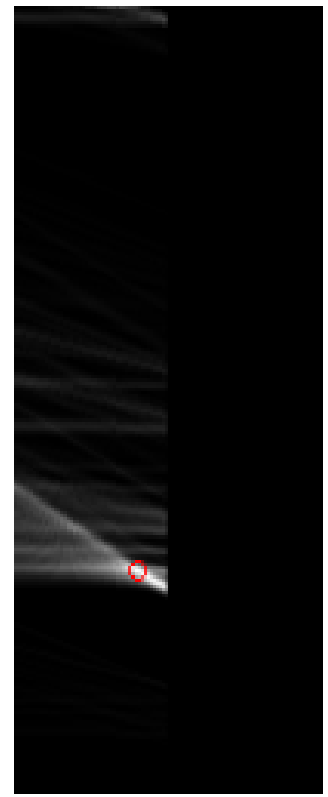

(a)

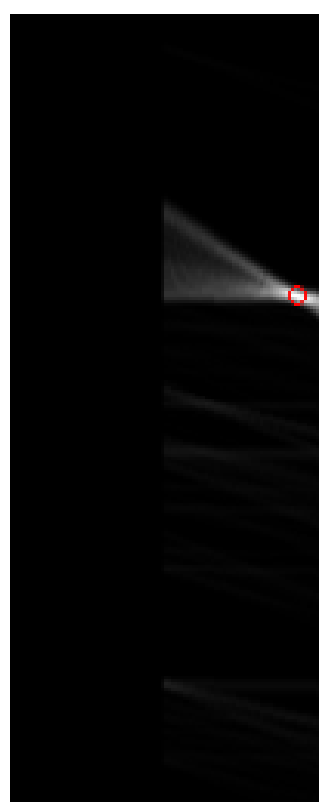

(d)

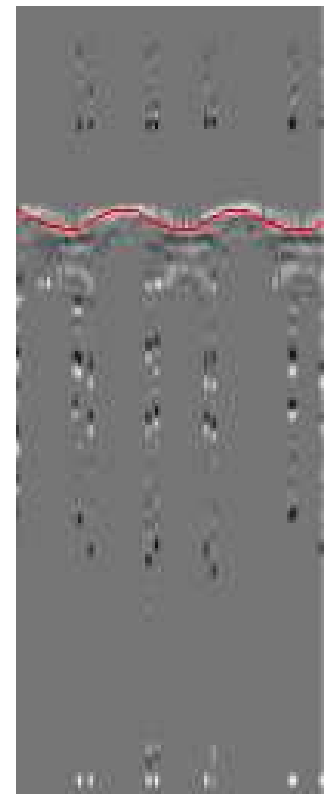

(b)

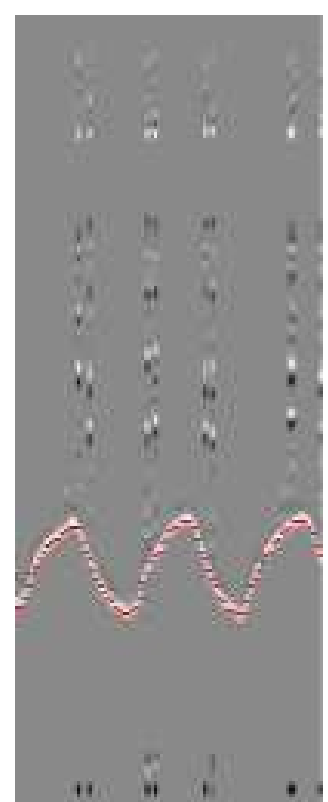

(e)

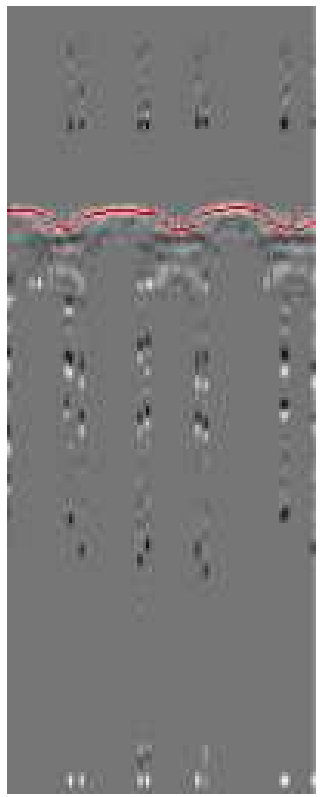

(c)

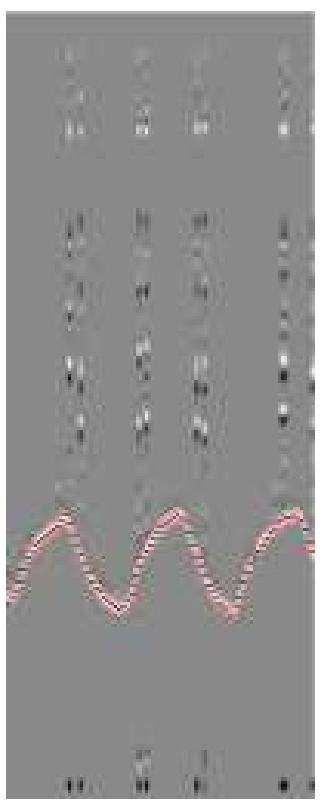

(f)

Figura 6.8: Comparação dos padrões respiratórios encontrados pela transformada de Hough modificada antes e depois do ajuste feito pelo método de contornos ativos. (a) Espaço paramétrico de Hough. Ponto de máximo indicado por círculo vermelho. (b) Imagem de arestas com a máscara aplicada - contorno superior do pulmão. Padrão respiratório, antes do ajuste por contornos ativos, encontrado indicado em vermelho. (c) Mesma imagem de arestas que a exibida em (b), porém com o padrão respiratório indicado em vermelho após o ajuste pelo método de contornos ativos. (d) Espaço paramétrico de Hough. Ponto de máximo indicado por círculo vermelho. (e) Imagem de arestas com a máscara aplicada - contorno inferior do pulmão. Padrão respiratório, antes do ajuste por contornos ativos, encontrado indicado em vermelho. (f) Mesma imagem de arestas que a exibida em (e), porém com padrão respiratório indicado em vermelho após o ajuste pelo método de contornos ativos. 


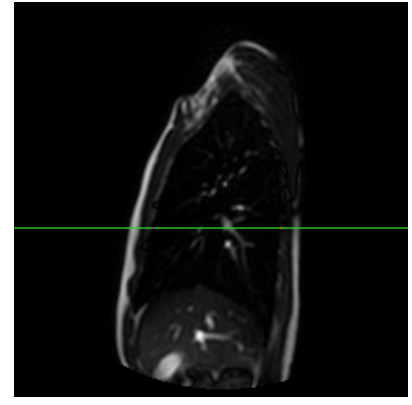

(a)

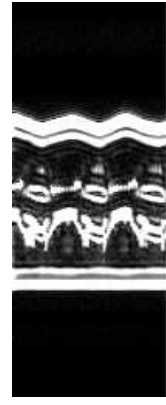

(b)

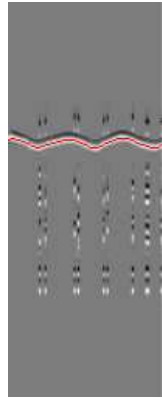

(c)

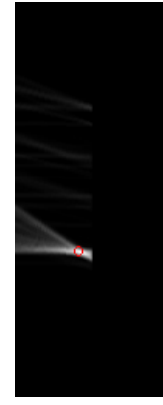

(d)

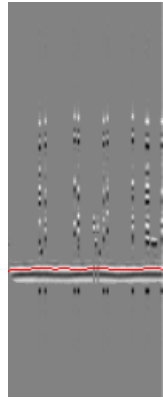

(e)

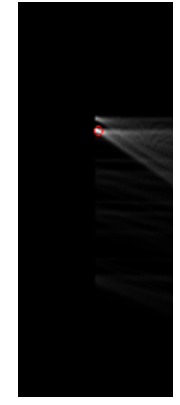

(f)

Figura 6.9: Ilustração do processamento temporal da imagem da Fig. 6.5(h) com uma imagem 2DST horizontal.(a) Imagem sagital de RM do pulmão (posição da imagem 2DST relativa a esta imagem está indicada em verde). (b) Imagem 2DST horizontal da imagem (a) criada na posição indicada. (c) O mapa de arestas referente ao contorno anterior com a máscara aplicada. (d) O espaço paramétrico de Hough mostrando a função respiração encontrada em (c). (e) $\mathrm{O}$ mapa de arestas referente ao contorno posterior com a máscara aplicada. (f) $\mathrm{O}$ espaço paramétrico de Hough mostrando a função respiração encontrada em (e).

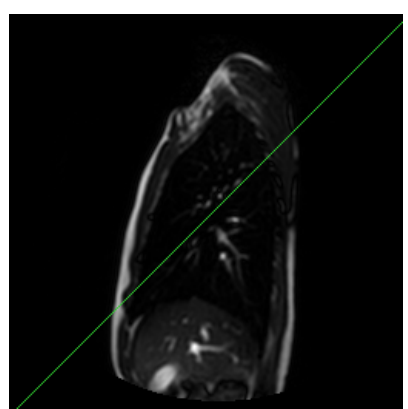

(a)

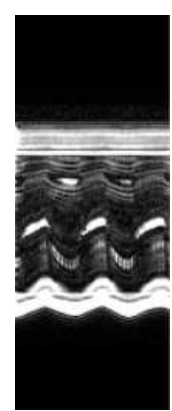

(b)

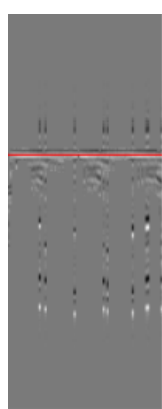

(c)

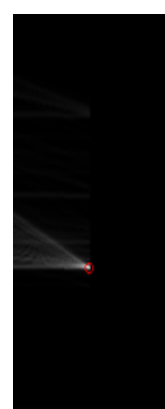

(d)

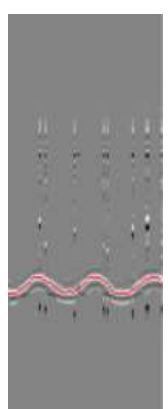

(e)

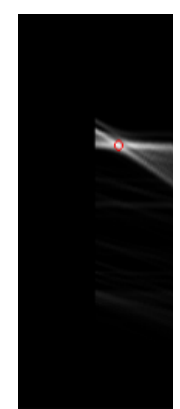

(f)

Figura 6.10: Ilustração do processamento temporal da imagem da Fig. 6.5(h) com uma imagem 2DST oblíqua $+45^{\circ}$.(a) Imagem sagital de RM do pulmão (posição da imagem 2DST relativa a esta imagem está indicada em verde). (b) Imagem 2DST oblíqua $+45^{\circ}$ da imagem (a) criada na posição indicada. (c) $\mathrm{O}$ mapa de arestas referente ao contorno posterior/superior com a máscara aplicada. (d) O espaço paramétrico de Hough mostrando a função respiração encontrada em (c). (e) O mapa de arestas referente ao contorno anterior/inferior com a máscara aplicada. (f) O espaço paramétrico de Hough mostrando a função respiração encontrada em (e). 


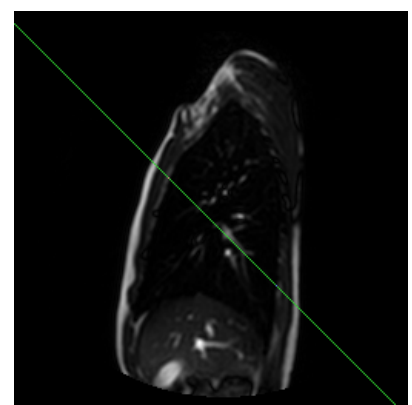

(a)

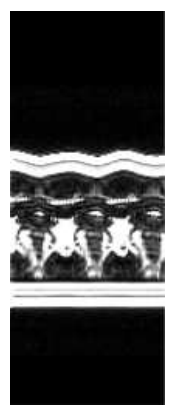

(b)

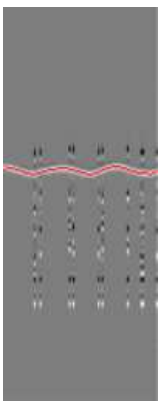

(c)

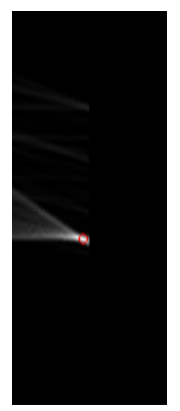

(d)

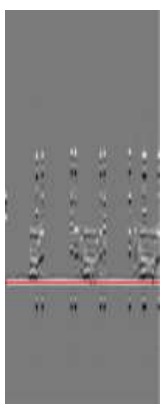

(e)

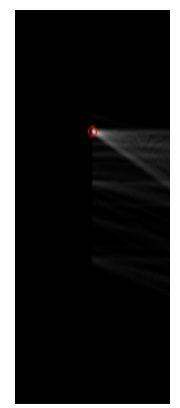

(f)

Figura 6.11: Ilustração do processamento temporal da imagem da Fig. 6.5(h) com uma imagem 2DST oblíqua $-45^{\circ}$.(a) Imagem sagital de RM do pulmão (posição da imagem 2DST relativa a esta imagem está indicada em verde). (b) Imagem 2DST oblíqua $-45^{\circ}$ da imagem (a) criada na posição indicada. (c) O mapa de arestas referente ao contorno anterior/superior com a máscara aplicada. (d) O espaço paramétrico de Hough mostrando a função respiração encontrada em (c). (e) O mapa de arestas referente ao contorno posterior/inferior com a máscara aplicada. (f) $\mathrm{O}$ espaço paramétrico de Hough mostrando a função respiração encontrada em (e).

em 50\% na dimensão de altura. A Fig. 6.13(b) apresenta o contorno inicial para a imagem da Fig. 6.13(a). Este contorno circular inicial converge para um contorno que passa por quase todos os pontos do contorno subjetivo. Pontos equivocados encontrados pelo processamento utilizando transformada de Hough modificada que se encontram distantes do contorno subjetivo não possuem força de atração suficiente para deslocar o contorno e são, como resultado, ignorados pelo algoritmo. O resultado da aplicação do algoritmo de contornos ativos com GVF para a imagem da Fig. 6.13(b) está apresentado na Fig. 6.13(c).

O contorno obtido nesta última etapa, porém, foi obtido apenas a partir dos pontos processados pela transformada de Hough modificada, que não cobrem todo o contorno do pulmão. Assim, há descontinuidades no contorno obtido que o algoritmo de contornos ativos não é capaz de resolver apenas a partir dos pontos processados. Na próxima etapa, então, o contorno será ajustado a partir de informações da imagem. O contorno atual é próximo suficiente do contorno desejado, então a aplicação tradicional de contornos ativos é a mais adequada por evitar que o contorno seja atraído por arestas mais afastadas. Por ser uma etapa de ajuste, poucas iterações são necessárias. A Fig. 6.14 apresenta o resultado do ajuste do contorno pelo algoritmo de contornos ativos, já como resultado final deste método. Na Fig. 6.14(a), o resultado é apresentado em comparação com a imagem base, e na Fig. 6.14(b), em comparação com os pontos obtidos pelo processamento temporal. 


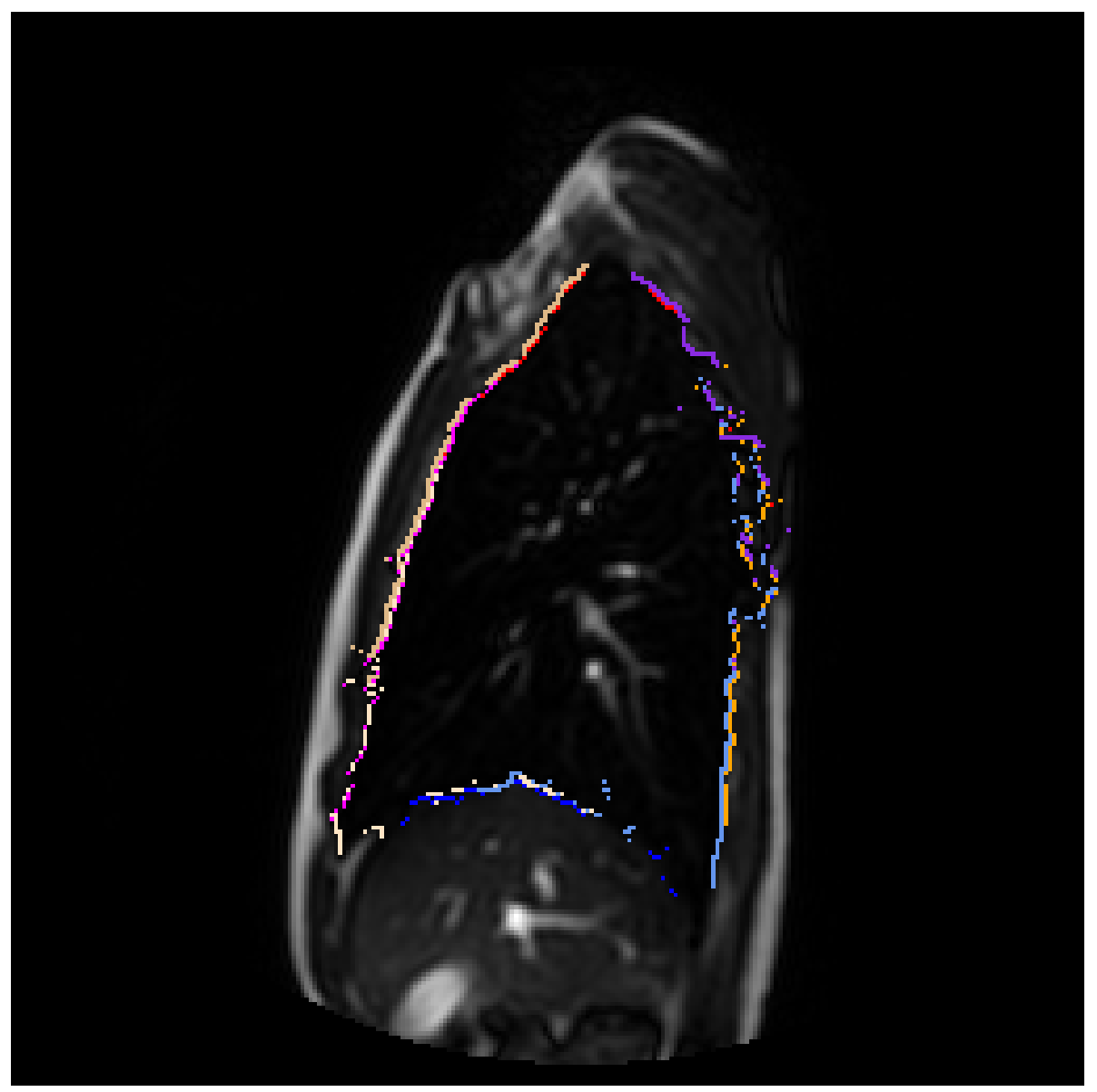

Figura 6.12: Resultado da aplicação do processamento temporal em todas as imagens 2DST verticais, horizontais e oblíquas $\left(+45^{\circ} \mathrm{e}-45^{\circ}\right)$ válidas. As cores indicam a origem do ponto: pontos em vermelho e azul foram obtidos através do processamento de imagens 2DST verticais (vermelho representa o contorno superior e azul, o inferior); magenta (anterior) e laranja (posterior) foram obtidos com imagens 2DST horizontais; creme (anterior/inferior) e roxo (posterior/superior), de imagens $2 \mathrm{DST}$ oblíquas $+45^{\circ}$; e, por fim, bege (anterior/superior) e ciano (posterior/inferior), de imagens 2DST oblíquas $-45^{\circ}$.

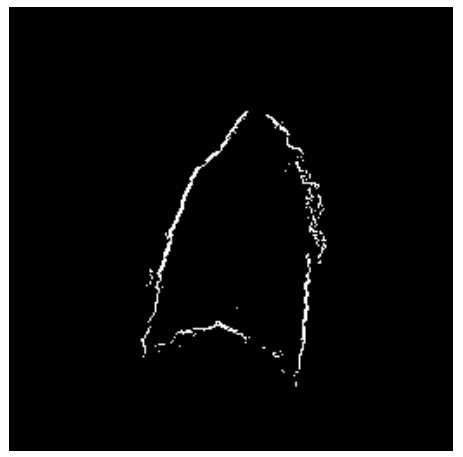

(a)

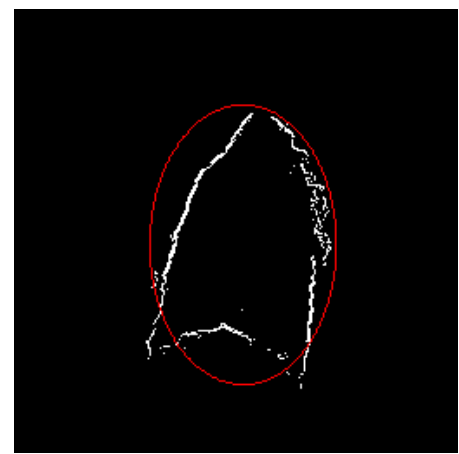

(b)

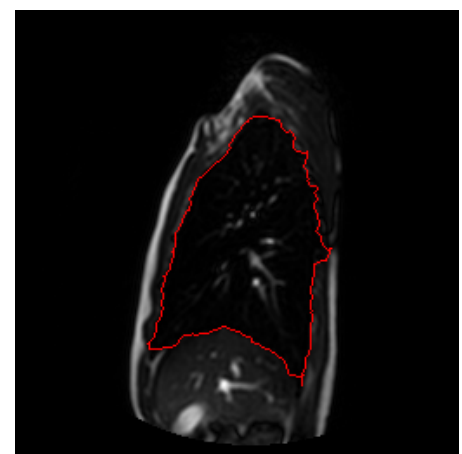

(c)

Figura 6.13: Obtenção de contorno a partir dos pontos encontrados pelo processamento temporal (referente ao resultado apresentando na Fig. 6.12). (a) Pontos encontrados. (b) Contorno inicial oval em vermelho. (c) Contorno resultado da aplicação de método de contornos ativos com GVF. 


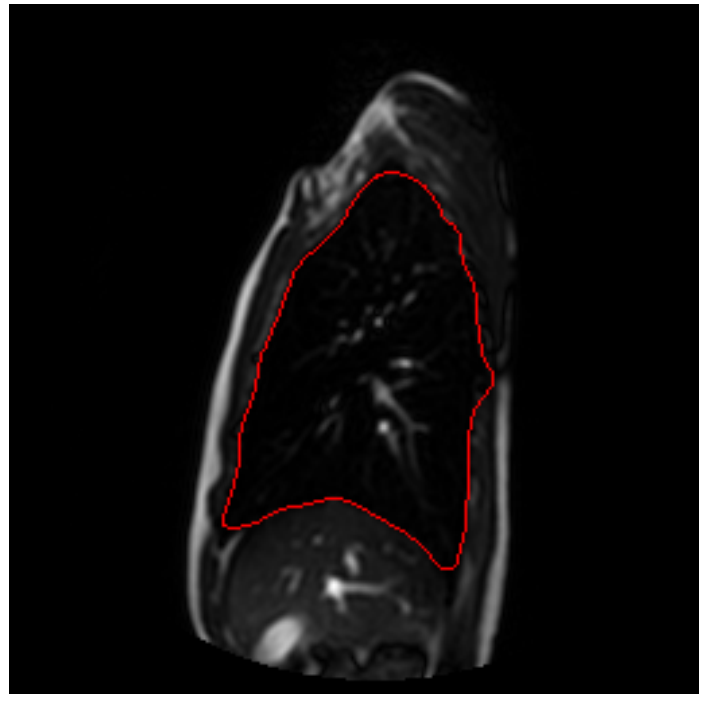

(a)

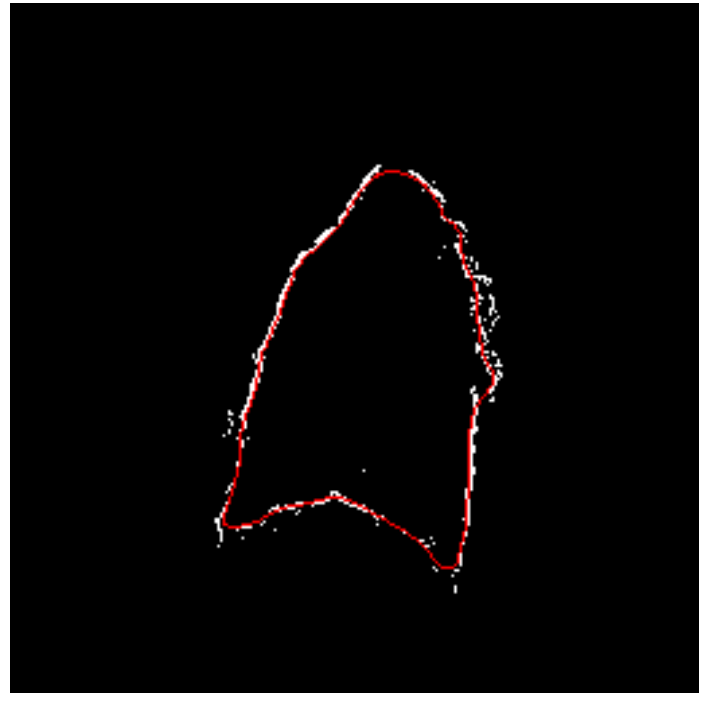

(b)

Figura 6.14: Resultado da aplicação dos contornos ativos com GVF. (a) Ilustração do resultado em relação à imagem. (b) Ilustração do resultado em relação aos pontos obtidos pelo processamento temporal. 


\section{$7 \quad$ Resultados}

As sequências de imagens utilizadas neste trabalho foram obtidas por um equipamento Symphony (1.5T), fabricado pela Siemens, com o método true FISP (Fast Imaging with Steady State Precession).

Figuras 7.1 e 7.2 exemplificam a segmentação do pulmão utilizando o primeiro método.

Inicialmente, as demonstrações e comparações serão feitas com os resultados preliminares do segundo método, isto é, sem a montagem e ajuste do contorno final. A série da imagem da Fig. 7.2 será utilizada para a apresentação de resultados do segundo método.

A máscara determina uma região de busca do contorno. A partir da imagem da Fig. 7.3(e), podemos aplicar o processo da segmentação temporal. Primeiramente, criamos uma imagem 2DST a partir do STV da série, e a essa imagem 2DST aplica-se um operador de gradientes para se obter uma imagem de arestas. Aplicando-se o processo de criação de máscaras para todas as imagens da série, obtemos um STV de máscaras. Pode-se, então, criar uma imagem 2DST de máscara, na mesma posição da imagem 2DST criada a partir do STV da série. Supondo-se que existirão dois contornos presentes nessa imagem 2DST (em uma imagem 2DST vertical, por exemplo, os contornos superior e inferior do pulmão), podemos separá-los e processá-los independentemente.

Figura 7.4(a) mostra a mesma imagem da Fig. 7.2, e também a posição do plano vertical para a criação da imagem 2DST vertical. A Fig. 7.4(b) mostra a imagem 2DST vertical criada. Os pixels de alta intensidade, que representam vasos sangüíneos ou gordura, foram filtrados. As Fig. 7.4(c) e (e) mostram as imagens de arestas criadas a partir da Fig. 7.4(b), mas com as máscaras aplicadas. A Fig. 7.4(c) mostra somente a região de movimentação do contorno superior, e a Fig. 7.4(e) mostra somente a região de movimentação do contorno inferior do pulmão. As Fig. 7.4(d) e (f) mostram os espaços paramétricos de Hough criados a partir das imagens de arestas das Fig. 7.4(c) e (e), respectivamente. 


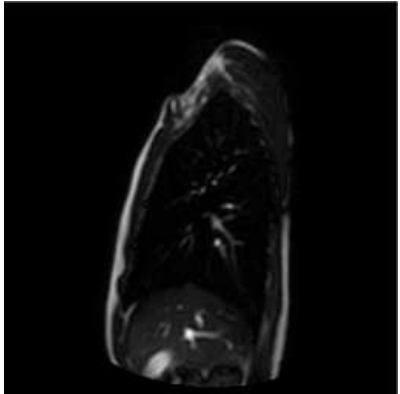

(a)

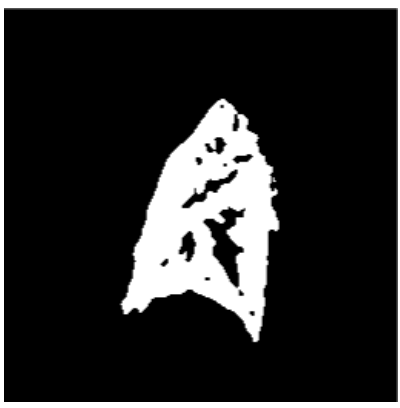

(d)

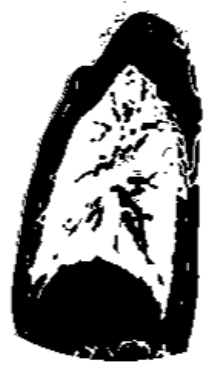

(b)

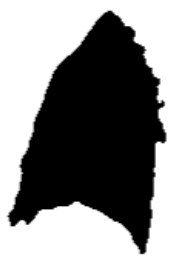

(e)

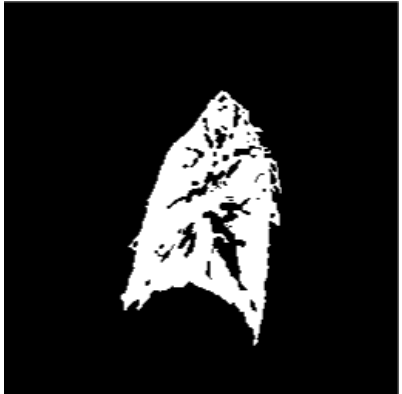

(c)

Figura 7.1: Segmentação do pulmão utilizando o primeiro método. (a) Imagem base. (b) Imagem binária. (c) Imagem após primeiro labeling. (d) Imagem após aplicação de filtro. (e) Imagem final, após segundo labeling.

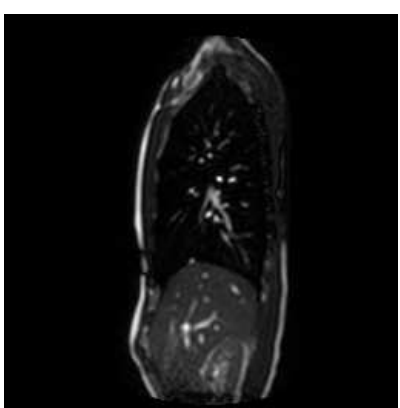

(a)

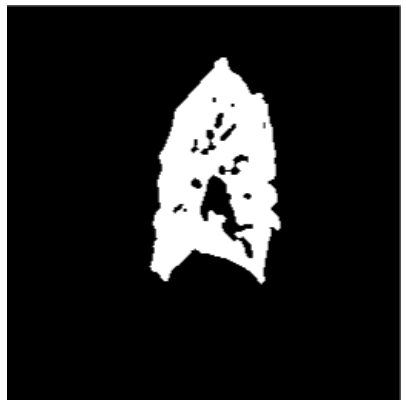

(d)

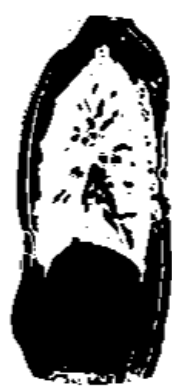

(b)

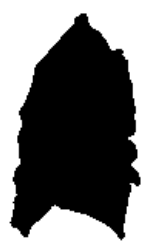

(e)

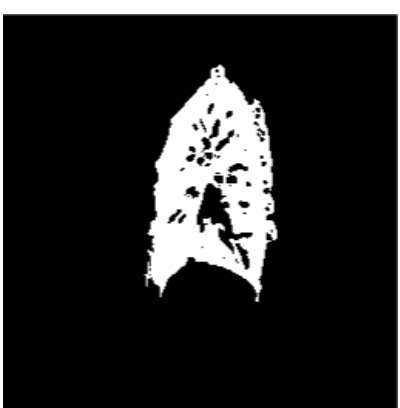

(c)

Figura 7.2: Segmentação do pulmão utilizando o primeiro método. (a) Imagem base. (b) Imagem binária. (c) Imagem após primeiro labeling. (d) Imagem após aplicação de filtro. (e) Imagem final, após segundo labeling. 


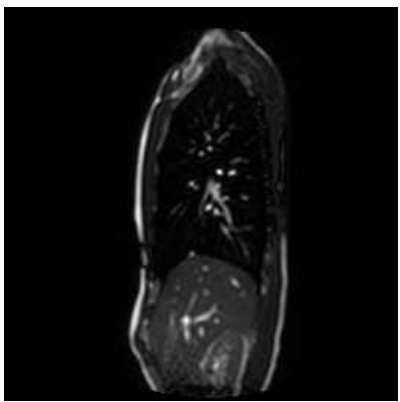

(a)

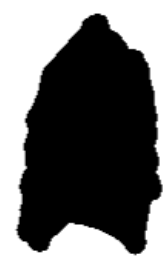

(d)

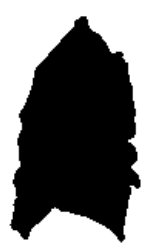

(b)

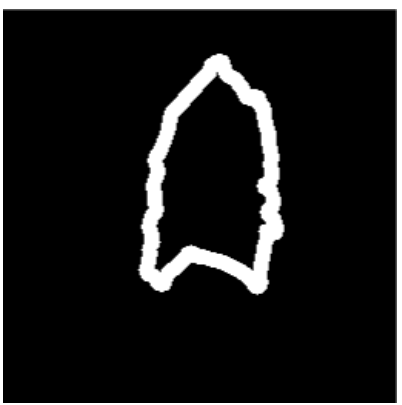

(e)

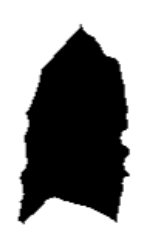

(c)

Figura 7.3: Criação da máscara de busca do contorno a partir de região determinada anteriormente. (a) Imagem base. (b) Região do pulmão obtida. (c) Imagem após dilatação morfológica. (d) Imagem após erosão morfológica. (e) Imagem final.

Como toma-se por hipótese que o pulmão é o órgão com movimento de maior amplitude e que durante a respiração contornos opostos possuem movimentos de fases opostas, podemos limitar a busca no espaço paramétrico de Hough para apenas um semiplano. No caso, a função respiração base foi tomada na região diafragmática - ou seja, contorno inferior do pulmão em uma imagem 2DST vertical - por esta região possuir a maior amplitude de movimento na respiração. Assim, para a busca de máximo no espaço paramétrico do contorno inferior, temos que a escala (parâmetro $a$ no espaço paramétrico) deve ser positiva, e portanto o máximo deve estar no semiplano $a \geq 0$ do espaço paramétrico, como indicado na Fig. 7.4(f). Analogamente, para o contorno superior, o máximo deve estar no semiplano $a \leq 0$ do espaço paramétrico de Hough, como indicado na Fig. 7.4(d). Os pontos de máximo indicados nas Fig. 7.4(d) e (f) representam as funções respiração apresentadas nas Fig. 7.4(c) e (e).

Figuras 7.5, 7.6 e 7.7 apresentam o mesmo processamento aplicado para imagens 2DST horizontal, e oblíquas $+45^{\circ}$ e $-45^{\circ}$, respectivamente.

Aplicando-se este procedimento para diversos planos verticais, horizontais e oblíquos, pode-se percorrer todo o pulmão. Todos os planos em que a maioria 


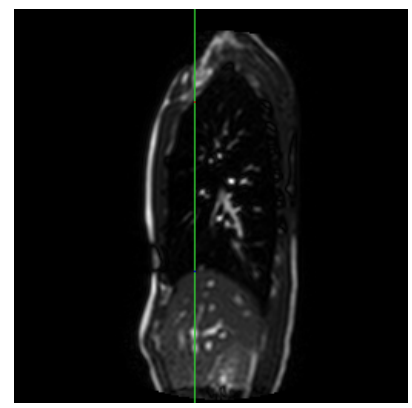

(a)

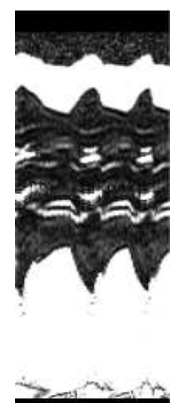

(b)

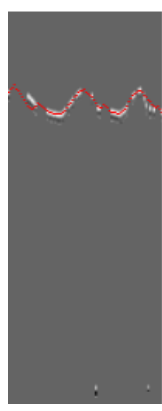

(c)

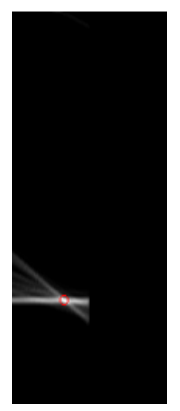

(d)

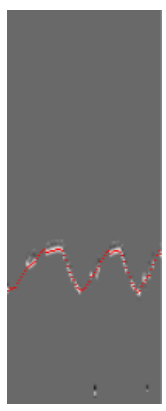

(e)

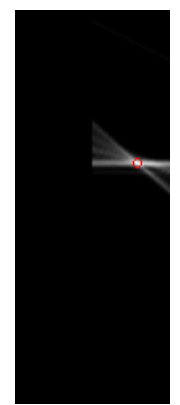

(f)

Figura 7.4: Processamento temporal com transformada de Hough modificada utilizando máscaras. (a) Imagem sagital - reta verde indica a posição da imagem 2DST vertical selecionada. (b) Imagem 2DST com pixels de alta intensidade filtrados. (c) Imagem de arestas com a máscara aplicada - contorno superior do pulmão. Padrão respiratório encontrado indicado em vermelho. (d) Espaço paramétrico de Hough. Ponto de máximo indicado por círculo vermelho. (e) Imagem de arestas com a máscara aplicada - contorno inferior do pulmão. Padrão respiratório encontrado indicado em vermelho. (f) Espaço paramétrico de Hough. Ponto de máximo indicado por círculo vermelho.

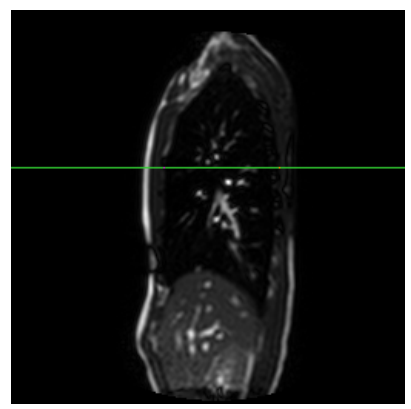

(a)

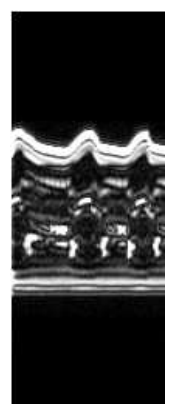

(b)

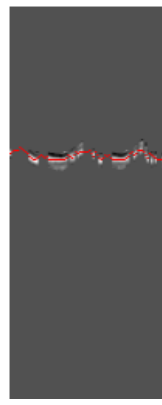

(c)

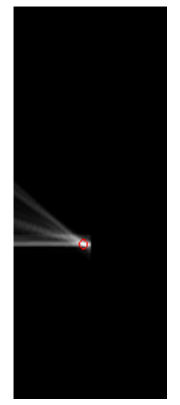

(d)

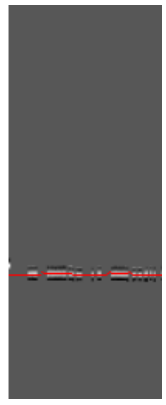

(e)

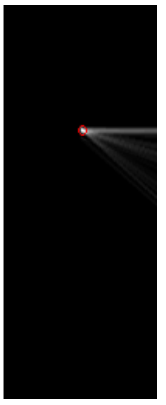

(f)

Figura 7.5: Processamento temporal com transformada de Hough modificada utilizando máscaras. (a) Imagem sagital - reta verde indica a posição da imagem 2DST horizontal selecionada. (b) Imagem 2DST com pixels de alta intensidade filtrados. (c) Imagem de arestas com a máscara aplicada - contorno anterior do pulmão. Padrão respiratório encontrado indicado em vermelho. (d) Espaço paramétrico de Hough. Ponto de máximo indicado por círculo vermelho. (e) Imagem de arestas com a máscara aplicada - contorno posterior do pulmão. Padrão respiratório encontrado indicado em vermelho. (f) Espaço paramétrico de Hough. Ponto de máximo indicado por círculo vermelho. 


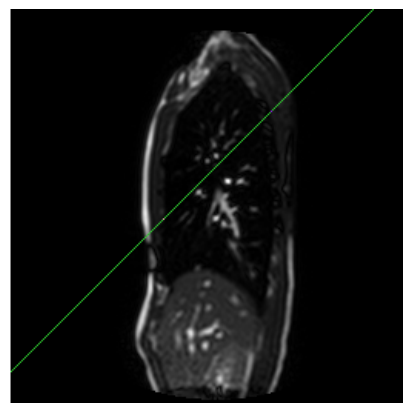

(a)

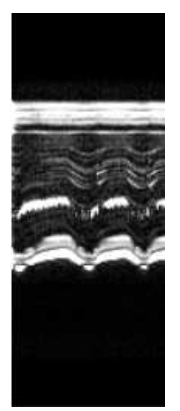

(b)

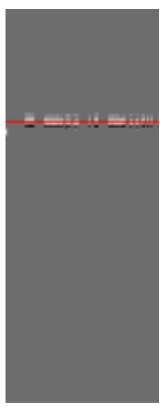

(c)

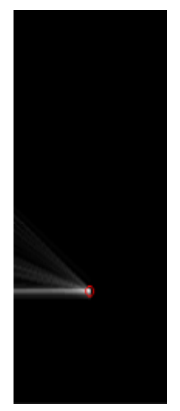

(d)

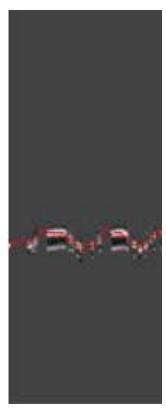

(e)

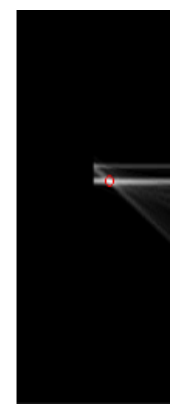

(f)

Figura 7.6: Processamento temporal com transformada de Hough modificada utilizando máscaras. (a) Imagem sagital - reta verde indica a posição da imagem 2DST oblíqua $+45^{\circ}$ selecionada. (b) Imagem 2DST com pixels de alta intensidade filtrados. (c) Imagem de arestas com a máscara aplicada - contorno posterior do pulmão. Padrão respiratório encontrado indicado em vermelho. (d) Espaço paramétrico de Hough. Ponto de máximo indicado por círculo vermelho. (e) Imagem de arestas com a máscara aplicada - contorno anterior do pulmão. Padrão respiratório encontrado indicado em vermelho. (f) Espaço paramétrico de Hough. Ponto de máximo indicado por círculo vermelho.

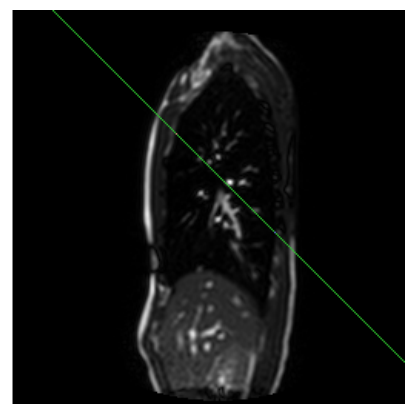

(a)

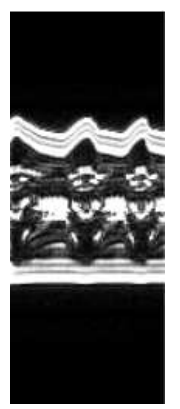

(b)

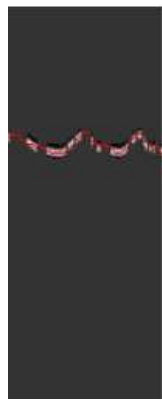

(c)

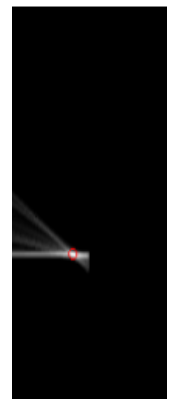

(d)

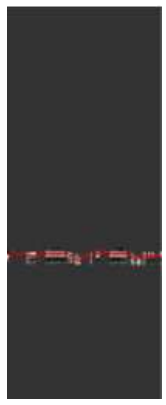

(e)

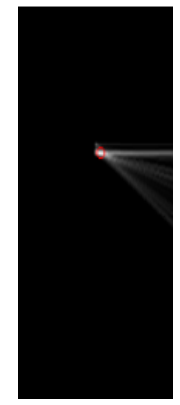

(f)

Figura 7.7: Processamento temporal com transformada de Hough modificada utilizando máscaras. (a) Imagem sagital - reta verde indica a posição da imagem 2DST oblíqua $-45^{\circ}$ selecionada. (b) Imagem 2DST com pixels de alta intensidade filtrados. (c) Imagem de arestas com a máscara aplicada - contorno anterior do pulmão. Padrão respiratório encontrado indicado em vermelho. (d) Espaço paramétrico de Hough. Ponto de máximo indicado por círculo vermelho. (e) Imagem de arestas com a máscara aplicada - contorno posterior do pulmão. Padrão respiratório encontrado indicado em vermelho. (f) Espaço paramétrico de Hough. Ponto de máximo indicado por círculo vermelho. 
das máscaras possui duas regiões de busca são considerados. A Fig. 7.8 ilustra o resultado da varredura nas quatro direções em diversos planos.

Figura 7.9 apresenta uma comparação entre os dois métodos apresentados. Em todas as imagens, o resultado do primeiro método está apresentado em verde, e o resultado parcial do segundo método, em lilás.

Figura 7.10 ilustra a vantagem do segundo método, que utiliza informações de movimento, sobre o primeiro método, que realiza a segmentação em cada imagem individualmente. O resultado do primeiro método está apresentado em verde, e o resultado parcial do segundo método, em lilás. As Fig. 7.10(a) a (d) apresentam quatro imagens em seqüência dessa série. As imagens das Fig. 7.10(a) e (d) possuem máscaras calculadas coerentes, as imagens das Fig. 7.10(b) e (c), não. O primeiro método falhou em segmentar o pulmão nas imagens das Fig. 7.10(b) e (c), apesar de tê-lo feito corretamente na Fig. 7.10(a) e (d). O segundo método, por utilizar informações de movimento, foi capaz de segmentar o pulmão mesmo em imagens em que as máscaras calculadas eram incoerentes.

Como comentado no capítulo 6, os resultados parciais do segundo método obtidos até esta etapa são conjuntos não-ordenados de pontos. Alguns pontos, inclusive, estão incorretos, e um ajuste precisa ser feito. Para que o ajuste seja feito utilizando o algoritmo de contornos ativos, é preciso criar um contorno coerente a partir dos pontos obtidos pelo processamento temporal realizado até aqui. A Fig. 7.11 mostra os pontos processados para a imagem da Fig. 7.8(a) como pontos brancos em uma imagem binária.

Figura 7.12(a) apresenta o campo GVF criado a partir da imagem da Fig. 7.11. As imagens das Fig. 7.12(b), (c) e (d) mostram ampliações de regiões da imagem da Fig. 7.12(a), cantos superior direito, e inferiores esquerdo e direito, respectivamente. É possível observar o longo alcance que as arestas possuem no campo GVF. Com a extensão do alcance, também, há uma competição entre as arestas por regiões de atração, isto, regiões em que possuem a capacidade de atrair o contorno para si.

O resultado da aplicação do método de contornos ativos com GVF, com o campo apresentado na Fig. 7.12, está apresentado na Fig. 7.13. Na Fig. 7.13(a), os pontos resultantes do processamento temporal, como na imagem da Fig. 7.11, com um contorno inicial oval arbitrário calculado a partir da posição dos pontos. Na Fig. 7.13(b), o contorno resultante é apresentado em vermelho. O contorno resultante passa pelos pontos provenientes do processamento temporal por transformada de Hough e máscaras. Nesta etapa, são utilizadas 75 iterações. 


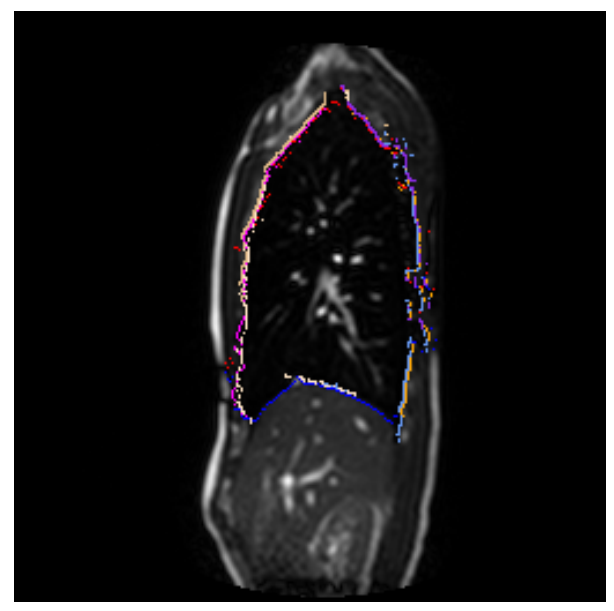

(a)

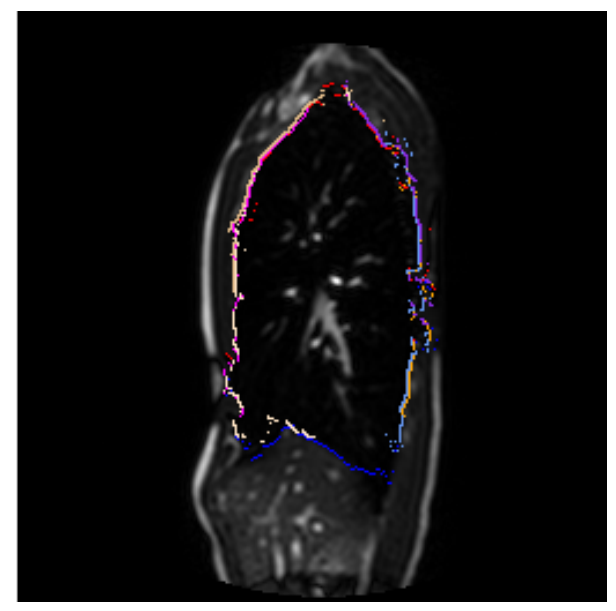

(c)

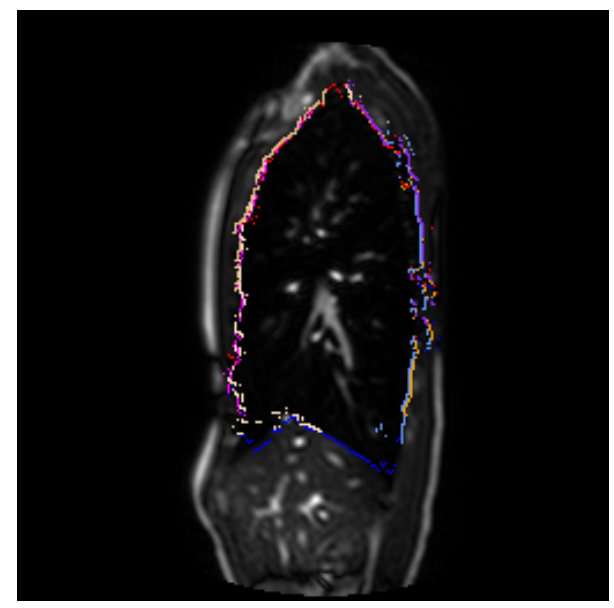

(e)

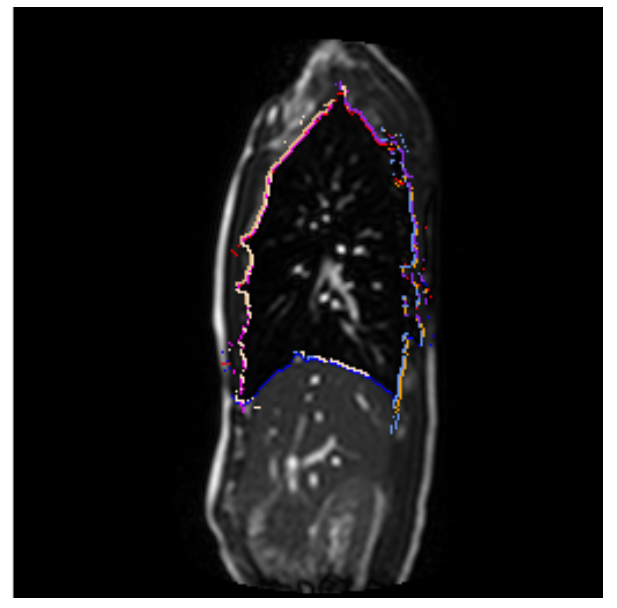

(b)

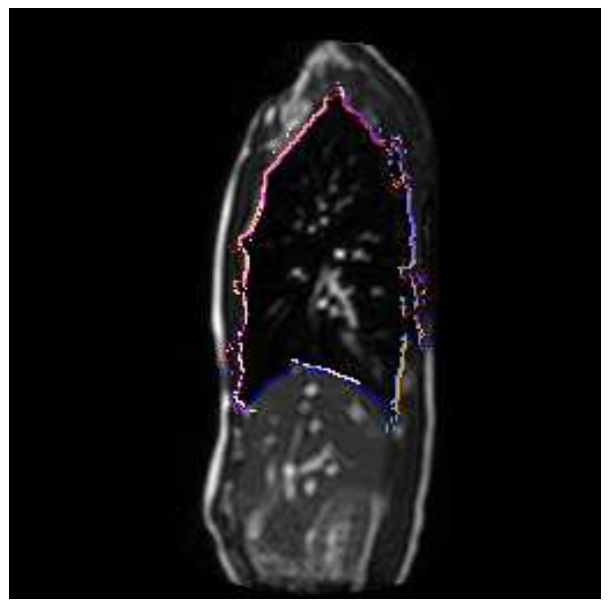

(d)

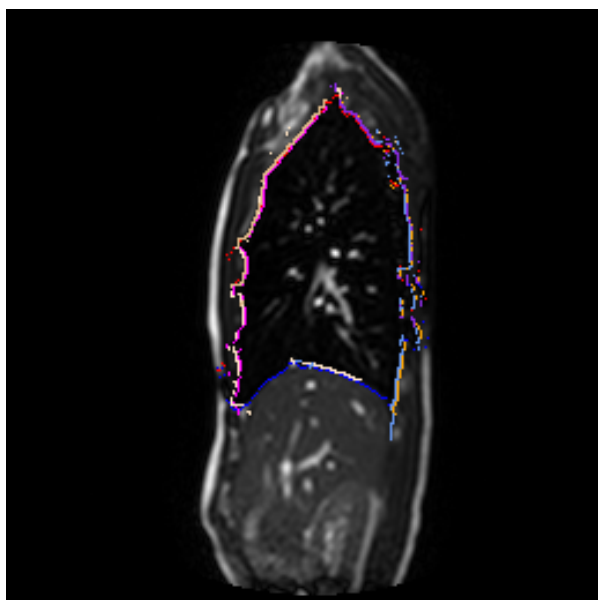

(f)

Figura 7.8: Resultados da segmentação temporal do pulmão para a mesma série apresentada na Fig. 7.2. As cores indicam a origem do ponto: pontos em vermelho e azul foram obtidos através do processamento de imagens 2DST verticais (vermelho representa o contorno superior e azul, o inferior); magenta (anterior) e laranja (posterior) foram obtidos com imagens 2DST horizontais; creme (anterior/inferior) e roxo (posterior/superior), de imagens 2DST oblíquas $+45^{\circ}$; e, por fim, bege (anterior/superior) e ciano (posterior/inferior), de imagens 2DST oblíquas $-45^{\circ}$. (a) Imagem 14. (b) Imagem 22. (c) Imagem 37. (d) Imagem 60. (e) Imagem 71. (f) Imagem 80. 


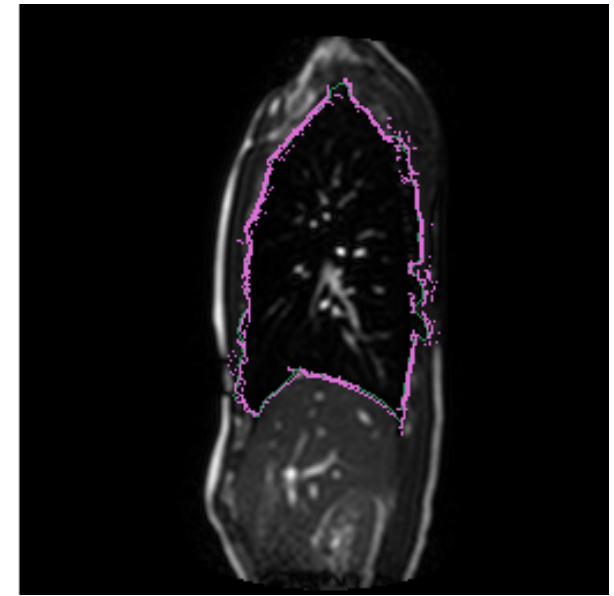

(a)

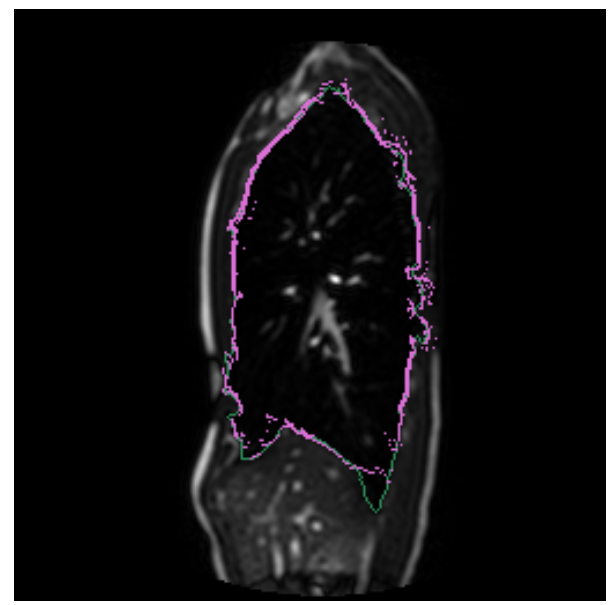

(c)

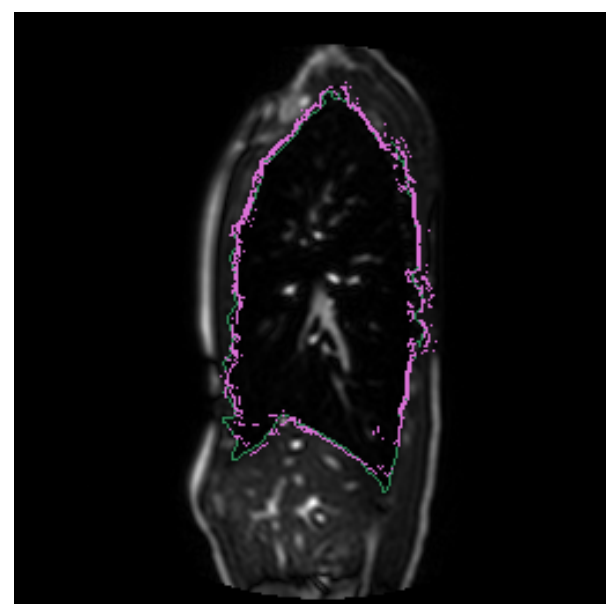

(e)

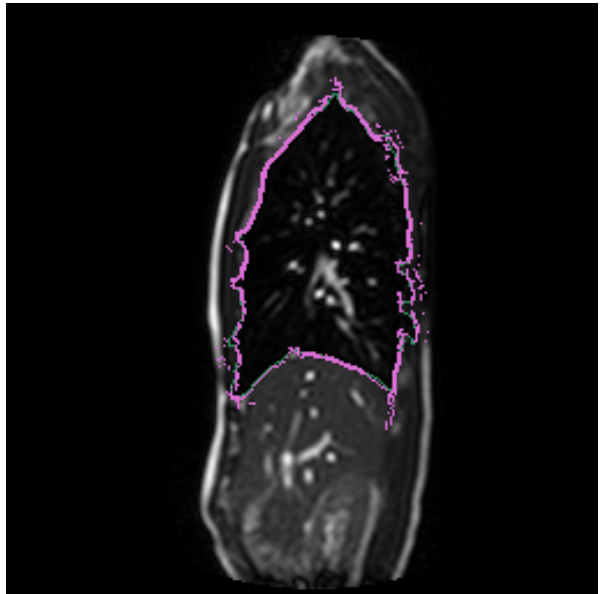

(b)

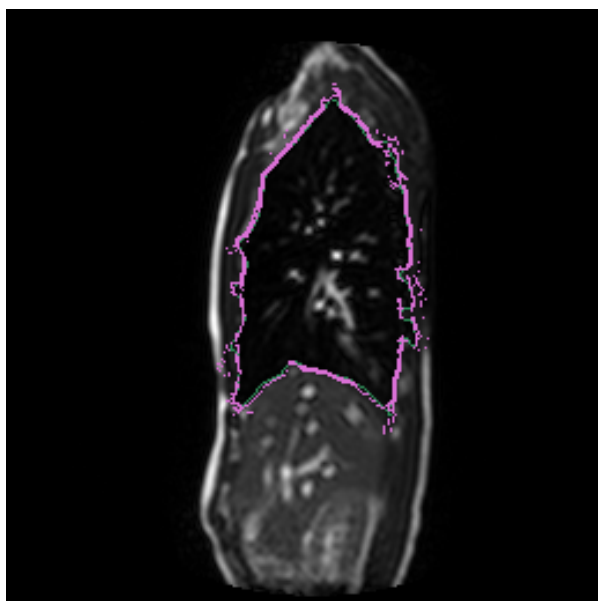

(d)

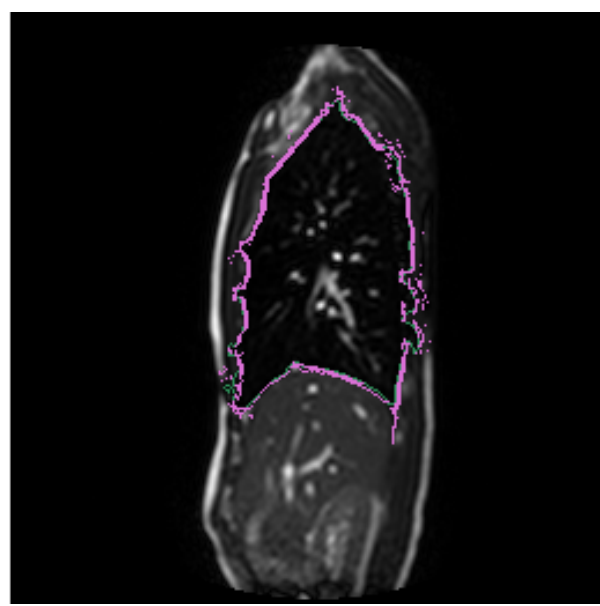

(f)

Figura 7.9: Comparação dos resultados obtidos pelos dois métodos de segmentação do pulmão para a mesma série apresentada na Fig. 7.2. O resultado do primeiro método está apresentado em verde, e o resultado parcial do segundo método, em lilás. (a) Imagem 14. (b) Imagem 22. (c) Imagem 37. (d) Imagem 60. (e) Imagem 71. (f) Imagem 80. 


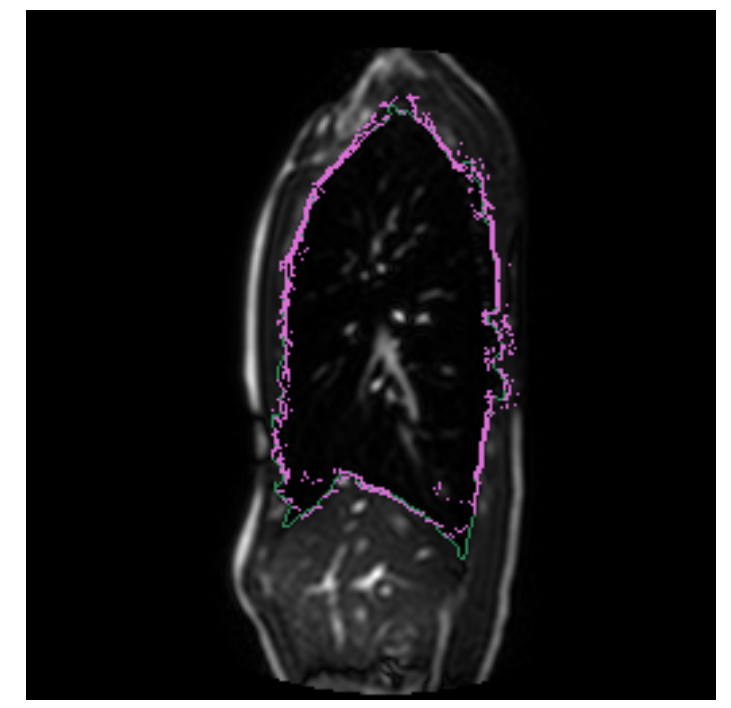

(a)

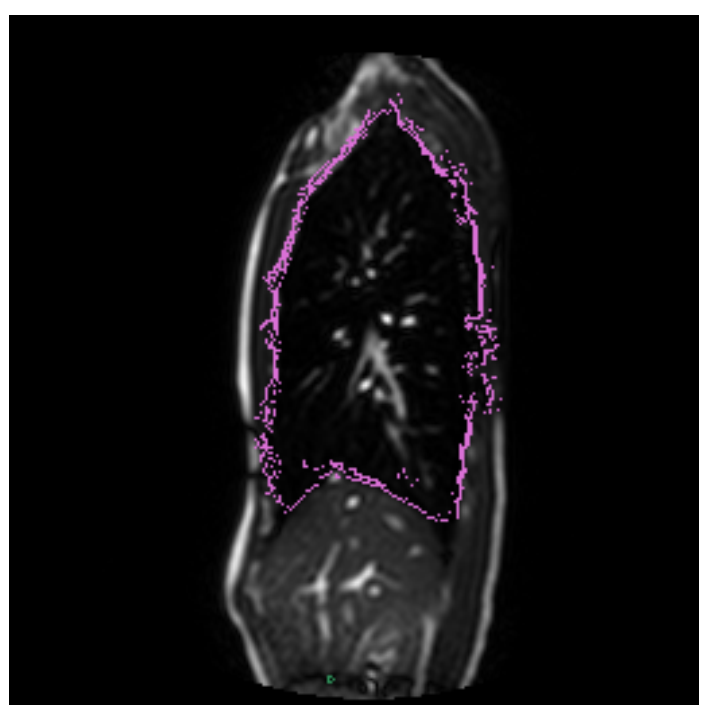

(c)

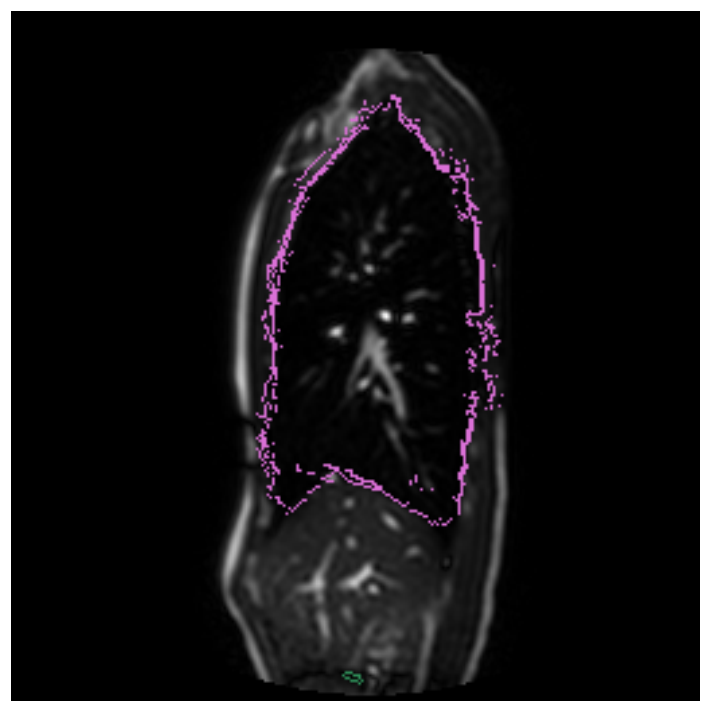

(b)

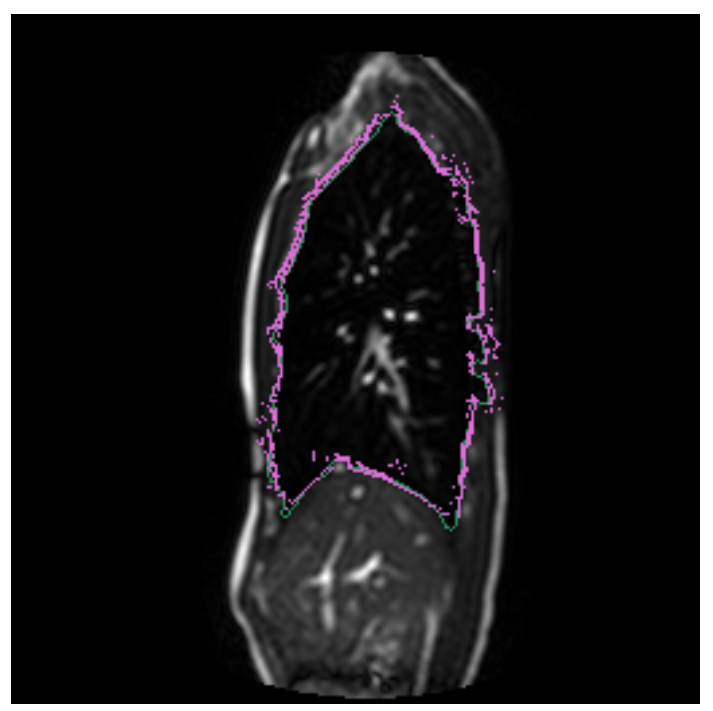

(d)

Figura 7.10: Ilustração da vantagem do segundo método apresentado. O resultado do primeiro método está apresentado em verde, e o resultado parcial do segundo método, em lilás. (a) Imagem 44. (b) Imagem 45. (c) Imagem 46. (d) Imagem 47. 


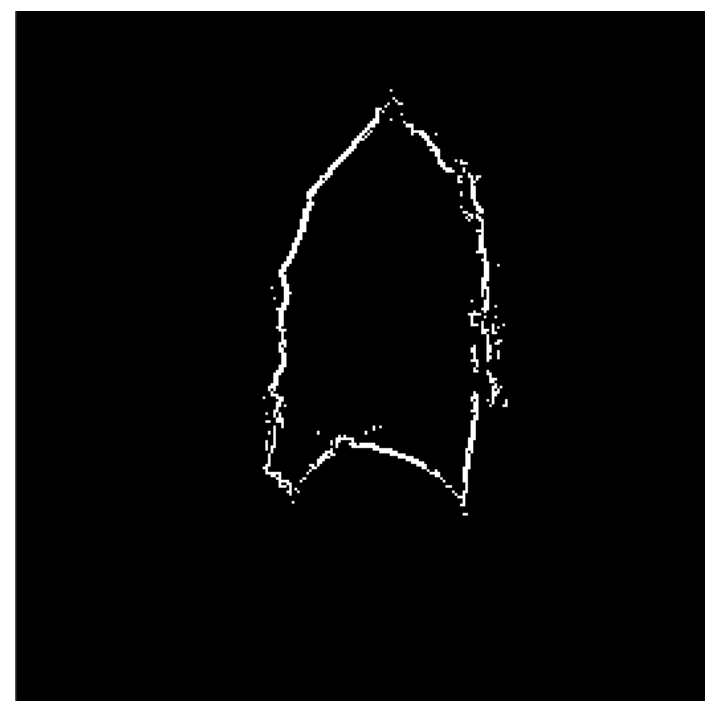

Figura 7.11: Pontos processados da imagem da Fig. 7.8(a) apresentados em uma imagem binária.

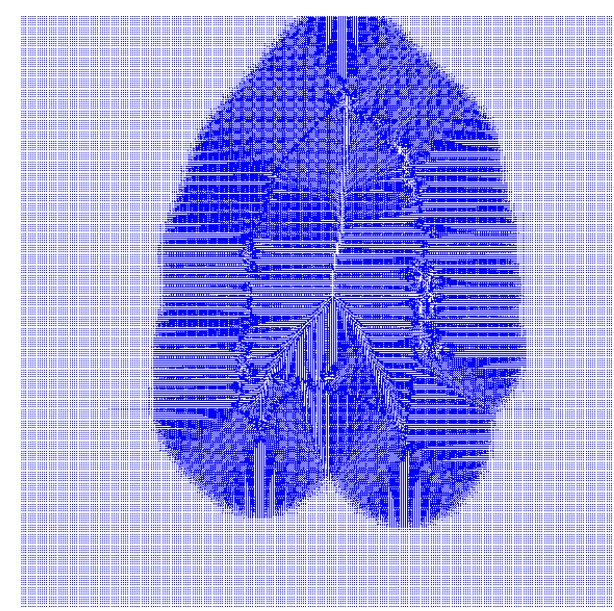

(a)

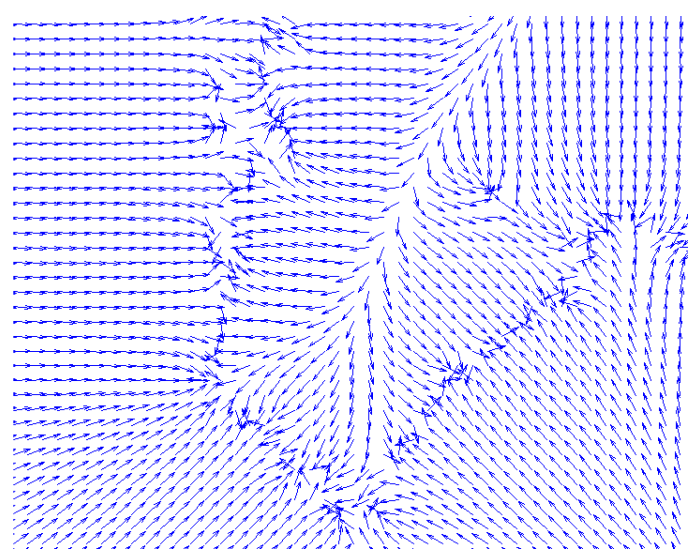

(c)

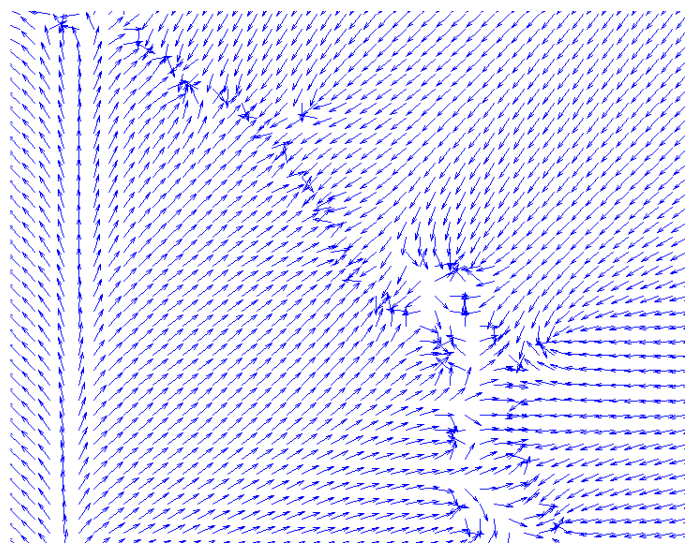

(b)

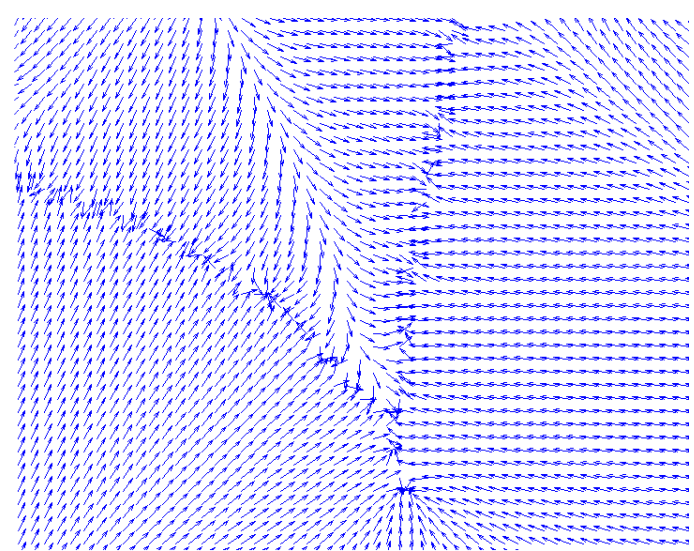

(d)

Figura 7.12: Campo GVF gerado a partir da imagem da Fig. 7.11. As setas indicam a direção do potencial dos gradientes. (a) Campo GVF. (b) Ampliação da região do canto superior direito da imagem (a). (c) Ampliação da região do canto inferior esquerdo da imagem (a). (d) Ampliação da região do canto inferior direito da imagem (a). 


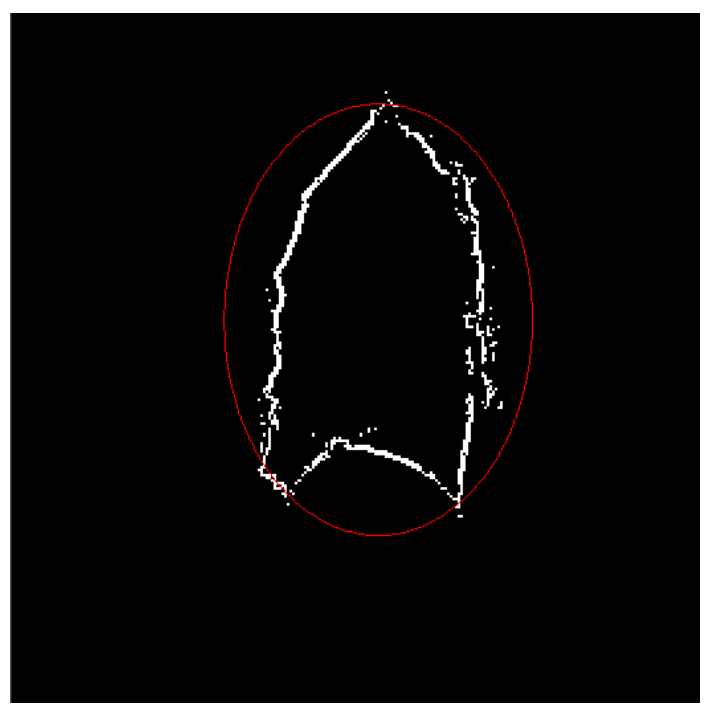

(a)

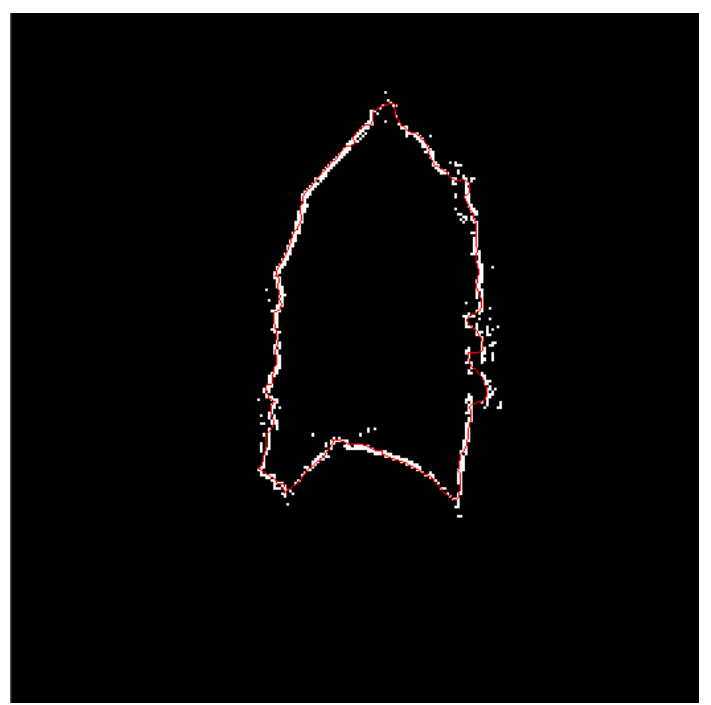

(b)

Figura 7.13: Aplicação do método de contornos ativos com GVF. (a) Pontos provenientes do processamento temporal e contorno inicial oval indicado em vermelho. (b) Contorno resultante da aplicação de contornos ativos com GVF indicado em vermelho.

Os pontos do processamento temporal agora foram transformados em um contorno coerente, mas que segue apenas esses mesmo pontos. Para adicionar informações da imagem neste contorno, ele deve ser ajustado por contornos ativos com a imagem original de base para o mapa de arestas. O método tradicional de contornos ativos é utilizado, uma vez que não queremos que arestas mais fortes, mas que não estejam próxima do contorno, movimentem o contorno para longe do contorno definido pelo processamento temporal. Poucas iterações são necessárias nesta etapa de ajuste (cerca de 25 iterações). O resultado desse ajuste, para a imagem da Fig. 7.13(b), está apresentado na Fig. 7.14. Na Fig. 7.14(a), o contorno resultante é apresentado em comparação com a imagem original. Na Fig. 7.14(b), o contorno resultante é comparado com os pontos provenientes do processamento temporal utilizando transformada de Hough modificada e máscaras. Este é o contorno resultante do segundo método proposto.

Figura 7.15 apresenta os contornos resultantes pelo segundo método proposto para as mesmas imagens da Fig. 7.8. Os cantos, ainda que suavizados, acompanham as imagens. A dificuldade está na região posterior, da coluna, em que os contornos parecem invadir. A dificuldade, neste caso, está na qualidade da própria imagem, e em uma análise visual para demarcação manual também apresenta a mesma dificuldade. Além disso, há uma sinuosidade pouco natural presente em quase todas as imagens, na região da coluna e, nas Fig. 7.15(b), (d) e (f), também na região anterior do tórax. 


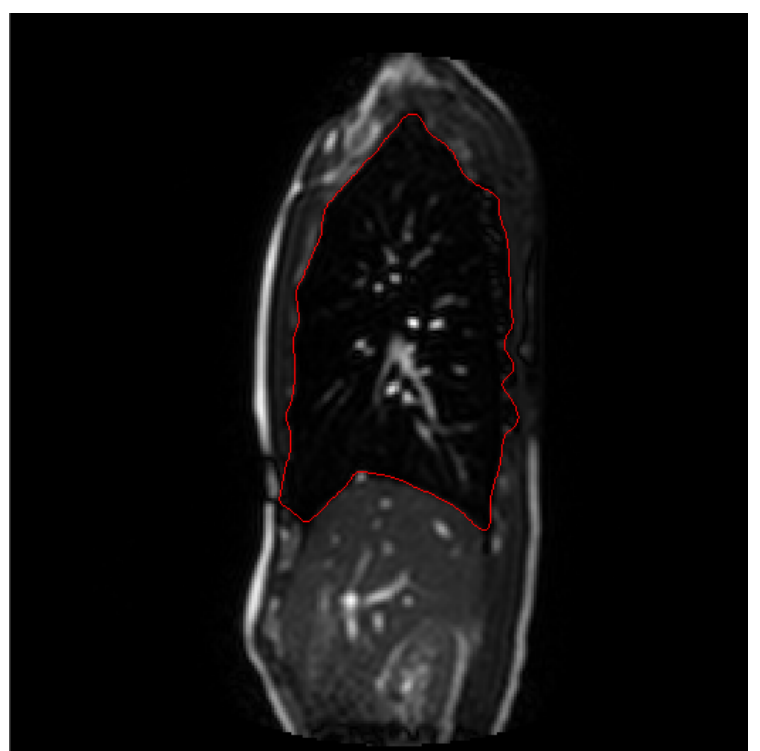

(a)

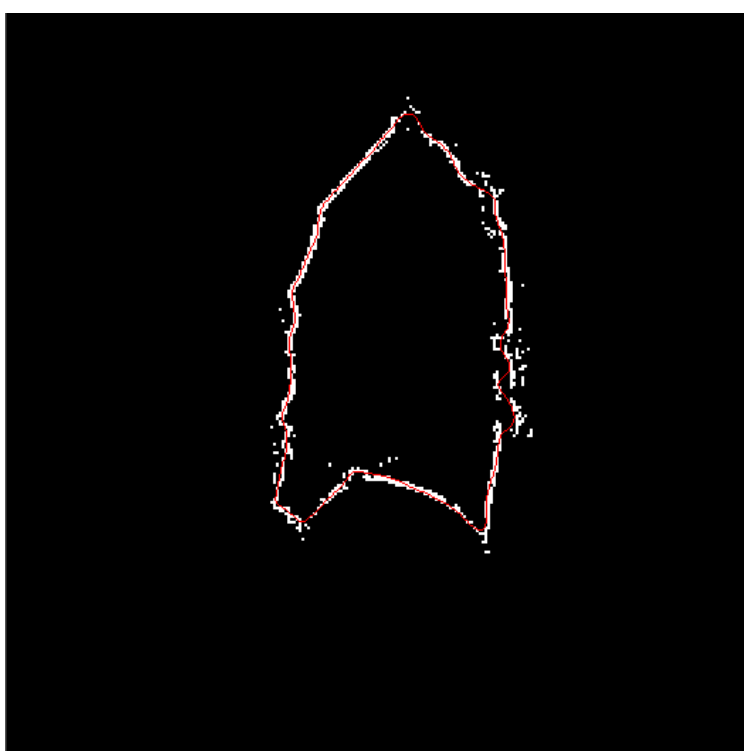

(b)

Figura 7.14: Resultado do segundo método proposto. (a) Contorno resultante comparado com a imagem original. (b) Contorno resultante comparado com os prontos obtidos por processamento temporal.

Figura 7.16 apresenta a comparação dos contornos resultantes do segundo método proposto com os pontos obtidos pelo processamento temporal utilizando transformada de Hough modificada e máscaras. Os contornos não necessariamente passam por todos os pontos por também adicionar informações provenientes da imagem individual. Na verdade, observa-se uma dispersa de pontos na região da coluna que dificulta a criação de um contorno suave. Além disso, o contorno subjetivo parece já possuir uma sinuosidade na região e, como é o caso da Fig. 7.16(d), há uma sinuosidade também na região anterior do tórax. Nas imagens das Fig. 7.16(c) e (e), das fases de inspiração, em que o contorno envolve maior área, percebe-se uma ausência de pontos nos cantos inferiores do pulmão. Essa falta de pontos dificulta a criação de um contorno com cantos mais agudos nessas regiões. No caso oposto, de expiração, apresentado nas Fig. 7.16(b) e (f), há um excesso de pontos na região, inclusive com muitos pontos inválidos, o que também confunde o algoritmo de contornos ativos. No geral, porém, os contornos produzidos são boas aproximações dos pontos obtidos pelo processamento temporal.

Figura 7.17 apresenta uma comparação dos dois métodos apresentados neste trabalho. Os dois contornos, nessas imagens, são muito próximos. O contorno produzido pelo segundo método é mais suave, parecendo mais natural. Em ambos, há a presença de uma sinuosidade pouco natural na região da coluna.

Por fim, na Fig. 7.18, está mostrada a mesma comparação feita na Fig. 7.10, 


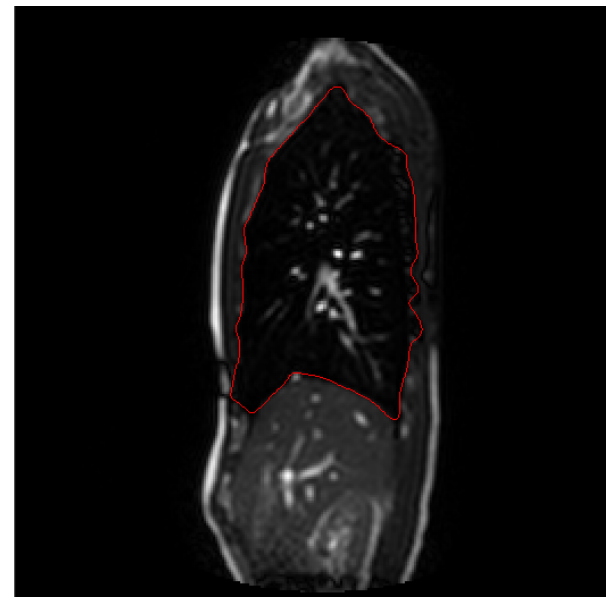

(a)

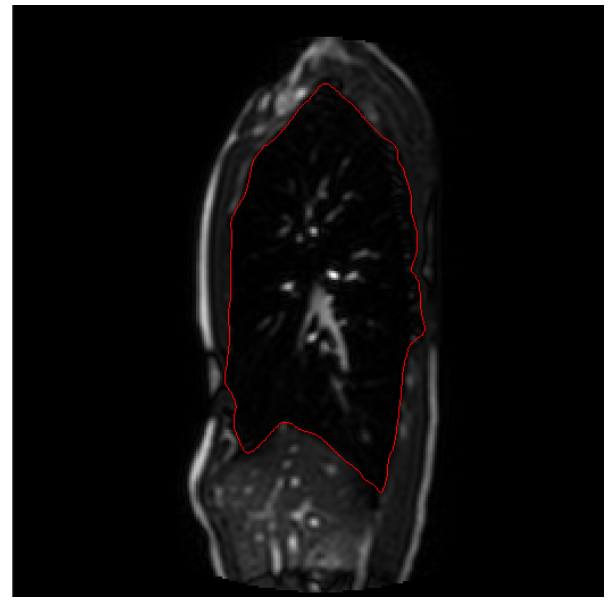

(c)

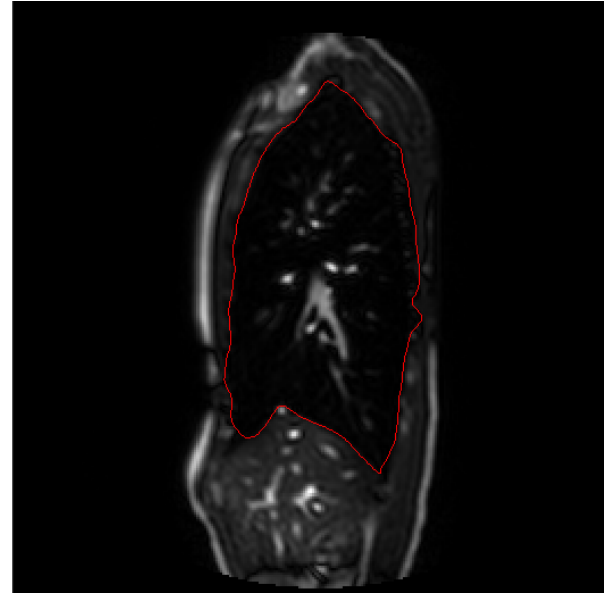

(e)

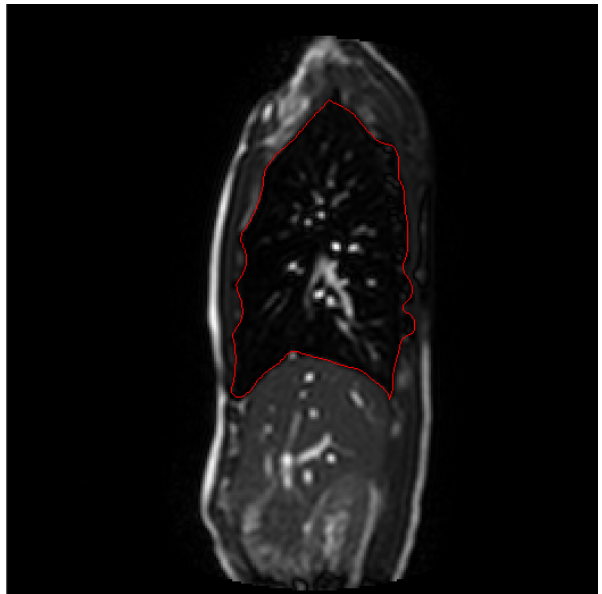

(b)

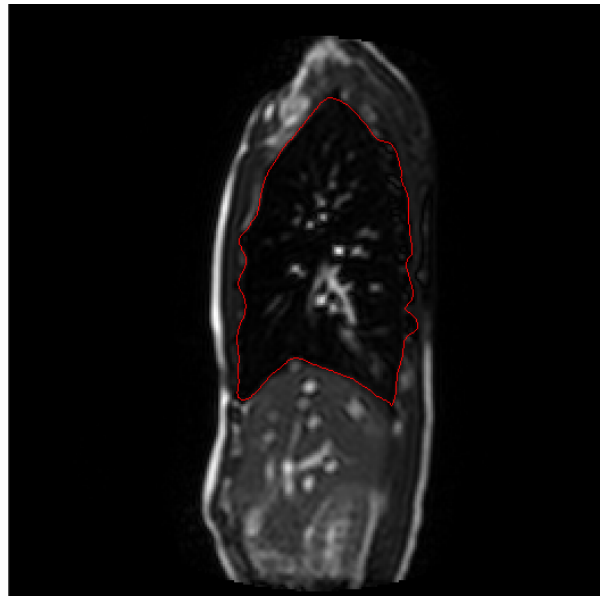

(d)

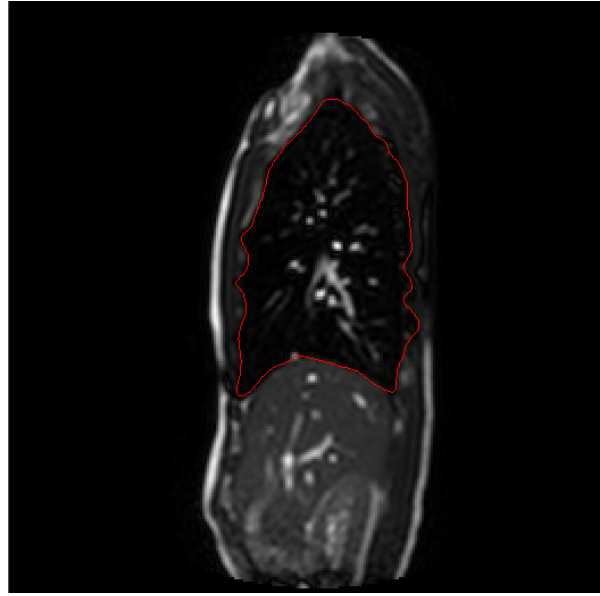

(f)

Figura 7.15: Resultados da segmentação do contorno do pulmão pelo segundo método proposto comparados com as imagens da série. (a) Imagem 14. (b) Imagem 22. (c) Imagem 37. (d) Imagem 60. (e) Imagem 71. (f) Imagem 80. 


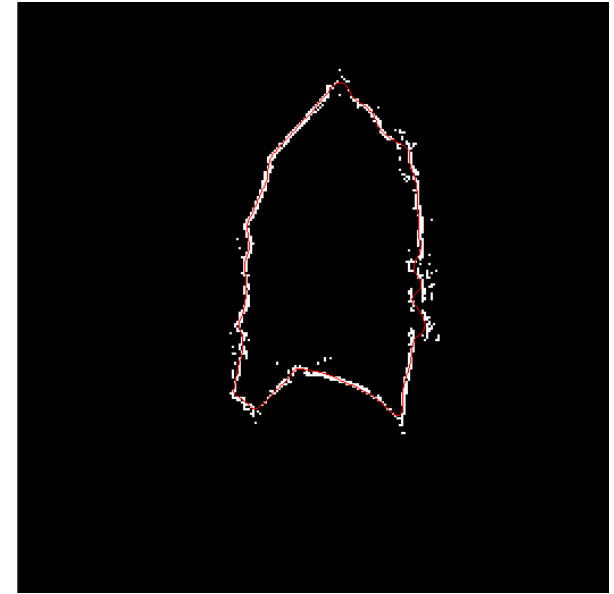

(a)

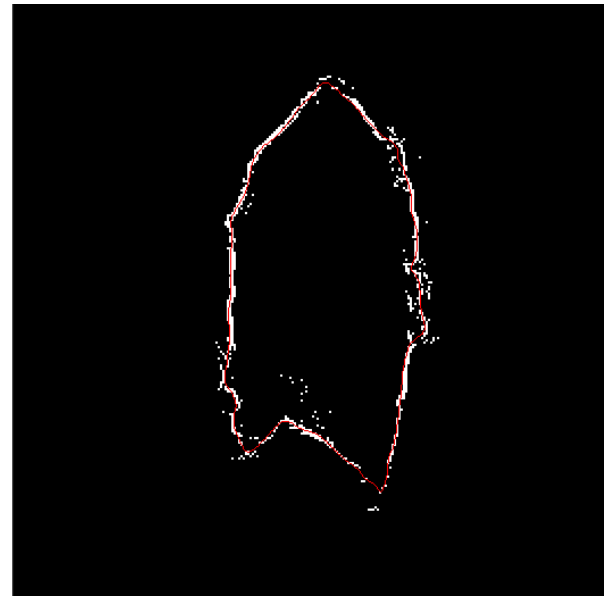

(c)

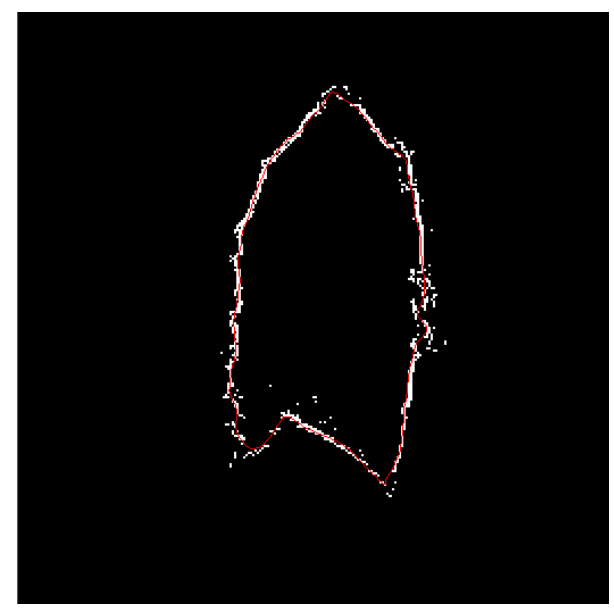

(e)

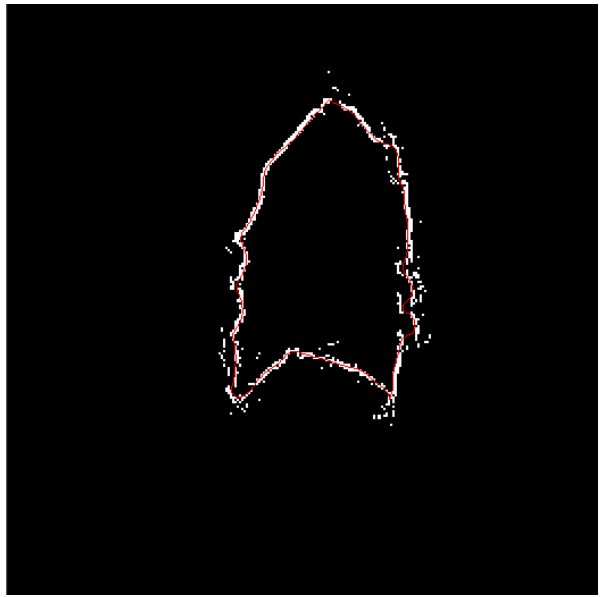

(b)

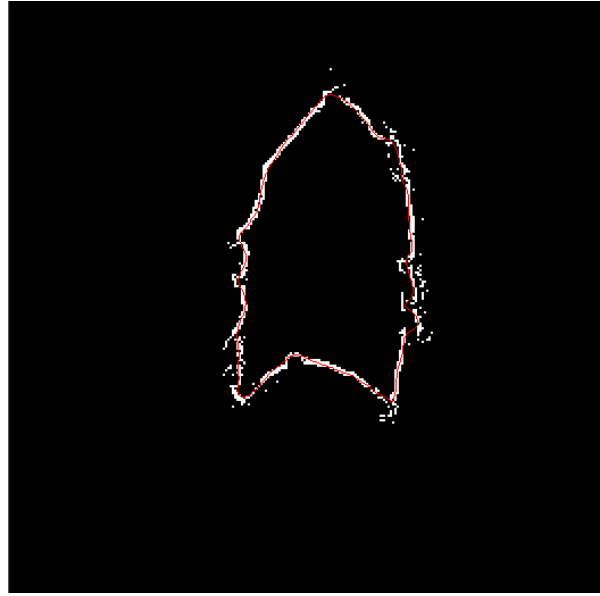

(d)

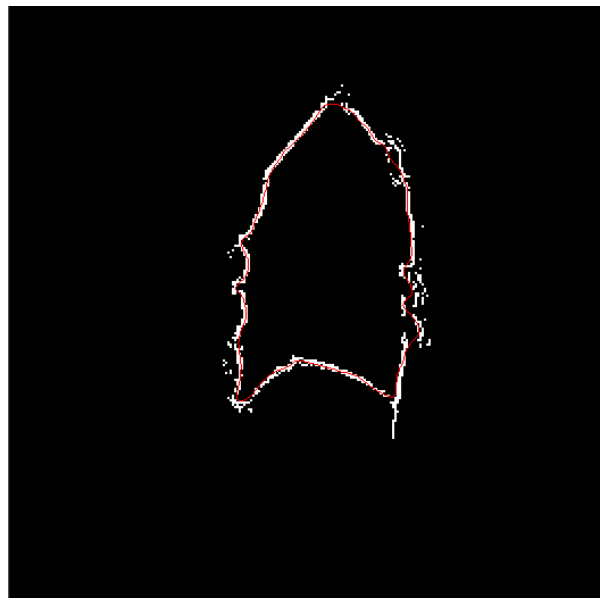

(f)

Figura 7.16: Resultados da segmentação do contorno do pulmão pelo segundo método proposto comparados com os pontos obtidos pelo processamento temporal. (a) Imagem 14. (b) Imagem 22. (c) Imagem 37. (d) Imagem 60. (e) Imagem 71. (f) Imagem 80 . 


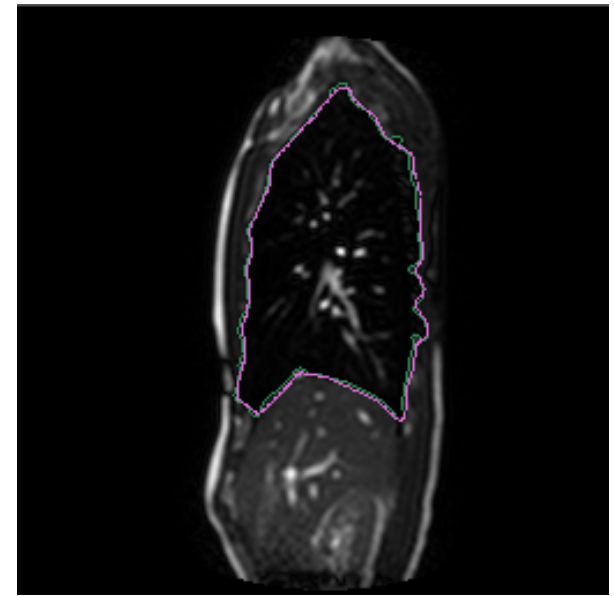

(a)

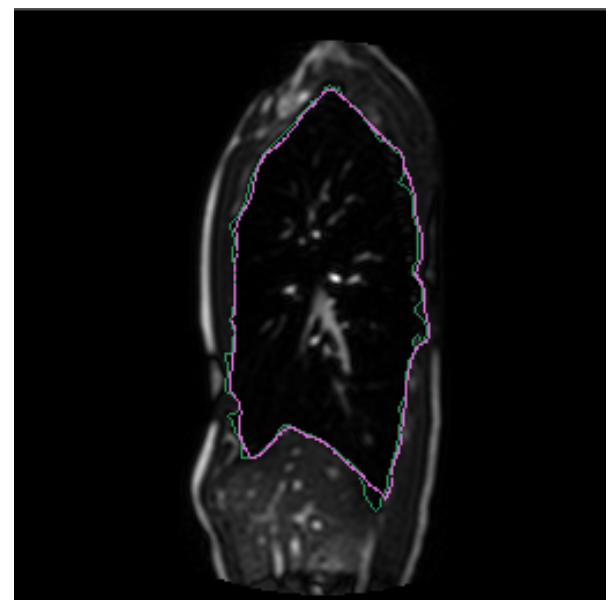

(c)

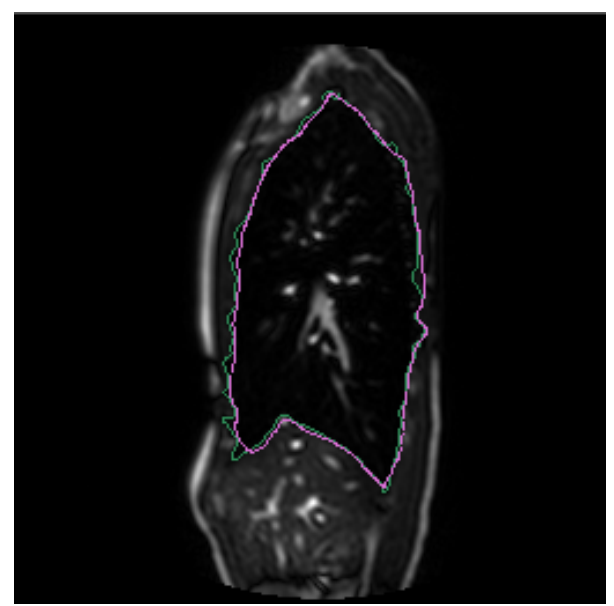

(e)

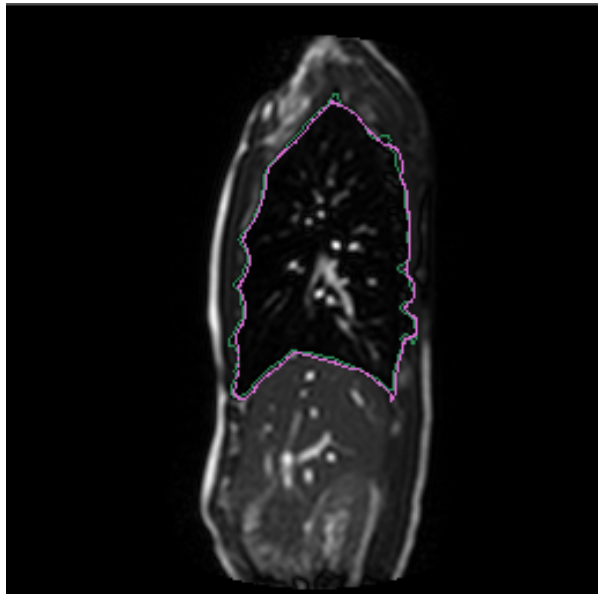

(b)

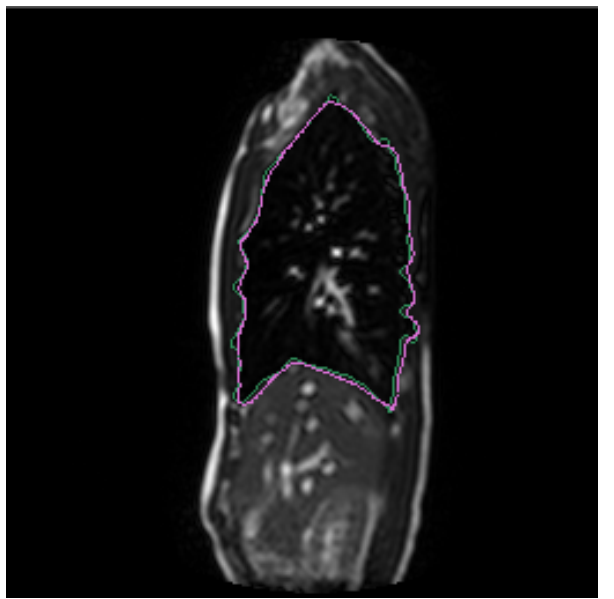

(d)

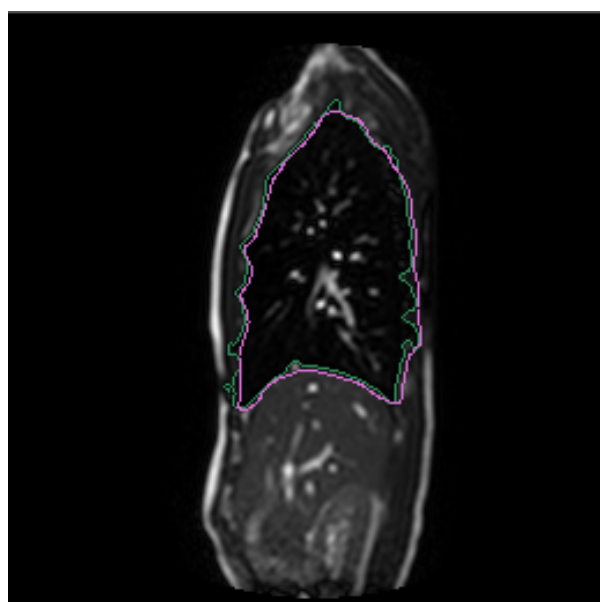

(f)

Figura 7.17: Comparação dos resultados obtidos pelos dois métodos de segmentação do pulmão para a mesma série apresentada na Fig. 7.2. O resultado do primeiro método está apresentado em verde, e o resultado do segundo método, em lilás. (a) Imagem 14. (b) Imagem 22. (c) Imagem 37. (d) Imagem 60. (e) Imagem 71. (f) Imagem 80. 
que ilustra a vantagem do segundo método de segmentação proposto sobre o primeiro. A seta amarela destaca o contorno inválido produzido pelo primeiro método. Mesmo quando o primeiro método proposto falha em determinadas imagens, o processamento temporal utilizando transformada de Hough empregado no segundo método proposto é capaz de produzir contornos resultantes válidos.

Figura 7.19 apresenta o resultado final para algumas das imagens da série utilizada no capítulo 6 . Os contornos estão suavizados, e os cantos estão próximos ao que se verifica nas próprias imagens (com exceção da maior dificuldade vista nas Fig. 7.19(c) e (e)). Em algumas imagens, também, verificou-se o contorno escapando para a região da coluna, algumas vezes criando sinuosidades pouco naturais, como pode ser observado na maioria dessas imagens apresentadas. Esta dificuldade, porém, já está presente nos pontos obtidos do processamento temporal, como pode ser visto na Fig. 7.20.

Na Fig. 7.20, os contornos resultantes são comparados com os pontos obtidos pelo processamento temporal. Os contornos produzidos são boas aproximações dos pontos produzidos pelo processamento temporal. A falta de pontos nos cantos inferiores dificultou a criação de cantos mais agudos, uma vez que a tendência dos contornos ativos a suavizar se sobrepõe às forças externas presentes na região. Além disso, outra dificuldade presente é a dispersão dos pontos na região da coluna e a já presente sinuosidade do contorno subjetivo.

Figura 7.21 apresenta uma comparação dos dois métodos apresentados neste trabalho para esta última série. Os parâmetros utilizados para criar o contorno utilizando o primeiro foram os mesmo utilizados como base para a segmentação temporal do segundo método. Nestas imagens, em particular nas imagens das Fig. 7.21(a), (b) e (d), é nítida a vantagem da utilização da segmentação temporal. Além disso, nas demais imagens, os contornos produzidos pelo segundo método são mais suaves. Ainda que os cantos inferiores estejam suavizados um pouco em excesso, os contornos resultantes do primeiro método não apresentam resultados muito superiores.

Figura 7.22 mostra a segmentação do pulmão a partir de imagens coronais, utilizando-se o primeiro método apresentado. No caso de imagens coronais, os pulmões direito e esquerdo são segmentados separadamente. Na Fig. 7.22, o pulmão direito é segmentado. A demonstração da criação das máscaras está apresentada na Fig. 7.23.

Figura 7.24(a) mostra a mesma série da Fig. 7.22, e também a posição do plano vertical para a criação da imagem 2DST vertical. A Fig. 7.24(b) mostra 


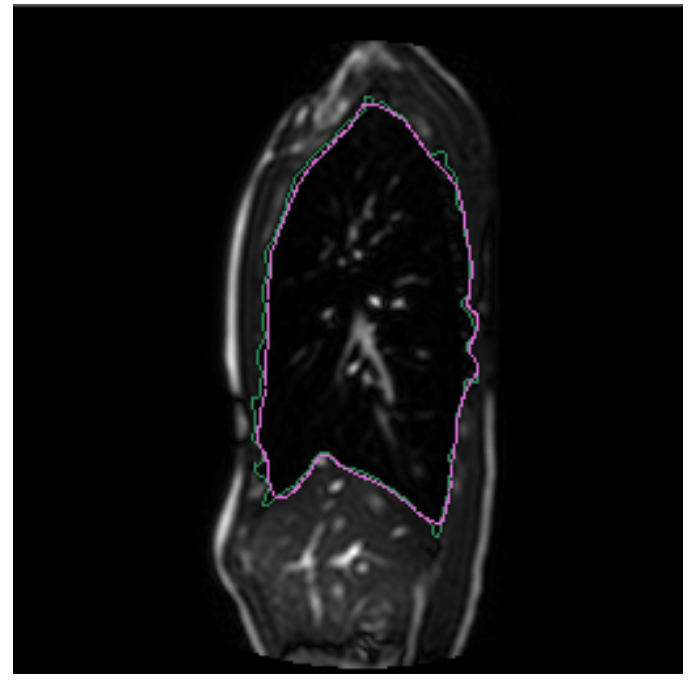

(a)

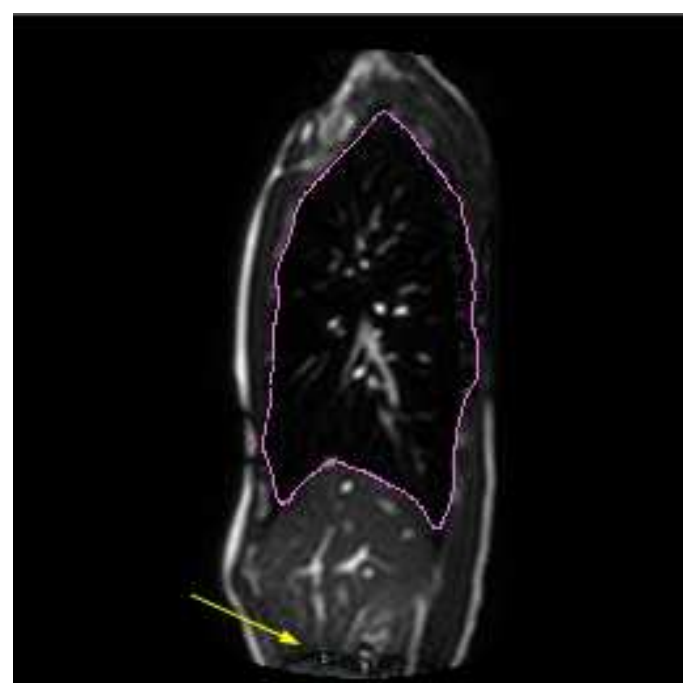

(c)

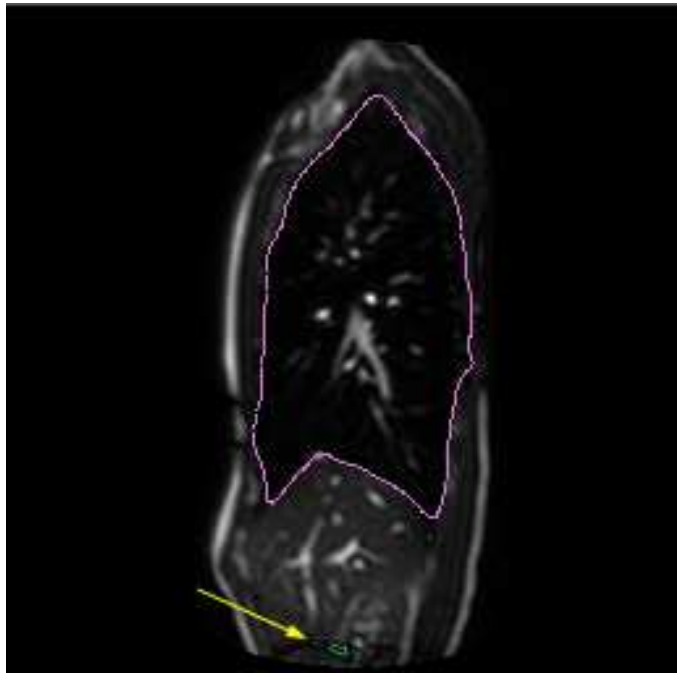

(b)

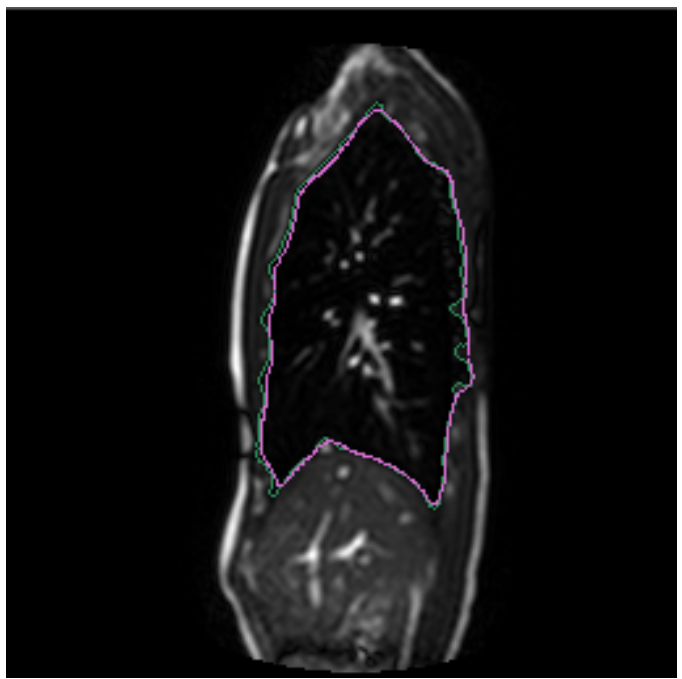

(d)

Figura 7.18: Ilustração da vantagem do segundo método apresentado. O resultado do primeiro método está apresentado em verde, e o resultado do segundo método, em lilás. (a) Imagem 44. (b) Imagem 45. A seta amarela destaca o contorno inválido produzido pelo primeiro método. (c) Imagem 46. A seta amarela destaca o contorno inválido produzido pelo primeiro método. (d) Imagem 47. 


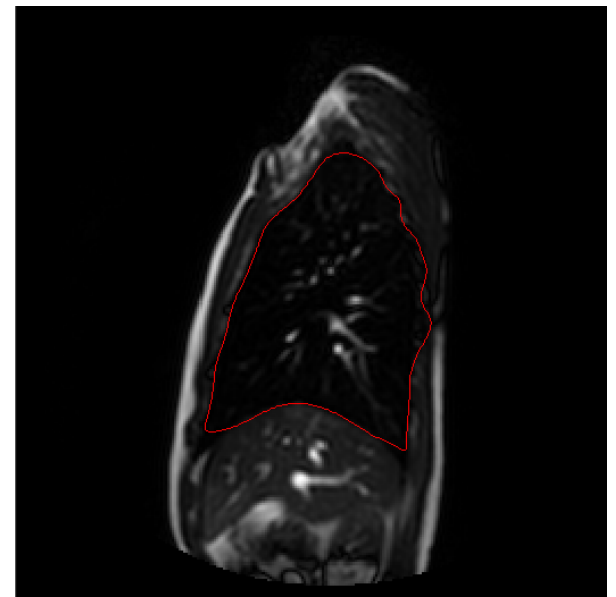

(a)

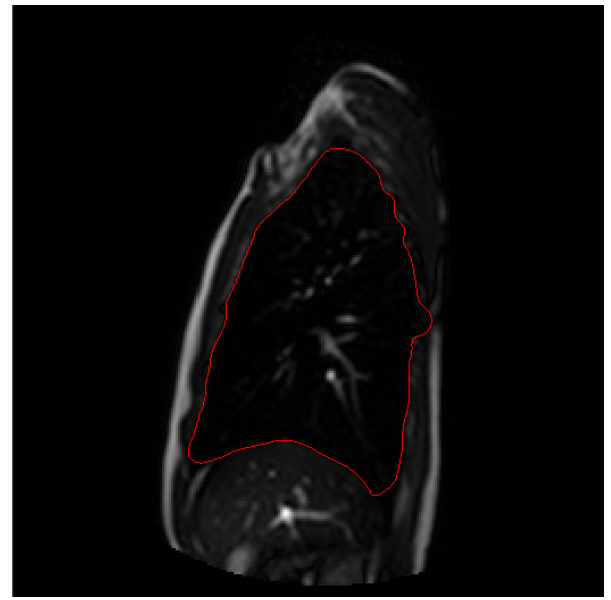

(c)

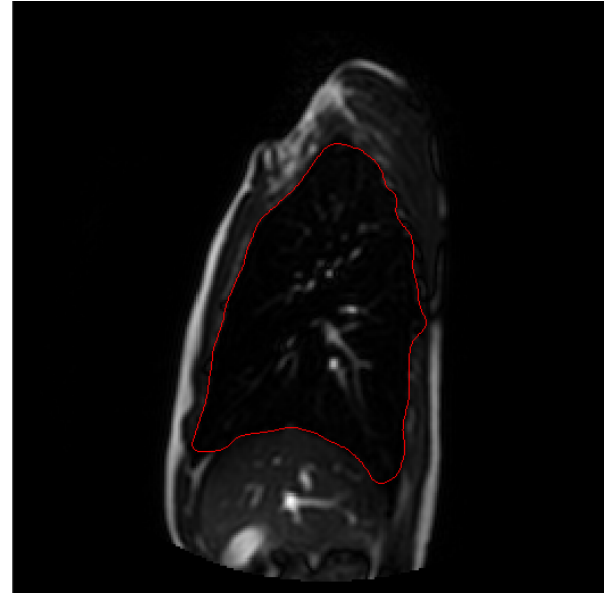

(e)

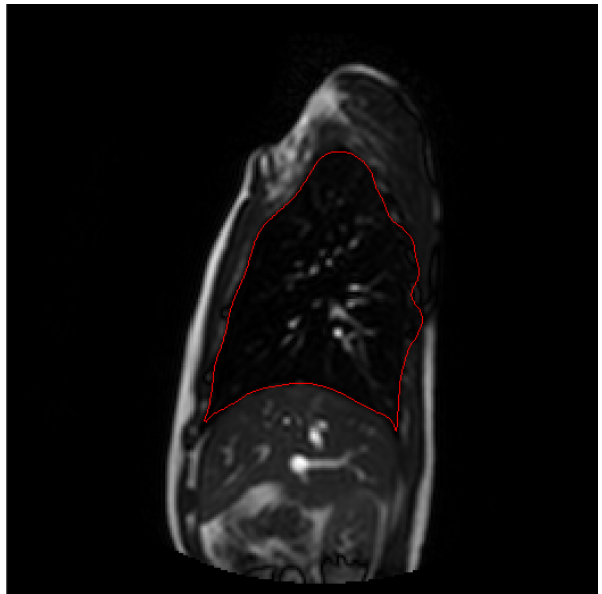

(b)

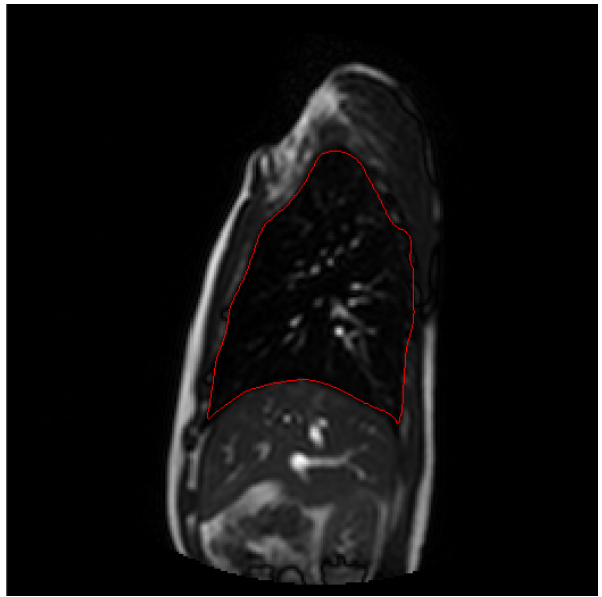

(d)

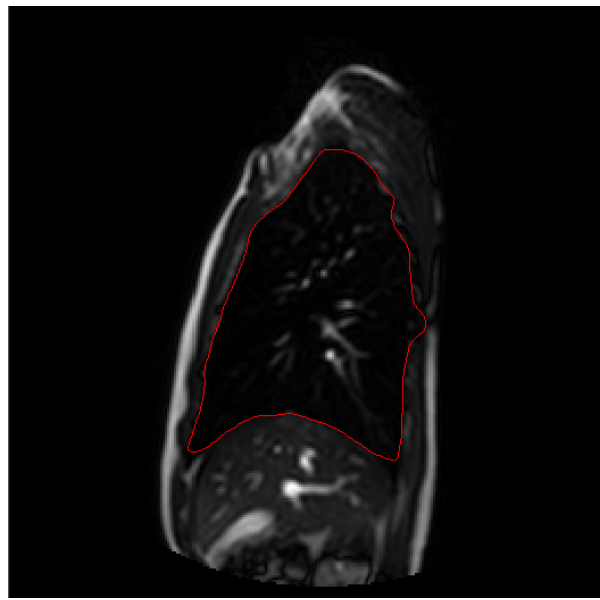

(f)

Figura 7.19: Resultados da segmentação do contorno do pulmão pelo segundo método proposto comparados com as imagens da série. (a) Imagem 07. (b) Imagem 15. (c) Imagem 30. (d) Imagem 45. (e) Imagem 54. (f) Imagem 64. 


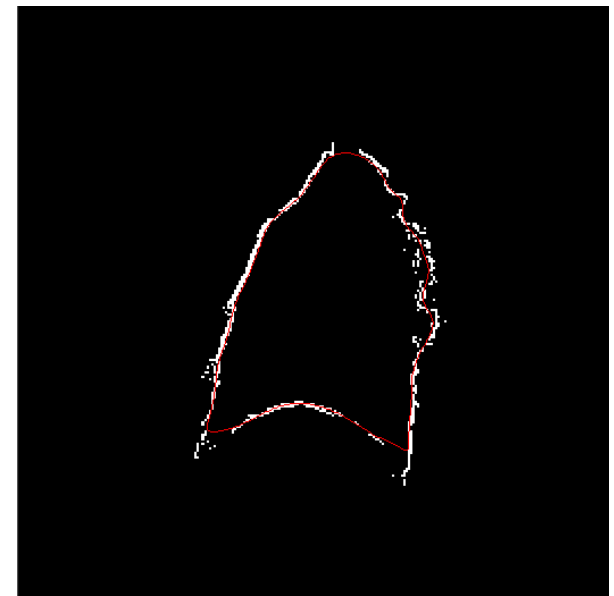

(a)

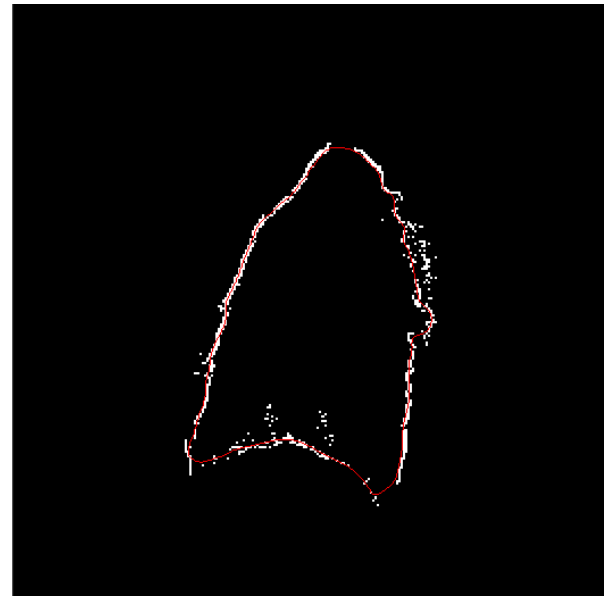

(c)

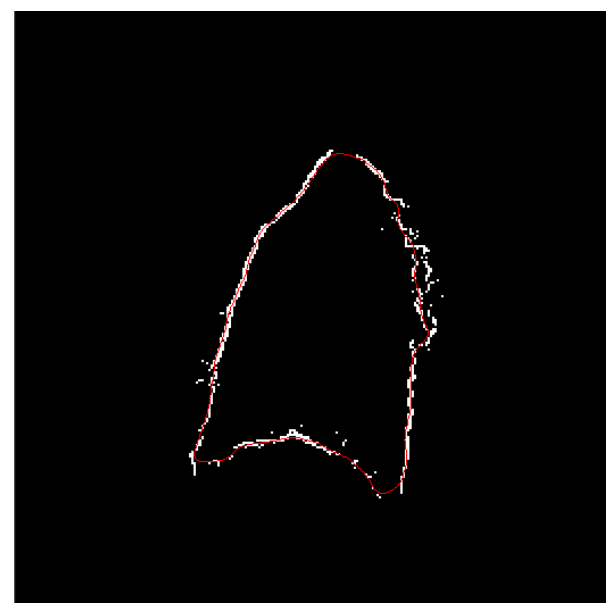

(e)

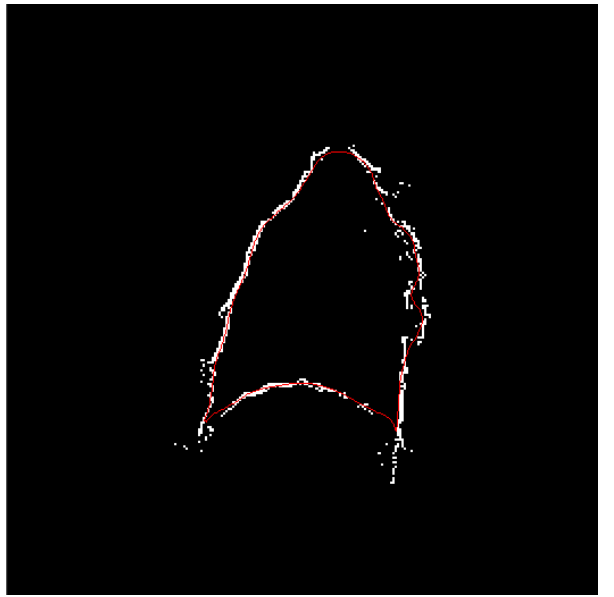

(b)

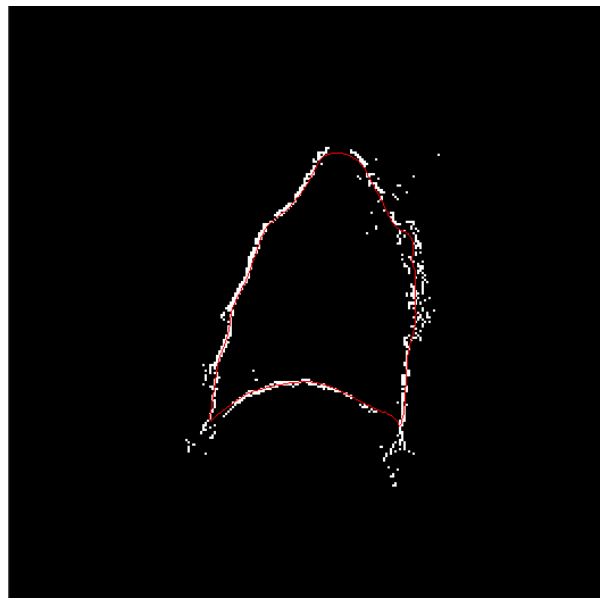

(d)

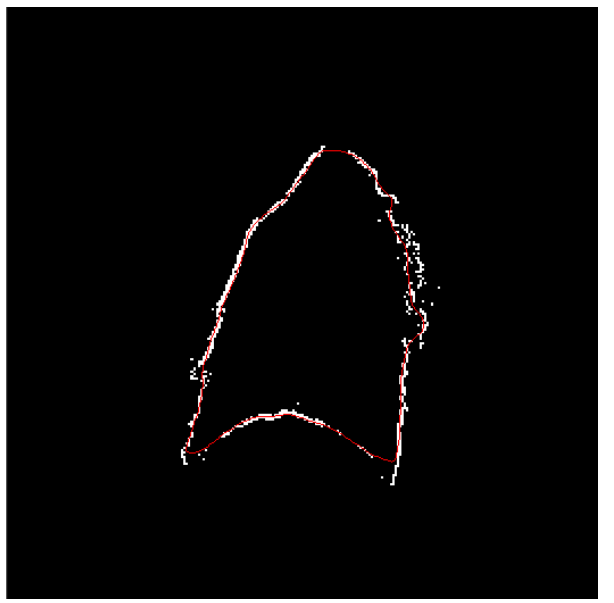

(f)

Figura 7.20: Resultados da segmentação do contorno do pulmão pelo segundo método proposto comparados com os pontos obtidos pelo processamento temporal. (a) Imagem 07. (b) Imagem 15. (c) Imagem 30. (d) Imagem 45. (e) Imagem 54. (f) Imagem 64. 


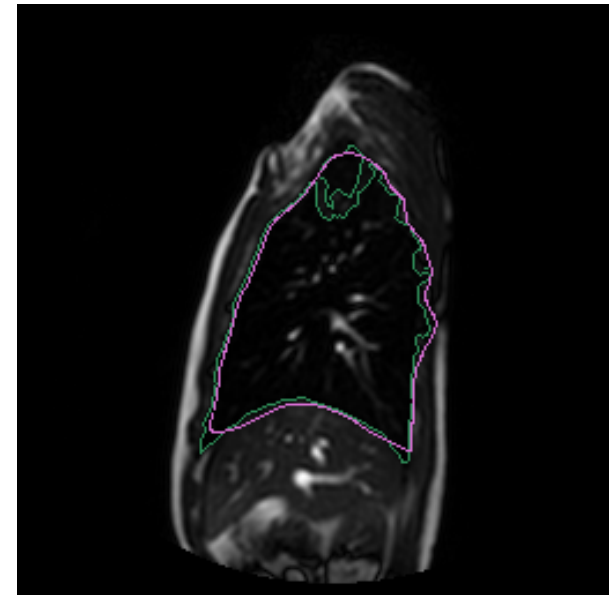

(a)

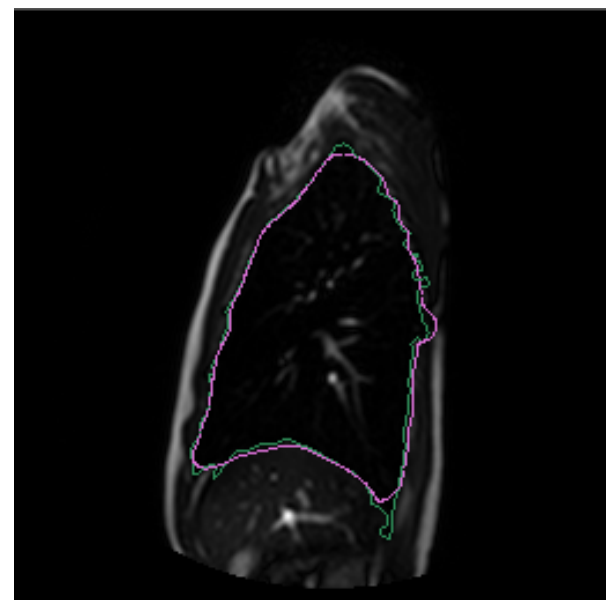

(c)

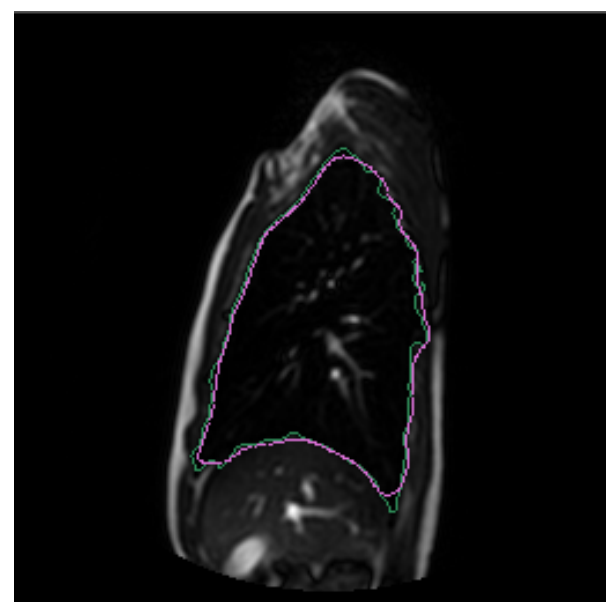

(e)

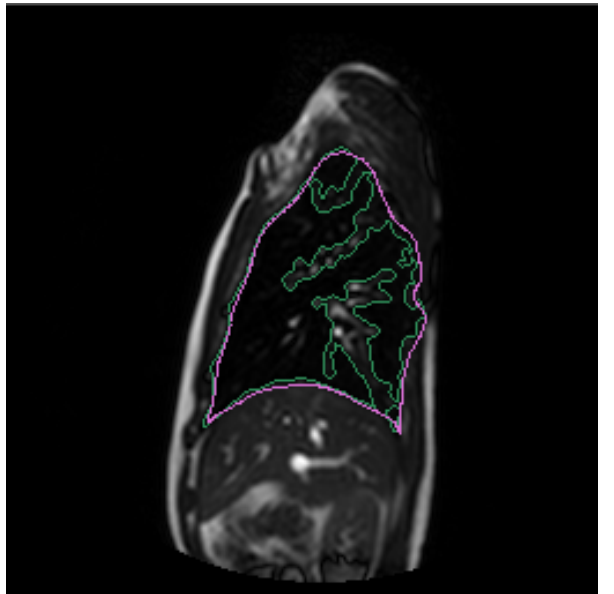

(b)

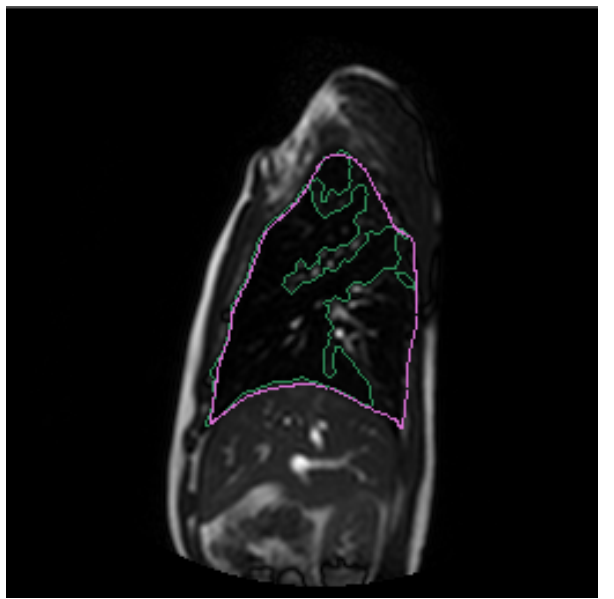

(d)

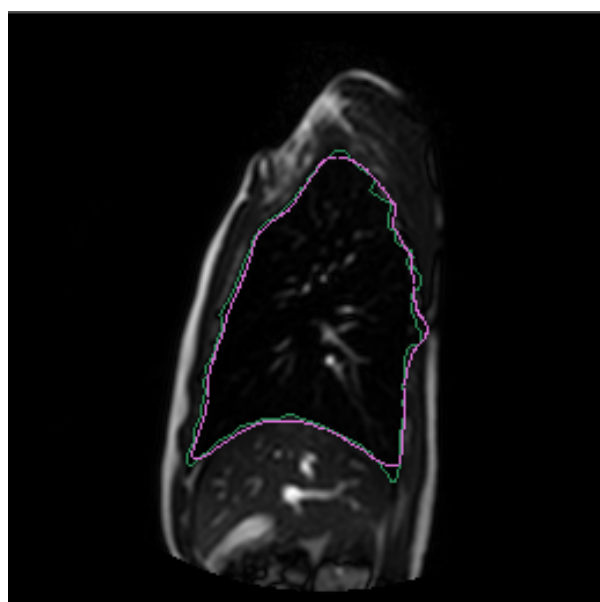

(f)

Figura 7.21: Comparação dos resultados obtidos pelos dois métodos de segmentação do pulmão para a mesma série apresentada na Fig. 7.19. O resultado do primeiro método está apresentado em verde, e o resultado do segundo método, em lilás. (a) Imagem 07. (b) Imagem 15. (c) Imagem 30. (d) Imagem 45. (e) Imagem 54. (f) Imagem 64. 


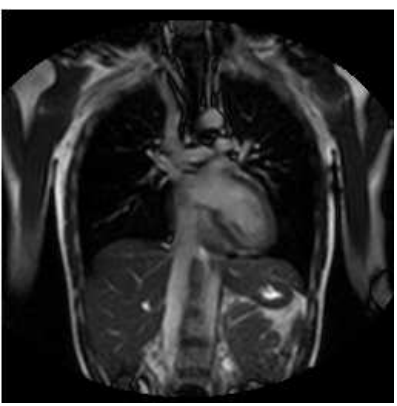

(a)

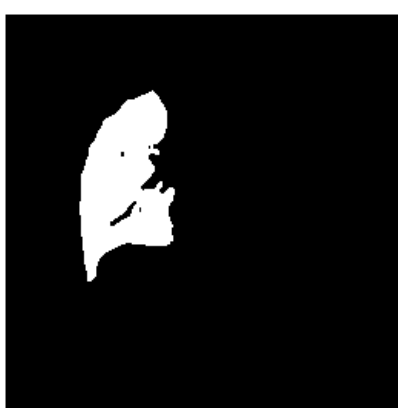

(d)

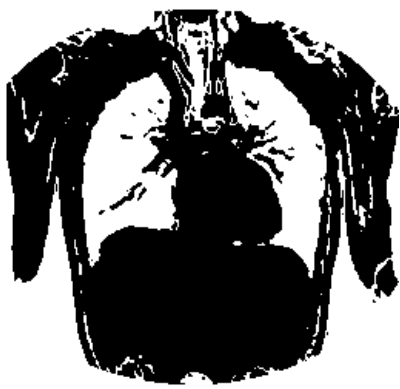

(b)

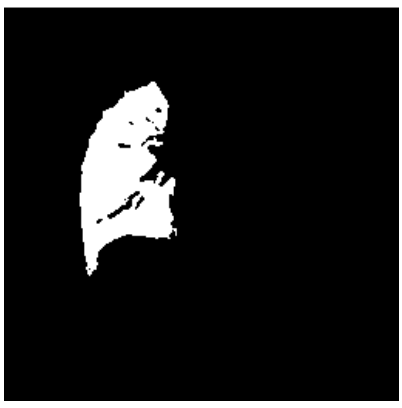

(c)

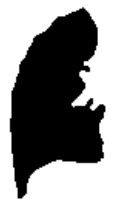

(e)

Figura 7.22: Segmentação do pulmão utilizando o primeiro método. (a) Imagem base. (b) Imagem binária. (c) Imagem após primeiro labeling. (d) Imagem após aplicação de filtro. (e) Imagem final, após segundo labeling.

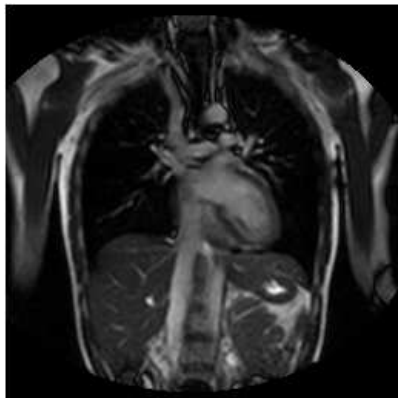

(a)

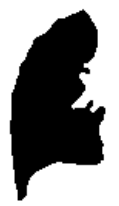

(b)

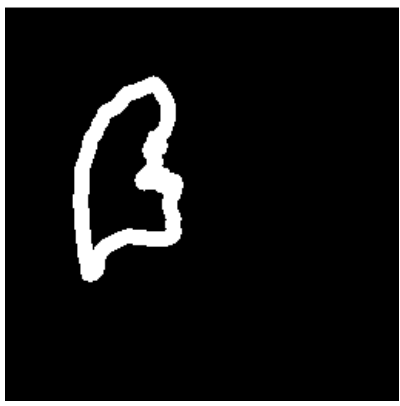

(e)

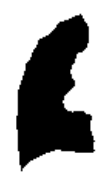

(c)

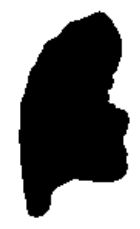

(d)

Figura 7.23: Criação da máscara de busca do contorno a partir de região determinada na Fig. 7.22. (a) Imagem base. (b) Região do pulmão obtida. (c) Imagem após dilatação morfológica. (d) Imagem após erosão morfológica. (e) Imagem final. 


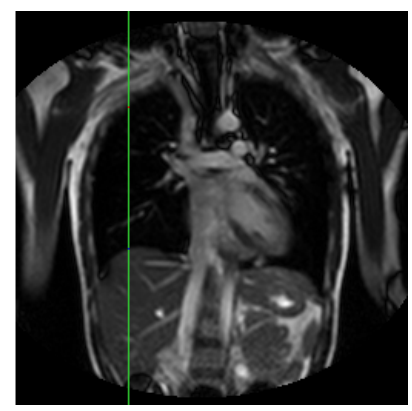

(a)

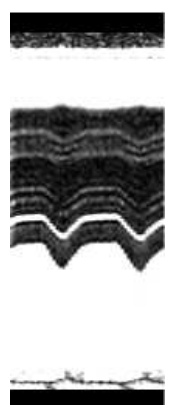

(b)

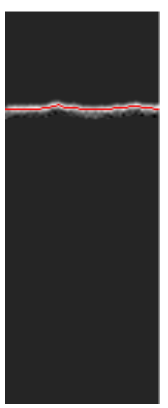

(c)

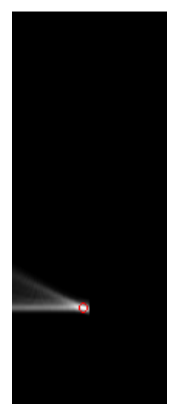

(d)

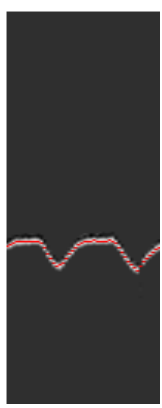

(e)

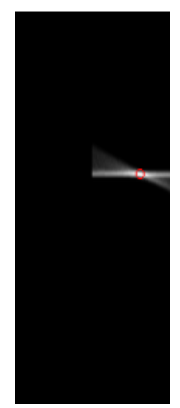

(f)

Figura 7.24: Processamento temporal com transformada de Hough modificada utilizando máscaras. (a) Imagem original - reta verde indica a posição da imagem 2DST vertical selecionada. (b) Imagem 2DST com pixels de alta intensidade filtrados. (c) Imagem de arestas com a máscara aplicada - contorno superior do pulmão. Padrão respiratório encontrado indicado em vermelho. (d) Espaço paramétrico de Hough. Ponto de máximo indicado por círculo vermelho. (e) Imagem de arestas com a máscara aplicada - contorno inferior do pulmão. Padrão respiratório encontrado indicado em vermelho. (f) Espaço paramétrico de Hough. Ponto de máximo indicado por círculo vermelho.

a imagem 2DST vertical criada. Os pixels de alta intensidade, que representam vasos sangüíneos ou gordura, foram filtrados. As Fig. 7.24(c) e (e) mostram as imagens de arestas criadas a partir da Fig. 7.24(b), mas com as máscaras aplicadas. A Fig. 7.24(c) mostra somente a região de movimentação do contorno superior, e a Fig. 7.24(e) mostra somente a região de movimentação do contorno inferior do pulmão. As Fig. 7.24(d) e (f) mostram os espaços paramétricos de Hough criados a partir das imagens de arestas das Fig. 7.24(c) e (e), respectivamente. Como, por hipótese, o pulmão é o órgão com movimento de maior amplitude e que durante a respiração contornos opostos possuem movimentos de fases opostas, podemos limitar a busca no espaço paramétrico de Hough para apenas um semiplano. No caso, a função respiração base foi tomada na região diafragmática - ou seja, contorno inferior do pulmão em uma imagem 2DST vertical - por esta região possuir a maior amplitude de movimento na respiração. Assim, para a busca de máximo no espaço paramétrico do contorno inferior, temos que a escala (parâmetro a no espaço paramétrico) deve ser positiva, e portanto o máximo deve estar no semiplano $a \geq 0$ do espaço paramétrico, como indicado na Fig. 7.24(f). Analogamente, para o contorno superior, o máximo deve estar no semiplano $a \leq 0$ do espaço paramétrico de Hough, como indicado na Fig. 7.24(d). Os pontos de máximo indicados nas Fig. 7.24(d) e (f) representam os padrões respiratórios apresentados nas Fig. 7.24(c) e (e).

Figura 7.25 ilustra o ajuste feito através dos contornos ativos. A Fig. 7.25(a) apresenta o espaço paramétrico de Hough referente ao contorno superior (ápice) 
do pulmão - a célula de máximo valor está indicada por um círculo vermelho. A Fig. 7.25(b) apresenta uma imagem de arestas com a máscara aplicada, e o padrão respiratório encontrado (em (a)) indicado em vermelho. Este padrão respiratório é totalmente síncrono ao padrão respiratório base. A Fig. 7.25(c) apresenta a mesma imagem da Fig. 7.25(b), mas ilustrando o padrão respiratório ajustado por contornos ativos. Da mesma forma, a Fig. 7.25(d) apresenta o espaço paramétrico de Hough referente ao contorno inferior (diafragmático) do pulmão - a célula de máximo valor está indicada por um círculo vermelho. A Fig. 7.25(e) apresenta a imagem de arestas com a máscara aplicada e o padrão respiratório encontrado (na Fig. 7.25(d)) indicado em vermelho, e a Fig. 7.25(f) apresenta a mesma imagem e ilustra o resultado da aplicação de contornos ativos. Em ambos os casos é possível observar as diferenças entre os padrões respiratórios antes e depois da aplicação dos contornos ativos.

Figura 7.26 apresenta o mesmo processamento aplicado para imagens 2DST horizontal. Fig. 7.27 ilustra o ajuste feito através dos contornos ativos. $\mathrm{Na}$ imagem da Fig. 7.27(a) está apresentado o espaço paramétrico de Hough, com a célula de máximo indicada circulada em vermelho. O padrão respiratório referente a essa célula de máximo está apresentado na Fig. 7.27(b). Nesta imagem, o padrão respiratório encontrado e apresentado é totalmente síncrono com o padrão respiratório base utilizado. Na Fig. 7.27(c), o resultado do ajuste do padrão respiratório na Fig. 7.27(b). Pode-se observar que as arestas ajustadas aproximam melhor as arestas presentes nas imagens de arestas em vez de respeitar totalmente o padrão respiratório base.

Figura 7.28 ilustra o resultado da varredura nas quatro direções em diversos planos. Fig. 7.29 apresenta uma comparação entre os dois métodos. Nesta série específica, o resultado do primeiro método se mostrou satisfatório em todas as imagens, não ocorrendo situações como a ilustrada na Fig. 6.1. Na Fig. 7.30 estão apresentados os contornos resultantes pelo segundo método proposto para as mesmas imagens da Fig. 7.8. A imagem da Fig. 7.30(a) apresenta o melhor resultado. As duas regiões de maior dificuldade, o canto inferior esquerdo e a região próxima do pulmão, estão bem delimitados. A imagem da Fig. 7.30(c) apresenta um resultado com cantos suavizados em excesso, produzida com os mesmos parâmetros que as demais imagens da série.

Figura 7.31 apresenta a comparação dos contornos resultantes do segundo método proposto com os pontos obtidos pelo processamento temporal utilizando transformada de Hough modificada e máscaras. Os contornos produzidos não necessariamente passam por todos os pontos por também adicionar informações 


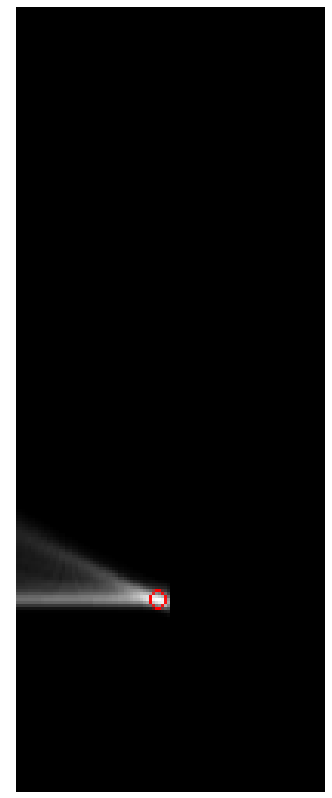

(a)

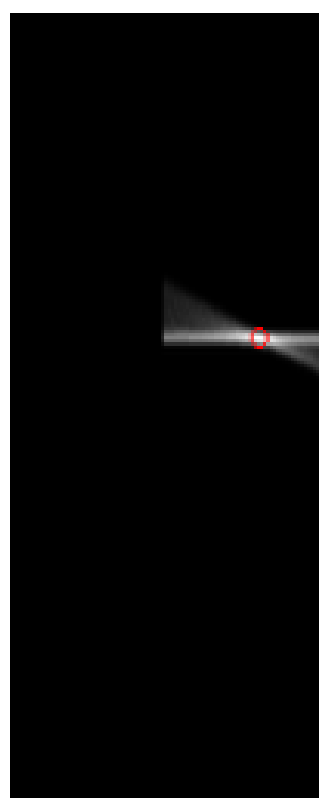

(d)

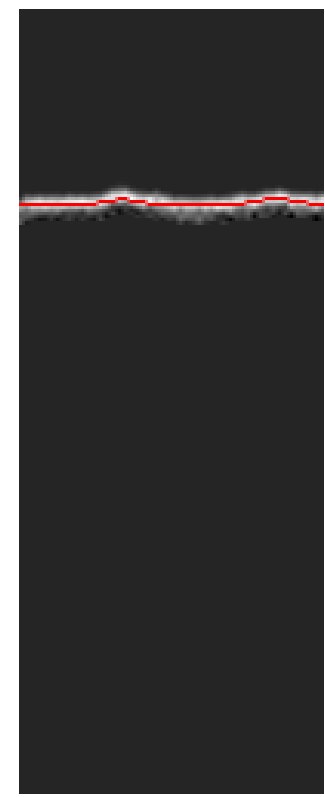

(b)

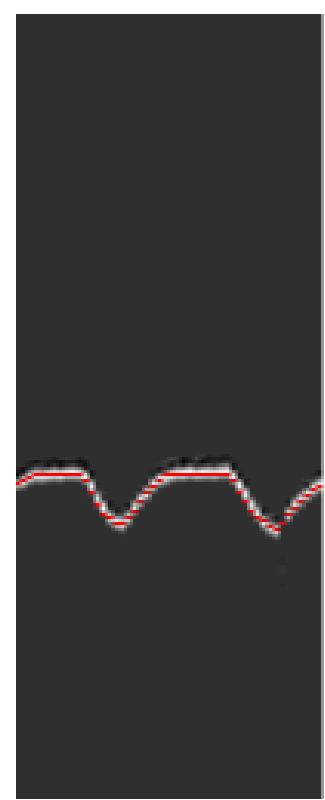

(e)

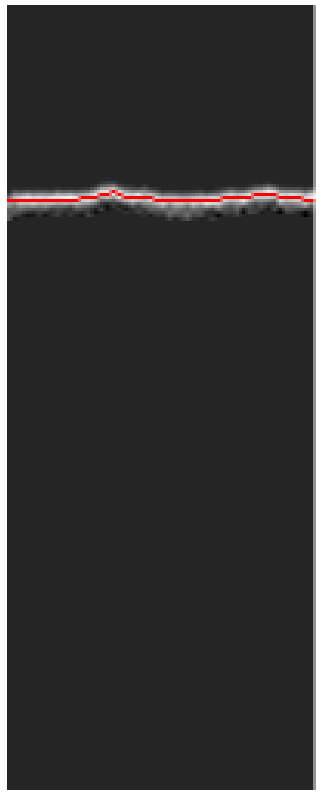

(c)

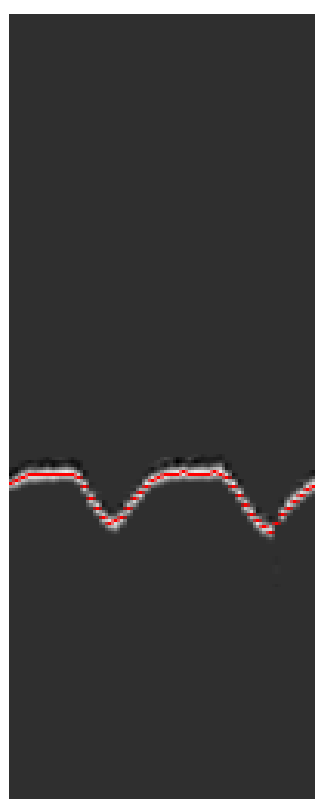

(f)

Figura 7.25: Comparação dos padrões respiratórios encontrados pela transformada de Hough modificada antes e depois do ajuste feito pelo método de contornos ativos. (a) Espaço paramétrico de Hough. Ponto de máximo indicado por círculo vermelho. (b) Imagem de arestas com a máscara aplicada - contorno superior do pulmão. Padrão respiratório, antes do ajuste por contornos ativos, encontrado indicado em vermelho. (c) Mesma imagem de arestas que a exibida em (b), porém com o padrão respiratório indicado em vermelho após o ajuste pelo método de contornos ativos. (d) Espaço paramétrico de Hough. Ponto de máximo indicado por círculo vermelho. (e) Imagem de arestas com a máscara aplicada - contorno inferior do pulmão. Padrão respiratório, antes do ajuste por contornos ativos, encontrado indicado em vermelho. (f) Mesma imagem de arestas que a exibida em (e), porém com padrão respiratório indicado em vermelho após o ajuste pelo método de contornos ativos. 


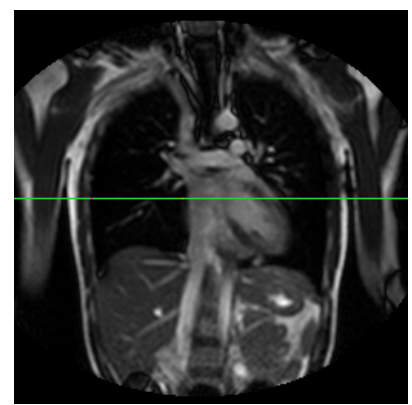

(a)

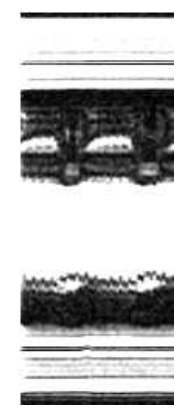

(b)

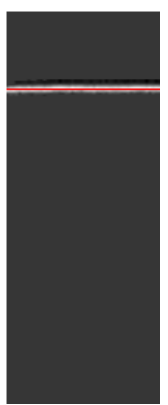

(c)

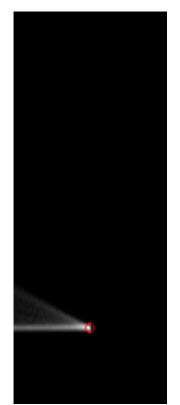

(d)

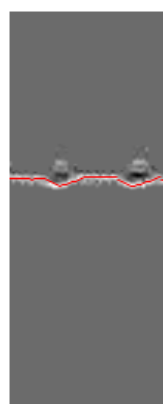

(e)

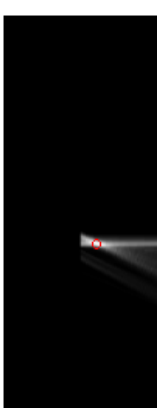

(f)

Figura 7.26: Processamento temporal com transformada de Hough modificada utilizando máscaras. (a) Imagem original - reta verde indica a posição da imagem 2DST horizontal selecionada. (b) Imagem 2DST com pixels de alta intensidade filtrados. (c) Imagem de arestas com a máscara aplicada - contorno anterior do pulmão. Padrão respiratório encontrado indicado em vermelho. (d) Espaço paramétrico de Hough. Ponto de máximo indicado por círculo vermelho. (e) Imagem de arestas com a máscara aplicada - contorno posterior do pulmão. Padrão respiratório encontrado indicado em vermelho. (f) Espaço paramétrico de Hough. Ponto de máximo indicado por círculo vermelho.

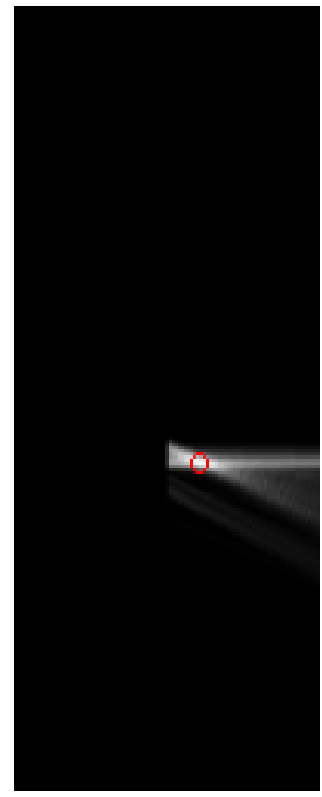

(a)

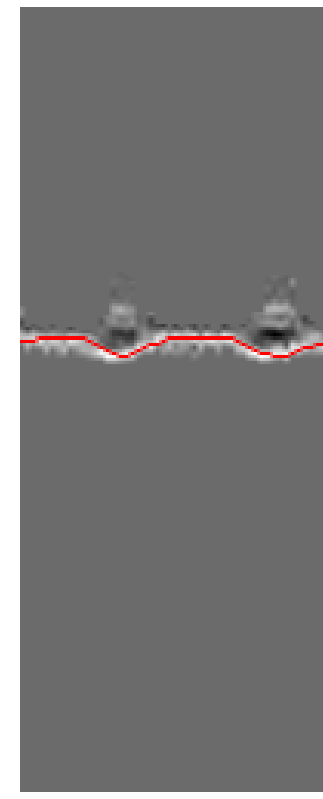

(b)

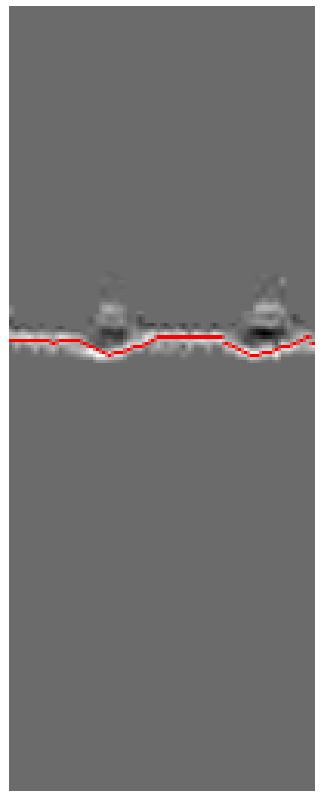

(c)

Figura 7.27: Comparação dos padrões respiratórios encontrados pela transformada de Hough modificada antes e depois do ajuste feito pelo método de contornos ativos. (a) Espaço paramétrico de Hough. Ponto de máximo indicado por círculo vermelho. (b) Imagem de arestas com a máscara aplicada - contorno posterior do pulmão. Função respiração, antes do ajuste por contornos ativos, encontrada indicada em vermelho. (c) Mesma imagem de arestas que a exibida em (b), porém com a função respiração indicada em vermelho após o ajuste pelo método de contornos ativos. 


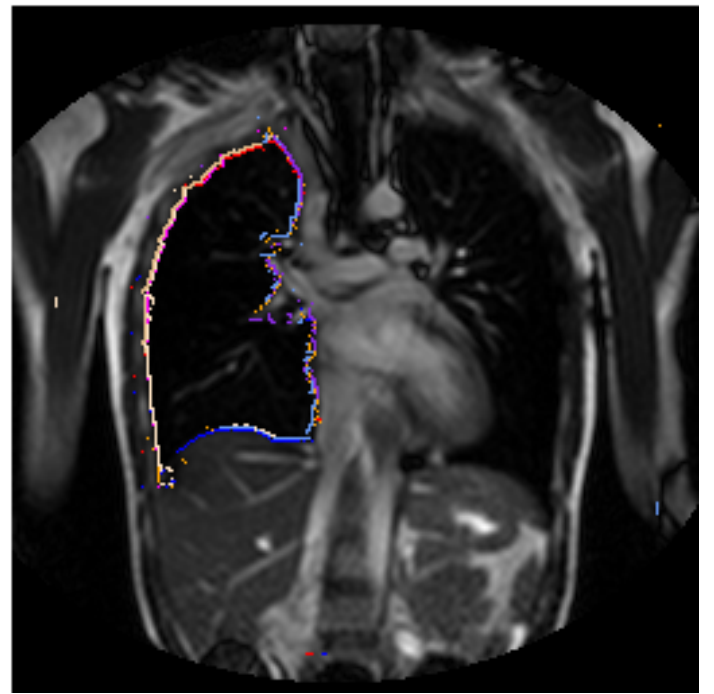

(a)

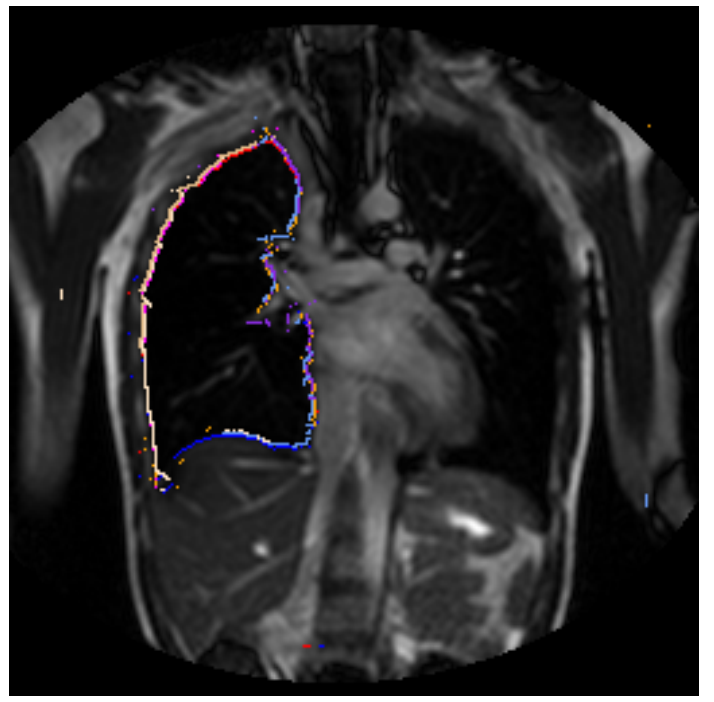

(c)

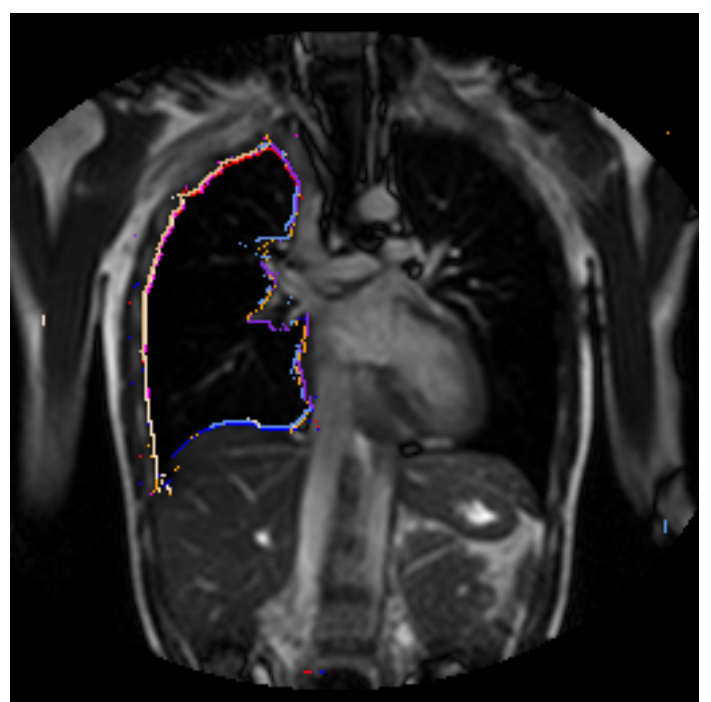

(b)

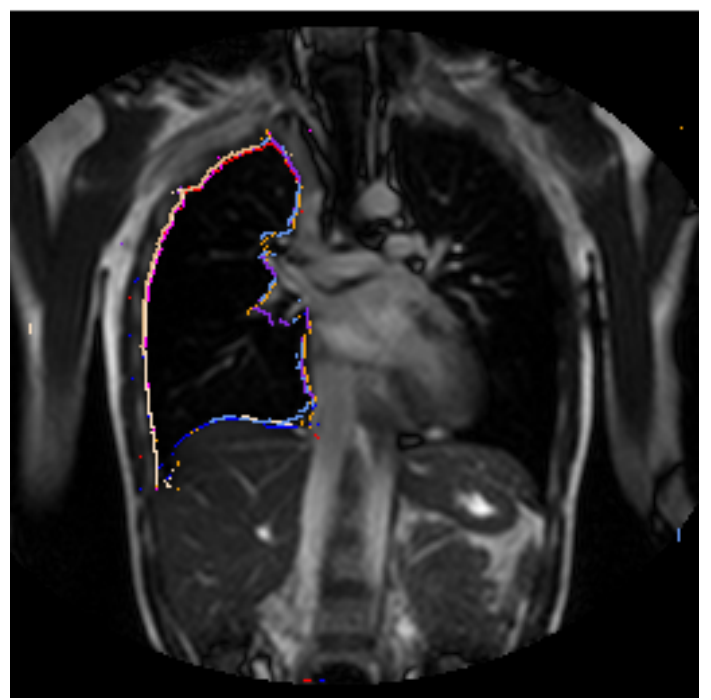

(d)

Figura 7.28: Resultados da segmentação temporal do pulmão para a mesma série apresentada na Fig. 7.22. As cores indicam a origem do ponto: pontos em vermelho e azul foram obtidos através do processamento de imagens 2DST verticais (vermelho representa o contorno superior e azul, o inferior); magenta (anterior) e laranja (posterior) foram obtidos com imagens 2DST horizontais; creme (anterior/inferior) e roxo (posterior/superior), de imagens 2DST oblíquas $+45^{\circ}$; e, por fim, bege (anterior/superior) e ciano (posterior/inferior), de imagens 2DST oblíquas $-45^{\circ}$. (a) Imagem 14. (b) Imagem 23. (c) Imagem 39. (d) Imagem 50 . 


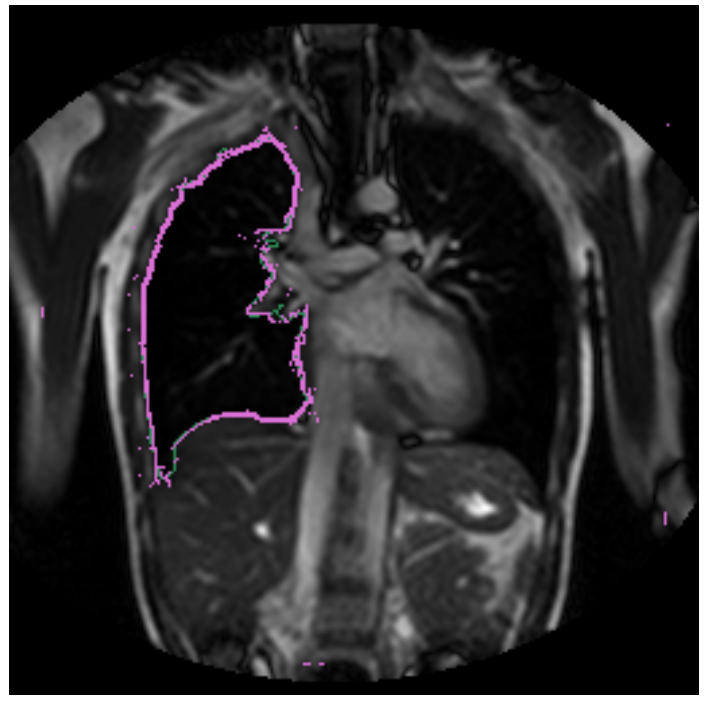

(a)

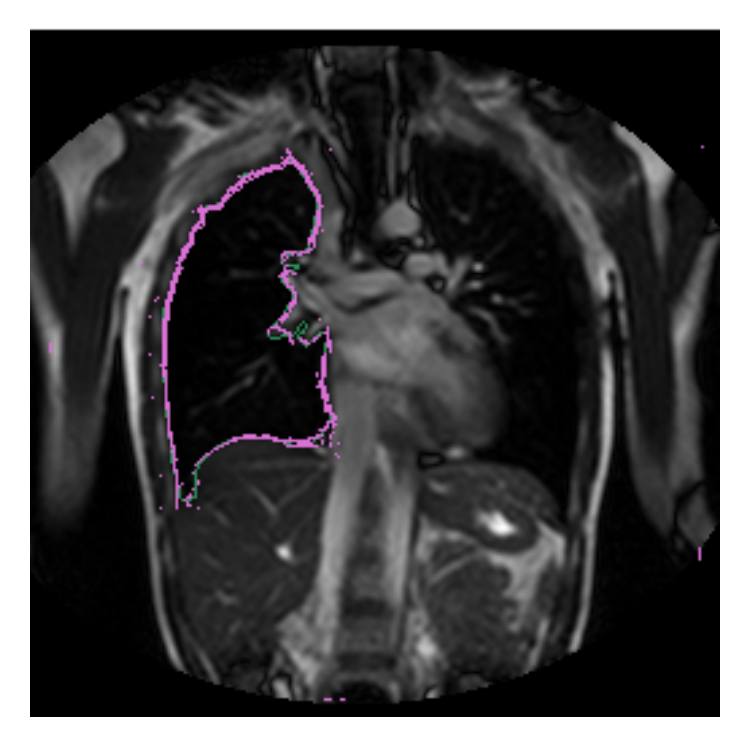

(c)

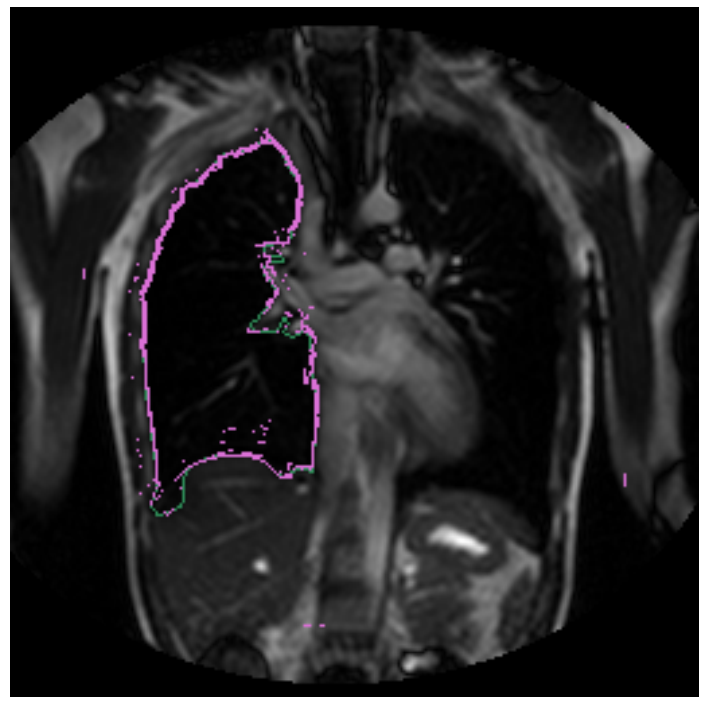

(b)

Figura 7.29: Comparação dos dois métodos para imagens coronais, com a segmentação do pulmão direito. O resultado do primeiro método está apresentado em verde, e o resultado parcial do segundo método, em lilás. (a) Imagem 23. (b) Imagem 42. (c) Imagem 50. 


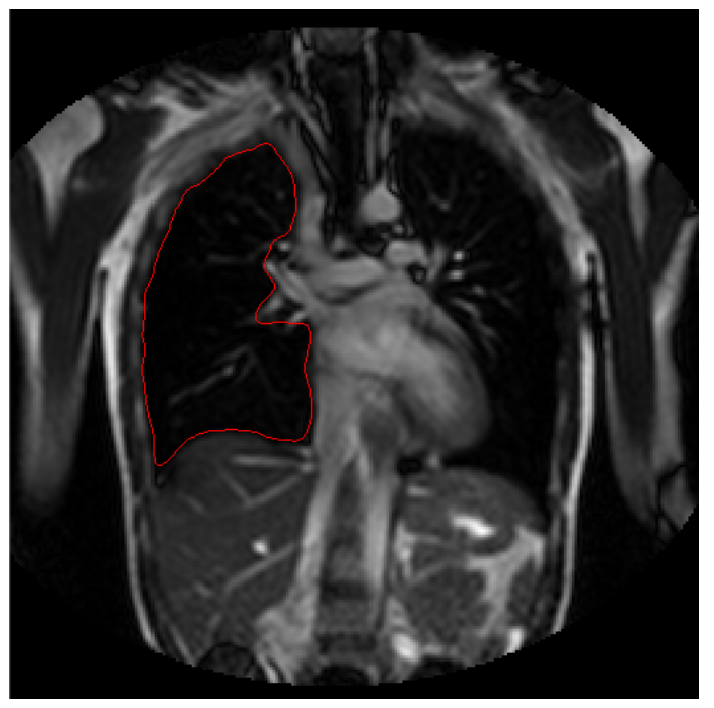

(a)

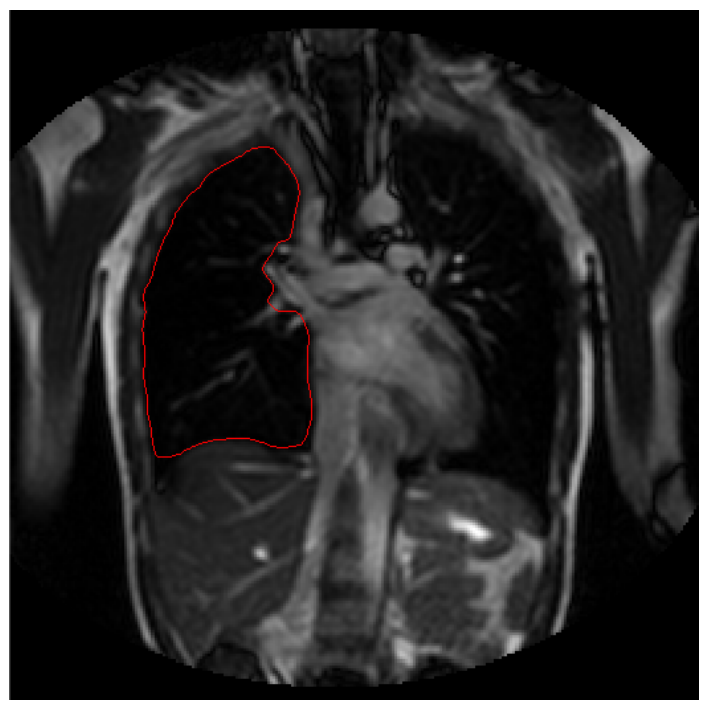

(c)

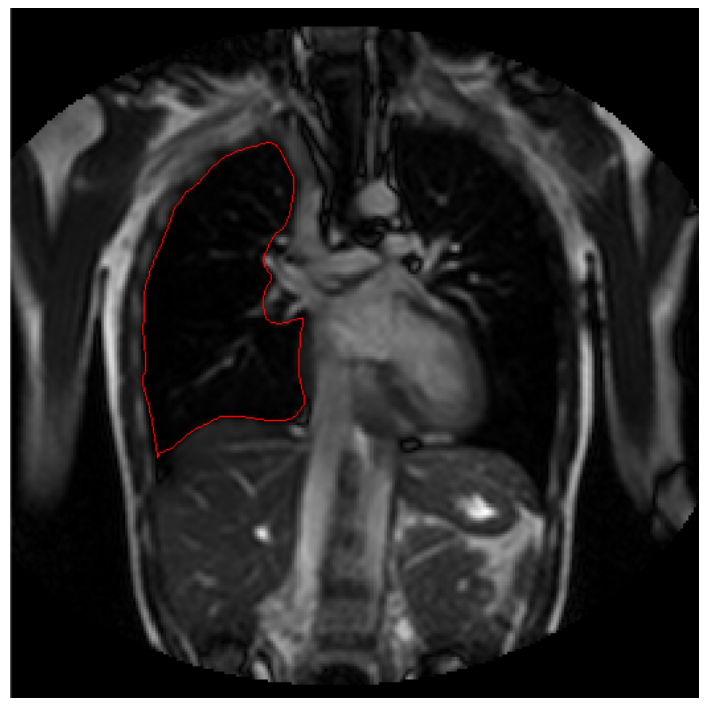

(b)

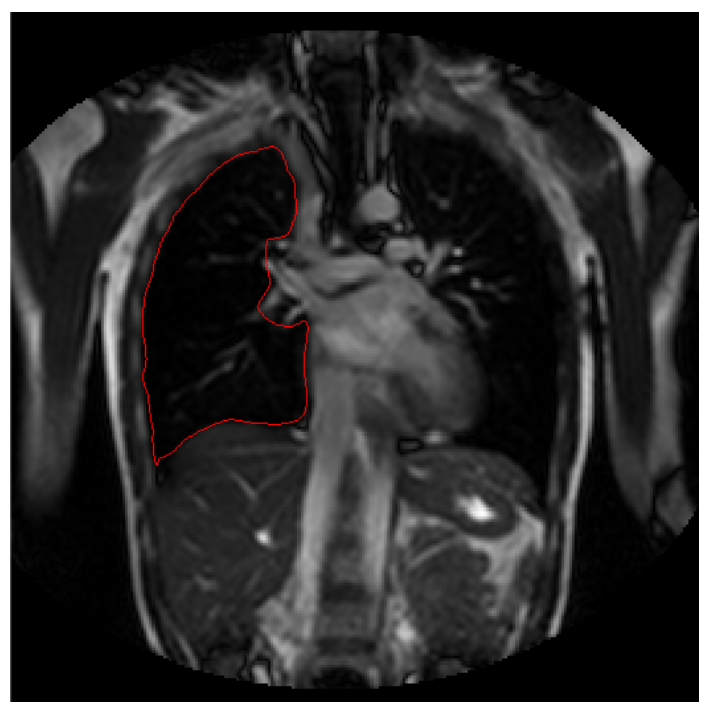

(d)

Figura 7.30: Resultados da segmentação do contorno do pulmão direito em imagem coronal pelo segundo método proposto comparados com as imagens da série. (a) Imagem 14. (b) Imagem 23. (c) Imagem 39. (d) Imagem 50. 
provenientes da imagem individual. A falta de pontos no canto inferior esquerdo dificultou a formação de um canto mais agudo, assim como na região próxima ao coração. Nas demais regiões com abundância de pontos, o contorno resultante é uma boa aproximação dos pontos.

A comparação dos dois métodos propostos para a segmentação do pulmão direito em imagem coronal está apresentada na Fig. 7.32. Nestas imagens, podemos observar que o contorno produzido pelo segundo método é mais suave, com menos sinuosidades. Por outro lado, os cantos também são mais suavizados do que nos contornos produzidos pelo primeiro método proposto. Ainda assim, analisando o canto inferior esquerdo do pulmão (nas imagens), o contorno produzido pelo primeiro método está muito alongado nessa região. Nesta série, o segundo método proposto produziu resultados muito bons, com a única região a ser melhor analisada sendo a reentrância próxima ao coração. Neste ponto, porém, mesmo em uma análise visual é difícil delimitar o pulmão. 


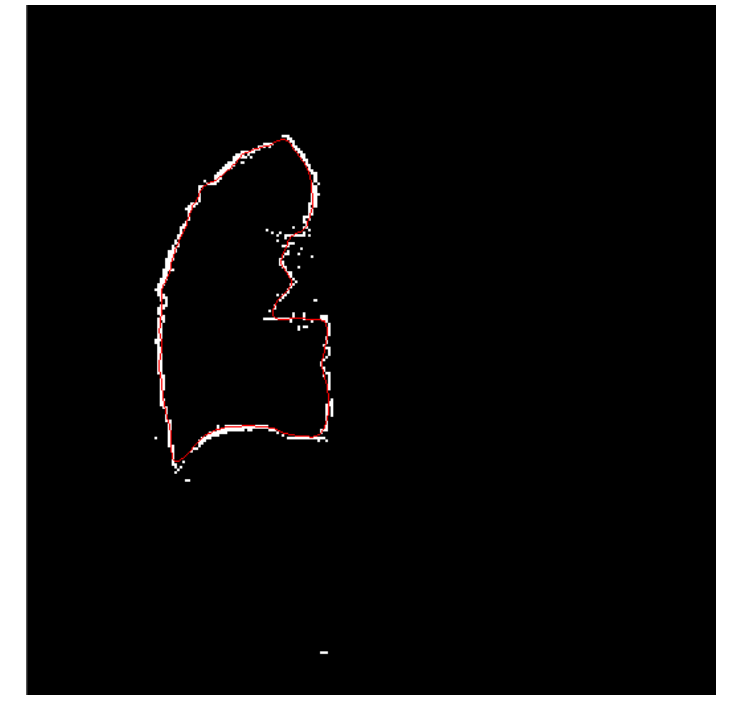

(a)

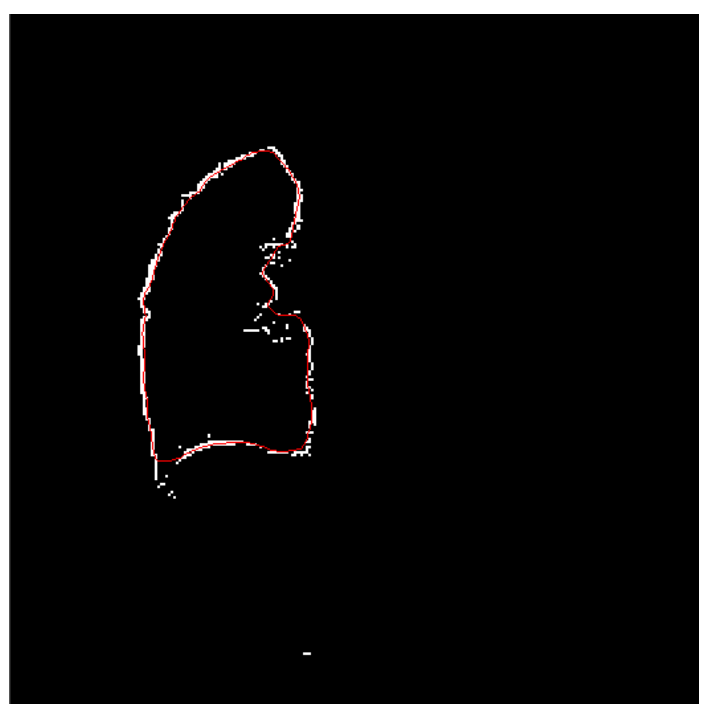

(c)

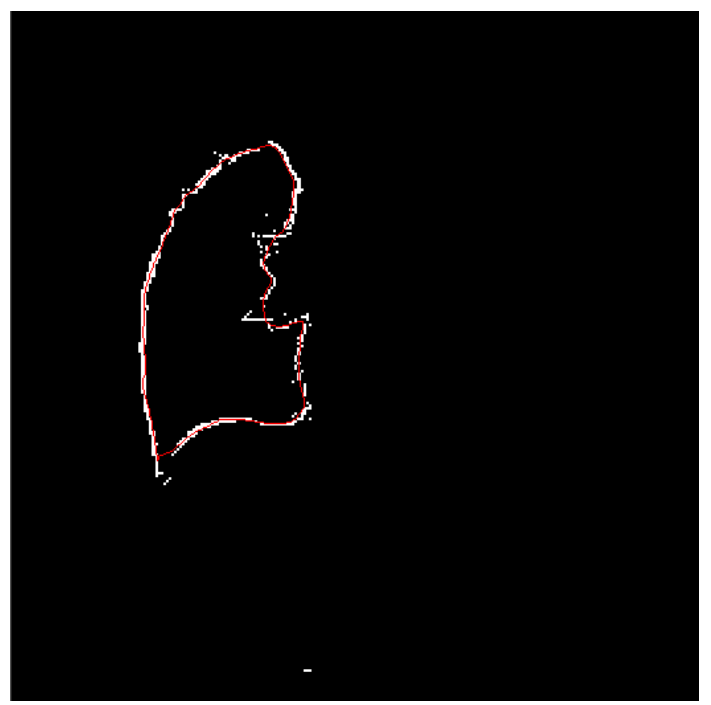

(b)

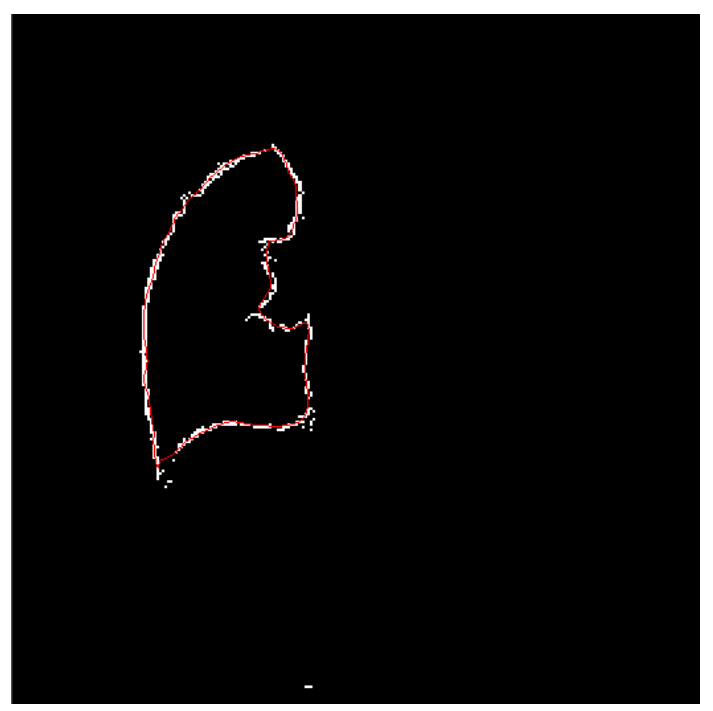

(d)

Figura 7.31: Resultados da segmentação do contorno do pulmão direito em imagem coronal pelo segundo método proposto comparados com os pontos obtidos pelo processamento temporal. (a) Imagem 14. (b) Imagem 23. (c) Imagem 39. (d) Imagem 50. 


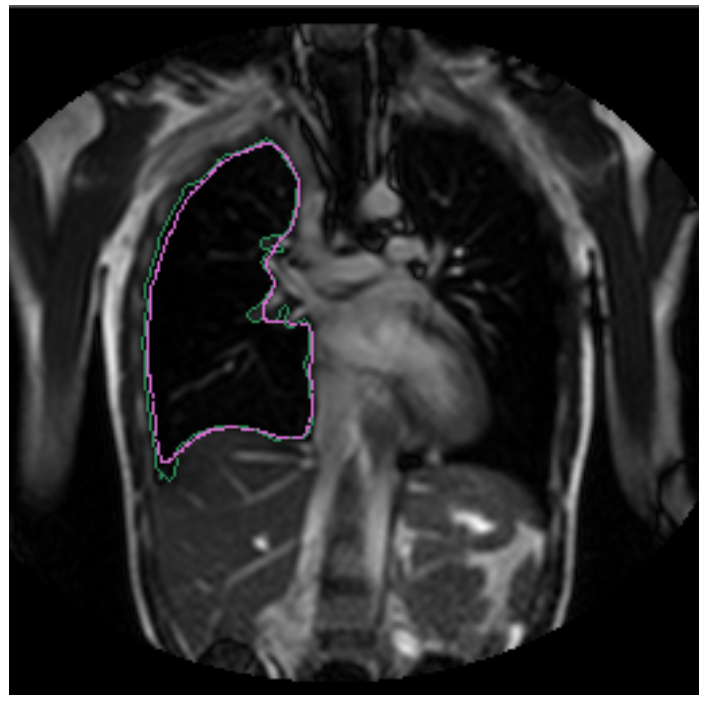

(a)

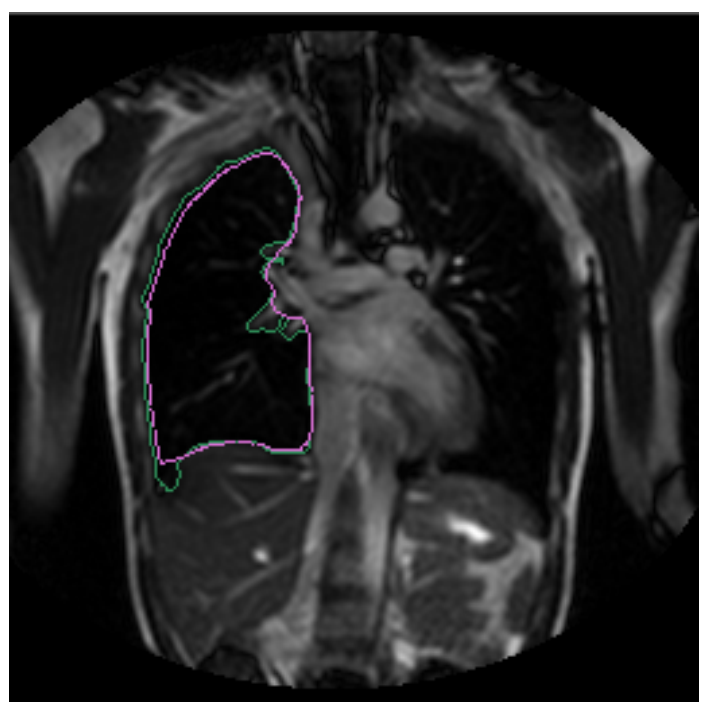

(c)

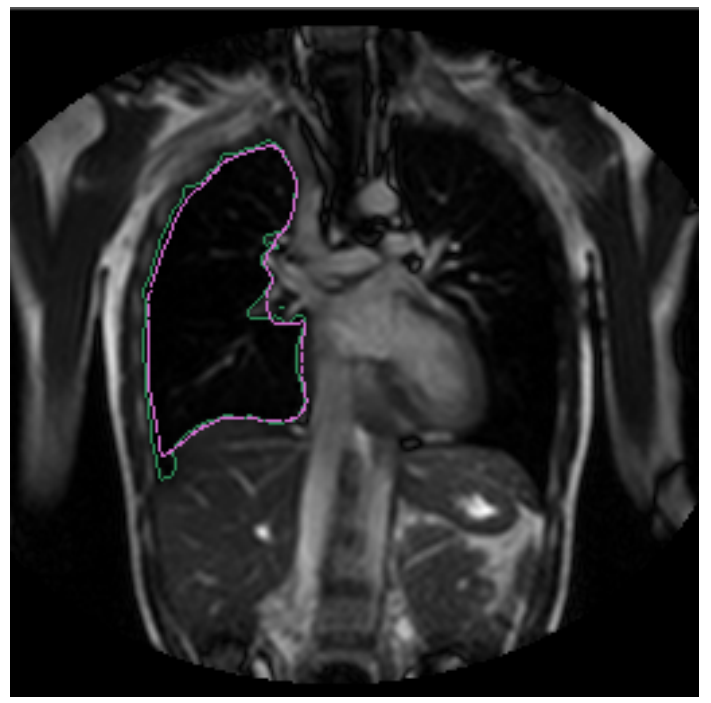

(b)

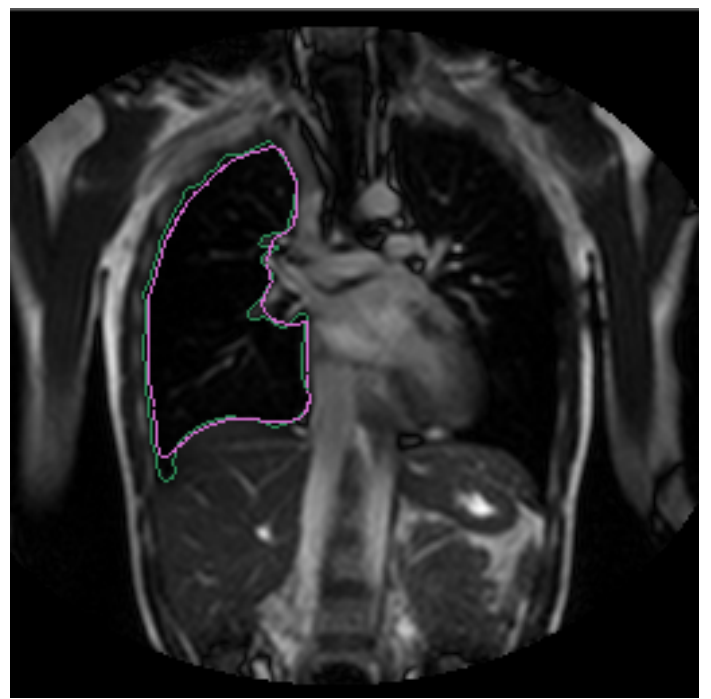

(d)

Figura 7.32: Comparação dos resultados obtidos pelos dois métodos de segmentação do pulmão direito em imagem coronal para a série abordada. O resultado do primeiro método está apresentado em verde, e o resultado do segundo método, em lilás. (a) Imagem 14. (b) Imagem 23. (c) Imagem 39. (d) Imagem 50. 


\section{Conclusões}

Neste trabalho foram apresentados dois métodos para a segmentação do pulmão em seqüências de imagens temporais de RM do pulmão.

O primeiro método proposto, segmentação do pulmão através de limiarização e labeling, apresentou resultados razoáveis, e possui a capacidade de criar contornos com cantos agudos. Seu ajuste, porém, é feito individualmente por imagem, pois apenas as informações em cada imagem individualmente são consideradas ao longo do processamento. Ainda assim, em algumas imagens os contornos são determinados de modo totalmente incorreto, geralmente devido à qualidade da imagem.

O segundo método proposto, segmentação temporal do pulmão, utiliza o resultado produzido pelo método anterior para delimitar uma região próxima ao suposto contorno do pulmão onde se realiza uma busca por padrões respiratórios através da transformada de Hough modificada. Com a utilização desses padrões respiratórios, contornos incorretos obtidos pelo método de segmentação através de limiarização e labeling podem ser corrigidos através do processamento temporal.

Este segundo método também apresenta bons resultados, com contornos suaves. Em alguns casos, o processamento temporal não é capaz de produzir pontos suficientes ou com a definição necessária para uma melhor precisão do contorno, em especial nos cantos, levando a contornos suavizados em excesso. Com a pouca definição da imagem, o contorno próximo à região da coluna cervical (em imagens sagitais), quando esteve presente, não foi bem delimitado em algumas imagens.

Na comparação dos dois métodos, apesar da dificuldade apresentada com os cantos em algumas imagens, os contornos resultantes do método de segmentação temporal são mais suaves e próximos às bordas do pulmão. Além disso, o método de segmentação através de limiarização e labeling apresenta dificuldades em algumas imagens da série, nas quais o método de segmentação temporal produz resultados válidos.

Assim, pode-se dizer que o primeiro método apresentado tem sua utilidade 
como etapa inicial da segmentação do pulmão ou em outros casos específicos, mas aplicação, em casos gerais, limitada. O método de segmentação temporal, apesar das dificuldades já explicitadas, possui seus méritos e apresenta bons resultados, podendo ser aplicado mais amplamente. 


\section{Referências}

1 TAVARES, R. S.; TSUZUKI, M. S. G.; GOTOH, T.; KAGEI, S.; IWASAWA, T. Lung movement determination in temporal sequences of MR images using hough transform and interval arithmetics. In: Proceedings of the 7th IFAC Symposium on Modelling and Control in Biomedical Systems. 2009. p. 192-197.

2 MORI, S.; KONDO, C.; SUZUKI, N.; YAMASHITA, H.; HATTORI, A.; KUSAKABE, M.; ENDO, M. Volumetric cine imaging for cardiovascular circulation using prototype 256-detector row computed tomography scanner (4-dimensional computed tomography) a preliminary study with a porcine model. Journal of Computer Assisted Tomography, n. 29, p. 26-30, 2005.

3 LUJAN, A. E.; LARSEN, E. W.; BALTER, J. M.; HAKEN, R. K. T. A method for incorporating organ motion due to breathing into 3D dose calculations. Medical Physics, n. 26, p. 715-720, 1999.

4 HERK, M. van. Errors and margins in radiotherapy. Seminars in Radiation Oncology, n. 14, p. 52-64, 2004.

5 KEALL, P. J.; JOSHI, S.; VEDAM, S. S.; SIEBERS, J. V.; KINI, V. R.; MOHAN, R. Four-dimensional radiotherapy planning for DMLC-based respiratory motion tracking. Medical Physics, n. 32, p. 942-951, 2005.

6 SARRUT, D.; DELHAY, B.; VILlaRD, P.-F.; BOLDEA, V.; BEUVE, M.; CLARYSSE, P. A comparison framework for breathing motion estimation methods from 4D imaging. IEEE Transactions on Medical Imaging, n. 26, p. 1636-1648, 2007.

7 HATABU, H.; ALSOP, D. C.; LiSTERUD, J.; BONNET, M.; GEFTER, W. B. $t_{2}^{*}$ and proton density measurement of normal human lung parenchyma using submillisecond echo time gradient echo magnetic resonance imaging. European Journal of Radiology, n. 29, p. 245-252, 1999.

8 KAUCZOR, H. U. MRI of the Lung. Berlim: Springer-Verlag, 2009.

9 SEnSAKOVIC, W. F.; III, S. G. A.; STARKEY, A.; CAliGIURI, P. Automated lung segmentation of diseased and artifact-corrupted magnetic resonance sections. Medical Images, p. 3085-3093, 2006.

10 Clarke, L. P.; VELTHIJIZEN, R. P.; CAMACHO, M. A.; HEINE, J. J.; VAIDYANATHAN, M.; HAL, L. O.; THATCHER, R. W.; SILBIGER, M. L. MRI segmentation: Methods and applications. Magnetic Resonance Imaging, n. 13, p. 343-368, 1995.

11 LAI, J.; YE, M. Active contour based lung field segmentation. In: International Conference on Intelligent Human-Machine Systems and Cybernetics. 2009. p. 288-291. 
12 IWASAWA, T.; KAGEI, S.; GOTOH, T.; YOSHIIKE, Y.; MATSUSHITA, K.; KURIHARA, H.; SAITO, K.; MATSUBARA, S. Magnetic resonance analysis of abnormal diaphragmatic motion in patients with emphysema. European Respiratory Journal, n. 19, p. 225-331, 2002.

13 CLUZEL, P.; SIMILOWSKI, T.; CHARTRAND-LEFEBVRE, C.; ZELTER, M.; DERENNE, J. P.; GRENIER, P. A. Diaphragm and chest wall: assessment of the inspiratory pump with MR imaging-preliminary observations. Radiology, n. 215 , p. $574-583,2000$.

14 MIDDLETON, I.; DAMPER, R. I. Segmentation of magnetic resonance images of the thorax by back-propagation. In: Proceedings of IEEE International Conference on Neural Networks. 1995. p. 2490-2494.

15 RAY, N.; ACTON, S. T.; ALTES, T.; LANGE, E. E. de; BROOKEMAN, J. R. Merging parametric active contours within homogeneous image regions for MRI-based lung segmentation. IEEE Transactions on Medical Imaging, n. 22, p. 189-199, 2003.

16 OSAREH, A.; SHADGAR, B. A segmentation method of lung cavities using region aided geometric snakes. Journal of Medical Systems, 2009.

17 ASAKURA, A.; GOTOH, T.; KAGEI, S.; IWASAWA, T.; INOUE, T. Computer aided system for respiratory motion analysis of the lung region by sequential MR images. Medical Imaging Technology, n. 23, p. 39-46, 2005.

18 TSUZUKI, M. S. G.; TAKASE, F. K.; GOTOH, T.; KAGEI, S.; ASAKURA, A.; IWASAWA, T.; INOUE, T. Animated solid model of the lung constructed from unsynchronized MR sequential images. Computer Aided Design, n. 41, p. 573-585, 2009.

19 MATSUSHITA, K.; ASAKURA, A.; KAGEI, S.; GOTOH, T.; IWASAWA, T.; INOUE, T. Shape tracking on chest MR sequence images using respiratory patterns. The Journal of the Institute of Image Electronics Engineers of Japan, n. 33, p. 1115-1122, 2004.

20 BLOCH, F. Nuclear induction. Physical Review, v. 70, p. 460-474, 1946.

21 PURCELL, E. M.; TORREY, H. C.; POUND, R. V. Resonance absorption by nuclear magnetic moments in a solid. Physical Review, v. 69, p. 37-38, 1946.

22 SANTARELLI, M. F. Basic physics of MR signal and image generation. In: LANDINI, L.; POSITANO, V.; SANTARELLI, M. F. (Ed.). Advanced Image Processing in Magnetic Resonance Imaging. Taylor \& Francis Group. cap. 1.

23 JAN, J. Medical Image Processing, Reconstruction and Restoration. Taylor \& Francis Group, 2006.

24 KIRYATI, N.; ELDAR, Y.; BRUCKSTEIN, A. M. A probabilistic hough transform. Pattern Recognition, n. 24, p. 303-316, 1991.

25 P.V.C.HOUGH. A method and means for recognizing complex patterns. 1962. US Patent 3069654. 
26 HEATH, M.; SARKAR, S.; SANOCKI, T.; BOWYER, K. Comparison of edge detectors: a methodology and initial study. Computer Vision and Image Understanding, n. 69, p. 38-54, 1998.

27 ABRAMS, S.; CHO, W.; HU, C.; MAEKAWA, T.; PATRIKALAKIS, N.; SHERBROOKE, E. Efficient and reliable methods for rounded interval arithmetic. Computer Aided Design, n. 30, p. 657-665, 1998.

28 TSUZUKI, M.; SHIMADA, M. Geometric classification tests using interval arithmetic in B-rep solid modeling. Journal of the Brazilian Society of Mechanical Sciences and Engineering, n. 25, p. 396-402, 2003.

29 KASS, M.; WITKIN, A.; TERZOPOULOS, D. Snakes: active contour models. International Journal of Computer Vision, n. 1, p. 321-331, 1988.

30 WILLIAMS, D. J.; SHAH, M. A fast algorithm for active contours and curvature estimation. CVGIP: Image Understanding, n. 55, p. 14-26, 1992.

31 SAKALLI, M.; LAM, K.; YAN, H. A faster converging snake algorithm to locate object boundaries. IEEE TRANSACTIONS ON IMAGE PROCESSING, v. 15, n. 5 , p. $1182-1191,2006$.

32 COHEN, L. D. On active contour models and balloons. CVGIP: Image Understanding, v. 53, n. 2, p. 211-218, 1991.

33 XU, C.; PRINCE, J. Snakes, shapes, and gradient vector flow. IEEE Transactions on Image Processing, v. 7, n. 3, p. 359-369, 1998.

34 PEDRINI, H.; SHWARTZ, W. R. Análise de Imagens Digitais. Thomsom, 2008. 